\title{
Living with less: Prospects for sustainability.
}

Citation for published version (APA):

Schreurs, J. (2010). Living with less: Prospects for sustainability. [Doctoral Thesis, Maastricht University]. Datawyse / Universitaire Pers Maastricht. https://doi.org/10.26481/dis.20101111js

Document status and date:

Published: 01/01/2010

DOI:

10.26481/dis.20101111js

Document Version:

Publisher's PDF, also known as Version of record

\section{Please check the document version of this publication:}

- A submitted manuscript is the version of the article upon submission and before peer-review. There can be important differences between the submitted version and the official published version of record.

People interested in the research are advised to contact the author for the final version of the publication, or visit the DOI to the publisher's website.

- The final author version and the galley proof are versions of the publication after peer review.

- The final published version features the final layout of the paper including the volume, issue and page numbers.

Link to publication

\footnotetext{
General rights rights.

- You may freely distribute the URL identifying the publication in the public portal. please follow below link for the End User Agreement:

www.umlib.nl/taverne-license

Take down policy

If you believe that this document breaches copyright please contact us at:

repository@maastrichtuniversity.nl

providing details and we will investigate your claim.
}

Copyright and moral rights for the publications made accessible in the public portal are retained by the authors and/or other copyright owners and it is a condition of accessing publications that users recognise and abide by the legal requirements associated with these

- Users may download and print one copy of any publication from the public portal for the purpose of private study or research.

- You may not further distribute the material or use it for any profit-making activity or commercial gain

If the publication is distributed under the terms of Article $25 \mathrm{fa}$ of the Dutch Copyright Act, indicated by the "Taverne" license above, 


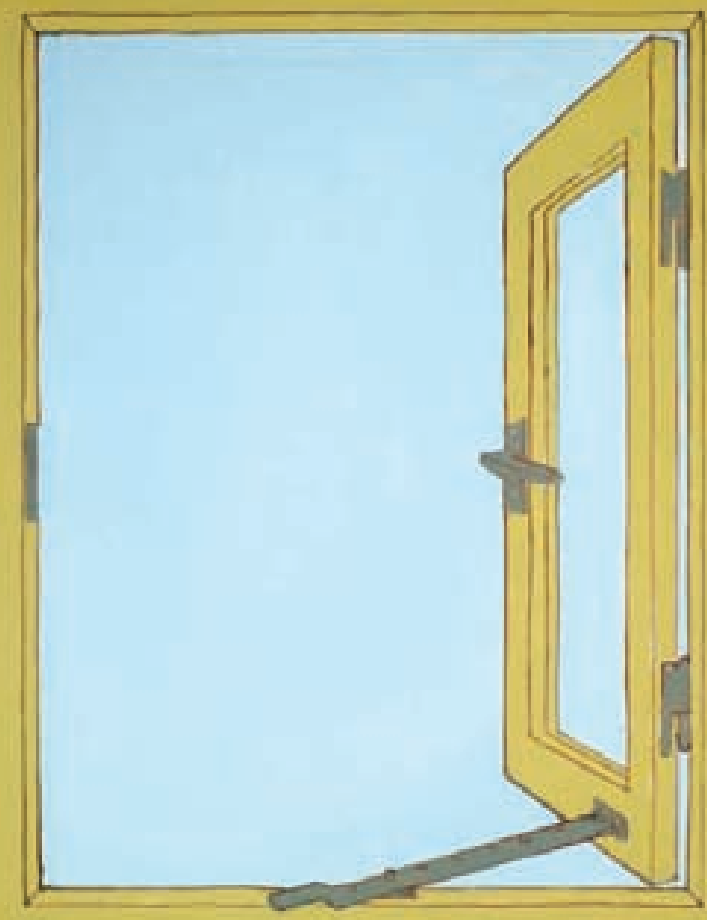

\section{Living with Less: \\ Prospects for Sustainability}

Jeanine Schreurs 


\section{Living with Less: Prospects for Sustainability}

Jeanine Schreurs 
This PhD was carried out at the International Centre for Integrated Assessment and Sustainable development (ICIS), Maastricht University, The Netherlands.

(C) Copyright: Jeanine Schreurs, Maastricht 2010

Cover picture: gouache 'Window', Erik van der Krogt (www.shapedcanvas.nl)

Print: Schrijen-Lippertz, Voerendaal.

Cover design: Erik van der Krogt en Quadro Vormgevers, Oss.

ISBN nummer 978-90-9025779-2 


\title{
Living with Less: Prospects for Sustainability
}

\author{
PROEFSCHRIFT \\ Ter verkrijging van de graad van doctor \\ aan de Universiteit Maastricht \\ op gezag van de Rector Magnificus, \\ prof. mr. G.P.M.F. Mols, \\ volgens het besluit van het College van Decanen, \\ in het openbaar te verdedigen op \\ donderdag 11 november 2010 om 14:00 uur \\ door
} Johanna Wilhelmina Rosalie Maria Schreurs 


\section{Promotores}

Prof. dr. Pim Martens

Prof. dr. Gerjo Kok

\section{Assessment Committee}

Prof. dr. Jan H. Stel (Chair)

Dr. Marius de Geus (Leiden University)

Dr. Ree Meertens

Prof. dr. Ko de Ruyter

This PhD. research was financially supported by:

Boxq O accountants, Flycatcher, Foundation Sobrietas, Publisher Uitgeverij Genoeg, municipality Landgraaf, SenterNovem, and Jenny Westrik. 


\section{Table of Contents}

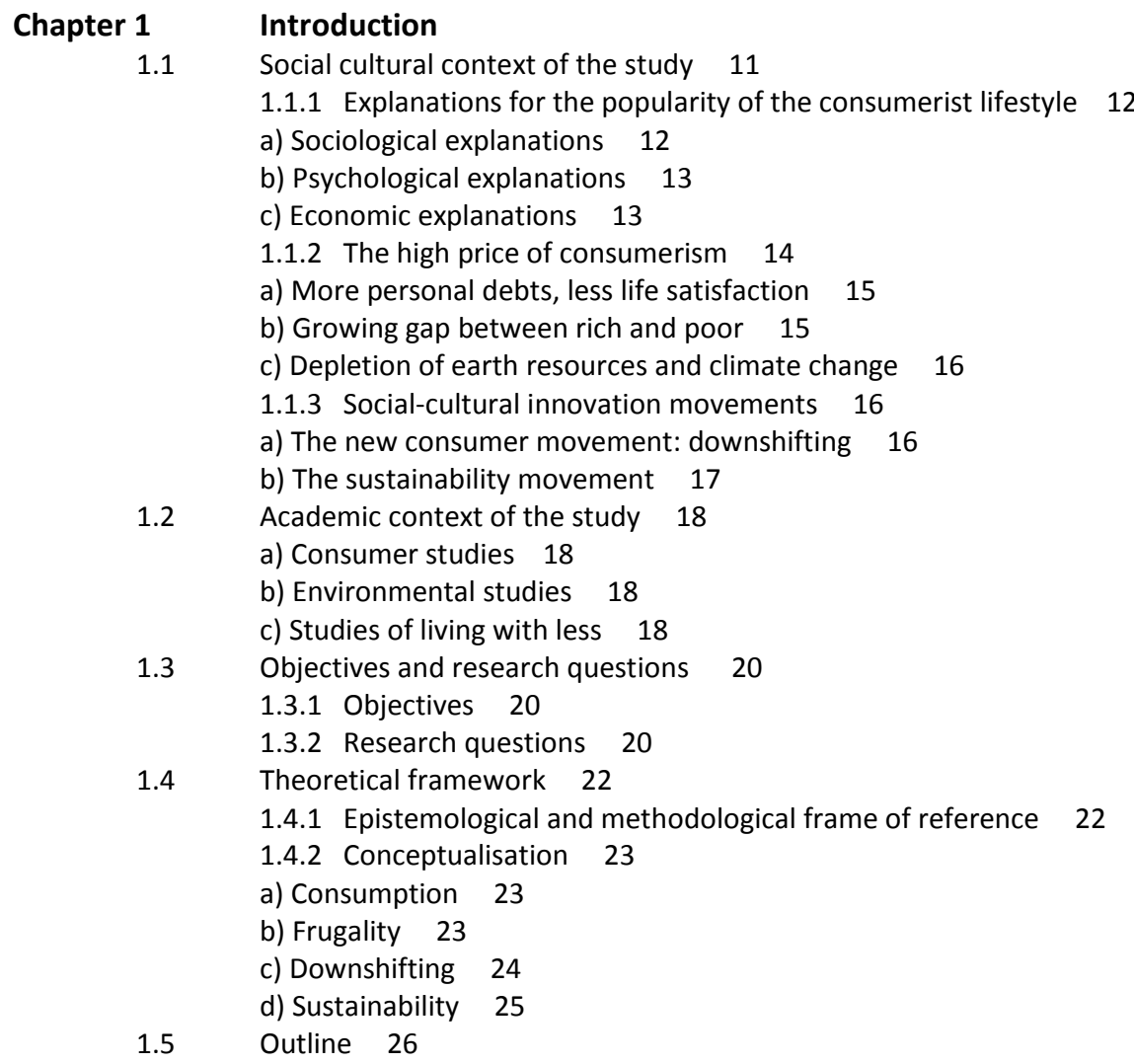

\section{Chapter 2 Out of sight, out of mind:}

Consumer studies in historic epistemic perspective

Abstract 30

2.1 Introduction 31

2.2 Out of sight: changed meaning of core concepts 32

a) Status, class and lifestyle 32

b) Consumption = buying 34

c) Consumer images 35

$2.3 \quad$ Into the political arena 36

2.4 Beyond: observations of current perspectives 38

2.5 Conclusions 40

Chapter 3 Frugality as a core principle in postmodern consumer society Abstract 44

3.1 Introduction 45

3.2 Explorations 47

3.2.1 Frugality and related concepts defined 47

3.2.2 The dual nature of frugality as personal and cultural trait 48 
3.2.3 Manifestations of the dual nature of frugality

a) Frugality in public policy 50

b) Frugality manifested in consumption and consumer behaviour 51

c) Frugality manifested in the marketing domain 52

3.3 Effects on the epistemic view 52

3.3.1 Frugality in consumer studies 52

3.3.2 Frugality in environmental studies 53

3.3.3 Frugality and new consumer studies 54

3.3.4 Conclusions with regard to the epistemic view 57

3.4 Historical theoretical explanations 57

3.4.1 Philosophical thinking on frugality 58

3.4.2 Frugality in religious thinking 59

3.4.3 Enlightenment philosophy and economics 61

3.4.4 Frugality in modern economics 62

3.5 Discussion and conclusion 63

\section{Chapter $4 \quad$ Living with less as a transformation process}

Abstract 66

4.1 Introduction 67

4.2 Literature review 67

4.3 Data collection and method 68

4.4 Results 70

4.4.1 The sample 70

4.4.2 Data analysis 71

4.4.3 The Transformation Model: Living with Less 72

4.5 Discussion and conclusions 78

4.5.1 Findings 78

4.5.2 Limitations 79

4.5.3 Implications 80

\section{Chapter 5 Meet the Dutch Downshifters}

Abstract 84

5.1 Introduction 85

5.1.1 Voluntary downshifting as a social trend 85

5.1.1.1 Downshifting in the Netherlands 86

5.1.1.2 Motivations for voluntary downshifting 87

5.1.2 Conceptual framework 87

5.2 Academic context, objectives, research questions

5.2.1 Research theme 1: Downshifting 89

a) Voluntary and involuntary downshifting 89

b) Socio-economic and demographic characteristics 90

c) Downshifting in postmodern consumption society 90

d) Experiences of downshifting 91

5.2.2 Research theme 2: Frugality 92

5.2.3 Research theme 3: Sustainability 93

5.3. Methods 94

5.3.1 Participants and procedure 94

5.3.2 Sample 95

5.3.3 Measures and approach to analysis 96

a) Demographic and socio-economic characteristics 96

b) Changes in finances and expenditures 97 
c) Experiences with downshifting 97

d) Frugality 97

e) Consumption practices 98

5.4 Results 98

5.4.1 Demographic and socio-economic characteristics 98

5.4.1.1 Weighted results 101

5.4.2 Changes in finances: household income and spending reduction 102

5.4.3 Changes in consumption expenditures 103

5.4.4 Positive and negative experiences of downshifting 108

5.4.4.1 Positive and negative experiences categories 108

a) Categories of both positive and negative experiences 108

b) Categories of positive experiences 109

c) Categories of negative experiences 109

5.4.4.2 Groups comparisons 110

5.4.5 Attitudes: frugality and autonomy 113

5.4.6 Consumption practices 116

5.4.6.1 Consumption practices and sustainability 120

5.5 Discussion and conclusions 120

5.5.1 Dutch downshifters and their foreign counterparts 121

5.5.2 Downshifters in a consumption society 123

5.5.3 Perspectives for sustainability 124

\section{Chapter $6 \quad$ Downshifting and Sustainability}

Abstract 128

6.1. Introduction 129

6.2 Prospects for sustainability 130

6.2.1 Frugality and sustainability in postmodern consumer culture 131

6.2.1.1 Implications for sustainability 132

6.2.2 Transformation process and sustainability 132

6.2.2.1 Implications for sustainability 133

6.2.3 Downshifters and sustainability 134

6.2.3.1 Implications for sustainability 136

6.3 A strategy to encourage sustainable living 136

6.3.1 Four priorities 137

6.4 Limitations of the study 140

6.5 Future research 142

Bibliography 145

Appendix Survey: The Genoeg Readers Study 160

Summary 166

Samenvatting 171

Acknowledgements 176

Dankwoord 179

Curriculum vitae 183 
Chapter 1

\section{Introduction}




\subsection{Social cultural context of the study}

The need to consume is not new. People have used resources in order to survive since early mankind. In the twentieth century yet, the commercialization of consumption has brought about radical changes in both the volume and the cultural significance of consumption (Assadourian 2010; Cohen 2004; De Geus 2003; Levine 2006; Maniates 2001, 2010; Miller 1995; Schor 1998; Worldwatch 2004). Discretionary consumption has become a mass phenomenon and not merely a privilege of the rich and middle class (Schor 1998: 217). As a result consumerism and the consumerist lifestyle have become dominant cultural features in the Western world and are rapidly spreading to other parts of the world. Consumerism is perceived as the possession and use of an increasing number of goods and services as the principal cultural aspiration and the surest perceived route to personal happiness, social status and national success (Ekins 1991).

Over 2 billion people are practicing a consumerist lifestyle and this number is expected to increase exponentially due to the economic boom in Asia (Assadourian, 2010). A large portion of the global consumer class lives in developing countries, China and India alone represent more than $20 \%$ of the global total. With combined numbers of 362 million, the consumer class in India and China together is larger than the consumer class in all of Western Europe. Considering the burgeoning populations of these countries and their relatively modest individual consumption levels compared to European consumers, there is enormous potential for growth (Worldwatch 2004; Assadourian 2010).

Worldwide, private consumption expenditures the amount spent on goods and services at the household level have increased six fold since 1950 (HDR 1998). Private consumption expenditures totaled $\$ 20$ trillion in 2000 (based on the dollar in 1995) and accelerated to $\$ 30.5$ trillion in 2006 (based on the dollar in 2008) (Assadourian 2010). This increase can only in part be attributed to population growth as population growth grew by a factor of 2.2 between 1960 and 2006 and the growth in consumption expenditures was much greater than 2.2. In the United States, a country that epitomizes consumerism, consumption per person doubled from $\$ 7000$ in 1950 to over $\$ 14,000$ in 1990 , and almost doubled again in the following two decades. The Netherlands shows a similar trend. Household consumption has increased substantially since the 1950s. Coinciding with increased social benefits and incomes, Dutch consumers increased their expenditures in all categories of consumer goods, culminating in a record $20 \%$ over the last ten years of the millennium. For the first ever, this increase in consumption is not in line with increases in income. Since 1999, Dutch consumers have been spending more than they earn. Their purchases are thus being paid via increased mortgages and personal loans. However, the recent economic crisis has halted this trend. In 2009, consumption expenditures decreased by $2.5 \%$ while savings increased (CBS 2010). 
Apart from the fact that the global consumer class is growing rapidly, measurements indicate that there is also an intensification of the consumerist lifestyle. Consumers not only spend more on clothing, transportation, food and fuel (CBS 2008; Assadourian 2010; HDR 1998) but also on other items. Numerous life domains have thus been infiltrated by consumption. For example, the costs of child rearing, education and training, as well as the costs of maintaining social relationships have increased in recent decades (Schor 1998). Currently, this trend has extended into leisure time activities. For instance, sports and recreation are now growing consumption categories.

\subsubsection{Explanations for the popularity of the consumerist lifestyle}

Indisputably, material goods have increased comfort and pleasure. The benefits of consumption have been spread far and wide and achievements contribute to human development (HDR 1998). Nevertheless, studies on the correlation between income growth and life satisfaction indicate that the association is strong in the lower income levels but weakens as income grows, with incomes above $\$ 15.000$ showing no correlation (Jackson 2008). Why is it then that people continue to consume in everincreasing amounts? What fuels the 'fire of desire' (Belk et al. 2002) when the conventional economic view of 'utility' falls short in light of declining life satisfaction? This fundamental question can be answered from sociological, psychological and economics perspectives.

\section{a) Sociological explanations}

According to sociology, individuals acquire or communicate a certain status through conspicuous consumption. Alexis de Tocqueville (2003) was the first social economic theorist who addressed this connection in his study of the development of democracy in the United States. He notes that industrialization increased the opportunities available to the lower classes and undermined the rigid separation between ranks and classes in society. Under these circumstances, consumption is considered a vehicle for upward mobility as well as an important status marker. As an individual's circumstances and social environment become less determinant for acquiring social position and individual capacities gain more significance, the function of consumption increases (Veblen 1948; Simmel 1997b, 1997c; Bourdieu 1984).

This mechanism was highlighted by Schor, who replaced the phrase: 'Keeping up with the Joneses' with 'Keeping up with the Gateses'. According to Schor, social cohesion is declining and keeping up with the Joneses is no longer the aspiration level of consumers. Currently, consumers aspire to the consumption levels of the rich and famous whose lifestyle can be viewed on television and in magazines emphasizing social differentiation. However, other researchers have stressed the democratizing or liberating dimensions of consumption (Kotlowitz 2000; Twitchell 2000; Fiske 2000; Wilson 2000). Kotlowitz explained the sudden popularity of Hush Puppies (C) - 'formerly a white, upper middle class brand' (2000:255) - with Bronx youth as a manifestation of their desire for upward mobility. By consuming specific goods, people access the world 
of those who create it. Tommy Hilfiger and similar brands are favourites of the hoi polloi because they are perceived as connectors to the more prosperous world of the upper class. The extent of this type of status consumption's influence on aspired social position however has hardly been tested empirically. Therefore, adequate data are lacking for a scientific basis of the status consumption thesis.

In accordance with Bourdieu (1984), critics such as Schor and Kotlowitz argue that the real determinants of status and social position are one's social and cultural capital. These are not a commodity but rather the result of upbringing and education, and reflective of elements of social-cultural inheritance. They describe the false expectations created by manipulative marketing. Indeed, the black rapper's Hush Puppies(C) do not make him upper middle class (Kotlowitz 2000).

In this respect, Douglas and Isherwood (1996) find that status increase is an indirect effect of consumption. In their view, products are bought to escape the more or less constraining 'pattern of periodicities of household processes' to gain more time for other more interesting and more highly valued tasks. Household consumption thus allows individuals to invest in activities that augment their social capital.

\section{b) Psychological explanations}

Psychologists attribute the need for ever-increasing levels of consumption to the insatiable nature of humankind. Feelings of satisfaction disappear quickly after the object of desire is acquired because of the principle of diminishing marginal utility. Because the value of the desired object decreases, the acquisition of new objects becomes necessary to attain the same level of satisfaction. Certain products have a social dimension because ownership of these products enhances one's standard of living. In this regard, De Geus rightly notes, 'Because of this social dimension of needs, yesterday's luxuries almost automatically and imperceptibly turn into today's' necessities' (De Geus 2003: 15). Additionally, Campbell (1989) argues that the desire for consumption does not end when a certain standard of living has been attained, because the desire itself is the main drive. Daydreaming and longing for certain goods are joyful sensations that people want to experience again and again after the desire is fulfilled (Scitovsky 1976; De Geus 2003).

Physiological studies refute this theory and contend that the real satisfaction lies in the moment of purchase itself. At that moment, the body releases serotonin, the 'happiness hormone', that produces a short, pleasant sensation. However, serotonin is quickly reabsorbed and the longing to re-experience this pleasurable sensation incites people to buy and, in extreme forms, leads to shopping addiction (Karsten \& Laansma 2003).

\section{c) Economic explanations}

If we consider the question of increased consumption in a broader context than consumer behaviour, we can contend that the spread and intensification of the consumerist lifestyle may also be related to the organization of the production system - the organization of the economy and consumption infrastructure. Strategic use of 
advanced production techniques has ensured that a greater variety of products are quickly released to the market (Sonntag 2003). The underlying theme is that supply creates demand. This reflects a vision, originally formulated by Galbraith (1962) that israrely disputed.

Increased production leads to increased consumption with advertising as the lubricant for the system. With daily exposure to an average of 1600 advertising messages in Great Britain and about 3500 in the United States, the consumer is inundated with consumer messages. Consumers in industrialized countries are constantly exposed to commercial messages. In particular, television plays a crucial role in spreading and strengthening material values, not only through advertising but also through exposure to popular shows where a lifestyle of luxury is promoted and the consumption aspirations of people are strengthened.

In the 1960s and 1970s, the discussion surrounding consumption focused on whether human needs are natured or nurtured. At the same time, the concept of manifest or latent need received significant academic and public attention. In light of the vast range of consumer goods available today and the explosive growth in advertising that consumers currently face, this debate is likely moot.

In conclusion, sociological and psychological motivators have resulted in a proliferation and intensification of the consumerist lifestyle. However, the popularity of the consumerist lifestyle can only be fully understood by examining the organization of the market economy and the consumption infrastructure. Increased consumption obviously has improved living conditions on a large scale; yet there is also a downside.

\subsubsection{The high price of consumerism}

The consumerist lifestyle has a costly price that increases as the lifestyle intensifies. In view of paid labor for instance - a first condition for consumption - people not only work harder and longer than before, the employment rate per household has also risen (CBS 2010; De Graaf 2002, 2003; EU-27; Ehrenreich 2005, 2006; Schor 1998; Soc.Ec.Trends 2009). The United States have the longest working hours in the industrial world. The average European works, per year, nine weeks less than his or her American counterpart. The Chinese have a mandated three weeks of paid leave, Australians four, and Europeans four to five, but, in the United States, there is no law that establishes a minimum paid leave (De Graaf 2003). The United States have also no paid leave for pregnancy and childbirth and only $40 \%$ profits from 12 weeks of unpaid leave. Also, average wages in the United States have fallen over the past half century generating additional pressure on labour. Consequently, Americans have to work longer to finance their consumption levels and the numbers of people working multiple jobs is rapidly increasing (Ehrenreich 2005; Schor 2000).

The situation in the Netherlands is similar. The employment rate per household has gradually increased as more women have entered the workforce and adolescents are commonly employed in paid work. The employment rate is higher in the Netherlands than in other countries in the European Union (EU-27). In 2008, more than $77 \%$ of the Dutch population aged 15 to 65 years had a paid job. Only Denmark has a higher employment rate (>78\%) but the gap is diminishing (CBS 2010). In twenty years, the 
number of two income families has more than doubled. This increase is especially significant in families with under-aged children (CBS 2009).

The paradox of well-being, as Jackson puts it (2008), counteracts the prevailing perception that the more people consume, the happier they will be again. The positive correlation between happiness and income is weak and even diminishes as income increases. In countries with average incomes above $\$ 15,000$, no improved life satisfaction could be measured (2008: 50).

\section{a) Growing personal debts}

Despite efforts to earn sufficient money to maintain a consumerist lifestyle, personal debt has increased. In 2002, 61\% of credit card users in the United States carried an average monthly balance of $\$ 12,000$ at an interest rate of $16 \%$. This amounts to about $\$ 1,900$ a year in finance charges which is an amount greater than the average per capita income of the inhabitants of at least 35 countries (in purchasing power parity).

Also the traditional image of Dutch thrift should be re-examined. Over the past decade, the Dutch have spent more than they earned. Expenditures have been financed by second mortgages on houses or by income derived from selling stocks. In 2009, shifts in saving and consumption behaviour among the Dutch occurred as a result of the economic crisis and financial uncertainty. In the preceding four years, 13 billion euros worth of savings were consumed and savings totaled 5.2 billion (CBS 2010).

Personal loans have become prohibitive for many and the number of personal bankruptcies is increasing. Debt relief workers are thus scrambling to meet demands and the number of wage earners in dire straits is growing rapidly.

\section{b) Growing gap between rich and poor}

While the number of people with financial problems increases, the wealth of the top income earners continues to grow. In the Western World, there is a growing gap between the rich and the poor particularly since the introduction of neoliberal politics in the 1970s (Miller 1995; UNDP 1998). The Human Poverty Index (HPI-2) shows that some $7-17 \%$ of the population in industrial countries is poor. Numbers are not related with average income. The United States with the highest average income has the highest number of poor. In the Netherlands, the purchasing power of old age pensions and other social benefits have not been indexed since the 1980s. Consequently, one in every ten households lives in poverty (SCP 2009).

The increasing gap between the rich and poor is a global phenomenon. Consumer society has become a global society, although not a homogeneous whole but rather a society that consists of 'islands of prosperity, oceans of poverty', as described by Indian ecologist Madhav Gadjil (1995: 35). Although the consumer class increases, great disparities remain. The $20 \%$ of the world's population that lives in the richest countries accounts for almost $80 \%$ of private consumption, while the $20 \%$ poorest population accounts for $1.5 \%$ (Worldbank 2008). Consumerism thus exacerbates inequalities both within and across nations. As a result, millions of people are migrating from rural areas to cities and from poor regions to richer parts of the world in the hope that they can improve their living conditions. This can generate social upheaval and imbalance. 


\section{c) Depletion of earth resources and climate change}

The cost of the globalization of the consumerist lifestyle has proven prohibitive for the earth. With a global population of 6.8 billion that continues to grow, the ecosystems upon which all life depends are being stretched to the limit because of record levels of consumption (Worldwatch 2007). The Ecological Footprint Indicator demonstrates clearly the link between prosperity levels (expressed in gross domestic product per inhabitant in purchasing power corrected dollars, ppp \$) and the carbon dioxide (CO2) emissions linked to the consumption level of the relevant country. So far, key driver of climate change are western nations although China, India and Brazil are speeding up in the carbon footprint ranking list (Jackson 2008).

The global use of fossil fuels, steel, wood, meat and seafood is contributing to the rapid depletion of the earth's resources and destroying biodiversity. At the same time, waste grows to non-recyclable proportions as exemplified by the plastic waste patch located in the Pacific Ocean that is conservatively estimated to be as large as France, Spain and Portugal combined. Recently, scientists have discovered a similar region in the North Atlantic Ocean where plastic debris accumulates. With a maximum 'plastic density' of 200,000 pieces of debris per square kilometres, it is comparable with the Great Pacific Garbage Patch (National Geographic 2010).

In sum, the $20^{\text {th }}$ century's growth of consumption puts a strain on the environmental resources and aggravates social and economic inequalities. The costs that come with consumerism and the consumerist lifestyle, despite its attractions, are rising substantially. Concurrently, risks are increasing: in personal life because of prohibitive debts, stress illnesses or impoverishment; at a global scale because of climate change, and social and political instability as a result of the growing gap between rich and poor.

\subsubsection{Social-cultural innovation movements}

Evidently, the environmental strain caused by the unprecedented growth of consumption has brought about numerous technological and economic innovations. Sustainable technologies and sustainable business are gaining more attention, as is exemplified by the popularity of production principles such as cradle-to-cradle. In discussions pertaining to sustainable economy, the topic of limiting growth has once again been placed on the agenda. Within the context of this study though we focus on the two large social-cultural trends that have developed in reaction to the high costs of consumerism, namely the new consumer movement, also known as downshifting, and the sustainability movement. We consider these developments to be innovation movements because they aim to diminish the negative effects of the consumerist lifestyle.

\section{a) The new consumer movement - downshifting}

There are strong indications that a social change towards a less consumerist and more restrained way of life is taking place. The Trends Research Institute (1995) first reported this significant and growing trend and qualified it as the most fundamental change in our way of life since the Depression. Subsequent studies seem to confirm 
this. Schor (1998) noted that, in the first half of the 1990s, one fifth of Americans voluntarily chose a different lifestyle. Additionally, Paul Ray and Ruth Anderson (2000) identified a social group (slightly over one quarter of the adult US population) that they labelled 'cultural creatives'. This group is averse to demonstrations of status and materialism. Later studies in Europe produced comparable results. Breakspear and Hamilton (2004) and Datamonitor (2003) found significant numbers of so-called 'simple livers' and 'downshifters'. The number of people dissatisfied with their lives and longing for a simpler, less stressful existence is even much higher, according to Datamonitor. Consequently, it appears that there is a large potential for the voluntary adoption of a less consumerist lifestyle in favour of more quality of life.

\section{b) The sustainability movement}

The second important innovation movement is the sustainability movement, or the societal trend to adopt concrete actions in favour of preserving the environment and saving the planet. The sustainability movement can be considered the practical successor of the environmental movement that started in the 1970s.

The results of the second annual National Geographic/GlobeScan 'Consumer Greendex' (2010) showed that, over the past year, consumers have adopted more environmentally friendly behaviour which has led to a general increase in Greendex scores. Because the Greendex measures the behavioural practices of citizens in 17 countries in both the developed and the developing world, the results indicate that growing numbers of citizens are not only convinced that measures should be taken to preserve the planet but that they are also willing to adjust their behaviour toward a more sustainable lifestyle.

This trend is also present in the Netherlands where sustainable banks such as ASN and Triodos and green energy suppliers saw growing numbers of customers over the past years. Government incentives for reducing carbon dioxide such as subsidies for solar power installations and alike are very successful. Also recycling of waste has become common practice in the Netherlands. In contrast to the prevailing view of the egotistical hedonistic consumer whose only aspiration is to have more, these new consumer trends reveal an alternative attitude towards consumption and a special commitment to sustainability.

Rounding up, we think that today it is commonly accepted that a more eco-friendly way of living is requisited in order to save the planet. Because sustainability requires that consumers limit the extent to which they exploit the earth resources (Assadourian 2010; Jackson 2010; Maniates 2009), studying people who actually try to reduce consumption could be very informative. Knowledge regarding experiences with downshifting and voluntary lifestyle changes might reveal new perspectives on sustainability and fuel the discussion on consumerist lifestyles. What does it mean to reduce expenses? What does it mean to have a smaller carbon footprint in a socialcultural environment that constantly encourages people to spend money? How can living with less money support sustainability? Answers to these questions are indispensable if sustainable development is to be successful. 


\subsection{Academic context of the study}

\section{a) Consumer studies}

Obviously, the issue of living with less should be examined within the context of consumer studies, which is a collective term comprising studies on consumption and consumer behaviour. However, as discussed in Chapter 2 of this thesis, in one and a half centuries of consumer studies, academic attention has focused mainly on purchasing behaviour and spending (Holbrook 1995: 12), or on those consumer traits or consumption issues that are directly related to purchasing behaviour. Information about consumer choices other than brand preference is rarely found in consumer studies and the concept of non-consumption has seldom been addressed (Holbrook \& Hirschman 1982; Holbrook 1995; Schor 2000, 2001; Lastovicka et al 1999; Miller 1995; Douglas \& Isherwood 1996; Firat 1987, 2000). Thus questions outside the purview of the market are often outside the scope of consumer studies (Belk 1995; Firat 1995).

Generally, within this tradition in consumer studies, relatively little attention has been given to moderating consumption or living with less. This observation motivated us to conduct an epistemological analysis of the development of consumer studies, which is presented in Chapter 2 of this dissertation.

\section{b) Environmental studies}

Another important academic context is environmental studies. For a long time, these studies mainly focused on production and rarely on consumption and consumer behaviour (Spaargaren 2003). The prevailing ecological modernization theories in the 1970 s and 1980s held that a green production system would automatically yield green consumption (Spaargaren 2006:3). However, concurrently, moderation of consumption arose as a possible solution in the sustainability debate and has since remained a favoured solution. For example, an important proponent of moderation, Warren Johnson, argued in his essay entitled Muddling toward Frugality (1978) for the adoption of a moderate lifestyle to secure natural resources. Many other appeals for reduced consumption and studies followed (Aarts 1999; De Geus 2003; Goudzwaard 2006; Maniates 2002, 2009; Nelissen 1995; Princen 1997, 2003). Nevertheless, empirical studies on how to best achieve moderation tended to focus on reducing energy consumption and not on lifestyle change as it was thought that a voluntary reduction in consumption would be discordant with prevailing socio-cultural values (Moll \& Groot-Marcus 2002; Peasch \& Schmidt 1999; Vlek \& Gatersleben 1995).

\section{c) Studies of living with less}

Further investigation of academic attention for reduced consumption and living with less, demonstrates that the relatively few studies at hand can be divided in four categories. Each category is characterized by a specific precept with regard to living with less that determines the intellectual frame of reference for the study. 
The first group of studies examined living with less in the context of poverty and deprivation and analyzed the issue from the perspective of a 'normal' standard of living. The assumption is that living with less deviates from mainstream behaviour (Bauman 1998), and represents abnormality, implying that living with less is a deviant, undesirable state (Hamilton \& Catterall 2005; Jansen 1990). The second group of studies positioned living with less within the context of environmentalism. Moderating consumption and having a smaller carbon footprint was considered necessary to overcome pollution and to create environmental change. The assumption in this category of studies is the belief that living with less is a desirable and socially conscious lifestyle (Aarts 1999; De Geus 2003; Goudzwaard 2006; Moll \& Groot-Marcus 2002; Peasch \& Schmidt 1999; Spaargaren 2001; Vlek \& Gatersleben 1995). Interestingly, also the opposite viewpoint can be observed: consuming less is then considered as an exponent of de-modernization strategy (Spaargaren 2005: 30) or of neo-Marxist or critical studies.

The third category concerns the predominantly non-European academic studies on downshifting and simple living (Craig-Lees \& Hill 2002; Datamonitor 2003; Elgin 1981; Etzioni 1998; Gandolfi \& Cherrier 2009; Hamilton 2003; Hamilton \& Mail 2003; Huneke 2005; Leonard-Barton 1981; Schor 1998; Pierce 2000). This perspective views living with less as a predominantly voluntary lifestyle change and a reaction to the high cost of the new consumerism, or to the continuous upward mobility through competitive spending (Schor 1998: 22).

The final category positions living with less within the moral debate on frugality or moderation as values or religious principles (De Geus 2003; Nussbaum 1999). This perspective assumes that living with less is value driven and grounded in universal life principles. Similar to the general topic living with less, also the concept frugality has long been ignored in scholarly literature on consumer behaviour (Firat 1995; Kasser 2007; Lastovicka et al. 1999; Miller 1995). While frugality is deemed an important virtue by most world religions and a determining factor in Western cultural history (Aarts 2000; De Geus 2003; Durning 1992; Goudzwaard 2006; Weber 2002), remarkably, it is not part of the VALS (acronym of Values, Attitudes and Lifestyles) or other inventories used to measure Western consumer values (Todd \& Lawson 2003). The first empirical study of frugality as a consumer trait was conducted in 1999 Lastovicka et al. (1999). Explanations for this neglect will be presented in Chapter 3 in which is explored how frugality is conceptualised, expressed and manifested in postmodern consumer society, as well as its influence on the epistemic view of consumer studies.

The four categories, differing with regard to the context in which the issue of living with less is positioned, share one common characteristic: living with less is associated with social, political, environmental or cultural problems, such as deprivation, pollution, excessive consumption, or abnormal behaviour. Consequently, the issue is polarized either as a problem cause or problem solution and therefore could easily get 'politicized'. This will be further analyzed and discussed in Chapter 2 and Chapter 3 of this dissertation. 


\subsection{Objectives and research questions}

\subsubsection{Objectives}

Considering this social-cultural and academic context, the aims of this study are to contribute to a better understanding of how reduced means impact consumer behaviour within the context of consumerism and today's consumption society. Further, findings are expected to contribute to a better understanding of the rise of new consumer movements such as downshifters and simplifiers. Finally, this study seeks to identify new possibilities for sustainable living. Hence, the specific aims of the study are:

* To investigate the epistemic development of consumer studies and its influence on the theories of consumption;

* To analyze the conceptualization of frugality from a cultural-philosophical perspective, as well as its influence on the epistemic view of consumer studies;

* To gain a better understanding of frugality as a lifestyle feature and its social and cultural meanings in postmodern consumption society;

* To map the changes which occur in people's life after a substantial decrease in income and spending; thus to map the process in consumer behaviour change after a decrease in spending;

* To provide detailed insight on the consumption practices and behaviours of voluntary and involuntary downshifters;

* To contribute to a better understanding of the emergence of these new consumer groups; and

* To explore the connection between living with less and sustainable lifestyles and identify the opportunities which restrained consumption offers sustainability.

\subsubsection{Research questions}

Given these research objectives this study addresses four broad research themes:

Because comparatively little academic attention has been paid to the topic of nonconsumption or living with less, the starting point of this dissertation was to study the fundamental question of how and under which conditions our thinking about consumption has developed in the past 150 years. Through an analysis of the epistemic development of consumer studies, we sought explanations for the focus on consumption and we considered the consequences of these perspectives and theories for consumption and consumer behaviour.

Research Question 1 in this study reads:

What is the epistemic development of consumer studies and how did it shape the consumption theories? 
The second theme concerns the concept of frugality. This concept is closely connected with ideas of non-consumption and living with less. Our investigation of frugality follows the observation that frugality is a contested topic in postmodern consumer society. Though, when considered from a cultural historical perspective, it might be reasonable to doubt that an ancient, almost universal human life principle such as frugality could be erased by a half century of consumption culture. Therefore, we explore how ideas about frugality and its manifestations have changed over the course of history from the time of the classical philosophers on, and how frugality is conceptualized and practiced in postmodern consumer society.

Research Question 2 in this study reads:

How is frugality conceptualised and manifested in postmodern consumer society and which influences on the epistemic view in consumer studies can be identified?

The third main theme focuses on contemporary experiences of living with less. We investigate the changes that occur when people reduce consumption and how this process of consuming less occurs. We also explore the lifestyle characteristics of those who actually live with less (downshifters) and how they manage to live with less in our postmodern consumer society.

Research Question 3 in this study reads:

Which changes do occur in people's life after a substantial decrease in income and spending?

Research Question 4 in this study reads:

Which socio-economic characteristics have Dutch downshifters?

The final major research theme of this dissertation is a discussion of the findings and results in the perspective of sustainability.

Research Question 5 in this study reads:

How can living with less contribute to more sustainability? Where lay opportunities and barriers for sustainable lifestyles? 


\subsection{Theoretical framework}

To accomplish the objectives of this study which generally addresses the interconnectedness of consumerism, downshifting, frugality and sustainability beyond the common conceptual framework, we constructed the following theoretical framework.

\subsubsection{Epistemological and methodological frame of reference}

Simmel's sociological theory and phenomenological theory provided an important inspiration for creating the epistemological framework for the study. Firstly, Simmel's dialectical approach and concern with interactions between opposed phenomena laid the foundation for our analysis of living with less. In his view, 'The world can best be understood in terms of conflicts and contrasts between opposed categories' (Levine 1971: XXXV). Simmel focused on dualism, conflicts and oppositions as primary constituents of his sociological analyses. In his view, sociologists study patterns and forms rather than immutable universal laws as do the natural sciences. Hence, we addressed frugality in terms of its specific relationship to the material world and living with less in its interconnectedness with consumerism. This perspective made it possible to analyze and understand frugality beyond a mere value, moral stand or an antiquated, obsolete cultural or personal trait.

Secondly, Simmel's phenomenological theory determined the methodology of our field research. The central elements of this philosophy of knowledge are phenomena or events that can be understood and studied as they occur: 'If we want to evaluate an event we should not look for meanings beyond the event. All that happens is entitled to be considered, just because it happens' (Simmel quoted in Maffesoli 1989: 148). Instead of searching for meanings external to an event, the phenomenological methodology aims to let things speak for themselves and aspires to describe behaviours as they manifest. We considered this approach to be most appropriate for our explorative empirical study of living with less because it can reduce bias in interpretations of frugality, poverty and sustainability.

Another reason for choosing this approach was because of its definition of the concept 'experience'. According to existential phenomenology, experience is a dynamic process in which certain elements alternate between the forefront and the background. However, the forefront and the background are not separate but rather constitute each other dynamically (Thompson et al. 1989). This epistemological perspective was in line with our study's intention to explore the complex interconnectedness of consumerism, downshifting and sustainability. Thus, we examined living with less as a series of specific life experiences following reduced spending. In essence, we explored living with less as a transformation process in consumer behavior. 


\subsubsection{Conceptualisation}

These theoretical perspectives were particularly relevant to the epistemological approach and methodology in this thesis. The following theories influenced the conceptualization of the main objects of this study: a) Consumption; b) Frugality;

c) Downshifting; and d) Sustainability.

\section{a) Consumption}

The anthropology of consumption informs this study. This means that consumption is perceived as a cultural-sociological construct rather than an individual activity that could be explained by psychological motives. As Mary Douglas argued: 'Consumption is an active process in which all social categories are being continually redefined'

(1976: 45). In her view, cultural analysis should focus on the whole tapestry, 'On the picture and the weaving process, before attending to the individual threads' (1976: 42). Douglas also emphasized that consumption can only be understood in conjunction with non-consumption.

Consequently we addressed the research topic using a multidisciplinary approach similar to Marcel Mauss' concept of a 'fait total social' (1990/1924: 76). Mauss considers consumption to be an activity with implications for every aspect of consumer life, both political and domestic: 'Being of interest both for classes and to clans and families' (Mauss 1990: 76). This means that consumption has to be examined using a broad context including the economic, legal, moral, aesthetic, mythological and socio-morphological arenas. Only by reconstructing the whole can the parts be understood.

\section{b) Frugality}

Frugality has been traditionally approached as a virtue, a value or a personal trait. However, from our detailed analysis of the theoretical and historical views of frugality and thrift - as described in Chapter 3 - it can be concluded that the practice of being frugal developed out of good housekeeping practices, as proposed by the classical historian Xenophon (2009) and the philosopher Aristotle (2005). It then became a main characteristic of the home economy, as evidenced by economic anthropological theory. Through the ages, notions of frugality were handed down through philosophical and religious writings, all reflecting a similar view, namely that frugality is proven best practice. The discourse was adjusted according to the specific time and context. Frugality became, 'God's will', 'a calling', 'a moral duty', 'a virtue' or 'wise stewardship'.

In this study, frugality is again seen from this practical perspective. Overall, frugality is considered a behavioural strategy that guides how people relate to the material and immaterial goods at their disposal. In accordance with Aristotle, Xenophon and the recent thoughts of Nussbaum (1999; 2000), frugality is considered to be a universal human life principle guiding life practices which are modelled specifically within socialcultural and economic contexts. 
Further, two anthropological theories on frugality were incorporated in our study.

First, Daniel Miller's (1998) concluding observations regarding domestic thrift in his theory of shopping provided the basis for our study of frugality as a core principle in postmodern consumer society. According to his theory, thrift should be understood as a vehicle shaping social relations. Focus is thus placed on its social-cultural function. We anticipated this view to be more useful for an analysis of frugality within consumer society than the common perception of frugality as a value or individual trait.

Second, although originally developed as a model for explaining the functioning of non-Western cultures, we used Gudeman \& Rivera's theory of the house economy versus the corporate economy in our discussion of the dichotomous character of frugality in postmodern consumer society (1990). In this theory, the house is a metaphor for the small-scale, locally-based economic system. Some examples include the hacienda, small agricultural or fishing enterprises, family shops and simple craft workshops. House economies are often organised by kinship and are never fully engaged or connected with the market. The house is the oldest economic model and it exists in all cultures and periods, including the household in postmodern consumer society. The concept of 'corporation' in Gudeman \& Rivera's model is a metaphor for the economic system that emerged with capitalism and flourishes in a market economy. Exchange is its basic mechanism. Profit-making and financial growth are its driving principles. Essentially, while the goal of the house economy is to 'maintain its base' (1990: 184), a corporate economy seeks growth and expansion. Both systems practice thrift; only its application differs (Miller 1995). In the context of the dual nature of frugality in postmodern society, we found it most inspiring to explore the distinction between the dynamics of the household and the economic system. This is analyzed in Chapter 3 of this dissertation.

\section{c) Downshifting}

Downshifting in the sense of reduced spending, is closely connected with the notion of frugal and simple living. This notion is spread among all cultures and religions and has a long history (Gandolfi \& Cherrier 2009: 4). Since the world's main religions preach a balance between excess and austerity, and teach the virtue of moderation (Craig-Lees \& Hill 2002; Gandolfi \& Cherrier 2009). In the fairly recent studies of this new trend, we came across various specific terms with regard to living with less.

The most common classification is Etzioni's (1998), who distinguishes three variations of voluntary simplicity, based on the amount of the consumption reduction:

1) Downshifters have the lowest level of reduction. Often there is not a coherent pattern of spending reduction, but people might downshift in one domain and consume conspicuously in another domain.

2) Strong simplifiers restructure their lives significantly. To this second category belong people who traded their often well paid jobs for more fulfilling, but less paid positions. Strong simplifiers also include people who voluntarily decide to retire, although their pension payouts will be lower.

3) The holistic simplifiers adjust their whole life patterns according to the ethos of voluntary simplicity (Etzioni 1998: 620). They are often dedicated members of the simple living movement, inspired by writers such as Duane Elgin (1981). 
The 3 types have in common a voluntary spending reduction of consumer goods and services and the cultivation of non-material sources of satisfaction and significance (1998: 620). Downshifters are the most moderate practitioners.

In this study, we apply the basic meaning of downshifting: namely the reduction of spending, whether voluntarily or involuntarily. Downshifters are defined as people who are living with less money than they did before; whether this is done voluntarily or involuntarily becomes relevant in second instance, as a criterion to determine two sub-samples of downshifters. The voluntary downshifters thus in this study are similar to what is defined as 'downshifters' in other studies.

\section{d) Sustainability}

Theory development on sustainable consumption is still in its infancy (Jackson 2008). Generally, this study may be situated within the broad school of thought known as the Theory of Ecological Modernization. Since the mid-1990s, this perspective has addressed the ecological dimensions of consumption, as well as the role of technological innovations in environmental reform, and the institutional and cultural dynamics of ecological modernization (Mol \& Sonnenfeld 2000). Within this school of thought, Spaargaren tackles the ecological implications of consumption practices and consumer behaviour with his Social Practices Model. He addresses ecological behaviour as a behavioural and social practice. As such, he broadens the social psychological perspective of the individual operating in a kind of vacuum, toward a contextual approach in which social practices are situated within time and space and shared with others.

This concept plays an important role as a frame of reference for this study, which intends to explore living with less in the context of consumerism and consumption society. Another parallel is Spaargaren's view that the actor (e.g. the consumer) has the power to change the course of action within a specific context, as well as his view that 'green lifestyles are composed of lifestyle segments or sectors that may vary considerably among themselves with respect to the contribution they make to the net environmental impact...'(2003: 689). Implicit in this quotation is the common definition of sustainable or green consumption as the use of products and services in order to minimize the environmental impact.

In this dissertation, we utilize the broad definition proposed by the 1994 Oslo Roundtable on Sustainable Production and Consumption: 'the use of services and related products which respond to basic needs and bring a better quality of life while minimizing the use of natural resources and toxic materials as well as emissions of waste and pollutants over the life cycle of the service or product so as not to jeopardize the needs of future generations.' (Linkages 2010). However, this study goes beyond sustainable consumption as it explores opportunities for a sustainable lifestyle. In line with Callenbach's (2002) green triangle we created the Dutch triple Gs of a sustainable lifestyle: geld (money), groen (eco-friendliness) and gezondheid/welzijn (healthwellbeing). This view posits that a sustainable lifestyle results from putting the right input into each of the three pillars. The basic assumption is the concurrency between the pillars and their mutual interdependence: changes in one influence the outcome of the other two. 
With this theoretical construct we could explore the connection between finances, quality of life, use of resources and other variables of sustainable consumption, resulting from our empirical researches as described in Chapter 4 and 5.

\subsection{Outline}

This doctoral dissertation is structured as follows.

This first chapter has provided a brief description of the development of consumerism and its global dissemination. Explanations for the popularity of the consumerist lifestyle have been provided. In a reaction to the negative effects of consumerism, two social-cultural innovation movements were explored: a) Downshifting; and b) The sustainability movement. The theoretical frame of reference was elaborated thereby illuminating our epistemological choices as well as the multidisciplinary positioning of the study. Research questions and objectives were then explicated. In this final section, an outline of this dissertation is provided.

Chapter 2 analyzes the epistemic development of consumer studies based on the changed meaning of the core concepts of social stratification, consumption and consumer image. The politicization of the discipline is discussed, as is its impact on recent trends in consumer studies. The chapter concludes by suggesting a new and more holistic and integrated approach to consumer studies.

Chapter 3 explores how frugality is conceptualized, expressed and manifested in postmodern consumer society, as well as its influence on the epistemic view of consumer studies. The central focus in this cultural philosophical study is frugality's dichotomous nature which is exemplified by the duality of virtue and vice and expressed in a range of oppositional connotations. Gudeman \& Rivera's theory of the house economy and the corporate economy is used to explain the dual nature of frugality in postmodern consumer society. A behavioural, practical approach is suggested as a valuable means for overcoming the controversy and tensions surrounding frugality.

Chapter 4 reports the results of an explorative field study that was conducted to map consumer experiences within the context of consumerism and consumerist society. The Transformation Model Living with Less is presented as a ideal-typical sequence model for consumer behavioural change. Implications for further theoretical study and application in practice are discussed.

Chapter 5 presents the results of a quantitative and qualitative study of downshifting in the Netherlands. Results of previous studies in the United States, Australia and the United Kingdom are discussed. The prevailing definition of downshifting is broadened including both voluntary and involuntary downshifters. Four themes are addressed:

1) The characteristics and experiences of downshifting; 2) Frugality; 3) Consumer motives and images; and 4) Sustainability. 
Finally, Chapter 6 recapitulates the main conclusions drawn in this study. Further, it reflects on the methodology and the implications of the study of downshifting and sustainability. It also provides recommendations for future research and offers a strategy for the promotion of sustainable living. 


\section{Chapter 2}

\section{Out of sight, out of mind}

This chapter is based on:

Schreurs, J., Martens, P., Kok, G. (2010) : Out of sight, into the political arena and beyond: Consumer studies in historic epistemic perspective. 


\section{Abstract}

The observation that consumer studies have given hardly attention to forms of consumption other than buying induced us to make an epistemological analysis. The study examines the thesis that consumption and consumer behaviour are predominantly studied outside their social, cultural and historical context, thus studied using a decontextualised approach. Simultaneously, and probably as a result of this epistemic process, consumer studies have entered the political arena.

Essential in our argument is the analysis of the changed meaning of 3 core concepts in consumer studies. In particular, we consider: 1) The conceptualization of the social stratification parameters: status, class and lifestyle; 2) The conceptualization of consumption; and 3) The prevailing images of the consumer in consumer studies. In the second section of this chapter, we examine how a political arena has been created in which adversaries take up their positions. We conclude with a discussion of recent trends in consumer studies and suggest the use of an integrated approach to guarantee for a more fruitful theory development. We advocate putting consumption as academic topic back into a broad context that includes the economic, juridical, moral, aesthetic, mythological, and socio-morphological arena. Since, as Mc Cracken states: 'The complexity and centrality of the role of consumption in the transformation of Western society makes this holistic approach not just desirable but apparently unavoidable' (1987: 140). 


\subsection{Introduction}

A popular exercise for participants in Dutch budgeting courses is to imagine that someone, somewhere in a European country needs another pair of trousers because the ones she has are worn out. However, there is one problem: she does not have the money to buy a new pair of trousers. What are alternative options? The exercise is meant to encourage participants to think outside the need-and-shop automatism. Over a dozen realistic alternatives for dealing with the trouser problem exist including sewing her own pair, swapping and dumpster diving. A radical option is to abandon the desire and be content with her worn out pair of trousers.

Although living in a highly developed consumer society such as the Netherlands offers a dozen or more possibilities for acquiring a pair of trousers without actually purchasing them, consumer studies still tend to focus on just one option, namely buying a new pair of trousers, and preferably a brand-name pair. Information about consumer choices other than brand preference is rarely found in consumer studies and the concept of non-consumption has seldom been addressed (Douglas \& Isherwood 1996; Firat 1987, 2000; Holbrook \& Hirschman 1982; Holbrook 1995; Lastovicka et al 1999; Miller 1995; Schor 2000, 2001).

At first sight, it may seem obvious that non-consumption would be excluded from 'consumer' studies, but an academic perspective that includes consumption and nonconsumption is fully plausible. To quote anthropologist Mary Douglas: 'To know why people do consume, we need to understand why they sometimes do not. Where do they get the strength of mind to resist? When the stuff is there, when credit is available, when the shops flaunt their wares, when advertisements wave it under their noses, how do they manage to resist?' (1979: 107). By studying consumption and nonconsumption in their synchronization, we may be able to, as Simmel's dialectic suggests, grasp the deeper meaning of both consumption and non-consumption (Simmel 1997).

Obviously, the specific academic setting in which consumer studies have taken place has set the tone and determined its focus. As Tucker states: 'Marketing academics studied consumers as fishermen study fish rather than as marine biologists might' (Tucker 1967) This approach has produced considerable knowledge about consumer behaviours, motives, buying and selling mechanisms, and above all, it has provided a wealth of empirical data that is useful for many other disciplines as well (Miller 1995). The primary purpose of these studies has been applied science with a clear managerial purpose, namely to collect insights and techniques useful as a guide for mass markets. It must be admitted, although, that since the 1970s, a broader perspective emerged because of the influence of disciplines other than economics and marketing.

Explanations at the level of science history are important if only to understand the relative significance of scholarly endeavours. In this study, however, we are mainly 
interested in how the specific setting of consumer studies has shaped the core ideas and concepts of this discipline. Therefore, we examine the development of consumer studies from an epistemic perspective, which we label 'decontextualization'. The term is derived from Russell Belk, who in reference to the methodology of modern academic studies, introduced the concept: 'decontextualised positivist methods' (2001: 66).

In our study, we use the following definition: Decontextualization is an epistemic approach in which the object of study is considered to be an independent entity that can be analyzed and understood without consideration for its background (Thompson 1989; Firat 1989; Holbrook 1995; Campbell 1994; Belk 1995; Miller 1995). Our thesis proposes that consumption and consumer behaviour are predominantly studied outside of their social, cultural and historical context, thus studied using a decontextualised approach. Simultaneously, and possibly as a result of this epistemic process, consumer studies have entered the political arena.

Our analysis of how the meaning of the core concepts in consumer studies has transformed is of crucial importance to this argument. In the first section of this chapter, we consider the changed signification of these concepts. In particular, we consider: 1) The conceptualization of the social stratification parameters: status, class and lifestyle; 2) The conceptualization of consumption; and 3) The prevailing images of the consumer in consumer studies. In the second section, we examine how a political arena has been created in which adversaries take up their positions. In the final section, we conclude with a discussion of recent developments in consumer studies and suggest a strengthening of multidisciplinary tendencies.

We acknowledge that a concise reflection on 150 years of consumer studies may not be fully nuanced, and we are aware that exceptions to our assertions can be found. Nonetheless, for the purpose of transparancy and because space is limited, we endeavor to sketch a general picture of the epistemic development of consumer studies.

\subsection{Out of sight: changed meaning of core concepts}

To clarify how the decontextualised approach has been applied in consumer studies, we analyze the changes in significances of the core concepts in consumer studies. Successively we consider the conceptualization of a) Status, class and lifestyle; of b) Consumption; and of c) Consumer.

\section{a) Status, class and lifestyle}

The prevailing classifications for social differentiation in consumer studies are status, class and lifestyle groups. These concepts originate from Max Weber's social stratification theory (Weber 1991/1968), where they have a multidimensional meaning based on economic factors, status and power. We observed two major shifts in consumer studies regarding the use of Weber's concepts. The first shift occurred in the use of 'class' and 'status'. Although Weber stated that class and status groups partly overlap, later studies showed a distinct separation between class and status 
groups (Campbell 1995). Class became associated with the objective structure: 'market' while status was allied with the subjective structure. This division between objective and subjective structure was consolidated and, in later consumer studies, the class dimension gradually disappeared as a constituting factor in social hierarchy. Hence, status or the honour element became the dominant criteria for social stratification.

Subsequently, a second major shift took place. Weber usually connected status with immaterial, social factors and especially with the concept of status honour. In consumer studies, status became associated with, and measured by, the acquisition of consumer goods and material possessions. The assumption was that some consumer goods endow the owner with more status than others. By this, the ruling definition of status groups became simply groups who share comparable consumption patterns. These are considered to be fundamental for social differentiation (Benschop 1987; Campbell 1995).

We may conclude that a definition that began as an empirical operationalization of a social concept became an explanation in and of itself, namely that ownership of prestigious goods or consumption patterns yields similar status. Over the last decades, non-material components of status disappeared from academic sight. Such a simplification of social processes has been criticized by, among others, Campbell (1995: 103). Agreeing with Weber, Campbell notes that there was not a single source of honour, although differences in status could be expressed in different lifestyles.

We found a comparable simplification in the way the concept of 'class' was redefined in consumer studies. Although original definitions of class referred to positions in the economic system, later the concept of class was operationalized such that spending habits and purchasing power were considered the basis for social differentiation. Thus, patterns of consumption and social stratification became closely linked (Fine 1995). As Douglas stated: 'Market researchers... define social classes in terms of spending habits and then anchoring this consumption-based definition to occupation and income grouping...' (Douglas 1996: 132). Consequently, to quote McCracken (1987: 148), class became 'an endangered species of academic thought.' This concept lingered until, eventually, it almost disappeared from the vocabulary of consumer studies (Douglas 1996; McCracken 1987; Miller 1995).

The disappearance of the concept of 'class' from the consumer researchers' frame of reference meant that the categorization of society members was no longer based on production-style criteria such as occupation, education or income, but rather on consumption-style criteria as the basis for consumer profiles. Instead of class, lifestyle became the new concept for social categorization. Lifestyle was defined as a collective construct (Holt 1997) or a subculture of consumption (Schouten \& Alexander 1995) that must be understood as self-selected groups 'based on a shared commitment to a particular product class, brand or consumption' (Holt 1997: 345). At the same time, 'Lifestyles are symbolic boundaries constructed in opposition to other lifestyles pronouncing what is distinctive in a consumption pattern in relation to another' (Holt 1997: 339). As such, lifestyle can be considered the sum of the consumption of goods and buying practices. In this regard, Campbell calls it a marketing category instead of 
sociological concept

A revival of the social-cultural dimension appears to have been launched by poststructuralists such as Douglas Holt (1997). Following Bourdieu (1984), he introduced a socially contextual approach in consumer studies. The rehabilitation of the concept of status, however, was fairly limited as he argued that the importance of the social-cultural dimension in society was weakening, at least with regard to status composition: 'Whereas becoming a pillar of the local community was once the pinnacle of status achievement, this position has now become devaluated as the middle class has become vested in national consumption patterns, leaving local status to the successful working class and the dominated middle class '(Holt 1997: 339). Then again, the empirical foundation for this observation is absent.

\section{b) Consumption = buying}

Whereas consumption is generally defined in economics as the purchase and use of goods, services, materials or energy, or as the amount of goods, services, materials and energy, the majority of consumer studies focus on the collection of goods in general and buying in particular (Firat 1987; Belk 1995). In addition, a fixation on the market and on market-related consumer practices is often noted (Firat 1987; Holbrook 1995). It appears that equating consumption with buying has resulted in a systematic neglect of alternative modes of consumption.

Although history may show that market relations tend to replace social relations, numerous consumption activities still take place outside the formal market (Belk 1995; Firat 1995). Common practices that are excluded by this definition of consumption are for instance bartering, flea markets, the handing down of redundant or unwanted goods within families or among friends, and do-it-yourself activities such as making clothes, or repairing and repurposing them. A recent initiative in the Netherlands is the so-called 'give-away shop' where people bring redundant goods which are 'sold' for free. Basically, there are numerous non-monetary transactions or exchanges of services in today's society. In practice, the use of consumption practices encompasses a much broader definition than buying practices, but these have rarely been examined. The predominant perception of consumption as buying has also provoked an augmented attention to buying as an instrument of social cohesion. As a result, other agents of social cohesion such as gift-giving and sharing, which can be found in many anthropological studies, have been kept outside the purview of consumer researchers (Douglas 1996; Miller 1998; Mauss 1990). Due to the focus on consumption as buying, moreover little knowledge about pre- or post-acquisition behaviour (Lastovicka et al. 1999) or the use process (De Young 1996; Lastovicka et al. 1999) is present.

As was demonstrated by the example at the beginning of this chapter, the focus of current research is limited and numerous non-buying alternatives that are still applied in contemporary postmodern high consumerist society are ignored. The narrow focus resulting from the perception 'consumption is buying' has also resulted in an overemphasis on human activities in the consumption process. Simultaneously, questions of consumption infrastructure and institutions have received far less attention, as have the interactions between infrastructural conditions such as the omnipresence of 
advertisements, easy access to credit or loans, the increase of shopping malls and supermarket formulas, and the decrease in the number of small local stores.

\section{c) Consumer images}

The decontextualized approach seems to fit only one image of man, namely that of the homo consumens, an individual whose main activity and concern in life is the acquisition of consumer goods and services. In this context, it appears that consuming is the alpha and omega of a meaningful existence. This idea is reflected in paradigms regarding the characteristics and motivations of people in consumer societies. One paradigm posits that the consumer is a passive information processor, comparable with an automaton or a computer (Belk 1995; Firat 2000; Schor 1998; Miller 1995).

In this perspective, humans are viewed as rational and economic (Belk 1995: 59). Although this paradigm prevailed when marketing dominated consumer studies, as Belk puts it, even after the disciplines became differentiated, most 'consumer research retained the strong rationality biases inherited from economics and the strong micro biases inherited from marketing' (Belk 1995: 60).

In the 1960s, another paradigm developed because of sociological and anthropological influence. Now, the consumer is ascribed a more active role and the prevailing image becomes homo consumens as an agent, actively making consumption decisions, motivated by the desire for self-definition and self-expression (Holbrook 1995; Belk 1995; Cohen 2004).This perspective culminated in the postmodern paradigm of the homo consumens who produces himself by consuming (homo producens hominem consumentem). According to this postmodern paradigm, consumers freely experiment with identities and lifestyles, independent of the social, economic or historic cultural context. Consumption is currently understood as a symbolic, significance-constructing activity (Belk 1995; Firat 1995: 260; 2007; Miller 2006: 246): 'This means that we do not study the consumer as someone seeking to satisfy an end (needs), but as someone seeking to produce (construct) symbols' (Firat 2007).

An additional paradigm is the image of the consumer formulated in the critical tradition of consumer studies. Here, the prevailing view is that the consumer is manipulated by an oppressing, exploitative system where he is considered either a victim or a fool (Baumann 2007).

Fundamentally, these prevailing paradigms reveal negative images of man. There is a common perception that the human species is characterized by competition and rivalry and not by cooperation and solidarity. Furthermore, the common image in recent studies is the consumer as a calculating maximizer (Miller 1995). Postmodernists describe the consumer as a hedonistic, materialistic individual driven by a desire for experience and pleasure. Nevertheless, to date, no empirical evidence for such a fundamental change in human nature, as suggested by these paradigm shifts, has been found (Miller 1995; Schor 2000). We might likewise formulate the hypothesis that, in the 1960s when families spent long evening hours gathered around the table shelling peanuts while recounting family stories or playing board games, people were hedonistic. 
The postmodern perspective that the consumer produces its proper social position by consuming is questionable as well. We must ask ourselves whether Richard Branson, the well-known owner of the Virgin Group, can assume a royal identity if he drives around in the gilded coach of the Dutch queen? As well, similarly questionable is the view that the postmodern consumer can freely choose and experience an identity, and, if he no longer likes it, replace it with another identity. According to Thompson, this is a too optimistic theoretical construction which was not confirmed by his study (Thompson 1989).

All in all, it appears that prevailing consumer images are likely to be the result of a decontextualized approach rather than universal concepts. As Douglas argues: 'If scholars don't pay attention to consumer strategies of exclusion, or conserving or reaching power and privilege, there is no other explanation available than consumer's irrationality, such as greed, envy, hedonism or competition as mechanisms for behaviour' (Douglas 1976: 132).

\subsection{Into the political arena}

According to Daniel Miller (1995), the development of consumer studies as described in the preceding section has colored the discipline in such a way that most studies can be situated in the political arena. Although Miller was referring to consumer studies in the 1970s, in our view, almost the entire history of consumer studies can be interpreted as a political debate between the right and left wing, between defenders of the capitalist economic system with consumption as its driving force on one side and its critical opponents on the other.

Overall, we note two trends with regard to the political dimension of consumer studies. In the dominant tradition derived from Adam Smith's Wealth of Nations, consumption was considered necessary to stimulate the economy and increase the public good. The leading paradigm was that consumption was an activity undertaken by free individuals who were personally responsible for their consumer choices (Firat 1995; Holbrook 1995; Schor 2000). This perspective reflects a specific political interpretation, namely the liberal view that all men are equal. It tends to neglect social stratification mechanisms other than consumer objects. In this perspective, consuming can be considered a liberating act (Schor 2000), a major force for upward mobility and a basic condition for democracy.

The postmodern perspective that the consumer is a producer of signs and symbols who creates his proper identity by consuming the right goods is an optimization of this liberal perspective. According to the postmodern perspective, one's position in society is not determined by one's position in a production system or in the power hierarchy (Marx 1973/1939), nor by one's social or cultural capital (Bourdieu 1984; Holt 1996; Schor 2000), nor by the social mechanisms of exclusion or inclusion (Douglas 1976). Fundamentally, one's position in society is purely determined by one's consumption practices. Only through the acquisition of possessions and goods people create their 
position in society (Firat 2008). Clearly, the view of the consumer as an authentic individual self was replaced by the idea of a made-up self (Firat 1995: 252). Since the 1980 s thus an extremely individualistic model has arisen, basically reflecting the neoliberal views of Thatcherism and Reaganism that developed more or less simultaneously (Schor 2001).

Whereas the neo-liberal trend in consumer studies is characterized by the neglect or denial of the class position and power dimension with regard to consumption, the second political trend in consumer studies is characterized by either a long-term neglect or denial of consumption as an important social-political force, or by an explicit ideological view on consumption. Since Marx, a main focus in the social sciences and political economy has been on production and not on consumption (Firat 1995; Miller 1995). Marxist scholars have tended to consider consumption insignificant as it was an expression of false consciousness or a vice. On basis of this, consumption was ignored by the social and political sciences until the 1970s, when adherents of the Frankfurter School such as Habermas and Marcuse (1964) and French scholars such as Baudrillard (1998), Bourdieu (1984) and Bataille (1991), following in the critical tradition, began to focus attention upon the negative, oppressing effects of consumer society, such as class inequality, manipulation and alienation. Consumption was considered to be either the result of manipulation or a form of escapism. In this perspective, consumers are seen as passive victims of a manipulative culture industry; estranged, bored, manipulated fools (Baumann 2008). The ideological position conflicted fundamentally with the liberal position (Miller 1995).

During this period, the negative macro effects of consumption received substantial attention. The environmental impact of consumerism and the growing poverty in the developing world were topics of public and academic concern. This was the starting point for environmental consumer studies and the awareness that 'buying and eating food is, like any act of consumption, political and even moral' (Schor \& Holt 2000: 426). A similar critical perspective on consumption can be noted in many anthropological studies (Miller 1995; Wilk 2002). Anthropologists saw consumption as a distortion of cultural identity and conveyed wanting to protect their subjects of study 'from being transformed by outside forces' (Miller 1995: 280). Like other disciplines, their concern was mainly with consumption (Miller 1995: 264). After the decline of Neo-Marxism around the 1990s, the social sciences predominantly shifted their interest to cultural aspects of society. Economics was taken for granted and the economic-political context and factors almost disappeared from the analytical scope of research (Miller 1995; Schor 2000). 


\subsection{Beyond: observations of current perspectives}

Beginning in the 1980s, business schools and marketing departments opened their doors to other disciplines. Theory development was both broadened and deepened. At the same time, the social sciences became interested in consumption issues. What did this mean for the content of consumer studies and, with regard to the main question of this chapter, did the social sciences provoke a change in the decontextualization trend?

The Journal of Consumer Research represents the new fields of interest in business and marketing traditions. Founded in the 1980s, the journal became a gathering point for innovative theoretical discussions by anthropologists, linguists and sociologists, mostly within the walls of business schools and within the marketing tradition. The focus of the journal has been and continues to be on 'qualitative, interpretive, ethnographic, videographic, netnographic, poetic and phenomenological consumer research'. Clearly, the journal offers a forum for a broad range of 'discussions' (Arnould \& Thompson 2005: 875) or, as Firat puts it, 'a multivocality of perspectives and approaches' (2000: 293).

Illustrative of the shift towards social sciences in consumer research is the pioneering work of anthropologist Mary Douglas and economist Baron Isherwoord. In their World of Goods (1979), they introduced anthropological insight to consumer studies, conceptualizing consumer goods as means of communicating socially shared meanings. Simultaneously, the study revitalized anthropology because it moved the academic focus from exotic tribes to Western society (Miller 1995). As a result, an interesting anthropology of consumption developed (Miller 1995; Wilk 2002), as did sociology of consumption (Bauman 2008; Campbell 1995; Featherstone 1991; Ritzer 1993). The influence of psychology and economics on consumer studies declined while at the same time the impact of other social sciences increased (Miller 2006). Social sciences theory building surrounding consumption began in earnest. Thus, the two disciplines moved towards one another. The new perspectives broadened the scope of consumer research rather than replaced them (Belk 1998; Cohen 2004; Holbrook 1995). As Belk puts it: Tthis (meaning the traditional positivistic perspective) consumer research retains the strong rationality biases inherited from economics and the strong micro biases inherited from marketing' (Belk 1995: 60). Perhaps the new perspectives introduced in consumer behaviour research were more like old wines in new bottles rather than new vintages. Evidently, the theoretical frame of reference was enlarged but the following observations do make the new perspectives suspect. We must ask, are they simply a vocabulary adjustment to describe a more complicated hyperconsumerist society rather than a fundamentally different theoretical perspective representing a paradigm shift?

The first observation of note is the dominance of the marketplace as the main context of analysis in postmodern consumer studies. The shift in focus from the individual consumer as the domain of study to the marketplace definitely positions consumption 
in a broader analytical context. However, it still reflects a limited epistemic view. To paraphrase Firat (1995) this perspective reduces all consumption into one single logic, namely the market logic. Indeed, history demonstrates that market relations tend to replace social relations (Firat 1987; Schor 2000, 2001). Consequently, the marketplace becomes a more important dimension of the social domain, nonetheless there are still numerous, although non-monetary, consumer activities outside the market (Firat 1995; Belk 1995).

Replacing the concept of social reality with the marketplace concept though is too drastic a simplification. In our view, social reality may be colored by, or even modeled on, market dynamics but the two should not be equaled. Such reasoning is analogous to the economic determinism of Marxism. Since, whereas Marxism positions the production system as the centre of analysis and proposes that everything is determined by economic patterns, postmodern consumer studies tend to centralize the consumption system and thus maintain that everything is determined by market patterns. Nonetheless, we contend that both perspectives are not much more than a replay of the same epistemological tune: a decontextualised approach with limited explanatory potential.

The second observation concerns the 'consumption as communication' paradigm. This view was originally derived from the anthropological theory of Levi-Strauss and Baudrillard (1998), and it was elaborated into a theory of postmodern consumer society which is widely applied in consumer studies. The central idea of this paradigm is that, in postmodern society, the symbolic value of consumption dominates the exchange value. Contrary to the prevailing theory regarding the nature of consumption in modern society, this paradigm contends that consumption is no longer an activity for fulfilling subsistence needs, but rather an activity that meets symbolic, communicative goals. Within this frame of reference, postmodern hyper-consumption could easily become a self-explanatory phenomenon.

The 'consumption as communication' paradigm is strongly disputed within anthropology (Miller 2006) and sociology (Campbell 1995). Campbell rejects the view that signs are more important than actual material consumption goods. He argues that this thought is nothing more than 'a platitude in social sciences... Indeed we can say it with flowers, or show our affection and gratitude, but in that case, the situation, time, space and context are clearly limited' (1995: 115). Moreover, the consumption as communication paradigm presupposes that other people can 'read' the language and that the message of the sender is correctly interpreted by the receiver. Campbell argues that this is not an easy process but rather one full of complications as was also shown for instance by McCracken's study (McCracken 1988).

Another objection to the 'consumption as communication' paradigm concerns the fact that the symbolic meaning of consumption goods is presented as a typical postmodern phenomenon, suggesting a detachment from former types of consumption as nonsymbolic, but more need-driven or aimed at subsistence. This reasoning reduces multilayered anthropological theory to a time- and space-bound explanatory frame of reference. We must ask, do an increase in consumption and an excess of consumer goods provide sufficient grounds for such a fundamental paradigm shift? From an 
epistemological perspective, however, we must wonder if the postmodern frame of reference of consumer goods as signs differs fundamentally from consumer goods as objects in modern consumer studies. Both perspectives employ a method of analysis that continues to be decontextualized.

Our final observation is a consequence of the epistemic approach that has been described in the two preceding observations. Our observation concerns the limited explanatory force of the prevailing approach due to its narrow frame of reference. The paradigm of consumption as a sign did produce many interesting studies on consumption issues but descriptions of changes in consumption practices are not equivalent to an explanation. Notwithstanding, such a circulus in probando (circular reasoning) is often found in consumer studies. For example, we found negative perceptions of postmodern consumer motives: the consumer as hedonistic, materialistic or competitive.

Yet we question to what extent these observations are reflections of presuppositions rather than empirical conclusions. While it is true that the market for luxury consumption goods did increase in the booming economy of the 1990s and its dotcom millionaires, the fact that sales in a specific market segment were rising does not necessarily imply that there was an overall change in consumers' motives. The epistemic failure whereby cause and effect are confused is easily made in consumer studies. It also raises the question as to whether or not the one-dimensional view of consumption as a marketplace activity or buying exaggerates the importance of consumer activities. If academics are blind to other social dimensions then, evidently, the marketplace will assume huge proportions. An analogy can be made between the narrow focus of consumer studies and the current practice of conventional medicine, where the focus on physical symptoms for diagnosis coincides with a limited array of explanations and treatments. Using a more holistic approach, thus enlarging the patient's context, would immediately offer more input for plausible diagnosis and greater chances for successful treatment.

\subsection{Conclusions}

Mechanisms of decontextualization have greatly influenced consumer studies. Significant data have been collected at the micro level of individual consumption. Politicization has occurred simultaneously. Mainstream studies neglect or deny the relevance of the third Weberian criterion for social stratification, namely the power dimension, while the critical stream disputes consumption and the market economy. Both positions are more ideological than empirical. From the simple fact that sales were rising, as happened in the 1980s and 1990s, one should not conclude that social differences were weakening (Kotlowitz 2000), or that manipulative techniques were successfully brainwashing the masses. Miller disputes the neo-liberal perspective that consumption is democratic by referring to the growing dichotomy between the rich and the poor in the developed world (Miller 1995). He observes that $20 \%$ of the rich 
belong to the richest class in Europe, while $20 \%$ of the poor at the lowest level of the income hierarchy in Great-Britain are the poorest people in Europe.

Our purpose was to illuminate tendencies towards decontextualization that appear to culminate in postmodern paradigms of the consumer-producer and consumption as communication. Our analysis has been sketched as a general picture. We note a turn towards broader, contextual-based consumer behaviour research (Belk 2001: 74) but it is clear that theory building is still in its early stages. In order to overcome the prevailing limitations, we suggest considering consumption as a fait social total (Mauss, 1990/1924); an activity with implications for every aspect of consumer life, both political and domestic, 'being of interest both for classes and to clans and families' (Mauss 1990: 76).

This means that we have to put consumption back into a broad context that includes the economic, juridical, moral, aesthetic, mythological, and socio-morphological arenas. As often the parts are best understood only by reconstructing the whole. Since, as McCracken argues: 'The complexity and centrality of the role of consumption in the transformation of Western society makes this holistic approach not just desirable but apparently unavoidable' (1987: 140). 


\section{Chapter 3}

\section{Frugality as a core principle in postmodern consumer society}

This chapter is based on:

Schreurs, J., Martens P., Kok, G. (2009). Frugality as a core Principle in Postmodern Consumer Society. 


\section{Abstract}

In this chapter is explored how frugality is conceptualised, expressed and manifested in postmodern consumer society, as well as its influence on the epistemic view of consumer studies. The central focus of the study is frugality's dichotomous nature, exemplified by the duality of virtue and vice and expressed in a range of oppositional connotations.

Firstly, an explorative analysis is made to illustrate how frugality is manifested in public policy, in consumption and consumer behaviour and in marketing. Further, we discuss the effects of the dual nature of frugality on the epistemic view in empirical studies. Three areas of research are investigated in which frugality has received specific academic attention: 1) Frugality as the object of consumer studies; 2) Frugality in environmental studies; and 3) Studies of frugality and the 'new consumer'. We conclude that the epistemic view mainly reflects the notion of frugality as form of deviancy.

Finally, philosophical theoretical explanations are formulated, applying Gudeman \& Rivera's model of house economy and corporate economy as a frame of reference. The question of how thinking about frugality has changed over time and circumstances is addressed by an historic analysis of the three major domains of thinking: classical philosophy, religion and economics. 


\subsection{Introduction}

Frugality is a controversial theme in postmodern consumer society (De Geus 2003; Miller 1995; Nash 1998). The concept has a long tradition as a virtue (Durning 1992; Weber 2002) and has been promoted as a solution for environmental problems and poverty (De Geus 2003; Goudzwaard 1995, 2006; Janssen 1990). However, frugality has also been perceived as an obstacle for achieving a modern consumer paradise and is often regarded as an archaic and even reprehensible concept. In this view, frugality has been degraded from a virtue to a vice (Nash 1998).

The controversy is easily understood in the context of the rapid development of Western consumer society. In just half a century, consumerism and the consumerist lifestyle have become dominant cultural features in the Western world and are quickly disseminating worldwide. Nowadays over 2 billion people are practicing a consumerist lifestyle and this number is expected to increase exponentially due to the economic boom in Asia (Assadourian, 2010). A large portion of the global consumer class lives in developing countries. China and India alone represent more than $20 \%$ of the global total. As noted in chapter one with combined numbers of 362 million, the consumer class in India and China together is larger than the consumer class in all of Western Europe. Considering the burgeoning populations of these countries and their current relatively modest individual consumption levels compared to European consumers, there is enormous potential for growth (Assadourian 2010; Worldwatch 2004).Worldwide, private consumption expenditures - the amount spent on goods and services at the household level - have increased sixfold since 1950 (HDR 1998). Private consumption expenditures totalled \$20 trillion in 2000 (based on the dollar in 1995) and accelerated to $\$ 30.5$ trillion in 2006 (based on the dollar in 2008) (Assadourian 2010). This increase can only in part be attributed to population growth as population growth grew by a factor of 2.2 between 1960 and 2006 and the growth in consumption expenditures was much greater than 2.2.The number of people living a consumerist lifestyle is not only increasing; also the level of consumption is rising. In the EU-15, household consumption expenditures increased by approximately $30 \%$ between 1990 and 2002 (European Environment Agency 2005) and, on a global scale, consumption expenditures are expected to double by 2030 (World Bank 2007). In the Netherlands, consumption expenditures have increased by $20 \%$ over the past decade (CBS 2003). Admittedly, the recent economic crisis has halted this trend. In 2009, consumption expenditures decreased by $2.5 \%$ while savings increased (CBS 2010).

These facts could easily be interpreted as signs that frugality, as a cultural trait and as a basic element of consumer behaviour, is fading (De Young 1996; Miller 1995). It seems this assumption has been generally accepted and has strongly influenced the epistemic view of consumer and environmental studies, whose paradigm is that man is a materialistic, hedonistic creature. Yet this paradigm appears inappropriate when confronted with a new consumer trend that rapidly spread since the 1980s. 
A fundamental change in values from materialistic to post materialistic has taken place (Inglehart 1977) and the rise of special consumer groups labeled cultural creatives (Ray \& Andersen 2000), downshifters (Datamonitor 2002; Schor 1998), simple livers (Datamonitor 2002; Elgin 1981; Etzioni 1998) or new ascetics (Osti 2006) has been noted. The numbers of these new consumers vary from country to country with 50 million cultural creatives in the United States and 12 million European downshifters, of which half a million are Dutch downshifters (Datamonitor 2002). These new consumer groups seem to question the cultural norm 'more is better'. They choose - often voluntary - a more frugal, moderate lifestyle (Breakspear \& Hamilton 2004; Cherrier \& Randolfi 2009; Dominguez and Robin 1999; Elgin 1981; Etzioni 1998; Hamilton 2003; Hamilton \& Mail 2003; Pierce 2000; Schor 1998).

Instead of labelling these groups 'anti-materialistic' or 'anti-consumerist', this study attempts to view these groups in a new light, presupposing that frugality and moderation continue to be determinant principles in postmodern consumer societies. Apart from providing a possible explanation for the rise of new consumer trends, the notion of frugality as a core principle in postmodern society is also supported by the observation that marketing discourses predominantly address financial advantages thus the frugality motives - of consumers. Public policy makers then use the same discourse to launch large scale moderation campaigns encouraging citizens to curtail specific forms of consumption and citizens are inclined to respond appropriately. Moreover, from a cultural-historical perspective, it is unlikely that a widespread, ancient, principle such as frugality could be erased by half a century of consumption culture, assuming that the rise of mass consumption following World War II marked a break with traditional consumption practices (Cohen 2003).

In this chapter we will explore how frugality is conceptualised, expressed and manifested in postmodern consumer society, and analyze influence on the epistemic view of consumer studies. The central focus is on frugality's dichotomous nature, exemplified by the duality of virtue and vice and expressed in a range of oppositional connotations. Explanations are given on basis of a theoretical historical analysis of the development of lines of thinking on frugality.

The chapter is organised in three sections. In the first section 'Explorations', after defining frugality and related concepts, we will explore the duality of frugality as both a personal and cultural trait and its manifestations in three main areas of postmodern consumer society, namely: a) Public policy; b) The domain of consumption and consumer behaviour; and c) The domain of marketing.

In the second section 'Effects on the Epistemic View' current empirical consumer study literature is reviewed to investigate how frugality's dual nature has influenced the epistemic view. We focus on three areas of research in which frugality has received specific academic attention: 1) Frugality as the object of consumer studies; 2) Frugality in environmental studies; and 3) Studies of frugality and the 'new consumer'. In the final section 'Historical theoretical Explanations', we are situating the discussion outside the context of postmodern consumer society and address the question of the dual nature of frugality from a theoretical historical perspective. 
Applying Gudeman \& Rivera's model of house economy and corporate economy as frame of reference, we discuss the development of lines of thinking on frugality in classic philosophy, medieval religious thought, Enlightenment economics and philosophy and in modern economics.

\subsection{Explorations}

\subsubsection{Frugality and related concepts defined}

A semantic analysis determines that frugality originates from the Latin word frux: meaning fruit. The word is also related to the Latin word frui, which means enjoy (Johnsson 1979; Oxford English Dictionary Online 2008). Dutch, French and German, have similar words: Frugaliteit, Frugalité and Frugalität, respectively (Janssen 1990). It must be noted that the Dutch also have the word zuinigheid. This term is rooted in the verb zien (to see) meaning seeing well or sharply (Etymologisch woordenboek 1997). Based on this semantic analysis, frugality can be understood as the 'joyful' use of one's 'fruits'. However, it has a double significance: the act is intrinsically pleasurable and it can also lead to 'joyful' effects, as in improving on overall quality of life. So the concept refers to an action as well as to the result of this action.

In current literature, the instrumental aspect predominates: frugality is a means to achieve future ends, generally referring to self-restraint in the use of money and other - mostly material - resources. A further narrowing of the original meanings can be noted in Lastovicka's definition, where he connects frugality with 'sacrifice' (1999).

However, the intrinsic gratifications of frugal living are also considered in various studies of new consumer behaviour (Dominguez 1999; DeYoung 1996). Although Nash (1998) recombined the two original meanings of frugality: 'it (frugality) generally implies both a reduction in the consumption of goods and different patterns or kinds of consumption' (421), he also distinguished a personal dimension and a social dimension. The personal dimension of frugality consists of the manifestations of frugality in the personal domain, namely: attitudes and norms, specific skills, behaviours and practices; all in the realm of the domestic and personal domain. The social dimension of frugality is how frugality is expressed in the non-personal domain; within culture, religion, economics, politics and society (Nash 1998).

In principle, frugality denotes thrift, miserliness, temperance, moderation and sufficiency. How are these concepts interrelated? The word 'thrift' has its roots in the Old Norse word thrifask - meaning to grasp - and the concept was introduced to Middle English during the13th century in the metaphorical sense of to grow, flourish or prosper (Merriam-Webster Online Dictionary 2009). Thrift is a synonym of frugality, meaning economical management and savings (Oxford English Dictionary Online 2008). Like frugality, thrift has a double meaning: the action of careful use and the result of this proper action, such as savings and profit. The concepts of temperance and moderation generally refer to practicing specific forms of restraint. 
Both views of frugality have a long academic history. In the classical philosophy of Aristotle, frugality and thrift were considered elements of one of the main virtues of humanity: achieving a balance between excess and deficiency (De Geus 2003: 183; Nash 1998; Nussbaum 1999). At the beginning of the twentieth century when temperance movements began in North America and Europe, temperance and moderation were generally associated with restraint in the consumption of alcohol, drugs and food (Witkowski 2009). Significantly, the sustainability movement also used these terms when referring to environmentally friendly behaviours, such as restraint in the use of natural resources and reductions in CO2 emissions (De Geus 2003; Princen 2003). The main difference between frugality and thrift concerns the use of restraint. As Nash notes, 'Frugality is considered as the economic subspecies of temperance' (Nash 1998).

The concepts of 'sufficiency' and 'plenitude' also emerged in the discourse of the sustainability movement (De Geus 2003; Nash 1998). Both concepts referred to a new ideal, contrary to the existing growth model of capitalist economy. Both concepts implied an amount, degree or quantity but obscured the strategy of restrained, disciplined consumption that is needed to realise this ideal. For this reason Nash (1998) argued that sufficiency and, to a greater extent, the concept of plenitude, have a mystifying effect.

Those who practice an exceedingly frugal lifestyle are often called 'misers', 'cheapskates' or 'tightwads'. Indeed, the reluctance to spend money can lead to extremes, as when denying oneself the most basic comforts. The term derives from the Latin miser, meaning 'poor' or 'wretched', which is comparable to the modern word 'miserable' (Wikipedia 11-09-2009).

Finally, there is the word 'asceticism', meaning practicing severe self-discipline and abstention from all forms of indulgence, typically for religious reasons. Although ascetic behaviour can be characterised as extremely frugal, asceticism is clearly not synonymous with frugality. Asceticism is an act of religious devotion and faith, while frugality is perceived as a practical strategy, a means, for the realisation of specific ends.

\subsubsection{The dual nature of frugality as personal and cultural trait}

The controversy surrounding frugality is not limited to the contradicting views of virtue and vice but embodies a range of oppositional cultural traits (Aarts 1999; De Geus 2003; Durning 1992; Janssen 1990; Lastovicka et al 1999; Miller 1998; Nash 1998). What, then, are exactly these conflicting traits and how is the dual nature of frugality expressed in postmodern consumer society?

When searching for an icon in western folk culture to illustrate the cultural expression of frugality, we discovered only two iconic representations of miserliness: Scrooge, and his cartoon counterpart, Scrooge McDuck (in Dutch, Dagobert Duck). Scrooge is the main character in Dickens' Christmas Carol in Prose (Dickens 2008). Scrooge McDuck is 
Disney's adaptation of Scrooge for a younger and more modern audience. Of course Scrooge and Scrooge McDuck can be perceived as metaphors or mythic archetypes (Barthes 1972; Campbell 1991; Thompson 2004). Both characters represent the miser in the extreme, who denies every pleasure, holds onto everything he possesses and obsessively avoids spending money. Not surprisingly, the spendthrift is the opposing archetype to the miser (Simmel 1977). No icon seems to exist in today's popular culture personifying frugality as a virtue and expressing its more positive aspects. There is the stereotype of the old, unworldly woman (Lastovicka et al. 1999) but it might be as unappealing a stereotype as the miser. Analogous to these characters, the literature revealed the following negative character traits associated with frugality: austerity and asceticism (Bruckner 2002; Nash 1998); stinginess and being a skinflint; being old-fashioned (Johnsson 1979; Nash 1998), anti-consumerist and deviant (Freud 2001; Levine 1991; Simmel 1977). As well, frugality has often been associated with the elderly or the poor, especially women (Lastovicka et al. 1999).

Frugality is also perceived as the cultural or behavioural trait that is principally opposed to hedonism (Dominguez \& Robin 1999; Kasser 2007), modernity and personal freedom (Bruckner 2002; Dominguez \& Robin 1999; Elgin 1981). Moreover Nash (1998) claims that frugality is often associated with rural, backward lifestyles and understood as being anti-technological and anti-intellectual. Within this perspective, Scrooge and his cartoon counterpart, Scrooge McDuck, represent the anti-thesis of the free and happy consumer. Their obsessive frugality directly opposes the lifestyle of the hedonistic profligate.

The aversion towards these characters might be understood as a rejection of frugality as a virtuous behaviour by Western consumer societies (Bruckner 2002; Dominguez and Robin 1999; Janssen 1990; Johnson 1979; Nash 1999). Indeed, at first glance, much behaviour may be seen as manifestations of the decline of the frugal attitude. For instance, the growth of personal bankruptcies (Schor 1998), the increased numbers of compulsive shoppers (Karsten 2003) and the waste of food could easily be interpreted as lack of frugality. Nonetheless, there are good reasons to question this obvious view, as will be demonstrated in the next section.

\subsubsection{Manifestations of the dual nature of frugality}

In contemporary consumer society, frugality as a personal and cultural characteristic might be in disfavour but does this indicate a general decrease in its influence as well? Could the effects of centuries of adherence to the values of thrift and frugality be erased by 6 decades of consumerism, assuming that the demotion of frugality as a virtue began in the middle of the last century? Such a fundamental cultural change does not seem probable. It may indeed be possible that frugality as a cultural and behavioural trait is more persistent and more valued than commonly perceived. To uncover manifestations of the duality of frugality, we explored three main domains of society, 1) Public policy; 2) The domain of consumption and consumer behaviour; and 3) The domain of marketing. Our findings support our first contention that frugality continues to be an integral, determinant aspect of postmodern consumer society in spite of - or from a dialectical perspective - synchronous with its negative connotations. 


\section{a) Frugality in public policy}

In most countries, governments contributed significantly to the realisation of an acquisitive society: societies whose tendency, focus and preoccupation is the acquisition of wealth (Tawney 1921/1982: 32). In this context, governments have been smoothing the way for an elaborate system of consumption and production. Production is stimulated through investment facilities, tax regulations, marketing support, educational programs and also subsidies for research and development. As well, governments have intervened by providing direct financial incentives through product subsidies, such as the Dutch promotional campaigns to increase the consumption of dairy products, meat, fruits and vegetables. Additionally, governments covered the costs of developing the elaborated consumption infrastructure (Otnes 1988) such as the cost of road construction, communication system protocols, civil engineering policies (e.g. by favouring the development of shopping centres). Additionally, governments had a hand in creating and supporting a legal and financial infrastructure encouraging consumption. Tax measures for credit card debt, mortgage deductions and subsidies for purchasing energy saving appliances or reducing home heating costs helped to spur consumption.

It is fair to say that without government support, consumer society, as it is today, would not have been possible. Government policies fostered the ideas that spending warranted government involvement, that lending money was morally and socially acceptable and that consumption was actually of the utmost importance. Never before was this governmental vision so clearly expressed as when New York Mayor, Rudolph Giuliani and former US President George Bush appealed to the American public not to curtail their spending shortly after the attack on the Twin Towers (Levine 2006: 2). As a matter of fact buying and consuming were presented as a patriotic duty. Consequently, non-consumption and frugality were presented forms of deviant behaviour or, even worse, indications of subversive behaviour.

Throughout history and up to the present day however, there also have been many government policies that encouraged citizens to be frugal and practice moderation. These policies were usually put in place during periods of scarcity such as during World War II (Cohen 2004; Schreurs 1989) and during the oil crisis in the 1970s. In his study of the frugality discourse in the United States, Witkowski (2009) cites a range of thrift movements endorsed if not supported by authorities throughout history. Starting with the American colonies' 'Non-Importation Movement' of 1765-1770 and continuing throughout the great Depression and World War II, American citizens were encouraged by government to handle goods resourcefully and save money. Albeit, as Witkowski notes, the aim was not anti-consumption but rather the proper choice and use of goods.

Currently, for instance the economical use of energy and water has become a main governmental goal in the Netherlands and many other European countries because of sustainability concerns. Campaigns for environmentally appropriate behaviours have been successful. The results have shown a slight decrease in $\mathrm{CO}_{2}$ emissions per household. In a number of EU countries other -also successful - campaigns encouraged citizens to recycle reusable resources such as glass, cans, paper and plastic 
www.milieucentraal.nl). Various public health campaigns have also appealed to frugal attitudes, such as campaigns that stressed the importance of moderating the consumption of alcohol and cigarettes. These and similar 'moderation' campaigns would not be successful unless citizens were receptive to the message of frugality and moderation (Aarts 1999; Kasser 2002).

\section{b) Frugality manifested in consumption and consumer behaviour}

As was the case with frugality and public policy, the duality of frugality can also be found in the domain of consumption and consumer behaviour. On the one hand there is the vision of the non -frugal, materialistic and hedonistic consumer. This perspective can be easily understood in the context of the rapid development of Western consumer society and increasing global consumerism. Although this vision of the nonfrugal consumer has been a persistent paradigm in consumer studies, it appears to be inappropriate when confronted with a new consumer trend that emerged in the 1980s: the voluntary downshifters and simple livers. On the other hand, many indications can be noticed supporting the idea that frugality is a determining, living consumption principle (Miller 1998) in modern society, especially if we consider frugality to be resourceful use and avoidance of waste (Lastovicka et al. 1998).

In his study of shoppers in London suburbs, anthropologist Daniel Miller (1995) concluded that frugality is still a decisive aspect of consumer behaviour: 'Yet this (frugality) may well still be a vital part of the moral economy of the home as well as an important element of rivalry and status competition between housewives' (37). He raises the question of whether bargain hunting and spending one's money economically are the most important motives for consumption and he criticises the view that the modern consumer is mainly driven by hedonism and materialism. According to Miller, there is no convincing evidence for a fundamental change in traditional consumer motives.

Bargain supermarkets, discount shops and special offers are very attractive to consumers (Karsten 2003). During sales, shops are crowded with people busily bargain hunting, trying to get as much value for their money as possible. The popularity of garage sales, second hand shops, eBay and other second-hand websites is further proof of people wanting to use their money as resourcefully as possible (Aarts 1999; Karsten 2003; Miller 1995; Nash 2007). However, Miller argues that there is another reason. Bargain hunting might have an important social effect as well. Sharing information about where to find the best deals can contribute to social prestige and status (Miller 1998). Another social function is mentioned by Bourdieu (1984), who connected moderate consumption with social distinction. People with high cultural capital ostentatiously demonstrate their non-consumption (Aarts 1999; Bourdieu 1984) to distinguish themselves from the conspicuous consumption of the nouveau riche. Other studies indicate that the upper classes have traditionally derived status and prestige from frugal behaviour (Bourdieu 1984; Montijn 1998). 


\section{c) Frugality manifested in the marketing domain}

Frugality is probably the source of inspiration for marketing strategies more often than materialism or hedonism. For example, brand campaigns usually appeal to the value for money principle (Packard 1960) rather than lavish improvidence. The advertisements often seem to imply that the product is everlasting. The advertisements never suggest, 'Buy this, if it does not satisfy, just throw it away and buy another one'. Selling points such as high quality, durability, long-lasting use and comfort and, in the case of commonplace products, advantageous prices are often mentioned. Quantity relationships are emphasized, discounts are offered or other premiums are promoted. Bargain hunting 'events' are deliberately staged by department stores with yearly special sale days. In the Netherlands, two of these 'frugality festivals' are De Drie Dwaze Dagen (The Three Silly Days) held at the Bijenkorf department store and Het Prijzen Circus (The Prices Circus) held at the V\&D department store (Karsten 2003).

Clearly, our analysis of the manifestations of frugality in public policy, consumption and marketing demonstrates that the concept of frugality is still present in consumer society. Indeed its manifestations are dichotomous and are accompanied by tensions, as Witkowski (2009: 24) argues in his recent study of the history of frugality. He indicates three contested areas in frugality discourse, namely religion, politics and society. In this chapter we will continue with investigating the effect of the duality of frugality on the epistemic view in empirical researches in consumer studies and environmental studies, which constitutes a main academic domain of this thesis.

\subsection{Effects on the epistemic view}

Our investigation of the socio-cultural meaning of frugality has found a sharp contrast between the practice of frugality and its negative connotations. We will now explore how frugality is conceptualised in empirical consumer research and discuss its epistemic view within the perspective of the contemporary duality of frugality. We will focus on three domains of research in which frugality has received specific scholarly attention: consumer studies, environmental studies and new consumer studies.

\subsubsection{Frugality in consumer studies}

Frugality has long been ignored in scholarly literature on consumer behaviour (Firat 1995; Kasser 2007; Lastovicka et al. 1999; Miller 1995). As was noted earlier in one and a half centuries of consumer studies, academic attention has focused mainly on purchasing behaviour and spending (Holbrook 1995: 12) or on those consumer traits or consumption topics that were directly related to purchasing behaviour. Overall, questions outside the purview of the market were outside the scope of consumer studies (Belk 1995; Firat 1995).

While frugality is deemed an important virtue by most world religions and a determining factor in Western cultural history (Aarts 2000; De Geus 2003; Durning 
1992; Goudzwaard 2006; Weber 2002), remarkably, it is not part of the VALS (acronym: Values, Attitudes and Lifestyles) or other inventories used to measure Western consumer values (Todd \& Lawson 2003). Interestingly, in Asian research the topic has been touched upon in questionnaires (Lastovicka et al. 1999).

The first empirical study of frugality as a consumer trait was conducted in 1999. In a six study program, Lastovicka et al. (1999) developed and evaluated the Frugality Scale, which resulted in the following conceptualisation of frugality: 'a lifestyle trait reflecting disciplined acquisition and resourcefulness in product and service use. Frugality is sacrifice in denying a series of short-term purchasing whims and industriousness by resourcefully using what is already owned or available for use; all of this is in service of achieving longer-term goals' (96). The study program determined that there is no correlation between ecocentrism and frugality or between frugality and age. The researchers also found that frugal people are less susceptible to interpersonal influence, less materialistic, make fewer compulsive purchases and are more price and value conscious compared to other consumers (Lastovicka et al. 1999: 96).

Findings of a New Zealand research study support Lastovicka and colleagues' contention that frugality could best be viewed as a lifestyle choice instead of a single value (Todd and Lawson 2003). In support of this, data from Israeli consumers also found that frugal consumers were more value and price conscious (Shoham \& Brencic 2004).

\subsubsection{Frugality in environmental studies}

In the 1970s, frugality and moderation were proposed as possible solutions for environmental damage caused by over-consumption. Warren Johnson was an important and influential proponent in this debate. In his essay entitled Muddling toward Frugality (1978), he argued for the adoption of a moderate lifestyle to secure natural resources for future generations and to bridge the gap between rich and poor countries. Many other appeals for frugality and studies on sustainable development followed (Aarts 1999; De Geus 2003; Goudzwaard 2006; Moll \& Groot-Marcus 2002; Peasch \& Schmidt 1999; Spaargaren 2001; Vlek \& Gatersleben 1995). Empirical studies on how to achieve the desired moderation and encourage frugality mainly focused on reducing energy consumption and not on moderation of consumption per se, as it was thought that a voluntary reduction in consumption would be counter to prevailing socio-cultural values (Moll \& Groot-Marcus 2002).

What do these studies demonstrate about frugality and moderate consumption behaviour? Overall, the results of these studies demonstrate that there is a potential for influencing the adoption of frugal attitudes in the sense of carefully handling and effectively reducing the use of resources such as energy and water (Moll \& GrootMarcus 2002; Peach \& Schmidt 1999; Staats \& Harland 1995; Staats et al. 2004). Furthermore, there is a strong indication that such a behavioural change has a lasting quality, although the measure of moderation may decline over the course of time (Staats \& Harland 1995; Staats et al. 2004). In this context, three specific results are notable. 
First frugality was not universally applied to all forms of energy consumption; rather, it was only applied selectively. Studies found that subjects had difficulty reducing car use, forgoing the use of appliances and restricting their choice of holiday destinations. These options for reducing energy use were perceived as too onerous with respect to maintaining the standard of living (Moll \& Groot-Marcus 2002). Thus, quality of life may be an important criterion for pro-environmental behaviour change.

Household energy reduction appeared to be encouraged by the presence of appropriate institutional and physical infrastructures, which ensured adequate public transportation, accessibility to provisions in the neighbourhood and the availability of technical provisions (Moll \& Groot-Marcus 2002; Spaargaren 2002). Results of the Dutch EcoTeam Programme showed the success of an intervention that combined information, feedback and social interaction in a group setting. A longitudinal study found that this approach resulted in a durable change towards more frugal and proenvironmental consumption (Staats et al. 2004).

A second category derived from the literature concerns basic human drives and moderation. In this respect, the discussion focused on two positions, namely egocentrism and ecocentrism (a human centred system of values versus a nature centred system of values). Studies showed that personal benefits have far more weight than environmental arguments (De Young 1996; Lastovicka et al. 1999; Moll \& GrootMarcus 2002; Peace \& Schmidt 1999). As Lastovicka and colleagues (1999) noted, 'A motivation to save the planet and being frugal are unrelated' (96). On the other hand, Shaw \& Newholm (2002), discriminated a category of ethical simplifiers, defining them as people who are motivated mainly by concern for the environment and social justice. The members of this group had very diverse perspectives and behaviours but shared the moral compulsion for ethical consumption. Studies on the motivations of voluntary simplifiers to reduce consumption behaviour demonstrated a sincere concern for the ecological environment (Craig-Lees \& Hill 2002; Huneke 2005; Leonard-Barton 1981).

Thirdly, with regard to the connection between status and voluntary moderation, Aarts (1999) assumed, in accordance with Bourdieu (1984), that cultural capital might be a source of status rather than the demonstration of economic capital through conspicuous consumption. Eventually, the results of the study yet did not confirm this hypothesis. Aarts concluded that the higher educated, high income group of participants was more conscious about the environment and more willing to moderate consumption but that their actual behaviour demonstrated the opposite: generally they had higher energy consumption, more car use, more flight kilometres and more use of household appliances.

\subsubsection{Frugality and new consumer studies}

The final source of information regarding frugality and moderation in consumer behaviour are the studies on new consumers such as the voluntary simplifiers and downshifters that emerged during the 1980s in the US and the 1990s in Europe 
(Datamonitor 2003; Elgin 1981; Etzioni 1998; Pierce 2000; Schor 1998). With regard to the size of these new consumer groups, Schor (1998) noted that almost one fifth (19\%) of adult Americans voluntarily chose a lifestyle change resulting in decreased earnings (excluding retirement). Another $12 \%$ involuntarily downshifted due to job loss, reduced working hours or pay cuts. Even in this group, $24 \%$ reported that the new situation was a blessing in disguise. Datamonitor (2003) estimated 12 million downshifters across Europe (2002). In the UK, an estimated $20 \%$ to $35 \%$ of adults between the ages of 30 and 59 had downshifted with an average income loss of $40 \%$ (Datamonitor 2003). Australian research showed that a quarter of the 30 to 59 age group had downshifted.

These new consumer groups are characterised by frugal attitudes or behaviour, expressed by voluntarily cutting expenses (Etzioni 1998; Schor 1998), maximising control and minimising consumption (Huneke 2005; Leonard-Barton 1981) or by limiting material possessions (Craig-Lees \& Hill 2002). Downshifters are defined as practicing the most moderate form (Etzioni 1998; Schor 1998).Voluntary simplifiers (term coined by Elgin 1981) or strong or holistic simplifiers (suggested by Etzioni 1998) are characterised by a more radical lifestyle change, often drastically curtailing income and consumption (Etzioni 1998; Schor 1998). In this respect, Elgin's criteria for defining voluntary simplifiers are commonly accepted in the literature and are as follows:

1) Practicing minimal consumption, i.e. living with less; 2 ) Increased focus on people;

3) Community-oriented; 4) Focused on harmony and self, well-being and growth; and

5) Environmentally and/or spiritually focused (Elgin 1981).

An investigation of the empirical studies concerning these new consumers resulted in a number of remarkable findings with regard to frugality. Firstly, demographic data on downshifters showed that they were represented across all age groups and social strata. This new consumer trend seems to cut across income groups, education levels, race and gender (Datamonitor 2003; Schor 1998). In both researches it was concluded that downshifters were not outsiders or countercultural. They are considered to be actively participating in society (Schor 1998). Demographic analyses of voluntary simplifiers yet show conflicting results. Some studies indicated that voluntary or strong simplifiers are highly educated, high earners (Etzioni 1998; Leonard-Barton 1981; Schor 1998) and are over-represented by middle class females (Schor 1998).

Pierce (2000) also found that females predominated, as did high educational levels but she noted a variation in income level. Finally, Huneke's (2005) nationwide sample of American consumers found that voluntary simplicity was often a deliberate choice, not only for high-income earners but also for more modest income earners. In this respect, Schor (1998) argues that it might be advantageous to avoid focusing too much on income levels. Inspired by Bourdieu (1984), she argued that simplifiers might be poor in economic capital but not in cultural capital: 'Unlike the traditional poor, they have options, including the option of jumping back into mainstream culture' (137).

Secondly, the empirical literature on new consumers provided evident motives for choosing a more frugal lifestyle. The following motives and reasons were mentioned: dissatisfaction with the work-and-spend culture and the need for more personal time 
and less stress (Craig-Lees \& Hill 2002; Etzioni 1998; Schor 1998); concern for the environment (Huneke 2005; Leonard-Barton 1981) as well as spiritual and self-interest motives such as personal growth and well-being (Craig-Lees \& Hill 2002).

The choice for voluntary simplicity can also be driven by a desire to fulfill higher needs (Maslow 1968), particularly the need for authenticity (Todd \& Lawson 2003; Zavestovski 2002).

Thirdly, the literature provided data about behavioural strategies and frugal practices. Downshifters and simplifiers seem to react primarily to the high cost of the new consumerism (remind Schor's ongoing up scaling of competitive spending) on their personal life and/or on the environment. Consequently, frugality, in the sense of reducing consumption, is chosen as a strategy 'to get control over their time, their money. They want to make deliberate decisions rather than feel they are conforming to the image advanced in advertising and popular culture '(Huneke 2005: 547).

Frugality, however, is not an overall strategy; it is often applied selectively (Huneke 2005; Pierce 2000; Schor 1998). Studies showed that expenses were cut to reduce clutter (Schor 1998) and energy consumption (Huneke 2005). Expenses were also cut for dining out, visiting theatres and cinemas and travel (Craig-Lees \& Hill 2002; Huneke 2005; Pierce 2000). This indicates a fundamental reprioritisation of consumption habits (Todd \& Lawson 2003).

Fourthly, the literature provided significant information regarding the characteristics of consumption behaviour. Schor's comprehensive and inspiring study (1998) showed that the importance of status consumption has strongly declined. According to her research, downshifters reject the standard meanings of commodities. They emphasise function over symbolism: ' $a$ car symbolizes air pollution instead of power or sexuality' (Schor 1998: 139). In line with this Craig-Lees \& Hill (2002) found that voluntary simplifiers are primarily value-for-money seekers. They do consume brands, not for status seeking but because of a well defined perception of product quality (Craig-Lees \& Hill 2002). Other studies of voluntary simplifiers also showed that, overall, status consumption has become less important.

In accordance with Etzioni's assumption that 'consumerism, not consumption, is the target of voluntary simplicity' (Etzioni 1998: 634), empirical studies have shown that voluntary simplifiers often have negative attitudes towards advertising and also watch less television (Schor 1998). Pierce (2000) found that the number of TV viewing hours among voluntary simplifiers was far less than the national average. Studies further indicated that unlike downshifters voluntary simplifiers tend to exhibit an anticonsumerist attitude (Cherrier \& Murray 2002; Etzioni 1998; Huneke 2005; Johnston \& Burton 2002; Schor 1998). But anti-consumerism should not be equated with antimaterialism. Interestingly, some studies suggested that downshifting and voluntary simplifying encourage a greater attachment to, and care for, material possessions (Dominguez \& Robin 1998; Elgin 1981; Pierce 2000). 
Is there a connection between the frugality of the downshifters and simplifiers and deprivation or anti-hedonism? Huneke (2005) found that simplifiers who reduced spending and used what they already had resourcefully did not see their behaviour as a form of deprivation. Instead, they felt it contributed to their quality of life. Pierce described this as follows: 'Living lightly on a material basis can translate into an emotional and spiritual lightness of being' (2000: 137).

\subsubsection{Conclusions with regard to the epistemic view}

The review of the empirical studies of frugality clarified the ruling epistemic view in each of the three domains of study. In the domain of consumer studies, we concluded that frugality was mostly ignored as an object of study.

From an epistemic point of view, the lack of emphasis on frugality has had an important effect. The dominant paradigm of traditional consumer studies assumes that consumers are mainly driven by materialism and hedonism (Firat 1995; Holbrook 1995; Kasser 2002). As a result, frugality has been conceptualised as being contrary to hedonism and materialism (Miller 1998; Pierce 2000; Todd and Lawson 2003) and has been associated with 'sacrifice'. As a consumer trait, frugality has been labelled 'antimaterialistic' and 'anti-hedonistic'. Within the context of this perspective, new consumers such as downshifters or voluntary simplifiers are labelled 'critical consumers', 'post-materialists' or 'people driven by anti-consumerism'.

Overall, the results of 'green studies' demonstrated that people are willing to moderate energy consumption and change their consumption behaviour as long as their quality of life is maintained and when adequate infrastructure and social conditions are actually present. Motives for moderation appeared intrinsic, based on egocentrism rather than on ecocentric motivations, although studies of voluntary simplifiers have shown that a moral compulsion or a commitment to the environment can play an important role.

Essentially, the epistemic view of frugality in 'green studies' is mixed. On the one hand, there is the notion that humans have the ability to realise pro-environmental change, i.e. to reduce their energy consumption pattern. On the other hand, ruling paradigm is that behavioural change is limited by the temptations of consumption or, in other words, by the hedonistic and egocentric human nature. Consequently, it is considered to be rather difficult - albeit impossible - to instill basic forms of frugality.

With regard to the dual nature of frugality, our overall conclusion may be that the epistemic view in empirical consumer research predominantly reflects the notion of frugality as a form of deviancy. We found frugality defined in opposition to an assumed social and cultural standard. Hence it is generally conceptualised in 'anti' terms, such as anti-materialistic, anti-egoistic, anti-hedonistic and anti-consumerist. 


\subsection{Historical-theoretical explanations}

In the final section of this third chapter, we are situating the question of the dual nature of frugality outside the context of postmodern consumer society and address it from a theoretical historical perspective. A major frame of reference in this discussion is Gudeman \& Rivera's model of the house economy and the corporate economy In this model, the house is a metaphor for the small-scale, locally-based economic system that wholly or partly produces its own means of maintenance (1990:39).

Some examples include the hacienda, small agricultural or fishing enterprises, family shops and simple craft workshops.

House economies are often organised by kinship and are never fully engaged or connected with the market. The house is the oldest economic model and it exists in all cultures and periods, including the household in postmodern consumer society. Conversely the concept of 'corporation' in Gudeman \& Rivera's model is a metaphor for the economic system that emerged with capitalism and flourishes in a market economy. Exchange is its basic mechanism. Profit-making and financial growth are its driving principles. While the goal of the house economy is to 'maintain the base', corporate economy seeks growth and expansion. Both systems thus practice thrift, although from a fundamentally different perspective (Miller 1995).

With this model in mind, we will now address the question of how thinking about frugality has changed over time and circumstances. The discussion will be situated in the three domains in which a specific body of thought has evolved: in (classical) philosophy and religion for obvious reasons, since these are the domains where traditionally the thinking on frugality has evolved. As will be demonstrated, since the rise of capitalism a major reformulation of the discourse on frugality has taken place in the third domain: economics.

\subsubsection{Philosophical thinking on frugality}

Two classical scholars are generally considered to be the founding theorists in the area of frugality: the philosopher Aristotle (384 BC - $322 \mathrm{BC}$ ) because of his work on ethics and the writer/historian Xenophon (ca. 430 BC - 355 BC) for his consideration of the home economy (De Geus 2003; Gudeman \& Rivera 1990; Nussbaum 1999; Schumpeter 1955: 54). Both philosophers have laid the basis for epistemic development in the domains of philosophy and economics.

Aristotle's work is of major importance for understanding the virtuous life in general and moderation in particular. In his Ethica Nichomachea, he described eleven domains, each representing a unique basic experience of human life (Hupperts \& Poortman 2005; Nussbaum 1999). All human beings have to deal with their mortality, their bodily desires and pleasures and their personal property. According to Aristotle, the behavioural alternatives are limited in each domain. He argued that humans were 
naturally inclined to choose the right behaviour; that is, humans tend to a virtuous life because the right attitude and behaviour will lead to happiness. In his view, a specific virtue is linked to each grounding life experience (a term proposed by Nussbaum 1999). The virtue of concern is moderation in the domain of desire and pleasure. For Aristotle, every human being's challenge is to achieve a balance between opposing forces. Thus, a virtue can be considered as a compass directing human acts in ways that promote balance. The virtue of moderation contributes to reach an equilibrium between excess and deficiency (De Geus 2003: 184). In this regard, frugality is the strategy for reaching the equilibrium that Aristotle labelled 'the golden mean'. The ideas of Aristotle have not only influenced modern thinking through its remnants in Western religious philosophy but his thoughts are still an integral, recognisable component of postmodern vocabulary and a relevant ideological frame of reference. Aristotle's philosophy also provides the ideological foundation for contemporary philosophers of sustainability and other 'green' theorists who discuss the excesses of today's consumer society (De Geus 2003). For example, the ecological virtues expressed by John Barry (1999) follow directly from Aristotle's original ethics.

The second influential classical philosopher is Xenophon. His work Oikonomikos is considered to be a forerunner of (political) economy. It contains the first description of the house economy (Gudeman \& Rivera 1990: 169; Schumpeter 1999), as well a description of a new role for women: the housewife as a manager of the household rather than a strain upon it (Glazebrook 2009). Xenophon describes the proper management of the house in detail, giving attention to industrious work, careful spending and the importance of the proper management of the house and its properties.

Similar ideas are found in early Latin texts by writers such as Cato Maior (234 BC - 149 $B C$ ), Columella (4 AD - $70 A D$ ), Varro Reatinus (116 BC- $27 \mathrm{BC}$ ) and Palladius (Gudeman \& Rivera 1990: 169; Schumpeter 1955). In his manual on farming entitled De Agri Cultura, Cato Maior mentions the importance of careful spending in order to ensure a surplus. Moral concerns about economic phenomena are also expressed in these writings, such as preaching against luxury and irresponsible wealth or urging restraint, moderation and charity. According to Schumpeter (1955: 71), here lies the foundation for early Christian thought rather than a scientific base for economics.

\subsubsection{Frugality in religious thinking}

It might seem obvious to start the discussion of frugality in religious thought with the ideas of Calvin, for the two have been intimately linked ever since Weber wrote his Protestant Ethic and the Spirit of Capitalism. But two meaningful developments in the Catholic medieval church clearly predated Calvin. Firstly, there was the rise of mendicant orders, which were founded to invigorate the life of the Catholic Church and reconnect with ordinary people. These new orders, among which the Friars Minors founded by Saint Francis (1181 - 1226), renounced all wordly possessions and devoted to serving the poor. Concurrently, developed the European scholasticism which was greatly influenced by classical works. The scholastics' sentiments can be heard in the 
texts of the schoolmen, of whom St Thomas Aquinas (1224 - 1274) was undoubtedly the most prominent theologian for the Catholic tradition. This Church Father offered, among other things, a remarkably systematic and thorough account of the virtues, reinterpreting the ethics of Aristotle.

In Aquinas' view, temperance was one of the cardinal virtues or one of the major principles of life, defined as the disciplined self-mastery (sophrosyne) of the bodily pleasures of touch and taste (Nash, 1998: 422). The subsidiary virtues that fall under temperance are quite remarkable because they serve to moderate the most insatiable human passions. For example, chastity, sobriety and abstinence, which denote restraint in the areas of sex, drink, and food, respectively, are all evident aspects of temperance. Also, humility is an aspect of temperance, since humility restrains the immoderate desire of what one cannot achieve. Likewise, temperance includes the virtues needed to master anger or curiosity. As Aquinas wrote: 'Whatever virtues restrain or suppress, and the actions which moderate the impetuosity of the passions, are considered parts of temperance' (ST Ilallae 161.4). Thus, contrary to the current limited connotations of temperance (namely restricted to alcohol, food and sex), it was a capital virtue in Aquinas' philosophy with a broad range of applications. It was a collective term for a specific way of life. In this sense, the concept of temperance denotes a basic attitude guiding specific behavioural practices in many life domains.

The scholastics reflected on the new developments brought on by the growing commercial economy of the age as well (Schumpeter 1955). More than a simple contribution to economics, as Tawney argues (1938: 44), their moral assumptions impacted the social thought in the sixteenth and seventeenth centuries. In their view, economic interests were subordinate to the real business of life, namely salvation.

Furthermore, the scholastics thought that economic conduct was an aspect of human conduct and was therefore regulated by the rules of morality. They advocated the wise stewardship of wealth and resources and defended limited acquisition of property. Admittedly, private property was valued because it stimulated industriousness but it was always seen as a means and not as an end in itself: 'Riches, as St. Antonio says, exist for men, not men for riches' (Tawney 1938: 45). Consequently, moderation, temperance and the careful handling of resources were major features in the Catholic tradition. Although temperance was advocated for its parishioners, the Roman Catholic Church itself presented the opposite image, namely one of luxury and ostentation. In the $16^{\text {th }}$ century, in reaction to this perceived excess, a reformative, protestant movement began.

Calvin was the most outspoken in his thoughts about moderation and the new economy. Contrary to Luther and the scholastics who saw economic life through the eyes of a peasant, Calvinism was an urban movement (Schumpeter 1955; Tawney 1938). Calvin (1509-1564) and others primarily addressed the leaders in the great business centres of the time. In essence, they addressed the very classes that were engaged in trade and industry (Tawney 1938: 105). Calvinism was crucial for the rise of capitalism because it provided the ethos in which capitalism could develop. 
According to Weber, the Calvinist interpretation of predestination urged its followers to work hard, avoid worldly pleasures and create business success as an overt demonstration of their salvation. It was: 'the religious valuation of restless, continuous, systematic work in a worldly calling, as the highest means of asceticism, and at the same time the surest and most evident proof of rebirth and genuine faith' (Weber 1958: 172).

Surely, the 'spirit of capitalism' did not promote greed, but rather the opposite (Ritzer 2000: 251). Work ethic and business acumen were practiced as a contribution to society and a means of demonstrating personal salvation. Frugality in business was thus considered a moral duty. It was not meant for reinvestment in the service of profit making, as is generally thought; the financial surplus was to benefit one's neighbours and society. Frugality was considered a means of serving society as well as a demonstration of personal salvation. This view meant a clear break with the prevailing morality that disapproved of accumulating wealth on just moral grounds. Calvin provided 'the first systematic body of religious teaching.... to recognize and applaud economic virtues' (Tawney 1938: 106). Calvin's theology of predestination turned profit making into a moral virtue. Fundamentally, he provided nascent capitalism with a moral frame of reference. In his reflections on the new concept of profit making, we can find the ethical foundation that began with Aristotle. Theoretically, Calvin can be seen as the bridge between two eras because he translated the vocabulary of the house economy into the new language of the market economy (Gudeman \& Rivera 1990).

\subsubsection{Enlightenment philosophy and economics}

From the 1750s on, a new era emerged in the economic sphere and in economic literature. The house as a metaphor for small-scale personal enterprises such as the farm, the craft workshop or the small shop was no longer representative of the economy. It had been replaced by the concept of the capitalist enterprise: the corporation. Gradually, the corporation became the focus of economic analysis, although the house model still continued to be central frame of reference.

The second transformation was the break with the morality that characterised earlier writings (Gudeman \& Rivera 1990; Schumpeter 1955; Tawney 1938). Instead, a secular, more rational and businesslike tone manifested itself in the discussion of frugality. In this respect, the Enlightenment philosopher, David Hume (1711 - 1776), and his contemporaries Adam Smith (1723 - 1790) and James Stuart (1713 - 1780), often referred to as the Scottish Enlightenment, strongly influenced the development of philosophy and economics. The three were ardent proponents of thrift: 'Parsimony, and not industry is the immediate cause of the increase of capital', wrote David Hume. Adam Smith, in his famous Wealth of Nations, expressed a similar sentiment: 'Every prodigal appears to be a public enemy, and every frugal man a public benefactor (1937: 362). In their view, savings could be made through thrift. Only in this way could capital be obtained and capital was seen as indispensable for reinvestment and 
necessary for productive use (Gudeman \& Rivera 1990: 178). From this, the precautionary function of frugality, previously restricted to the domain of the house, was now extended towards the monetary market system. An extra dimension yet was added: frugality was also perceived as a means to make financial profit, apart from a means of salvation, which, from a transcendental viewpoint, also might be understood as a form of profit.

Another new theme concerned the relationship between the house economy and corporate economy. 'Savings private can be a boundary for economic growth', stated Adam Smith (1776/1937). Frugality as a precautionary measure in the home economy became questioned. Increasingly, the interests of the house economy and thus of the household began to diverge from the interests of the corporate economy.

\subsubsection{Frugality in modern economics}

A major theme in how we think about frugality is the question of how to handle limits. In the case of emerging capitalism, it concerns the limits of growth, demands, populations and possibilities. These questions, which were framed by Aristotle in terms of moderation and the golden mean, were now being studied within the new context of the market economy, as in the writings of Malthus (1766 - 1834). Addressing the economic depression resulting from the Napoleonic wars, Malthus (who is well known for his principle of population and the law of diminishing returns that started a discussion about effective demands) formulated the doctrine of proportions. In his view, the main challenge of political economy is to achieve the right balance between the interrelated parts. The main question is not how to create the 'wealth of nations' but rather how to create the right optimum. Malthus, in addressing the adequate and effective forms of consumption brought Aristotle's principle of the golden mean back into the discussion, but now directly related to economics (Malthus 1951). In his Theory of Gluts, he presents the idea that a strong increase in consumption is socially undesirable: an increase in demand lowers prices and, by consequence, diminishes the general prosperity of a nation.

A defense of limited growth can also be found in the work of John Stuart Mill 1806 - 1873). In his Principles on Political Economy (1929/1848), the liberal thinker argued that only a stationary, sustainable economy can guarantee the improvement of the human condition. Therefore, economic growth should be limited by the demands of nature and other's interests (Mill 1911; Gudeman \& Rivera 1908: 181). In Mill's era during the nineteenth century, indeed thrift and saving were seen as common practices in households. Rural peasants as well as middle class city dwellers still adhered to their traditions and created reserves to make provisions for the future. This attitude required hoarding wealth and keeping money out of the profit-making economy.

The discussion on hoarding disappeared until Keynes (1883-1946) expressed his view that thrift and savings were obstacles to economic growth. He argues that it is in the interest of the economy that people increase their spending. According to John 
Maynard Keynes, the natural, instinctive impulse of man had to be overcome: 'The weakness of the inducement to invest has always been the key to the economic problem... The desire of the individual to augment his personal wealth by abstaining from consumption has usually been stronger than the inducement to the entrepreneur' (Keynes 1964 [1936]: 347-8). Interest paid on money invested was considered the reward for not hoarding. In his model, interest is not the result of abstinence, thrift or restraint but constitutes a return for giving up the security of a liquid hoard. This leads to Keynes' Paradox of Thrift: the automatic response to save in times of economic crisis hinders the resolution of the crisis. What is right for the individual is harmful for society. This proposition has been widely accepted by economists and politicians and has been transformed into the widely accepted view of consuming as a patriotic duty. Paraphrasing Adam Smith's statement, the ruling paradigm in postmodern consumer society has become: every frugal is an enemy and every prodigal a public benefactor.

\subsection{Discussion and conclusion}

In this chapter, we examined how frugality is conceptualised and practiced in postmodern consumer society. Our analysis of practices in three areas, namely public policy, consumption behaviour and marketing, provided support for the view that frugality in postmodern consumer society has a dichotomous nature, consisting of a range of positive and negative connotations that go beyond the obvious contradiction of virtue and vice. This duality indicates a more fundamental cultural narrative of 'deviancy versus normality', which would be a very interesting issue for further study. The analysis of how the epistemic view in empirical consumer studies was influenced by the duality of frugality could be the initial impetus for such investigation.

From our detailed analysis of the theoretical and historical views of frugality and thrift, we conclude that the practice of being frugal developed out of good housekeeping practices, as stated by classical philosophers. It then became a main characteristic of the home economy, as evidenced by economic anthropological theory. Through the ages, notions of frugality were handed down through philosophical and religious writings. Interestingly, all reflecting a similar view, namely that frugality is proven best practice. As we found, the discourse was adjusted according to the specific time and context. So frugality was perceived as, 'God's will', 'a calling', 'a moral duty', 'a virtue' or 'wise stewardship'.

A turning point in this homogenous narrative is noted with the rise of a capitalistic market economy as an economic sphere distinct from the home economy. At that time, a new concept of frugality entered the discourse, namely frugality as a means for financial savings and profit making. Whereas the main goal of the house economy is to maintain and strengthen the base, the corporate economy's goal is growth and expansion. Both areas apply frugality, although each with a different purpose.

From this, the source of the dual nature of frugality may be determined. As long as the interests of the house economy (or modern household) are congruent or even strengthened by those of the corporate economy, frugal practices will not be disputed. Evidently, when consumer frugality becomes an obstacle for economic growth, for 
example, in times of crisis or in the building of mass consumption in the 1950s (Cohen 2003), corporations will increase marketing efforts as well as use other stimuli to enhance sales. The marketing vocabulary and strategies nevertheless are translated into the 'language' of the house economy because frugality continues to be the main principle in the domain of the house economy (Gudeman \& Rivera 1990; Miller 1998).

Gudeman \& Rivera's model of the house economy and the corporate economy provided a potential explanation for the dual nature of frugality in postmodern consumer society and shed light on the tensions surrounding frugality noted by Witkowski (2009). Instead of explaining frugal or non frugal consumer practices in terms of subjective consumer motives (Douglas 1996) such as hedonism, antimaterialism, being old fashioned or being ethical, the discussion could better be situated in a structural-functional perspective to overcome the dichotomous approach which continues to influence the epistemic view of consumer research. 


\section{Chapter 4}

\section{Living with less as a transformation process}

This chapter is based on:

Schreurs, J., Martens, P., Kok, G. (2010): Living with Less as a Transformation Process:

Existential phenomenological Study of Consumer Behaviour Reform. 


\begin{abstract}
Which changes occur in people's life after a substantial decrease in income and spending? This is the guiding question in this chapter. Generally living with less is associated with a social, political or cultural problem. As a result, the issue is polarized either as a problem cause or problem solution. By examining living with less as a series of specific life experiences this study aims to avoid the common polarization.

A phenomenological field study was conducted to examine the transformation process within the context of consumer society. Results indicated a consistent pattern independent of voluntary or involuntary downshifting, or the amount of reduction. This led to the construction of a behavioural change model: The Transformation Model Living with Less.

This ideal-typical sequence model maps the seven stages of consumer behavioural reform; each stage is discussed according to the characteristics: event, action, barrier, and stimulus. An important result of the study was the finding that living with less was primarily an existential question instead of a purely financial matter. We found that in many cases reorganizing expenses coincided with reorganizing life.

It is argued that this model may offer an interesting direction for future research, either applied, or theoretical. Several implications for further theoretical study as well as the practical applicability are discussed.
\end{abstract}




\subsection{Introduction}

In one and a half centuries of consumer studies, academic attention has focused mainly on purchasing behaviour and spending (Holbrook 1995: 12), or on those consumer traits or consumption issues that are directly related to purchasing behaviour. Questions outside the purview of the market are often kept outside the scope of consumer studies (Belk 1995; Firat 1995). Within this tradition, relatively little attention has been given to moderating consumption or living with less. Moreover, the few studies available have studied the issue within the specific framework of a social problem (Bauman 1998), such as poverty and deprivation, environmental concerns or overconsumption. Consequently, adequate empirical data on living with less that has been acquired in a value-free conceptual context are largely lacking.

In order to examine living with less from this relatively new perspective, our investigation used an experiential point of view, applying existential phenomenological methodology to catalog life changes after a substantial decrease in income and spending. Concrete experiences were placed within the frame of transformation, assuming that a serious reduction in income and spending results in definite changes to peoples' lives. By using permanent comparison, we discovered a sequence in this process that we formalized into a seven-stage model.

This chapter presents the results of this research as a living with less transformation model. We begin by reviewing previous studies on living with less and will elaborate on the details of their theoretical assumptions. We then outline how data were collected and analyzed in our study. Finally, the Living with Less Transformation Model will be presented and conclusions arising from the research will be discussed.

\subsection{Literature review}

Previous studies have provided the basis for this investigation in various ways.

First, we opted to view the notion of living with less as not a static but a dynamic issue. In fact, this is implicitly or explicitly present in many studies of new consumers (Pierce 2000; Huneke 2005). Schor, for example, hinted at the process aspect of living with less when she quoted one respondent as saying: 'You cannot make huge transitions at once. You kind of do it in stages' (1998: 120). Overall, however, the process approach was not the focus of her study.

Second, because many researchers in new consumer trends (Craig-Lees \& Hill 2002; Datamonitor 2003; Elgin 1981; Etzioni 1998; Gandolfi \& Cherrier 2009; Hamilton 2003; Hamilton \& Mail 2003; Huneke 2005; Leonard-Barton 1981; Schor 1998; Pierce 2000) refer to the maxim that less is more, we choose to explore the connection between a reduction in spending or consumption levels and an improvement in life quality. 
Third, the reduce-reuse-recycle concept is often seen as an environmentally friendly consequence of living with less. We considered this to be a useful frame of reference for the classification of general experiences of living with less.

Fourth, the common distinction between voluntary and involuntary downshifters has been avoided in this study as a main selection criterion in advance. We were questioning the unambiguous meaning of the terms on basis of reports in for instance Schor's study (1998; 119) of 'blessing in disguise' experience by involuntary downshifters. It appeared that involuntary downshifters often adopted their new way of life positively along the process of downshifting.

Fifth, studies of the ethical dimensions of moderation (Durning 1992; Etzioni 1998; Lastovicka et al. 1998; Wilk 1996) influenced our view that living with less is embedded in a solid cultural/ideological frame of reference. Although this frame of reference was not the core object of our study, the notion shaped our expectation that respondents might formulate their experiences in moral terms.

Despite the fact that earlier studies provided us with the foundation and inspiration for our research, our study is unique in that, instead of formulating financial standards to categorize living with less practices, as is the case with most poverty studies, our study aims to transcend fixed measures for standards of living. Any standard is considered to be an interpretation of criteria that are relative to the time and cultural setting of the study. As argued in Chapter 2, this study also aims to avoid the polarization which characterizes most studies of living with less. Therefore, the significant difference between our study and previous studies is its focus on the experience of living with less in terms of acts, deeds and concrete behaviour (Thompson, Locander \& Pollio 1989). Respondents were invited to tell their life stories in terms of acts; they were stimulated to give concrete descriptions of the circumstances and context concerned when they reported emotions and moral interpretations. This general approach resulted in a factual, neutral description of the research topic. In doing so, the study aimed to present a panorama of experiences with living with less, instead of focusing on some practices, some motives, some values or some coping strategies. Our aspiration was thus to construct a prototype of the transformation process 'living with less'.

\subsection{Data collection and method}

Phenomenological field research was conducted to examine the experiences of individuals living with less within the context of consumerism and consumerist society. The study attempted to discover new phenomena in order to contribute to theory building about the experience of living with less in mass consumer society. In depth interviews were conducted with 15 informants, each of which lasted from about two to six hours over a 12 month period. This resulted in approximately 60 hours of taped 
and transcribed interviews. All were semi-structured long interviews (McCracken 1988). Interviews were conducted at the participants' residences, with one exception. It must be underlined that interviews were conducted in a semi-structured, nondirective way. All interviews began with the same opening question, 'You are living with less money now than you did before. Will you tell me what happened?'

The target population consisted of people who had reorganized their lifestyles after a spending reduction of 25 percent or more. We selected a minimum loss of $25 \%$ because we expected that a decrease of this volume would require a number of serious lifestyle changes. The average decrease in income was 40 percent.

Two cases deviated from the criteria. One respondent was included because he had experienced a debt settlement resulting in a decrease of 20 percent. The other respondent had experienced a bureaucratic error leading to a $14 \%$ decrease in their welfare payments. All but one respondent began living with less at least five years ago, with one exception of 20 years. This respondent was included because he met the criteria of secondarily voluntariness.

Besides the percentage of the decrease in income or remuneration, another main criterion for selection was the cause of the reduction: voluntary choice, illness, dismissal or debt. We looked for variation along certain dimensions that we thought might be meaningful. These dimensions were: social class, age, sex, family situation, religion, education and occupation. Also variation was sought in the financial situation of the respondents. We thus considered various income levels (before and after reduction) and the source of income (self employed, wage earners, salaried positions and welfare recipients).

The criterion of voluntariness was restricted to those who decided to live a modest life without the constraints of physical or psychological problems and who had realistic alternatives to increased spending. Consequently, the woman who resigned from her job solely to care for her children was seen as a voluntary downshifter. However, the lawyer who resigned because she could not tolerate the commercial office culture after a take-over by an American law firm, and who subsequently suffered from serious health problems was not considered a voluntary downshifter.

A combination of purposive and convenience sampling was used to enlist respondents in the study. An article in the Dutch magazine Genoeg (= Enough; a bimonthly publication focusing on consuming less; volume of 10.000 copies) generated ten respondents, three of which were accepted for the study. Three respondents contacted the magazine Genoeg in reaction to a previously written article. Two respondents contacted the researchers after being informed about the study at a living with less workshop. One respondent was contacted through the Centre for a New American Dream. Finally, three respondents who had reduced their spending due to debt were contacted via weblogs. 


\subsection{Results}

\subsubsection{The sample}

The sample consisted of nine female and five male respondents. The ages ranged between 26 to 60 years. Five respondents lived in major Dutch cities, six respondents lived in smaller towns and three lived in villages. Seven respondents had a higher professional or academic education; seven had a moderate or low level of professional education.

\begin{tabular}{|c|c|c|c|c|c|c|c|}
\hline $\begin{array}{l}\text { Gender/ } \\
\text { Residence }\end{array}$ & Birth & Education & Profession & $\begin{array}{l}\text { Net } € \\
\text { Income } \\
\text { before }\end{array}$ & $\begin{array}{l}\text { Net } € \\
\text { Income } \\
\text { after }\end{array}$ & Decrease & Reason \\
\hline $1 \mathrm{M} / \mathrm{C}$ & 1946 & $\mathrm{C}$ & $\begin{array}{l}\text { Social worker } \\
\text { Photographer }\end{array}$ & 1500 & 750 & $50 \%$ & Voluntariness \\
\hline $2 \mathrm{M} / \mathrm{T}$ & 1958 & $\mathrm{C}+$ & IT manager & 8000 & 800 & $90 \%$ & Dismissal \\
\hline $3 \mathrm{~F} / \mathrm{T}$ & 1961 & $\mathrm{C}$ & Teacher & 1750 & 745 & $58 \%$ & Illness \\
\hline $4 \quad \mathrm{~F} / \mathrm{T}$ & 1975 & $\mathrm{C}+$ & Pastor & Student & 900 & ---- & Voluntariness \\
\hline $5 \mathrm{M} / \mathrm{C}$ & 1970 & $\mathrm{H}$ & None & 700 & 200 & $70 \%$ & Dismissal \\
\hline $6 \mathrm{M} / \mathrm{T}$ & 1969 & $\mathrm{C}+$ & Trainer & 2000 & 1000 & $50 \%$ & Resignation \\
\hline $7 \quad \mathrm{~F} / \mathrm{C}$ & 1965 & $\mathrm{C}+$ & Lawyer & 6000 & 4000 & $33 \%$ & Illness \\
\hline $8 \mathrm{~F} / \mathrm{C}$ & 1949 & $\mathrm{C}$ & Music teacher & 3300 & 2100 & $33 \%$ & Illness \\
\hline $9 \quad \mathrm{~F} / \mathrm{V}$ & 1957 & $\mathrm{C}$ & Housewife & 2500 & 1500 & $40 \%$ & Voluntariness \\
\hline $10 \mathrm{~F} / \mathrm{C}$ & 1954 & $\mathrm{C}$ & Volunteer & 700 & 600 & $14 \%$ & $\begin{array}{l}\text { Bureaucratic } \\
\text { error }\end{array}$ \\
\hline $11 \mathrm{~F} / \mathrm{V}$ & 1951 & $\mathrm{C}-$ & $\begin{array}{l}\text { Middle } \\
\text { manager }\end{array}$ & 790 & 400 & $48 \%$ & $\begin{array}{l}\text { Family } \\
\text { problem }\end{array}$ \\
\hline $12 \mathrm{M} / \mathrm{V}$ & 1980 & $\mathrm{H}$ & Journalist & 1550 & 1250 & $20 \%$ & Debt \\
\hline $13 \mathrm{~F} /$ & 1962 & $\mathrm{C}-$ & Office worker & 1400 & 1000 & $29 \%$ & Debt \\
\hline $14 \mathrm{~F} / \mathrm{T}$ & 1953 & $\mathrm{C}$ & Accountant & 1800 & 1350 & $25 \%$ & Debt \\
\hline $15 \mathrm{~F} / \mathrm{T}$ & \multicolumn{7}{|c|}{ Try-out } \\
\hline
\end{tabular}

Symbols: $\mathrm{M}=$ male; $\mathrm{F}=$ female; $\mathrm{C}=$ major Dutch city (Amsterdam, Rotterdam, The Hague); $\mathrm{T}=$ town; $\mathrm{V}=$ village; $\mathrm{C}=$ college (higher vocational education); $\mathrm{C}+=$ master education; $\mathrm{C}_{-}=$lower vocational education; $\mathrm{H}=$ high school. 


\subsubsection{Data analysis}

The constant comparative method (Glaser \& Strauss 1967) and grounded theory techniques (Strauss \& Corbin 1997) were used to analyze the data. In the process of generating and interpreting data, findings were shaped and reshaped as the analytical work proceeded. The emic approach posited by grounded theory guided the data analysis as follows: During the first intensive readings of the interview transcripts, we concentrated on the main theme of our research, namely the changes that occur in peoples' lives after a spending reduction. Gradually, a pattern of life domains in which the changes occurred emerged. We found that living with less provoked a variety of changes in the financial domain, and in the social, pedagogical, emotional, and work domains, as well as in other activities. In addition, we registered changed attitudes towards money, consumer society, society, politics and life - and finally - we noted that the living with less experience also affected the personal domain. Further reading of the data found striking similarities between the obstacles experienced by the respondents and the motivations for the living with less experience. Respondents reported experiencing the following obstacles: social pressures and criticism, financial difficulties in meeting fiscal obligations, and debt. A special category was the emotional obstacles; These included worrying, having a negative self-image, feelings of shame and feeling guilt. The motivations for living with less included the challenge of coping with the new financial situation, positive personal feelings of autonomy and improvement in life quality.

Through this 'thematic' exploration of the data, two specific patterns became manifest. The positive and negative experiences of living with less were connected either with the individual/personal dimension or with the social dimension. The majority of the negative experiences reported by the respondents had a social character. However, the positive experiences typically had an individual character. Furthermore and most importantly, the living with less process appeared to follow a specific sequence of changes. With these findings, we went back to the data, carefully rereading each interview and focusing on the specific characteristics of the stages in the transformation process and the social and individual dimensions of the living with less experience. Initially, the contours of ten possible stages in the process of living with less were identified as 1 . Prelude; 2 . Shake; 3. Shame and blame; 4 . Facing reality; 5. Out of the closet; 6. Restyling; 7. Repositioning; 8. Redefining; 9. Consolidation; 10. Ongoing process.

In retesting this preliminary classification, we found that the classification criteria were a mixture of emotional and behavioural concepts blurring the line between interpretations (emotions) and actions (mere research facts). We then adjusted the model to correspond to our research parameters, and focused on actions and behaviours as characteristics. Consequently, we integrated the second stage, Shake, and the third stage, Shame and Blame, into Facing reality and Out of the closet, respectively. With regard to the ninth stage, Consolidation, we concluded that there were insufficient specific data to maintain it as a distinguishable stage. We found that the life transformation after a decrease in spending did not have a clear end point; rather, respondents reported experiences that revealed an ongoing process 


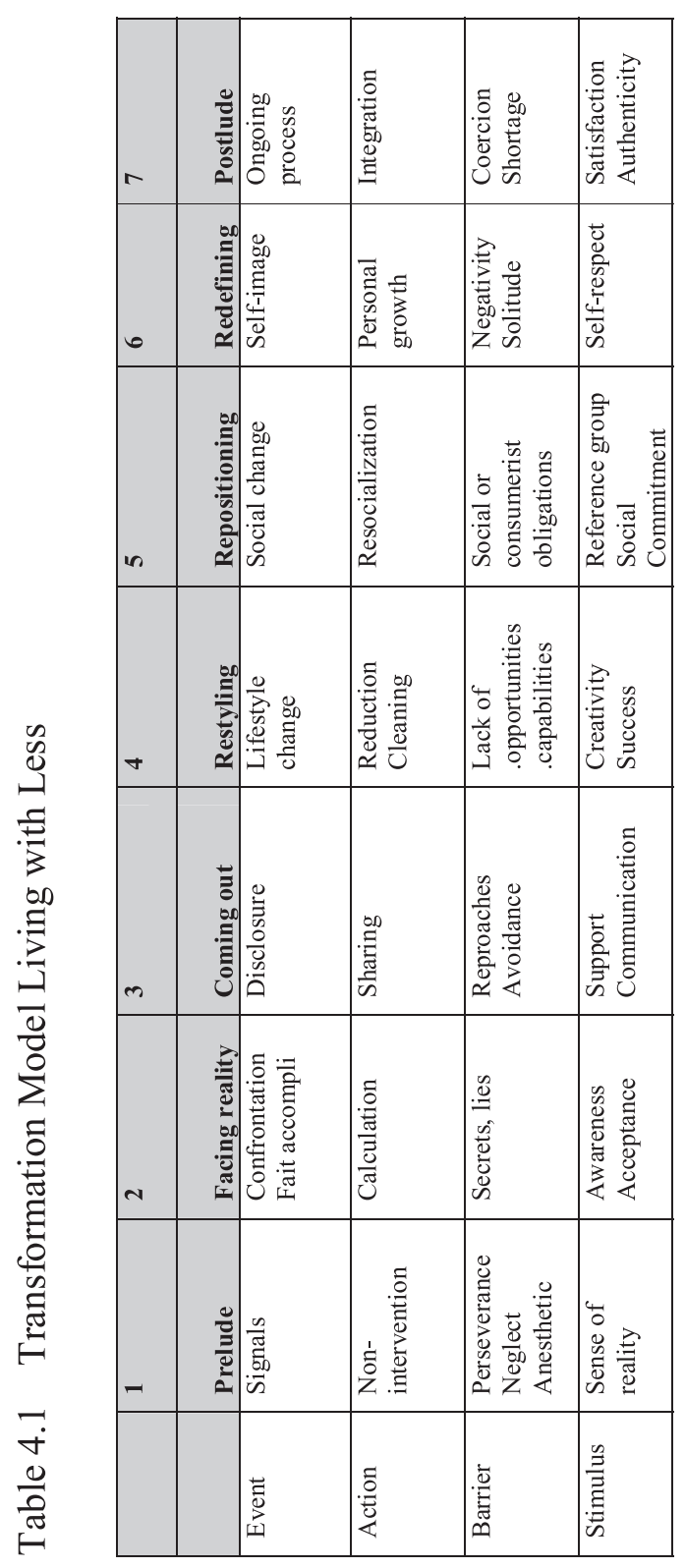




\subsubsection{The Transformation Model Living with Less}

Based on the preceding analyses, we constructed a transformation model consisting of seven stages. It is a sequential model in that the described patterns of behaviour develop in an orderly sequence, although they are not necessarily experienced by all respondents in the same order, or over the same time span. The model describes the process of behavioural changes resulting from, or linked to a considerable decrease of income or spending. The model has been constructed as an ideal-typical sequence model. It should be viewed as a theoretical abstraction of an actual social phenomenon in order to provide a better understanding.

The model is presented as a matrix. Each stage is discussed using the following themes: 1. Event (the characteristic); 2. Action (the behavioural activities); 3. Barrier (an obstacle to progress and its opposite); and 4. Stimulus. The latter two themes may refer to personal matters, such as attitudes, skills or emotions; or social matters.

\section{Stage 1: Prelude}

The experience of living with less rarely occurs unexpectedly. Problems at work start to intensify, the marriage becomes increasingly untenable, or the secret weight of gambling or shopping addictions becomes unbearable. Yet, like a deer caught in the headlights, the individual is paralyzed, incapable or unwilling to take action. Oblivious to the danger signs, respondents struggle to persevere. Stress-related health problems such as insomnia, nervousness and anxiety are ignored. 'I literally got short of breath at my job,' One respondent reported, 'But it took me another year to quit.' Paralyzed like the deer, the individual does not move, but sticks to the status quo. Bank statements are put aside unopened, another credit card is obtained to settle immediate needs, because 'once you cross the initial threshold of taking on debt, it is easier to continue to accumulate more debt than to pay it off '. Lacking appropriate coping methods to deal with the situation, respondents compensated with alcohol or drugs, or lived in denial. For some this stage ends abruptly with a wake up call; often remembered as a clear defining moment: 'I continued my life like a rat on a treadmill, speeding up more and more, until suddenly someone put a stick in the spokes. Then I was thrown out and smashed on my face.' Others came to the realization gradually, as they made the decision to live with less.

\section{Stage 2: Facing reality}

In the second stage the situation comes to a head, and respondents have to face the harsh reality. The defining characteristic of this stage is the awareness that living with less is inevitable. A paycheck becomes substantially lower, the first alimony payment is due or received, or cash is denied at the ATM. The turning point is typically tied to a concrete life event with serious financial consequences such as an actual reduction in income or loss of capital. The life event may be a positive one such as a marriage, a birth, or perhaps the acceptance of a more fulfilling but lower paying position. It may also be due to a negative life event, such as job loss, dismissal, divorce, illness, or the loss of a partner. The event may be purely financial in nature, such as a bailiff's letter, 
a personal bankruptcy, a garnishment of wages or huge losses at the stock exchange. The new reality forces to sort out affairs, willingly or unwillingly. For most people, dealing with this new reality means gaining insight into their new financial situation. Concrete numbers are formulated to measure the amount of damage, or if the situation was chosen voluntarily, an estimation of their basic living expenses is determined. This is called the calculation stage.

Facing reality is a necessary starting-point for making do with what one now has. However, the transition may be complicated by feelings of failure and shame: 'I felt like such a loser,' is a common reaction in this stage. Even people who face the financial consequences of a positive life event may have feelings of shame: 'I was astonished that I was so reluctant to inform others about my career break, even though it was the outcome of a deliberate choice. Self reflection showed that I was ashamed of not being able to continue the life I was supposed to be leading.'

Thus, an important feature of this stage is the confrontation with one's own deviance. Downshifters soon realize that their financial situation deviates from the standard norm of social progress and upward mobility. Calculating their new finances also means measuring one's chances of becoming an outsider. This consequence may be so difficult to face that many people keep their new financial situation secret for a time. They remain isolated while keeping up appearances. This tendency is likely enhanced if contact with others entails spending money, such as for travel, gifts or dinners. Avoidance then becomes the characteristic behaviour: invitations to parties are ignored, excuses are invented to cancel weekends out with friends, and contributions to collective presents are avoided. At the same time, certain possessions gain new importance: 'Of course I knew that it would be much cheaper not to drive the car, but it gave me a sense of freedom. Besides, other people would notice that I was in trouble when I left my car unused.' Of course secrecy may be functional in gaining time to get used to the new financial situation and it may also have a protective function, as in the case of financial professionals, whose professional reputations could be at risk if their financial problems became known.

Facing reality though does not mean acceptance. This is especially the case when the financial situation has an external cause, such as a bureaucratic mistake, fraud or a forced dismissal. It is more difficult to accept a new financial situation that is perceived as a flagrant injustice. All together, most people succeed in accepting the reality of the situation as a starting point for dealing with the problem: 'My friends remarked that the only topic I talked about was money; it was like a mirror,' explained the woman whose living expenses were reduced to 15 euro a week. 'To overcome my frustrated obsession, I decided to come to terms with my financial situation, regardless of how restrictive it was.'

\section{Stage 3: Coming out}

Downshifters are often reluctant to inform others about their decrease in finances. It even appears that it is more socially acceptable to discuss sexual problems than financial difficulties. Eventually however, most people break the taboo, seeking to relieve their anxiety and garner support or compassion: 'Finally, my anxiety overcame 
my shame,' a woman explained, 'I turned to my mother for help.' Others approach friends, relatives, the church or professionals for support and advice. Some respondents have consulted a financial coach, or are forced to do so due to personal bankruptcy or debt restructuring. For some, the threshold to openly communicate financial difficulties remains an insurmountable obstacle. By using a pseudonym, they seek comfort in the anonymity of a weblog.

This reluctance to go public is not without cause. All participants mentioned negative initial reactions from others; they were often confronted with blame and reproach. In most cases, early negative reactions turned into support and practical offers to help. Even the anonymous webloggers received considerable mail with advice and offers to help. However, there is one remarkable exception. Understanding is less forthcoming for many voluntary simplifiers. Becoming a voluntary simplifier, so choosing to live frugally on a minimal budget, requires a great deal of social courage, considering the reactions that voluntary downshifters are often confronted with: 'My parents continue to bring me home equipment and other stuff; they don't want to accept that I have chosen to live minimally,' one respondent explained. 'My family always says that I have to stop dreaming and take responsibility,' another voluntary simplifier noted.

\section{Stage 4: Restyling}

This is the stage when one rolls up the sleeves and adapts one's lifestyle to fit the new financial situation. People focus on making ends meet mainly by seeking ways to cut expenses. Obviously, common areas slated for reduction are energy use, restaurant and café visits, leisure activities and clothes. Others adjust their diet, sometimes very drastically: "I became a vegetarian and stopped drinking alcohol because it was cheaper, yes, but mainly because it was better for my health,' a former manager who used to be a heavy drinker explained. Also, shopping behaviour is commonly targeted for change. Shopping lists are made and discount supermarkets and thrift shops are frequented. Respondents have become more aware of prices and make comparisons. Essentially, good value for money is sought. Another practice for reducing expenditures is called 'dollar stretching' which means using goods frugally, reducing waste and using articles until they wear out. Some people sell their surplus possessions to get extra money or just to clean up before moving to another smaller and cheaper place: 'I decided to sell my art collection, books, watches; all the stuff I collected. I needed the money, but I also wanted to get rid of the memories of the past.' Goods appear to be materialistic expressions of meanings and memories of former lifestyles. Getting rid of them might represent a rite of passage.

The restyling process often coincides with taking stock and balancing the positives and negatives. People may do this in concrete form and take inventory of their possessions. Often the list appeared to be much larger than expected. This discovery may provide the person with feelings of comfort and security. Regardless of the amount of reduction one has to achieve, everyone places limits on what they are willing to give up. Like frontiers or boundaries, these limits protect them from complete degradation or total disorientation. Most respondents drew the line at giving up their home, even though the cost of maintaining it becomes disproportionately high. Moreover, everyone had a specific personal 'sacred' domain: 'My car made me thumb my nose at 
the situation in which I found my self.' Others continued to eat high quality food, kept a cherished piece of art, drank a daily glass of wine, purchased an extravagant, expensive pair of shoes or maintained a relatively expensive hobby. These personal choices were often misunderstood by others and were regularly attacked by critics, especially if the downshifter was in a debt-restructuring program.

In this respect, restyling activities often produced unexpected personal creativity and activity. Apart from budgeting, other new skills were developed and practiced, such as cooking meals from scratch, gardening to obtain fresh vegetables and fruit, and acquiring new home maintenance skills. Once committed to adjusting their lives to their new financial circumstances, people realized that the issues they were addressing went far beyond money: 'How to spend my reduced income appeared to be connected with how I wanted to organize my life.'

\section{Stage 5: Repositioning}

Living with less may affect one's position in society in several ways. First, people can be forced into another position by changing jobs or moving to another house. They literally move into another position in society such as a new neighborhood or a new working environment. The greater the distance from the former position, the greater the worry: 'I was afraid that the new neighborhood might be noisy and shabby but, to my relief, it wasn't,' a respondent reported. Second, a change in shopping behaviour may have notable social consequences. 'The first time I went to a discount supermarket, I was afraid of meeting someone I knew. I heard my mother's voice echo that this was beneath our family standard,' a woman explained who had quit her job to care for her three children. Third and most importantly, reduction measures themselves often have a social effect. How do you tell your friends that you fired your house cleaner and now you do the cleaning yourself? Who dares to ask for the leftovers after a family dinner, or to propose swapping children's clothes with friends? If this is new behaviour, it presupposes having the social courage to do so.

Furthermore, social talk is often concerned with consumer activities such as purchases, going on holidays or restaurant and shopping experiences. If one is reducing expenses and forgoing these experiences, an important component of social conversation disappears. Some individuals do not want to lose their social contacts and invent coping strategies to maintain them by reducing the cost: 'We used to meet each other monthly in chic restaurants. Since I started budgeting, I organize the meetings, so I can influence the choice of an affordable place.' Actually, the new consumer activities may also lead to new social contacts, especially if one becomes a member of a simplicity circle or other organization that supports downshifting activities: 'In the simple living group I learned about myself by watching others,' said one respondent.

Social repositioning as a consequence of reducing expenses is often accompanied by a reorientation of the dominant characteristics of today's society. All respondents stressed that they considered the consumption pressures in today's society to be a serious obstacle for spending reduction. Some take protective measures, such as posting refusal stickers for advertising papers, or muting the volume on the TV during advertisements. Frequently commercial as well as social pressures to consume are described as major obstacles to mastering a decrease in expenditures. This is of 
particular concern to people raising children: 'It is difficult to raise your children in amoderate way with all these advertisements and excessive materialism. At school they meet others who don't have the same financial restrictions.'

All respondents mentioned developing a more critical attitude towards consumerism: 'I hesitate to express this opinion in public being a former big spender myself but today I get so annoyed with all the waste and especially with the easy, unattended way of life of our friends.' Others are less reluctant to share their new insights, deriving additional motivation from the need to protect the environment. In the process of repositioning, all respondents become aware of the fact that - notwithstanding serious financial distress - there was no risk of starvation, want or deep poverty. They understood that they belonged to the rich minority of the world. Even the woman whose weekly budget was limited to 15 Euro expressed this sentiment, 'With my house, my car, my health insurance and always more than enough to eat, I had far more than the majority of the world population. In moments of despair, I repeated these facts as a mantra.'

As a result of these experiences with society and social reorientation, downshifters tend to develop a new commitment to society. Most respondents said that they volunteered for community activities or coaching work. Hereby a variety of social, political or environmental activities was undertaken, ranging from social buddy or church activities to anti-globalism studies. Some mentioned a more profound change as they made a radical career switch from business to social work. Finally, respondents pointed at new reference groups. These were often virtual and took form as web communities and indeed, weblogs.

\section{Stage 6: Redefining}

Increasing self-awareness was mentioned as a main component of this stage. New behaviours that were adopted to reduce expenses may have provoked a new selfimage: 'Is this me, I wondered, when I found myself happily biking home with saddlebags filled with groceries, instead of using the station wagon that we had recently sold.' Another respondent exclaimed, 'Suddenly I found myself dumpster diving to find a chair and other home equipment. That was a revolutionary thing to do; in my former life, I would not have dared.' This stage in the transformation process of living with less thus concerns the growing self-knowledge that results from the changes made in the previous stages. A respondent described the increased consciousness simply: 'By saying 'no', I discovered to what I wanted to say 'yes' to.' The choices they had to make about expenditures appeared to touch upon personal choices regarding how to organise one's life.

The challenge of cutting expenses made it necessary to thoroughly examine the assumptions upon which they had previously based their lives. This re-orientation may in many cases result result in a strong personal commitment to the new lifestyle: ' $M y$ path is not an easy one but it fits,' said one respondent. Participants described their new lifestyle as more 'authentic' and mentioned personal growth as a major positive effect of the experience of spending reduction. 
In this stage, most people welcomed new role models. They strengthened ties with family members or a neighbor with a comparable lifestyle to share experiences. Books about simple living or the Dutch magazine Genoeg (Enough) may have served as a reference for self-identification. Others sought companionship in simple living circles or in website forums. New skills such as growing vegetables, making their own meals, baking and so on, contributed to a new self-image. Also, the mere act of budgeting enhanced pride and self-esteem. Some however, continued to struggle with their selfimage, swinging back and forth between the image of being a failure and one of success and self-respect: 'It is remarkable. I used to live moderately before, but now I am forced to do so; it is difficult to accept.'

\section{Stage 7: Postlude}

The experience of living with less provoked far-reaching changes that continued even when the financial position improved or even when the respondents found a new balance and accepted their new situation as normal. In this sense, the transformation can be seen as a multidimensional and ongoing process. As one participant reported: 'I discovered that living with less is not simply about reducing expenses; it is about how you spend your money; so basically it is about how you organize your life.' Thus, reorganizing expenses for most participants meant drastically reorganizing their lives. In some respects, this may be a positive change. New skills and knowledge are integrated in the life pattern and become unexpected, though important, sources of pleasure, or at least of satisfaction: 'After I dismissed the cleaning woman, I had to get used to doing the work myself, but I started liking it. My house became more my own.' Others reported that the lasting changes included increased creativity and selfawareness, and a less materialistic, less consumerist attitude: 'My creativity and ingenuity to save money still continues,' an informant explained. 'It is as if I developed a sense for reduction that never stops.' Some participants, despite an improved financial situation, also continued to live on a reduced budget to create a nest egg or to support others, because 'spending money can also be an act of love and attention.'

\subsection{Discussion and conclusions}

\subsubsection{Findings}

The present study examined how a substantial decrease in income and/or spending affected peoples' lives. Results of the explorative field research indicated a consistent pattern in the change process independent of involuntary or voluntary downshifting, or of the amount of reduction. These insights led to the construction of a behavioural change model: the Transformation Model Living with Less. The model describes seven stages derived from behaviours and experiences on the basis of the following criteria: event, action, barrier and stimulus. Although the seven stages are presented in sequence, this does not imply a compelling order. The staging should be understood as a ideal typical reconstruction of a multi-layered change process. 
A significant result of the study was the finding that living with less was primarily a life matter instead of a purely financial issue: reorganizing expenses means reorganizing life. The study demonstrated that in order to deal with serious financial problems one has to address other life domains as well. Nonetheless, although financial problemsappear to be connected to non-monetary issues, it does not mean that serious attention to money management is unnecessary.

This study also sheds light on the learning aspect of the transformation process. In practice, progress depends not only on acquiring financial knowledge and skills such as budgeting, but also on acquiring practical skills related to housekeeping and do-ityourself work. The ability to strengthen personal attributes such as resilience, independence and flexibility, and the ability to maintain psychological and physical health appeared to equally contributing to success.

Another striking finding was the observation that the living with less experience was, for those who involuntarily engaged in living with less, not as dramatic and negative an experience as the respondents had anticipated at the beginning of the process. All respondents mentioned a variety of positive experiences as well as permanent changes in behaviours and attitudes, which were often viewed as changes for the better. Positive experiences included feelings of relief when they discovered that they could actually live on much less money than before; pleasure through practicing new skills or activities; satisfaction with the success of the transformation; and feelings of contentment due to improved social connections.

Last but not least, we found that the transformation process itself could be a major positive experience. Even respondents who were unintentional downshifters with very low incomes reported positive experiences such as contributions to personal growth, unexpected support or gratitude for possessions or immaterial assets such as health, social relations and other benefits.

\subsubsection{Limitations}

Significantly, there were two main limitations in this study. First, the study was conducted using a relatively limited number of respondents. Furthermore, none of the respondents suffered from pathological financial behaviours, such as obsessive speculation, gambling addiction or receptivity for cheating. Although some respondents in debt showed indications of problematic financial behaviour resulting from psychological or emotional problems, overall, the mental constitution of respondents was rather good. This leads us to suspect that the transformation process would be far more complicated in cases of serious personal problems. A second limitation might be geographical since our study was conducted solely in the Netherlands. Here the strong social welfare system guarantees that every person's basic living needs are met. People might respond differently to a living with less challenge in a region without an extensive public financial safety net. Again, it would be useful to do further research on this aspect. 


\subsubsection{Implications}

This study indicates that a living with less experience is a major life-transforming event that touches the foundations of peoples' lives. Using the phenomenological approach (Thompson e.a.1989), practices and behaviour could be explored as a process of consumer behavioural reform after a financial decrease. The contribution of this study is that it provides a multi layered picture of this process, integrating determinant aspects of consumption as a coherent whole. By determining which aspects of peoples' lives were affected by a substantial financial decrease, the study goes beyond single factor consumption studies, such as consumption and identity, consumption and social status or lifestyle studies.

Also, this study used an integrating approach in the selection of the target group. By using a substantial financial decrease as the main selection criterion, the study bypasses the common segmentation of research between intentional downshifters and low-income consumer groups (Etzioni 1998; Gandolfi \& Cherrier 2008; Hamilton 2005; Huneke 2005; McDonald 2006; Schor 1999). By using this approach in future research, meaningful similarities could emerge - such as the ground pattern of the transformation process of living with less. This offers a theoretical framework to discuss results of other consumption studies, such as studies of simple living practices (Huneke 2005) or definition studies (McDonald 2006; Etzioni 1998) that may be positioned in the Restyling stage or the Redefining stage, respectively. With regard to the latter group of studies, our findings indicate that the three stages of the Downshifters Identity Transition Model: 1) Discontentment with life; 2) Questioning consumer culture; and 3) Discovering new meanings of consuming (Cherrier 2008: 48) could relate to unintentional downshifters as well.

Regardless of the reason for consumption decrease, indications were found particularly in the dimension of questioning consumer culture and discovering new meanings of consumption. As opposed to the customary approach to frugality in consumer studies, namely as a lifestyle choice or value (Lastovicka et al 1999; Todd \& Lawson 2003), this study conceptualizes frugality as a way of action.

Additionally, Results of the study shed new light on the marginalizing effects of living with less as noted by Bauman (2005) and in studies of low income consumers (Hamilton \& Catterall 2005) and of downshifters (Schor 1998). The reporting of intense confrontations with social conventions regarding consumption that defined the Coming Out stage actually appeared to be similar to the experience of 'coming out of the closet' for gays and lesbians. In addition, there are indications that feelings of deviance from mainstream consumer aspirations (more is better), are internalized as negative self-images, such as feelings of being a loser or failure. In this context, intentional downshifters also experienced these negative self-images. These findings may be supported by the outsider theory (Becker 1963).

The final theoretical contribution of the study concerns the relationship between consumption reduction and quality of life. Until now in consumer studies, quality of life was mainly defined in terms of consumer goods, such as the belief that less stuff is 
easier to handle, a smaller house is cheaper and easier to clean (Schor 1998), or in terms of realizing a more fulfilling life. Results of our study not only seem to support these findings, but additional dimensions emerged concerning the quality issue. For many living with less turned out to be an unexpected life experience of adventure (Campbell 2005), even for respondents with very low-incomes. The transformation process itself, appeared to be an important quality aspect. This observation might be congruent with the theories of positive psychologists such as Czicksentmihalyi's flow theory or with Scitovski's observations in Joyless Economy (1977). For both scholars argue that genuine happiness and joy are rather resulting from personal challenges and effort than from an uncomplicated consumption of entertainment.

Two possible practical approaches may emerge from this study. The model could be applied as a frame of reference for assistance in dealing with individual cases of personal financial problems such as in debt reduction programs. Also an overview of relevant stages, as well as the barriers and stimuli in the process could be applied as starting points for behavioural change. Undeniable, further empirical testing will be needed to validate the model. In the meantime, the model may offer an interesting direction for future research, either applied, or theoretical.

Partly guided by the results of this qualitative field research, in the next chapter we will continue with the second empirical study of this dissertation. Again we will focus on transformations in consumer behaviour and practices, but now the purpose is to examine empirically how downshifting could contribute to sustainability. 
Chapter 5

Meet the Dutch downshifters 


\section{Abstract}

The results of an empirical quantitative and qualitative study on downshifting are presented. The study focused on transformations in consumer behaviour and practices realized by living with less money in a postmodern consumer society. Within this broad research topic, three themes are addressed: downshifting, frugality and sustainability. The differences between three groups, namely voluntary downshifters, involuntary downshifters and non-downshifters, were investigated.

This socio-economic study illuminates the phenomenon of downshifting as a new consumer trend in postmodern consumer society. Characteristics of downshifters are presented, as are extensive data on changed consumption practices and expenditures. The results of the qualitative study are introduced as a list of positive and negative experiences with downshifting. The chapter ends with a discussion of the results for sustainability. As a frame of reference Callenbach's (2002) green triangle is applied, converted into the Dutch triple Gs of a sustainable lifestyle: geld (money), groen (ecofriendliness) and gezondheid/welzijn (health/wellbeing). It is concluded that downshifting can contribute to sustainability as this way of life fundamentally resonates with the three pillars of the Dutch triple Gs of a sustainable lifestyle. 


\subsection{Introduction}

This fifth chapter follows the academic tradition of consumer research that addresses transformations in consumer behaviour in an effort to explore solutions for problematic aspects of consumption, including the massive environmental problems which societies currently have to face. Particularly, the academic interest for critical consumers groups and anti-consumption trends is growing in the past decades. In this context, this study elaborates on the insights and findings provided by studies conducted with new consumer groups such as downshifters and voluntary simplifiers.

The definition of downshifting used in this study differs somewhat from the prevailing one. We defined downshifting as economizing and restricting spending and contend that with downshifting, gradual change can be observed between prior and current consumption levels and/or between the downshifter lifestyle and the lifestyle of peers. Thus, downshifting is defined simply as a reduction in spending, regardless of the motivation (voluntary or involuntary), and regardless of fluctuations in income.

By focusing on spending reduction, we broadened our research population to include involuntary downshifters. This has provided our study with a differentiated subcategory and allowed us to make comparisons between the two categories of downshifters, thus shedding more refined light on the main research question, namely what changes occur in consumption and the consumer behaviour of downshifters and what do these changes mean for sustainability?

In this section we first introduce recent downshifting developments in Western consumer society and clarify the conceptual framework of the study before presenting and discussing the general research results.

\subsubsection{Voluntary downshifting as a social trend}

In 1994, Trends Research Institute director, Gerard Celente, first used the term downshifting to describe a growing trend in consumer societies and he predicted that later generations would follow the path of the boomers by seeking deeper life meaning outside of materialism. His prediction appears to have been validated by a number of surveys. A nationwide survey conducted by Juliet Schor (1998) in the USA revealed that $19 \%$ of American adults had voluntarily reduced their income and spending in the five years prior to the study. In Australia, a nationwide survey showed that $23 \%$ of adults aged $30-59$ had downshifted over the ten years prior (Hamilton \& Mail 2003). Likewise, in Britain, a study demonstrated that $25 \%$ of British adults aged 30-59 had downshifted over the ten years prior to the study (Hamilton 2003).

The sociological impact of this phenomenon is not merely incidental but rather representative of a growing trend of major importance (Datamonitor 2003; De Geus 2003; Cherrier \& Gandolfi 2009; Schor 1998). Researchers have concluded that the growing numbers of downshifters reflect that downshifting is a social force with far 
reaching implications, because downshifters persevere against strong critical social pressures and tend to persist in their decision to change their way of life. The widespread prevalence of downshifting has thus led researchers to conclude that downshifting is no longer an act of personal deviancy but rather an indication of a radical change in consumer society.

\subsubsection{Downshifting in the Netherlands}

Inspired by American initiatives, voluntary simplicity and downshifting were introduced to the Netherlands in the early 1990s. The handbook, Your Money or Your Life (Dominguez \& Robin 1992) was translated into Dutch and the Tightwad Gazette (Dascyzyn 1998) served as the model for the Dutch equivalent, De Vrekkenkrant (translated as the Scrooge newspaper). In addition, Dutch equivalents of simplicity circles were also formed (Andrews 1998).

At its inception, voluntary downshifting was generally viewed with derision. However, towards the second half of the 1990s, a radical change occurred. The somewhat provocative title Vrekkenkrant (Scrooge newspaper) was replaced by the more appealing title Genoeg, (translated as Enough) and the circulation of the downshifter's magazine increased. Website traffic on downshifting websites also expanded, as did the number of web discussion groups. Although precise numbers for the Netherlands are lacking, downshifting is believed to be a relatively rapidly growing trend (De Geus 2003). Based on the overall growth in the numbers of European downshifters found by Datamonitor (an increase from 12 million voluntary downshifters in 2002 to an estimated 17 million in 2007), we contend that the Netherlands is likely to have experienced a comparable increase (Datamonitor 2002).

\subsubsection{Motivations for voluntary downshifting}

What motivates people to downscale their lifestyle when the dominant culture advocates upward social mobility through increased consumption? To start with, the literature indicates that people are motivated by the desire to escape from life's excessive pressures. In fact, Schor (1998) was the first to mention a desire to break the 'work-and-spend' cycle as a primary motivation for downshifting.

Breakspear and Hamilton (2004) later outlined four specific reasons for downshifting:

1) The desire for a more balanced life that allows one to better deal with the demands of work, family, social life and personal development; 2) A clash between personal values and beliefs, on the one hand, and the values and culture of the workplace, on the other; 3) A search for a more fulfilling life; and 4) Health and wellness-related reasons. Significantly, a nationwide study conducted in Britain demonstrated similar results, although, in that study, adopting a healthier lifestyle was a more prominent motivation for downshifting.

In sum, particularly the desire to improve one's quality of life is considered a major motivation for voluntary downshifting (Breakspear \& Hamilton 2004; De Geus 2003; Huneke 2005; Schor 1998). 


\subsubsection{Conceptual framework}

Downshifting, in the sense of reduced spending, is closely related to the model of frugal and simple living. This ideal is present in all cultures and religions and has a long history (Gandolfi \& Cherrier 2009: 4). The major religions of the world advocate maintaining a balance between excess and austerity, and teach the virtue of moderation (Craig-Lees \& Hill 2002; Durning 1992; Gandolfi \& Cherrier 2009). At the end of the $19^{\text {th }}$ century, Henri David Thoreau (1854), who embarked on a two-year experiment in simple living, provided a secular version of this ideal when he moved to a small, self-built house at Walden Pond. Thoreau is generally credited with the classic non-sectarian view advocating a life of simple and sustainable living in his book Walden (1854). His ideas resonated with the emerging critics of urban industrial life and his experiment was imitated by, among others, Frederik van Eden in the Netherlands and the British organization The Fellowship of a Good Life which includes the Fabian Society.

From the 1920 s to the 1960 s, a number of American authors articulated both the theory and practice of simple living, among them Gandhian Richard Gregg (1936), economist Nearing (1970) and utopian writer Ernest Callenbach (1973). Lastly, Duane Elgin ensured that the philosophy and principles of simple living reached a broad contemporary audience in his widely received description of voluntary simplicity as 'Outwardly simple and inwardly rich' (1981)

Relatively recent studies of this consumer trend outline several approaches by which living with less can be categorized. The most commonly used classification was posited by Etzioni (1998) who distinguished three variations of voluntary simplicity based on the level of reduction in consumption:

1) Downshifters engage in the lowest levels of reduction. Often among this group there is no coherent pattern of spending reduction and they may downshift in one domain and consume conspicuously in another.

2) Strong simplifiers restructure their lives significantly. This second category includes those who give up their well-paid job for a more fulfilling but lower-paid job. 'Strong' simplifiers also include those who decide to retire voluntarily even though their pension payouts will be lower.

3) Holistic simplifiers adjust their entire lives, adhering to the ethos of voluntary simplicity (Etzioni 1998: 620). Among this group there are often dedicated members of the simple living movement, inspired by writers such as Duane Elgin (1981).

In principle, all three groups voluntarily reduce their spending on consumer goods and services and cultivate non-material sources of satisfaction and significance (1998: 620). It must be noted, though, that the degree of reduction varies. Downshifters are the most moderate practitioners. In her socio-economical research on downshifting, Juliet Schor (1998) defines the phenomenon as the voluntary reduction of income and consumption. Theoretically, Schor considers downshifting to be a special category within the generic category of voluntary simplicity. 
Breakspear and Hamilton (2004) use a similar definition in their study of Australian downshifters, as did Hamilton (2003) in his study of British downshifters. Downshifting is understood to be a voluntary decision to change one's life in ways that reduce income and spending. In this respect, downshifting is perceived as a voluntary life change connected with a reduction in income and spending (Breakspear \& Hamilton 2004). Dominant features thus are the voluntary nature and a significant reduction in income and consumption. These definitions differ from Etzioni's, as he positions downshifting as the most modest level in the spectrum of voluntary simplicity.

In addition, Shaw and Newholm (2002) have applied Etzioni's definition but introduced the concept of 'motivation' as a core characteristic: 'voluntary simplicity is a generic term for a variously motivated contemporary phenomenon: the foregoing of maximum consumption and, possibly, income' (1998: 170). In their view there are two variants contingent on whether the motivation is egoistic or altruistic, namely downshifting and ethical simplicity. In their view, downshifters are voluntary simplifiers who are motivated mainly by egocentric considerations such as the intention to increase one's quality of life. Ethical simplifiers, in contrast, voluntarily reduce their consumption behaviour because of 'some ethical considerations of the environment and other social concerns' (2002: 184).

Finally, Tim Jackson (2006) adds that involuntary simplicity is, 'a completely autonomous lifestyle change movement, initiated by individuals, spontaneously, away from the dominant-high consuming lifestyle and towards voluntary simplicity' (2006: 352).

Overall, the term downshifting refers to income and consumption reduction. Interestingly, the Dutch neologism, consuminderen, only refers to consuming less. This Dutch term first appeared in the 1970s in environmental debates and in instances of political cabaret. In 1997, the national dictionary, Van Dale, registered the term and assigned it the following definition: 'to use less consumer goods in an effort to save the environment'.

In sum, downshifting definitions range from abstract outlooks and visions at one end of the spectrum to concrete action at the other end. It seems that the most comprehensive is Elgin's definition of voluntary simplicity as it encompasses lifestyle, attitude and behaviour.

Etzioni's definition concentrates only on behaviour and is similar to Schor's definition of downshifting as both refer to a lifestyle of reduced consumption (Shaw \& Newholm 2002). The main difference between the two is the extent to which spending is reduced. In general, voluntary simplifiers make a more radical lifestyle change and achieve greater reduction than downshifters. Another difference is the element of 'working less' that Schor introduced as a core characteristic. Although all of the abovementioned definitions differ to some degree, one important similarity remains: the basic assumption of all definitions is that the lifestyle change is voluntary (Jackson 2005). 


\section{Definition of downshifting in the present study}

In this study, we use the basic definition of downshifting, namely a reduction in spending, but include both a voluntarily and involuntary dimension. Downshifters are quite simply defined as people who are living with less money than they did before, regardless of whether the change is voluntary or involuntary. Therefore, in this study, the term 'voluntary downshifters' is analogous to what other researchers refer to as 'downshifters'.

\subsection{Academic context, objectives and research questions}

The overall purpose of this section was to determine empirically how downshifting can contribute to sustainability. The study builds upon the results and insights of our field study on living with less in which we focused on the changes that coincide with living with less money and the role of the social and cultural environment. In line with our field study, our focus in this research was placed on consumer practices, experiences and concrete behaviour rather than on motivations, feelings or intentions. As such, we deliberatedly opted again for the phenomenological approach which is considered appropriate to reduce bias.

Our research questions were derived from three themes, namely downshifting, frugality and sustainability. How we view these themes and the academic context of this study, as well as the research questions and hypotheses will be explained below.

\subsubsection{Research theme 1: Downshifting}

Apart from a nationwide British study and a marketing study conducted by Datamonitor (2003), no empirical data on European downshifting were available prior to this study. Therefore, our study's objective was to extend knowledge about downshifting and to compare voluntary and involuntary downshifters.

a) The first downshifting topic we investigated concerns the voluntariness and involuntariness of downshifting as a selection criterion. Based on the findings of our pilot study that demonstrated the highly complex nature of this prevalent connotation of downshifting in existing studies, we concluded that the assumed voluntariness of downshifting might be an 'a posteriori' interpretation of the decision to downshift, rather than an actual choice. For this reason, we choose to define downshifting as a reduction of spending per se, regardless of the voluntary or involuntary nature of the decision. We were curious to see if the voluntary or involuntary nature of a downshifting experience influenced consumption experiences and practices. In particular, we wanted to find out if the voluntary or involuntary nature of the decision had an impact on sustainability. 
b) The second topic explored was the socio-economic and demographic characteristics of downshifters. Unlike the popular belief that voluntary downshifting is predominantly an upper middle class phenomenon, empirical data have revealed a different view. In Britain (Hamilton 2003) and in Australia (Breakspear \& Hamilton 2004; Hamilton \& Mail 2003), voluntary downshifters appear to be spread relatively evenly across all socio-economic classes (2003: 15). What seems common is that bluecollar and white-collar workers are equally represented (Schor 1998). Generally, high income groups did have fewer numbers of downshifters. Diversity is another aspect mentioned by anthropologist Richard Wilk, who described downshifters as a very heterogeneous group consisting of 'neo-primitivists, romantic 'back-to-the-landlocalists', people looking for ways to downshift to less stressful jobs, environmental activists and retirees' (2001: 257). Research conducted in the USA (Schor 1998) and in Australia (Breakspear \& Hamilton 2004) found that men and women were evenly represented, while British research has shown greater numbers of women. Finally, all studies reported that people in their thirties are more likely to downshift than those in their forties and fifties. These considerations led to the following research question and hypothesis:

Q 1 What are the characteristics of downshifters? Do voluntary downshifters, involuntary downshifters and non-downshifters differ on these characteristics?

H 1 Downshifters do not differ significantly from the general population in terms of age, gender or education.

c) The third topic studied focused on the changes in consumption expenditures. We know, from our field study, that living with less money impacts important life domains because it demands the reduction of specific expenditures. This finding prompted us to collect empirical data on changes in consumption expenditures so that we could explore prioritizations of consumption expenditures. This is why we included an apparently counterintuitive question regarding increases in expenditures so as to gain more insight regarding the prevalent notion that (voluntary) downshifters are mainly driven by the desire to increase their quality of life (Breakspear \& Hamilton 2004; Elgin 1981; Etzioni 1998; Huneke 2005; Schor 1998).

Q 2 How do downshifters adjust their consumption expenditures and do voluntary downshifters and involuntary downshifters differ in this respect?

Q 3 On what goods and services did expenditures increase and do voluntary and involuntary downshifters differ in this respect? 
d) The fourth topic explored experiences of downshifting in the context of postmodern consumer society. No doubt, the experiences of voluntary downshifters have been discussed in several studies. Downshifting has been found to engender feelings of relief or provide a sense of 'personal freedom'. Other positive experiences reported include feelings of being in control of one's life, reduced stress and the acquisition of a more fulfilling life. Downshifters have also reported having a more critical attitude towards society and higher levels of active social engagement. As well, downshifters reported investing more time in personal growth and, in particular, in creative or musical pursuits (Breakspear \& Hamilton 2004). Likewise, greater emphasis on health has been noted (Drake 2000). Lastly, Hamilton (2003) concluded that downshifting is a change process in which money and material possessions actually play a relatively minor role.

Negative experiences reported include increased anxiety over finances as a major obstacle to downshifting. In particular, concerns regarding one's ability to provide for one's retirement have been noted, as have fewer opportunities for 'luxury' or 'splurge' spending (Breakspear \& Hamilton 2004). Overall, disciplined financial planning and careful spending have thus been perceived as negative aspects of downshifting (Drake 2000). Critical reactions from friends and family have also often been reported as negative (Breakspear \& Hamilton 2004).

Because our study focused on the experiences of both voluntary and involuntary downshifters, and given the explorative character of the dissertation, we used a number of open-ended questions to examine downshifting experiences.

\section{Q $4 \quad$ What are positive experiences associated with living with less money? \\ Q $5 \quad$ What are negative experiences associated with living with less money?}

Q 6 Does the voluntary or involuntary nature of downshifting affect whether experiences are perceived to be positive or negative?

Our field research finding that voluntary downshifters were confronted with reproach and critique from their peer group appears to be confirmed by Breakspear and Hamilton (2004), who also reported that the downshifters in their study received negative reactions from their social environment. These findings further encouraged us to test the following hypotheses:

$\mathrm{H} 2$ Voluntary downshifters are confronted with more negative social reactions than involuntary downshifters.

H 3 Voluntary downshifters enjoy more positive individual experiences than involuntary downshifters. 
Since downshifters do not live in a social vacuum but interact with their social-cultural context, a major objective of this study was to examine this interplay. Social-cultural consumption theories in the tradition of Veblen (1948), Bourdieu (1984) and anthropologist Douglas (1996) form the academic frame of reference for our study of downshifting (De Geus 2003; Holt 1997; 1998; 2003; Schor 1991; 1998). In particular, Schor's theory on postmodern consumption acceleration, known as the principle 'keeping up with the Gateses', guided our analyses.

We assumed that downshifting, as a consumption phenomenon, is entangled with postmodern tendencies of hyper-consumption. Theories of post materialism (Inglehart 1977; 1997) and characteristics of new consumer groups (Etzioni 1998; Ray \& Anderson 2000; De Geus 2003) inspired us to hypothesize about the downshifter's aspirations of autonomy and self-determination. These expectations were substantiated by results of the field study showing a number of negative reactions and critiques from the social environment. As such, we added both hypotheses as proposition 9 and 10 to Lastovicka's Frugality scale, which is part of the survey, as described below in 5.2.2 Research theme 2: Frugality.

$\mathrm{H} 4$ Downshifters are less receptive to inter-personal or commercial influences than non-downshifters.

H 5 Downshifters have stronger feelings of autonomy and self-determination, and a greater tendency to organize their life according to their own system of standards and values than non-downshifters.

\subsubsection{Research theme 2: Frugality}

Traditionally, discourses about frugality and moderation primarily have occurred outside the domain of consumer studies. In our analysis of the development of consumer studies, as described in Chapter 2 of this dissertation, we explained this omission as the result of the specific academic context of consumer studies. The fact that frugal consumption was not a topic of interest in consumer studies does not mean that it did not exist. Our analysis of frugality in postmodern consumer society, as described in Chapter 3, demonstrates that frugality is still an important cultural characteristic, albeit it now has a dichotomous character.

Therefore one of the main objectives of the present study was to investigate the significance and practical effects of frugality in postmodern consumer society. In particular, we explored practices and applications of frugality in consumer behaviour.

The guiding principle for this approach is our definition of frugality as previously outlined in Chapter 3: 'Frugality is a strategic behavioural practice characterized by careful handling of what is at one's disposal: material goods, money, resources - as well as immaterial resources, such as services, personal energy, time and relationships in order to achieve a more balanced life.' Thus, in this study the frugality issue is predominantly addressed through implicit operationalizations such as reduced expenses and living with less. 
The issue of frugality is also addressed explicitly by Lastovicka and colleagues' Frugality scale (1999). We used this scale to measure the dominant attitudes that direct frugal behaviour. Since the propositions in this scale mainly address practices this measure appeared to be congruent with the general research focus on concrete consumer behaviour. For this reason the research question is:

Q 7 Do voluntary downshifters, involuntary downshifters and non-downshifters differ significantly with respect to their Frugality scale scores?

Despite Lastovicka and colleagues' expectation that frugality scores increase with age, his study found no association between age and Frugality scale scores. This finding, coupled with the mixed results concerning the association between age and downshifting in other studies of downshifting, were used to formulate a more specific hypothesis about Dutch downshifters.

H 6 There is no association between age and Frugality scale score in Dutch downshifters.

\subsubsection{Research theme 3: Sustainability}

Due to recent discussions on climate change, the argument for moderating consumption has increasingly become more compelling. Although for many governments technical solutions remain the primary focus of attention, seeking to change consumer behaviour is receiving increasing support. This attention is not limited to reducing the use of fossil fuels. It also includes lowering $\mathrm{CO}_{2}$ emissions, limiting waste and moderating the use of natural resources. These steps are perceived as not only necessary but also inevitable if we are to increase ecological sustainability (Jackson 2009; Worldwatch 2010).

We address the issue of sustainability by exploring opportunities for sustainability via the reduction of consumptive expenses. Our definition of sustainable living is a modification of the triple bottom line: people, profit, planet. It is what we refer to as 'the Dutch Triple Gs of a Sustainable Lifestyle': geld (money), groen (eco-friendliness), gezondheid/welzijn (health/wellbeing). This model is similar to Callenbach's Green Triangle which comprises money, environment, and health and was originally developed 'to generate ideas for personal, community and national change' (1990: 2). Likewise, in our view, sustainable living is more than simply eco-friendly behaviour. It includes appropriate financial management and behaviours that are beneficial for health and wellbeing. On this reading, a sustainable lifestyle is the combined synergistic outcome of activities in all three areas: 'Anytime you do something beneficial for one of them, you will almost inevitably also do something beneficial for the other two - whether you're hoping to or not' (1990: 2). 
Our vision of a sustainable lifestyle was operationalized, firstly, as eco-friendly consumption practices, as measured on basis of the Ecological Footprint (Rees 1998), and as two other dimensions of sustainable living, namely finance and happiness, which were measured by items derived from the list of simple living practices (Huneke 2005). In sum, the purpose of this aspect of the study was to examine the connection between sustainability and living with less and to identify its triple determinants, as exemplified in the following research question and hypothesis:

Q 8 How does downshifting contribute to sustainability and do voluntary downshifters, involuntary downshifters and non-downshifters differ in this respect?

H 7 Downshifters maintain a more sustainable lifestyle than non-downshifters.

\subsection{Methods}

\subsubsection{Participants and procedure}

The readers of the Dutch magazine Genoeg, a bimonthly publication focusing on consuming less, were recruited for this study as they were assumed to be representative downshifters. Our survey was developed in cooperation with the magazine's publisher and pre-tested twice with small groups of Genoeg readers. A paper version of the survey was inserted into the 8000 copies of the December 2006 edition. Readers were also invited to complete the digital version available on the publication's website (www.genoeg.nl) if they preferred that format. Completed surveys were accepted from December $1^{\text {st, }} 2006$ until January $31^{\text {st }} 2007$. We received 1068 responses (13.35\%) of which 630 were digital and 438 paper versions. Sixty-two surveys were incomplete or otherwise invalid, reducing the total to 1006 participants. The first descriptive analyses were conducted in February and March 2007, and mainly addressed the reader profiles and opinions about the magazine. Results were published in the April/May 2007 edition. Additional descriptive and correlative analyses were performed between March and May 2009, and directly addressed the abovementioned research questions and hypotheses on downshifting, frugality and sustainability. At this time, we also categorized and quantified responses to the openended questions on positive and negative experiences.

Table 5.1: The sample

\begin{tabular}{|l|c|c|}
\hline The sample & N & \% \\
\hline & 461 & 46 \\
\hline Voluntary downshifters & 280 & 28 \\
\hline Involuntary downshifters & 265 & 26 \\
\hline Non-downshifters & $\mathbf{1 0 0 6}$ & $\mathbf{1 0 0}$ \\
\hline \multicolumn{1}{|c|}{ Total } & & \\
\hline
\end{tabular}




\subsubsection{Sample}

Our sample (see Table 5.1) of 1006 participants comprised three groups: voluntary downshifters $(\mathrm{N}=461)$, involuntary downshifters $(\mathrm{N}=280)$ and non-downshifters $(\mathrm{N}=265)$. The selection criteria and our assumptions are briefly discussed below.

Downshifters were identified by their response to the question, 'Did you, at some point in your life, deliberately reduce your expenditure pattern?' (Survey question 35 in Appendix). This formulation might seem artificial but, after pre-testing several alternative formulations, this one appeared to elicit the most appropriate responses. The term 'live with less money' used in the field study was found to be insufficiently discriminative as almost all respondents could identify a time in their life when money was tight. The term 'income reduction' excluded respondents who reduced expenses regardless of income and the term 'consume less' was misinterpreted by the pre-test participants to pertain only to the consumption of food and not to the consumption of goods and services in general. Finally, phrases such as 'living more frugally' or 'living more moderately' were also found to yield multiple interpretations. Specifically the term 'frugal' as simply living with less money was poorly understood by respondents. They thought it implied practicing an attitude of frugality. The question, 'Did you, at some point in your life, deliberately reduce your expenditure pattern?' was found to be the most adequate formulation. The word 'deliberately' was necessary to discriminate between single experiences and significant life-changing experiences. Because the pretest affirmed the assumption that spending less could take place without a reduction in income, we chose spending reduction as the selection criteria instead of income reduction, which is the prevailing criterion in studies of downshifters.

The total number of participants that met the criterion for downshifters $(N=741)$ were further classified as either voluntary or involuntary downshifters. This was determined on basis of the following questions: "How did the household income change when you deliberately reduced your expenditure pattern?' and 'What was the reason for the change in net household income?' With respect to the latter, one of the response options was 'voluntary choice', thus determining whether the respondent was a voluntary downshifter (survey questions 36 and 37 in Appendix ).

In total, 55\% of all downshifters changed their expenditure patterns after a reduction of income ( $\mathrm{N}=422)$ while $34 \%$ opted to downshift despite experiencing no change in income $(\mathrm{N}=260)$. Surprisingly, an additional $11 \%$ choose to downshift after an increase in income $(\mathrm{N}=87)$. Of those who experienced a reduction in income, this reduction was voluntary for $29 \%(\mathrm{~N}=114)$ and involuntary for the remaining $71 \%(\mathrm{~N}=280)$.

All in all, the group of voluntary downshifters ( $N=461)$ comprised: 1 ) Participants with equal household income $(\mathrm{N}=87)$; 2) Participants with higher household income $(\mathrm{N}=260)$; 3) Participants with a consciously chosen lower household income ( $N=114)$. The respondents who experienced a decrease in household income and answered 'no' to the question of whether voluntary choice was the reason for the decrease, were classified as involuntary downshifters $(\mathrm{N}=280)$. 


\subsubsection{Measures and approach to analysis}

The survey, entitled The Genoeg Readers Survey (see Appendix) comprised the following three sections:

Part 1: Background Information: Items measuring background information such as demographic and socio-economic characteristics. To note, results pertaining to question 10 ('Hours of unpaid work') and question 12 ('Charitable donations') are not reported here. For these questions were added on special request of the publisher in support of marketing policy.

Part 2: Items measuring opinions of the magazine Genoeg and reading habits. Results are not reported here.

Part 3: Finances and lifestyle: Items measuring one's financial situation and lifestyle (attitudes and consumption practices).

To note: Part 1 and Part 3 were combined to comprise the survey used in the Living with Less study.

With the exception of two open-ended questions, the answer options were ordinal or nominal and scored on 5-point or 7-point scales. Items addressed the following issues:

\section{a) Demographic and socio-economic characteristics}

The demographic characteristics measured included age, gender, educational attainment and household composition. Socio-economic variables measured were net monthly income, income maintenance, paid employment and unpaid activities.

The variable education was dichotomized into high level (higher secondary school, higher vocational education, and university) and moderate to low level (intermediate and lower secondary school, intermediate and lower vocational training). With respect to religion and spirituality, respondents were given two answer options by which they could indicate whether religion and spirituality is actually important or unimportant to them.

Net monthly household income was initially scored as falling into one of six ranges of net household income (in Euros). Subsequently, the lowest two categories 'less than $€ 900$ ' and 'between $€ 900$ and $€ 1250$ ' were combined into one category, namely 'less than $€ 1250$ '. For the variable income maintenance, answers were assigned to one of six classifications, namely 'salary', 'relative/partner','(early) pension','self employment', 'benefits' and 'equity'.

Paid employment was divided into three categories, namely no paid employment, part-time employment for less than 30 hours per week, and full-time employment for more than 30 hours per week. Unpaid activities were divided into four categories, namely 'housekeeping and volunteer work', 'housekeeping and care', 'volunteer work' and 'none'. 
Descriptive and inferential analyses were conducted. In order to determine differences between the various groups of downshifters, we used SPSS Custom Tables. Means for continuous variables (e.g. age) were compared using t-tests. Column proportions for categorical variables (e.g. gender) were compared using z-tests. Tests were adjusted for all pairwise comparisons within a row of each innermost subtable using the Bonferroni correction.

\section{b) Changes in finances and expenditures}

Changes in financial situation were classified under one of three categories: 'increase in income', 'decrease in income' or 'unchanged income'. Changes in expenditures were measured using a list of sixteen consumption items (e.g. 'When you deliberately reduced your expenditure pattern, did you spend less, more or the same amount on the following items?').

Differences between the groups were determined using SPSS Custom Tables. Again column proportions were compared using z-tests and through the Bonferroni correction, tests were adjusted for all pairwise comparisons within a row of each innermost subtable.

\section{c) Experiences with downshifting}

Positive and negative experiences with spending reductions were measured using two open-ended questions that invited participants to provide three positive and three negative experiences. Two evaluators categorized the results separately. In this way, nine categories of positive experiences and eight categories of negative experiences emerged. Then, two additional evaluators processed the responses separately and classified all but three responses identically.

Differences between the groups were determined using SPSS Custom Tables. Column proportions were again compared using z-tests as well as the Bonferroni correction.

\section{d) Frugality}

Frugality was measured by Lastovicka et al's Frugality scale (1999; Tables 5.9 and 5.10) which is a measure of frugal attitudes consisting of eight statements that each reflect a specific aspect of frugality (e.g. 'If you take good care of your possessions you will definitely save money in the long run'). Answers were scored on 5-point scale ranging from 'strongly disagree' to 'strongly agree' with an additional response option of 'not applicable'. The higher the score, the more strongly the respondent agreed with the proposition and the more frugal the respondent. In order to be able to test Hypothesis 5 and Hypothesis 6 that investigated the assumption that downshifters are less susceptible to interpersonal or commercial influences, two propositions addressing respondents' autonomy were added.

Descriptive analyses and analyses of variance (ANOVA) were conducted. Scale means were compared using t-tests. Means for the two extra items were also compared. Further, Pearson correlations between the Frugality scale scores and age were calculated. 


\section{e) Consumption practices}

A list of 34 items (Table 5.14 en Table 5.15) measured concrete consumption practices across six domains: purchasing, food, leisure, environment, do-it-yourself and mobility. Answers were provided on a 5-point scale. In line with our definition of sustainability described in Chapter 2, which stated that sustainability is a way of life that benefits the environment as well as personal and financial wellbeing, this measure addressed a broad range of activities. The list combined a selection of items from the Ecological Footprint measure (item 7, 8, 9, 10, 23, 24, 25, 26, 31, 32, 33, 34) with items from the List of Simple Living Practices and the Simple Living Scale (items 1, 2, 3, 6, 7, 8, 9, 12, $13,14,15,16,17,18,19,20,22,23,25,26,29,31,32,33$; Huneke 2005). High scores on the following items were considered indicative of sustainability and simple living: Purchasing: 1 - 6; Food: 7, 9, 10, 11; Leisure: 13, 15, 16, 18, 19, 22; Environment: 23 27; Do-it-Yourself: 28, 29, 30; Mobility: 32, 33, while low scores on the following items were considered indicative of sustainability: $8,12,17,21,31$, and 34 .

Scale means were subsequently calculated and compared. Multiple testing correction was applied using the Bonferroni correction.

\section{$5.4 \quad$ Results}

\subsubsection{Demographic and socio-economic characteristics of Dutch downshifters}

Q 1 What are the characteristics of downshifters and do voluntary downshifters, involuntary downshifters and non-downshifters differ on these characteristics?

H 1 Downshifters do not differ significantly from the general population in terms of age, gender or education.

Table 5.2 presents demographic and socio-economic characteristics for voluntary downshifters, involuntary downshifters and non-downshifters. Table 5.3 compares the total sample of Genoeg readers (downshifters and non-downshifters) to the general population in the Netherlands.

Most generally, the results presented in Table 5.2 show that downshifters tend to be highly educated females. Most voluntary downshifters were under 50 years of age. Half of the involuntary downshifters were over 50 years and had low to intermediate educational attainment. Voluntary downshifters tended to receive income from contract work and from paid employment (supplemented with other income), while involuntary downshifters tended to obtain their income from benefits, (early) retirement or equity. A large portion of voluntary downshifters (42\%) were couples with children. Involuntary downshifters were more likely to be single (28\%) or single with children (13\%). 
Table 5.2 Demographic and socio-economic characteristic

\begin{tabular}{|c|c|c|c|c|c|c|}
\hline & \multicolumn{2}{|c|}{ Voluntary downshifters } & \multicolumn{2}{|c|}{ Involuntary downshifters } & \multicolumn{2}{|c|}{ Non-downshifters } \\
\hline & $\mathbf{N}$ & $\%$ & $\mathbf{N}$ & $\%$ & $\mathbf{N}$ & $\%$ \\
\hline \multicolumn{7}{|l|}{ Sex } \\
\hline Male & 65 & 14 & 33 & 12 & 46 & 17 \\
\hline Female & 396 & 86 & 247 & 88 & 219 & 83 \\
\hline \multicolumn{7}{|l|}{ Age } \\
\hline $20-40$ & 161 & 35 & 70 & 25 & 63 & 24 \\
\hline $41-50$ & 168 & 36 & 69 & 25 & 90 & 34 \\
\hline $51-80$ & 132 & 29 & 141 & 50 & 112 & 42 \\
\hline \multicolumn{7}{|l|}{ Education } \\
\hline Low - intermediate & 196 & 43 & 131 & 47 & 97 & 37 \\
\hline High & 265 & 58 & 149 & 53 & 168 & 63 \\
\hline \multicolumn{7}{|l|}{ Religion/spirituality } \\
\hline Important & 294 & 64 & 180 & 64 & 166 & 63 \\
\hline Unimportant & 167 & 36 & 100 & 36 & 99 & 37 \\
\hline \multicolumn{7}{|c|}{ Household composition } \\
\hline Single & 93 & 20 & 78 & 28 & 49 & 19 \\
\hline Single with children & 30 & 7 & 36 & 13 & 14 & 5 \\
\hline Couple & 132 & 28 & 90 & 32 & 88 & 33 \\
\hline $\begin{array}{l}\text { Couple with } \\
\text { children }\end{array}$ & 192 & 42 & 73 & 26 & 104 & 39 \\
\hline Other & 14 & 3 & 3 & 1 & 10 & 4 \\
\hline \multicolumn{7}{|l|}{ Income } \\
\hline$<€ 1.250$ & 75 & 16 & 86 & 31 & 36 & 14 \\
\hline$€ 1.250-€ 1.850$ & 100 & 22 & 70 & 25 & 53 & 20 \\
\hline$€ 1.850-€ 3.050$ & 160 & 35 & 78 & 28 & 87 & 33 \\
\hline$>€ 3.050$ & 89 & 19 & 31 & 11 & 65 & 25 \\
\hline No answer & 36 & 8 & 14 & 5 & 24 & 9 \\
\hline \multicolumn{7}{|l|}{ Income maintenance } \\
\hline Salary & 270 & 59 & 103 & 37 & 140 & 53 \\
\hline Relative/partner & 62 & 13 & 27 & 10 & 23 & 9 \\
\hline (Early) pension & 35 & 8 & 53 & 19 & 40 & 15 \\
\hline Self employment & 66 & 14 & 35 & 13 & 44 & 17 \\
\hline Benefits & 20 & 4 & 52 & 19 & 12 & 5 \\
\hline Equity & 8 & 2 & 10 & 4 & 6 & 2 \\
\hline \multicolumn{7}{|l|}{ Paid employment } \\
\hline $\begin{array}{l}\text { No paid } \\
\text { employment }\end{array}$ & 125 & 27 & 139 & 50 & 78 & 29 \\
\hline$<30 \mathrm{hrs}$ & 193 & 42 & 84 & 30 & 105 & 40 \\
\hline$>30 \mathrm{hrs}$ & 143 & 31 & 57 & 20 & 82 & 31 \\
\hline \multicolumn{7}{|l|}{ Unpaid activities } \\
\hline $\begin{array}{l}\text { Housekeeping and } \\
\text { volunteer work }\end{array}$ & 48 & 10 & 40 & 14 & 33 & 13 \\
\hline $\begin{array}{l}\text { Housekeeping and } \\
\text { care }\end{array}$ & 95 & 21 & 76 & 27 & 59 & 22 \\
\hline Volunteer work & 27 & 6 & 29 & 11 & 21 & 8 \\
\hline None & 291 & 63 & 135 & 48 & 152 & 57 \\
\hline Total & 461 & 100 & 280 & 100 & 265 & 100 \\
\hline
\end{tabular}


A salary was the main source of income for most voluntary downshifters (59\%) while proportionally more involuntary downshifters reported living on benefits (19\%) or having retired (early) (19\%). Half of the involuntary downshifters appeared to have no paid work. One third reported having a part-time paid job. Voluntary downshifters appeared to have the highest percentage of part-time employment (42\%). Regarding unpaid activities, involuntary downshifters reported the highest scores. More than a quarter (27\%) did housekeeping and care and $14 \%$ reported doing housekeeping and volunteer work. Overall, voluntary downshifters engaged in less unpaid activities than involuntary downshifters. Also, the answer category 'none' was selected more often by voluntary downshifters (63\%) than by non-downshifters $(57 \%)$.

A number of remarkable differences between the household incomes of voluntary and involuntary downshifters were noted, as demonstrated by Figure 5.1. Voluntary downshifters were more often found in higher income categories while involuntary downshifters were largely represented in the lowest income categories.

Voluntary downshifters reported higher household incomes (above net $€ 1850$ per month) and more paid employment (mostly part-time) than involuntary downshifters, but less paid employment than non-downshifters and involuntary downshifters that gain income through self-employment or through a relative or partner. Involuntary downshifters were also more often single or single parents. Their income was also more likely to be derived from (early) retirement or benefits. This may explain why relatively more involuntary downshifters fell into the lowest income category (less than net $€ 1850$ per month). Finally, non-downshifters reported working more hours and were more frequently self employed. They were also more likely to be couples without children.

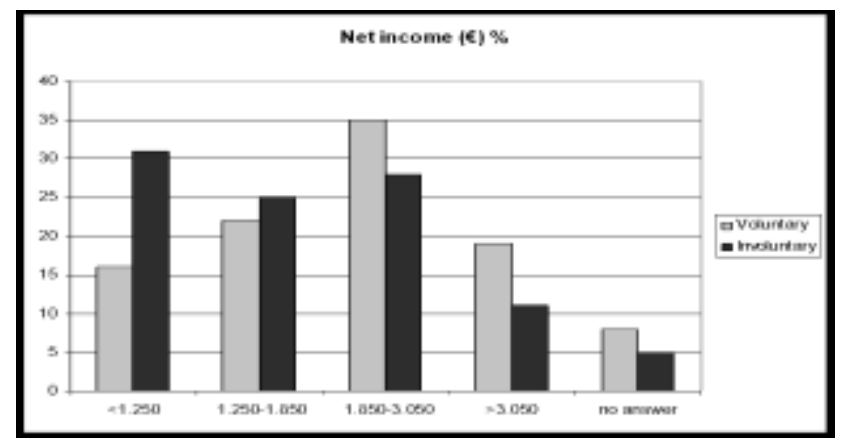

Figure 5.1: $\quad$ Monthly net household incomes 


\subsubsection{Weighted results}

For the total sample, data on sex, age, education and paid employment were adjusted to represent the Dutch population. This was done as follows. First, sample data on sex and age were compared with the CBS 2008 data on gender and age for Dutch people between 20 to 80 years. In the total sample there were relatively more women, especially between 41 to 50 years, and relatively less men, especially between 20 to 40 years. The following weights were calculated: Men: 20 to 40 years: 6.45; from 41 to 50 years: 2.43 ; 51 to 80 years: 2.9. Women: 20 to 40 years: 0.74 ; from 41 to 50 years: 0.38 ; 51 to 80 years: 0.64 . Then, the weighted data for downshifters were compared to the overall Dutch population.

Table 5.3: Demographic characteristics (weighted)

\begin{tabular}{|l|c|c|c|}
\hline & $\begin{array}{c}\text { Downshifters \% } \\
\mathbf{N = 7 4 1}\end{array}$ & $\begin{array}{c}\text { Non-downshifters \% } \\
\mathbf{N = 2 6 5}\end{array}$ & General population \% \\
\hline Sex & & & \\
\hline Male & 48 & 55 & 50 \\
\hline Female & 52 & 45 & 50 \\
\hline Age & & & 37 \\
\hline $20-40$ & 42 & 24 & 24 \\
\hline $41-50$ & 21 & 43 & 40 \\
\hline $51-80$ & 38 & & 73 \\
\hline Education & & 33 & 25 \\
\hline Low - intermediate & 41 & 68 & 38 \\
\hline High & 59 & 26 & 4 \\
\hline Paid employment & & 2 & 6 \\
\hline None & 33 & 8 & 9 \\
\hline$<10 \mathrm{hrs}$ & 3 & 16 & 21 \\
\hline $10-20 \mathrm{hrs}$ & 8 & 31 & 22 \\
\hline $20-30 \mathrm{hrs}$ & 15 & 18 & \\
\hline $30-40 \mathrm{hrs}$ & 28 & & \\
\hline$>40 \mathrm{hrs}$ & 12 & & \\
\hline
\end{tabular}

As shown in Table 5.3, downshifters had a relatively higher level of education and were more frequently between the ages of 20 and 40. Downshifters were also more frequently female but the difference with the general population was small. Further, downshifters were more frequently engaged in paid employment, particularly parttime work. The numbers of downshifters working more than a full-time job was far below the Dutch average. Finally, compared to the general population, downshifters had more children and a greater tendency to live in cooperative housing projects or have a different type of household composition.

\section{Results for Hypothesis 1}

Our first hypothesis that downshifters do not differ significantly from the general population in terms of age, gender or education was not confirmed and is thus rejected. 


\subsubsection{Changes in finances}

Respondents were asked if their net household income had changed when they decided to reduce their spending. Table 5.4 shows the results.

Consistent with our selection criteria, all involuntary downshifters had experienced a decrease in household income. Over half (56\%) of the voluntary downshifters decided to reduce spending while their income remained the same and one fifth reported an increase in household income when they decided to reduce expenses. About $16 \%$ of all downshifters reported choosing to reduce spending to repay debts. Notably, only a quarter of the voluntary downshifters had experienced a decrease in household income. Over half of all downshifters (52\%) reported wanting to increase their savings as a reason for decreasing expenses. If we consider the income situation for all downshifters, we can conclude that over half the sample $(53 \%)$ had experienced a decrease in household income.

Table 5.4: Changes in household income

\begin{tabular}{|l|c|c|c|c|}
\hline & \multicolumn{2}{|c|}{ Voluntary } & \multicolumn{2}{c|}{ Involuntary } \\
\hline & $\mathbf{N}$ & $\mathbf{\%}$ & $\mathbf{N}$ & $\mathbf{\%}$ \\
\hline Decrease & 114 & 25 & 279 & 100 \\
\hline Increase & 87 & 19 & 0 & 0 \\
\hline No change & 260 & 56 & 0 & 0 \\
\hline \multicolumn{1}{|c|}{ Total } & $\mathbf{4 6 1}$ & $\mathbf{1 0 0}$ & $\mathbf{2 7 9}$ & $\mathbf{1 0 0}$ \\
\hline
\end{tabular}

The differences in the reasons for income decreases as shown in Table 5.5 are also noteworthy. Voluntary downshifters reported resignation from a job and job change as the main reasons for their decreased income. Involuntary downshifters reported illness, divorce and resignation as main reasons for decreased income. For the 'other' category, participants mentioned significant life events such as the death or illness of a partner, which caused a loss in household income, or the failure of an enterprise.

Table 5.5: Reasons for decrease in income

\begin{tabular}{|l|c|c|c|c|}
\hline & \multicolumn{2}{|c|}{ Voluntary } & \multicolumn{2}{c|}{ Involuntary } \\
\hline & $\mathrm{N}$ & $\%$ & $\mathrm{~N}$ & 11 \\
\hline Resignation & 39 & 34 & 32 & 21 \\
\hline Let go & 8 & 7 & 58 & 11 \\
\hline Job change & 26 & 23 & 32 & 11 \\
\hline (Early) retirement & 4 & 4 & 32 & 9 \\
\hline Benefits & 3 & 3 & 4 & 24 \\
\hline Decrease in benefits & 1 & 1 & 68 & 4 \\
\hline Illness & 8 & 7 & 10 & 3 \\
\hline Exhausted savings & 5 & 4 & 7 & 23 \\
\hline No child allowance & 4 & 4 & 63 & 24 \\
\hline Divorce & 15 & 13 & $\mathbf{3 9 8}$ & $\mathbf{1 0 0}$ \\
\hline Other & 34 & 30 & $\mathbf{1 0 0}$ & \\
\hline \multicolumn{1}{|c|}{ Total } & $\mathbf{1 4 7}$ & & & 24 \\
\hline
\end{tabular}


As shown in Table 5.6, the amount of spending reduction reported appears to be remarkably similar for both voluntary and involuntary downshifters. Almost one third reported a reduction between $€ 100$ and $€ 250$ and over one fifth reported a monthly spending reduction between $€ 250$ and $€ 500$.

Table 5.6: Amount of spending reduction

\begin{tabular}{|l|c|c|c|c|}
\hline & \multicolumn{2}{|c|}{ Voluntary } & $\mathbf{2}$ & Involuntary \\
\hline & $\mathbf{N}$ & $\mathbf{\%}$ & 47 & 17 \\
\hline$€ € 100$ & 77 & 17 & 89 & 33 \\
\hline$€ 250-€ 500$ & 148 & 32 & 58 & 21 \\
\hline$€ 500-€ 1000$ & 106 & 23 & 22 & 8 \\
\hline$>€ 1000$ & 38 & 8 & 12 & 4 \\
\hline No answer & 18 & 4 & 47 & 17 \\
\hline Total & 70 & 15 & $\mathbf{2 7 5}$ & $\mathbf{1 0 0}$ \\
\hline
\end{tabular}

\subsubsection{Changes in consumption expenditures}

Q 2 How do downshifters adjust their consumption expenditures and do voluntary downshifters and involuntary downshifters differ in this respect?

Q 3 On what goods and services did expenditures increase and do voluntary and involuntary downshifters differ in this respect?

Results (see Figure 5.2 and Table 5.7) showed that a substantial majority of downshifters reduced expenses on particularly restaurant and cafe visits, impulse buying and clothes. Other frequently mentioned items were furniture, books, CDs and holidays. About half of the participants spent less on gifts, theatre and concert tickets, holidays and hobbies.

'Despite all my efforts to reduce the energy I use, it seems as if the electricity bills never stop rising,' a participant sighed. Energy spending was reported by a majority of participants and more often by voluntary than by involuntary downshifters $(74 \%$ versus 60\%). Overall, involuntary downshifters reported higher percentages of reduction for all items, except for energy use.

The least likely items on which expenditures were reduced were insurance and housing $(<46 \%)$. In response to the open-ended answers, participants reported that they spent less on subscriptions, telephone and internet costs and less on personal care such as the hairdresser and cosmetics. In addition, childcare expenses were frequently listed as an area in which one could reduce spending. 


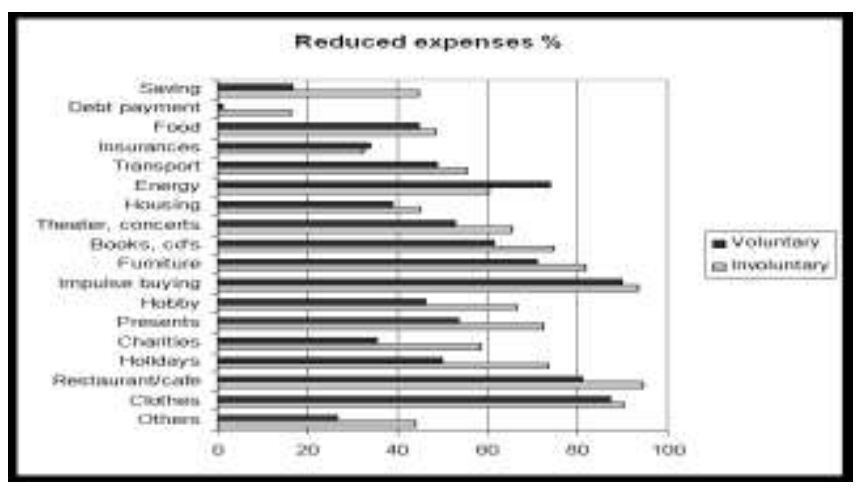

Figure 5.2: Reduced expenses

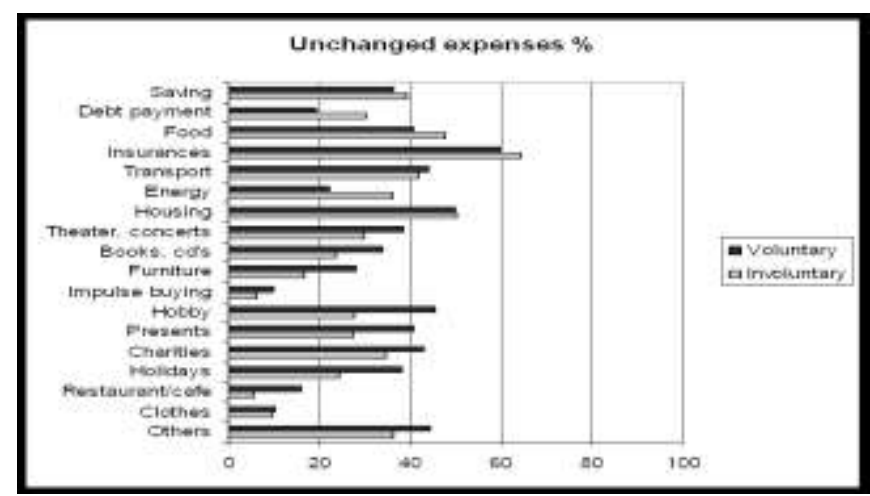

Figure 5.3: Unchanged expenses

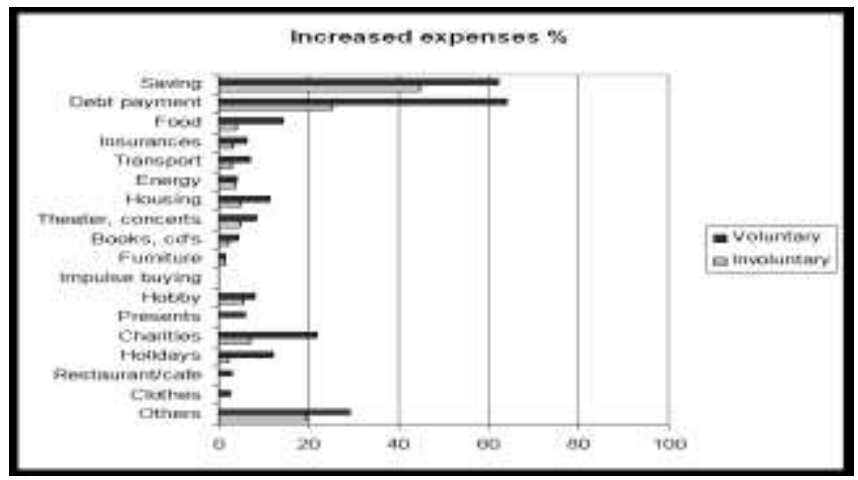

Figure 5.4: Increased Expenses 
With regard to unchanged expenses (see Figure 5.3 and Table 5.8), approximately half of the participants listed spending on insurance and housing. Food and transportation expenses were also frequently reported as stabile. There were significant differences between voluntary and involuntary downshifters in expenses related to hobbies $146 \%$ versus $28 \%$ ) and holidays (38\% versus $24 \%$ ). Again, there were also differences in spending on gifts, restaurant and cafe visits, and costs for books and CDs. Notably, these costs were more frequently reported as unchanged by voluntary than by involuntary downshifters.

Voluntary downshifters were also more likely to report increased expenditures on certain items (see Figure 5.4 and Table 5.9). The most frequently reported items were charitable contributions (22\%), food (14\%) and holidays (12\%). In the 'other' category, respondents mentioned that they spent more money on education, personal development and on living or special treatments and therapies. The least favorite items on which to increase spending for both types of downshifters were impulse buying and clothes.

Finally, significant findings for debt repayment and savings were observed. We found that around $60 \%$ of voluntary downshifters reported an increase in debt repayment ( $62 \%$ ) and savings (64\%). The results from involuntary downshifters showed that $45 \%$ increased debt repayments and $25 \%$ increased their savings.

In conclusion, the results have demonstrated a definitely differentiated pattern of spending changes. Shifting spending preferences appears to be more likely than across the board cut backs. Except for energy use, no differences were noted between voluntary and involuntary downshifters in spending reductions on consumption items. However, the extent of reduction did differ. Involuntary downshifters reduced all expenses more often than voluntary downshifters.

The finding that downshifting involves more of an adjustment of expenses rather than an overall decrease is also suggested by the findings that some voluntary downshifters increased spending on particular items (i.e. charities, food and holidays) and reduced spending on energy consumption. Another significant observation was that both debt repayment and investing in savings increased considerably for both groups of downshifters. 
Table 5.7: Reduced expenses

\begin{tabular}{|l|c|c|c|c|}
\hline & \multicolumn{2}{|c|}{ Voluntary } & \multicolumn{2}{c|}{ Involuntary } \\
\hline & $\mathrm{N}$ & $\%$ & $\mathrm{~N}$ & $\%$ \\
\hline Food & 204 & 45 & 120 & 48 \\
\hline Clothes & 408 & 87 & 227 & 90 \\
\hline Restaurants/cafes & 348 & 81 & 206 & 95 \\
\hline Holidays & 214 & 50 & 172 & 74 \\
\hline Charities & 152 & 35 & 136 & 59 \\
\hline Gifts & 243 & 53 & 182 & 73 \\
\hline Hobby & 207 & 46 & 158 & 67 \\
\hline Impulse buying & 371 & 90 & 196 & 93 \\
\hline Furniture & 271 & 71 & 163 & 82 \\
\hline Books, CDs & 273 & 62 & 181 & 75 \\
\hline Theatre, concerts & 217 & 53 & 143 & 66 \\
\hline Housing & 175 & 39 & 106 & 45 \\
\hline Energy & 340 & 74 & 151 & 60 \\
\hline Transportation & 224 & 49 & 137 & 55 \\
\hline Insurance & 152 & 34 & 80 & 33 \\
\hline Debt repayment & 2 & 1 & 15 & 16 \\
\hline Savings & 76 & 17 & 101 & 45 \\
\hline Other & 38 & 26 & 40 & 44 \\
\hline
\end{tabular}

Table 5.8: Unchanged expenses

\begin{tabular}{|l|c|c|c|c|}
\hline & \multicolumn{2}{|c|}{ Voluntary } & \multicolumn{2}{c|}{ Involuntary } \\
\hline & $\mathbf{N}$ & $\mathbf{\%}$ & $\mathbf{N}$ & $\mathbf{\%}$ \\
\hline Food & 187 & 41 & 119 & 48 \\
\hline Clothes & 48 & 10 & 24 & 10 \\
\hline Restaurants/cafes & 69 & 16 & 12 & 6 \\
\hline Holidays & 164 & 38 & 57 & 24 \\
\hline Charities & 185 & 43 & 80 & 35 \\
\hline Gifts & 186 & 41 & 68 & 27 \\
\hline Hobby & 204 & 46 & 66 & 28 \\
\hline Impulse buying & 40 & 10 & 13 & 6 \\
\hline Furniture & 107 & 28 & 33 & 17 \\
\hline Books, CDs & 150 & 34 & 57 & 24 \\
\hline Theatre, concerts & 158 & 39 & 65 & 30 \\
\hline Housing & 224 & 50 & 118 & 50 \\
\hline Energy & 103 & 22 & 90 & 36 \\
\hline Transportation & 202 & 44 & 104 & 42 \\
\hline Insurance & 271 & 60 & 158 & 64 \\
\hline Debt repayment & 59 & 36 & 36 & 39 \\
\hline Savings & 88 & 19 & 68 & 30 \\
\hline Other & 64 & 44 & 33 & 36 \\
\hline
\end{tabular}




\begin{tabular}{|l|c|c|c|c|}
\hline & \multicolumn{2}{|c|}{ Voluntary } & \multicolumn{2}{c|}{ Involuntary } \\
\hline & $\mathbf{N}$ & $\mathbf{\%}$ & $\mathbf{N}$ & $\mathbf{0}$ \\
\hline Food & 65 & 14 & 10 & 4 \\
\hline Clothes & 11 & 2 & 1 & 0.4 \\
\hline Restaurants/cafes & 12 & 0 & 0 & 0 \\
\hline Holidays & 52 & 12 & 5 & 2 \\
\hline Charities & 94 & 22 & 16 & 7 \\
\hline Gifts & 26 & 6 & 1 & 0.4 \\
\hline Hobby & 36 & 8 & 13 & 6 \\
\hline Impulse buying & 2 & 0.5 & 1 & 2.5 \\
\hline Furniture & 5 & 1 & 3 & 2 \\
\hline Books, CDs & 20 & 5 & 5 & 5 \\
\hline Theatre, concerts & 35 & 9 & 10 & 5 \\
\hline Housing & 51 & 11 & 11 & 4 \\
\hline Energy & 18 & 4 & 9 & 3 \\
\hline Transportation & 32 & 7 & 7 & 45 \\
\hline Insurance & 28 & 6 & 8 & 25 \\
\hline Debt repayment & 101 & 62 & 41 & 20 \\
\hline Savings & 291 & 64 & 57 & 18 \\
\hline Other & 42 & 29 & &
\end{tabular}

Table 5.10: Mean scores for expenses

\begin{tabular}{|l|c|c|c|c|c|c|c|}
\hline & \multicolumn{3}{|c|}{ Voluntary } & \multicolumn{3}{c|}{ Involuntary } & \\
\hline & Mean & SD & N & Mean & SD & N & P-value \\
\hline Food & -0.35 & 0.716 & 452 & -0.48 & 0.589 & 270 & .02 \\
\hline Clothes & -0.85 & 0.408 & 456 & -0.9 & 0.322 & 275 & n.s. \\
\hline Restaurants/cafes & -0.8 & 0.457 & 403 & -0.93 & 0.263 & 229 & .00 \\
\hline Holidays & -0.39 & 0.662 & 423 & -0.66 & 0.538 & 247 & .00 \\
\hline Charities & -0.14 & 0.697 & 420 & -0.51 & 0.607 & 257 & .00 \\
\hline Gifts & 0.49 & 0.745 & 434 & -0.14 & 0.864 & 251 & .00 \\
\hline Hobby & 0.48 & 0.561 & 128 & 0.33 & 0.709 & 94 & n.s. \\
\hline Impulse buying & -0.52 & 0.555 & 448 & -0.69 & 0.471 & 272 & .00 \\
\hline Furniture & -0.4 & 0.632 & 428 & -0.63 & 0.596 & 251 & .00 \\
\hline Books, CDs & -0.92 & 0.294 & 391 & -0.91 & 0.312 & 220 & n.s. \\
\hline Theatre, concerts & -0.64 & 0.523 & 373 & -0.79 & 0.452 & 207 & .00 \\
\hline Housing & -0.6 & 0.599 & 426 & -0.73 & 0.51 & 262 & .00 \\
\hline Energy & -0.45 & 0.629 & 392 & -0.66 & 0.557 & 232 & .00 \\
\hline Transportation & -0.24 & 0.642 & 435 & -0.4 & 0.595 & 252 & .00 \\
\hline Insurance & -0.68 & 0.535 & 451 & -0.59 & 0.563 & 271 & .03 \\
\hline Debt repayment & -0.4 & 0.598 & 444 & -0.49 & 0.577 & 268 & n.s. \\
\hline Savings & -0.25 & 0.538 & 442 & -0.22 & 0.511 & 267 & n.s. \\
\hline Other & 0.03 & 0.779 & 172 & -0.21 & 0.784 & 113 & .01 \\
\hline
\end{tabular}




\subsubsection{Positive and negative experiences with downshifting}

The qualitative section of the survey was an exploration of the participants' experiences with downshifting. Participant reports resulted in the categorization of nine positive and eight negative experiences (see Table 5.11). Below, we first explain these categorizations and then compare voluntary and involuntary downshifters' scores.

\subsubsection{Positive and negative experiences categories}

Q $4 \quad$ What are positive experiences associated with living with less money?

Q $5 \quad$ What are negative experiences associated with living with less money?

The results of the open-ended questions generated nine positive and eight negative categories of experiences of living with less money: a) Three categories concern both positive and negative experiences; b) Six categories are specifically positive; and c) Five categories are specifically negative.

\section{a) Categories of both positive and negative experiences}

The category challenge included the concept that the task of making ends meet is perceived as a sport or game. Downshifting thus is seen to have a competitive element in which downshifters attempt to adjust expenses and consumption patterns to the new financial standard. This experience was described by respondents as a 'sport' or 'game'. The experience can be labeled as positive (a sport as in a special task assignment that has to be overcome and that provides a stimulating experience encouraging respondents to achieve). The challenge can also be viewed as a negative experience. In this case, the task of making ends meet is experienced as too onerous or too difficult or even impossible. Respondents mentioned, for example, that the involuntariness of spending reductions makes it difficult to adjust their expenses to the new consumption standard.

Budgeting denotes explicit financial planning. The term includes the inventory of financial means, the preparation of an overview and the calculation of a budget. Budgeting may be experienced as positive or negative, depending on the person's ability to succeed in this, for most respondents, new task.

The category psychological effect refers to the emotional and psychological consequences of living with less. It has two dimensions as respondents reported both positive and negative psychological experiences. The positive consequences included increased self-esteem, confidence, pride, independence and an increased sense of autonomy. Additional positive consequences were the strengthening of one's personality and increased self-knowledge. Negative psychological experiences reported included feelings of stress, worry and guilt, especially toward one's children. Feelings of being a personal failure or being deficient and low self-esteem were also reported. 


\section{b) Categories of positive experiences}

The category financial effect denotes the results and outcomes of living with less such as increased savings, debt reduction and the possibility of being able to afford special purchases or support one's children's education.

Personal growth denotes the knowledge and skills gained during the process of living with less. Respondents mentioned that they became more creative because of downshifting and developed particular skills or gained particular knowledge.

The category Post-materialism denotes the acquisition of a changed attitude toward money and material possessions. As a positive experience, it puts the importance of material possessions into perspective and respondents reported that they became less attached to material possessions while, at the same time, placing increased value on what they already owned.

The social effect refers to the strengthening of social ties such as family relationships and friendships. This category also includes reports of changes in social contacts because of living with less, such as meeting new soul mates and ending other relationships.

Quality of life represents having an increased appreciation of life and is analogous with reports of less fatigue, less stress, more free time and/or having a more adventurous life. It also includes reports of improved health and better physical condition resulting from less stress and/or better food.

Better citizen refers to all positive evaluations of living with less that impact the world. For example, respondents mentioned that spending their money more consciously has allowed them to positively contribute to the environment and/or made them more compassionate toward the underprivileged. This category is also connected to greater engagement with issues of poverty, pollution and global concerns, and includes a critical awareness of the social pressures of consumerism.

\section{c) Categories of negative experiences}

In the responses to the question on negative experiences, a substantial number concerned familial relationships within the immediate family such as with a partner, children and other close family members. Respondents mentioned discussing expenses with their relatives and being met with protest, critique and arguments. With regard to the nature and the intimate character of the bonds, this specific type of social effect was identified as a separate category and distinguished from the category 'social effect' in the list of positive experiences.

The category poverty includes all direct reports of poverty as well as more descriptive reports such as 'too little money to cope', and 'unable to buy essentials'.

Sacrifice includes reports of material or immaterial items that are no longer affordable, as well as activities which are considered to be too costly and therefore forsaken. 
The category criticism/incomprehension includes the comments and lack of understanding that respondents reported receiving from their social environment. The intensity of negative reactions varied from slightly negative surprise to severe forms of disapproval or ridicule.

Isolation includes the experience of becoming a social outsider as a result of the decision to downshift or the inability to invest in social obligations (e.g. gifts) and social activities such as parties, going out with friends or colleagues, and so on.

\subsubsection{Groups comparison for positive and negative experiences}

Q 6 Does the voluntary or involuntary nature of downshifting affect whether experiences are perceived to be positive or negative?

H 2 Voluntary downshifters are confronted with more negative social reactions than involuntary downshifters.

H 3 Voluntary downshifters enjoy more positive individual experiences than involuntary downshifters.

The results presented in the Figures 5.5 and 5.6 and in Table 5.11 indeed show remarkable differences between the experiences of voluntary downshifters and the experiences of involuntary downshifters.

The most apparent finding is that involuntary downshifters reported higher scores for all negative experiences, except for the category incomprehension/criticism, while voluntary downshifters reported higher scores for all positive experiences.

When we consider the nature of the experience - positive or negative - the following finding is of note: In the range of negative experiences, almost half of the involuntary downshifters $(46 \%)$ and over half of the voluntary downshifters $(53 \%)$ reported having no negative experiences or non response.

The negative experience that scored the highest among voluntary downshifters concerned the category incomprehension/criticism (17\%). Participants reported that they were confronted with critique and negative judgment from their social environment.

Involuntary downshifter scores were significantly higher in two categories: sacrifice (19\%) and challenge (16\%). Also the category psychological effect (16\%) showed higher scores, although not significantly. Respondents reported that trying to cope with less money was a difficult task. There was a concern to make ends meet, to give children what they need and worries about falling into poverty. In addition, the financial restrictions were experienced negatively: 'Always, always count,' said one respondent. Some people reported being unhappy with the adjustments they made in order to lower their standard of living: 'We now skip the daily glass of wine,' or 'I gave up my daily newspaper.' The sacrifice may indeed cause problems within the family, particularly if children are demanding expensive brand-name clothes or other luxury items that assign them a particular social status. 
With regard to positive experiences, the highest scores among both the voluntary and involuntary downshifters were reported in the categories 'post-materialism' and 'psychological effect'. About $40 \%$ of involuntary (43\%) and voluntary downshifters (37\%) reported that they valued material possessions and money differently than before. Also, a positive psychological and emotional effect was reported by $29 \%$ of voluntary and $23 \%$ of involuntary downshifters. This was described as feeling independent and autonomous and feeling good about the fact that they now could master their finances.

Increased quality of life (26\% of voluntary downshifters) was also reported to be connected with pleasure derived from engaging in new activities as a result of living with less money. Respondents described their new lifestyle as more creative and adventurous. They reported doing nicer things such as going on sporting holidays, going for nature walks and picking fruit and mushrooms. In addition, the discovery of unexpected talents (e.g. gardening, cooking, do-it-yourself projects) contributed to the quality of life experience. Also, one fifth of the voluntary downshifters reported a change in attitude and a new commitment to society and the world, which we labeled as being a better citizen. Lastly, respondents reported that they had become more generous and more committed to the environment and/or the eradication of world poverty.

Table 5.11: Positive and negative experiences*

\begin{tabular}{|c|c|c|c|c|c|}
\hline \multirow[b]{2}{*}{ Positive experiences } & \multicolumn{2}{|c|}{ Voluntary } & \multicolumn{2}{|c|}{ Involuntary } & \multirow[b]{2}{*}{ P-value } \\
\hline & $\mathrm{N}$ & $\%$ & $\mathrm{~N}$ & $\%$ & \\
\hline Challenge/process & 43 & 9 & 28 & 10 & n.s. \\
\hline Budgeting & 73 & 16 & 41 & 15 & n.s. \\
\hline Financial effect & 121 & 26 & 34 & 12 & .00 \\
\hline Personal growth & 63 & 14 & 33 & 12 & n.s. \\
\hline Psychological effect & 135 & 29 & 63 & 23 & .04 \\
\hline Post-materialism & 169 & 37 & 119 & 43 & n.s. \\
\hline Social effect & 42 & 9 & 21 & 8 & n.s. \\
\hline Quality of life & 121 & 26 & 46 & 16 & .00 \\
\hline Better citizen & 97 & 21 & 27 & 10 & .00 \\
\hline Not applicable/no positive & 63 & 14 & 73 & 26 & .00 \\
\hline \multicolumn{6}{|l|}{ Negative experiences } \\
\hline Challenge/process & 49 & 11 & 46 & 16 & .02 \\
\hline Budgeting & 32 & 7 & 30 & 11 & n.s. \\
\hline Psychological effect & 53 & 12 & 44 & 16 & n.s. \\
\hline Family problems & 29 & 6 & 19 & 7 & n.s. \\
\hline Poverty** & 6 & 1 & 8 & 3 & -- \\
\hline Sacrifice & 60 & 13 & 54 & 19 & .02 \\
\hline Incomprehension/critics & 79 & 17 & 19 & 7 & .00 \\
\hline Isolation $* *$ & 9 & 2 & 13 & 5 & -- \\
\hline Not applicable/no negative & 242 & 53 & 130 & 46 & n.s. \\
\hline
\end{tabular}

* The list of positive and negative experiences resulted from a categorization of the responses to two openended questions to which participants could provide a maximum of three answers.

$* *$ numbers were too small for testing 


\section{Results for Hypothesis $\mathbf{2}$ and Hypothesis $\mathbf{3}$}

In conclusion, our expectations (Hypotheses 2 and 3) were partly affirmed by the findings. Generally, involuntary downshifters reported more negative experiences than voluntary downshifters, except for the category 'postmaterialism' which was selected more often by involuntary downshifters. In general, it was shown that voluntary downshifters reported more positive experiences. An exception to this finding was that they selected the negative experience 'incomprehension/critics' more frequently than involuntary downshifters. These results suggest the affirmation of Hypotheses 2 and 3 that voluntary downshifters experience more negative social reactions and more positive individual effects.

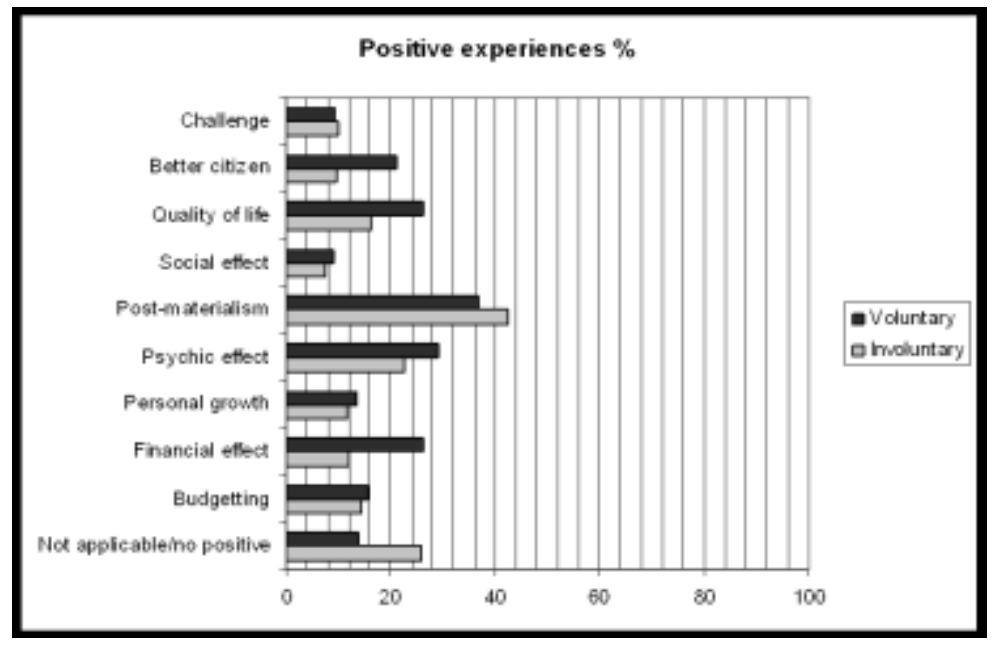

Figure 5.5 Positive experiences

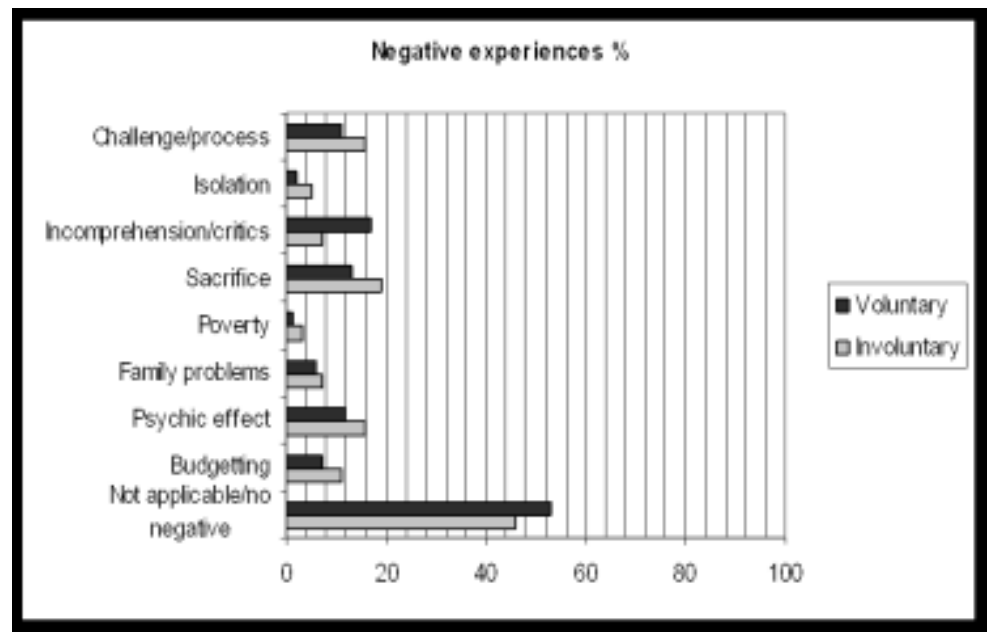


Figure 5.6 Negative experiences 


\subsubsection{Attitudes: frugality and autonomy}

Q 7 Do voluntary and involuntary downshifters differ significantly with respect to their Frugality scale scores?

H 4 Downshifters are less receptive to inter-personal or commercial influences than non-downshifters.

H 5 Downshifters have stronger feelings of autonomy and self-determination, and a greater tendency to organize their life according to their own system of standards and values than non-downshifters.

H6 There is no association between age and Frugality scale score in Dutch downshifters.

The Frugality scale results (Table 5.12 and Table 5.13) show that, in general, all participants reported being fairly frugal. However, some significant differences between the groups of downshifters were found. When we consider the mean scale scores, the non-downshifters appeared to be less frugal than the downshifters (Table 5.13). The mean scale scores of voluntary and involuntary downshifters showed no significant differences (Table 5.12).

When we consider the scores for the individual propositions, downshifters appeared to agree significantly more often than non-downshifters with proposition 1: 'If you take good care of your possessions, you will definitively save money in the long run'; and as well as with proposition 5: 'I believe in being careful in how I spend my money'; with proposition 6: 'I discipline myself to get the most from my money'; with proposition 7: 'I am willing to wait for on a purchase I want do that I can save some money'; and with proposition 8: 'If you can re-use an item you already have, there's no sense in buying something new' (Table 5.13).

Comparisons between the scores of voluntary and involuntary downshifters (Table 5.12) showed one significant difference, namely for proposition 6: 'I discipline myself to get the most from my money.'

\section{Results for Hypothesis $\mathbf{4}$ and Hypothesis $\mathbf{5}$}

The differences in the scores for proposition 9 between downshifters and nondownshifters were non-significant. Consequently, the expectation that downshifters are less susceptible to commercial influence than non-downshifters was not affirmed. However, the results for proposition 10 showed that downshifters actually affirmed the proposition significantly more often $(P=.00)$ than non-downshifters. Thus it can be concluded that downshifters have greater feelings of independence and autonomy

\section{Results for Hypothesis 6}

Pearson correlations between the Frugality scale scores and age were calculated. The results show a positive association between age and score on the Frugality scale. Accordingly, Hypothesis 6 is rejected. 
Table 5.12 Frugality scale: Voluntary and involuntary downshifters

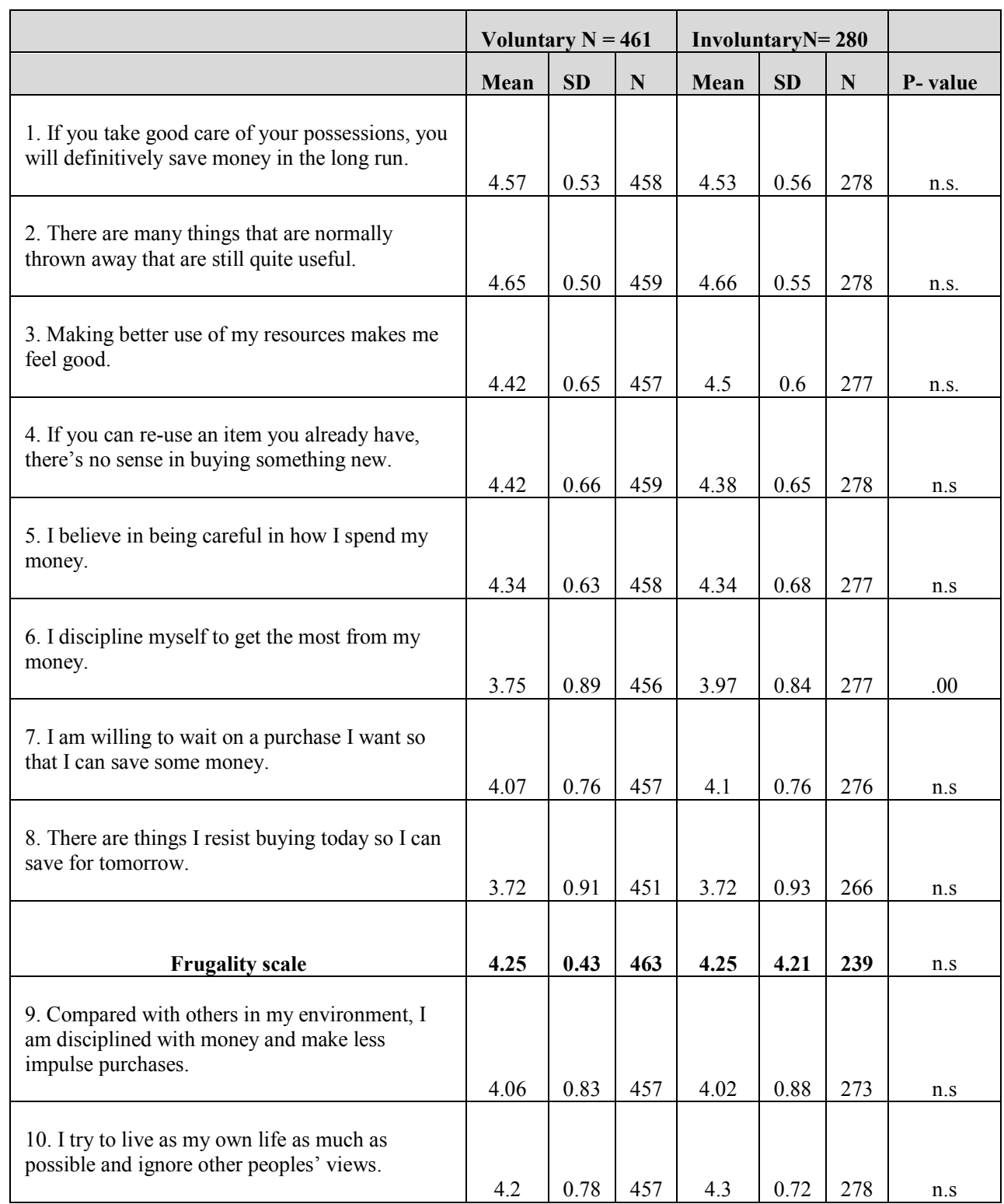


Table 5.13: Frugality scale: Non-downshifters and downshifters

\begin{tabular}{|c|c|c|c|c|c|c|c|}
\hline & \multicolumn{3}{|c|}{$\begin{array}{c}\begin{array}{c}\text { Non-downshifters } \\
\mathbf{N}=\mathbf{2 6 5}\end{array} \\
\end{array}$} & \multicolumn{3}{|c|}{$\begin{array}{c}\begin{array}{c}\text { Downshifters } \\
\mathbf{N}=741\end{array} \\
\end{array}$} & \multirow[b]{2}{*}{ P-value } \\
\hline & Mean & SD & $\mathbf{N}$ & Mean & SD & $\mathbf{N}$ & \\
\hline $\begin{array}{l}\text { 1. If you take good care of your possessions, } \\
\text { you will definitively save money in the long } \\
\text { run. }\end{array}$ & 4.44 & 0.56 & 264 & 4.55 & 0.54 & 736 & .01 \\
\hline $\begin{array}{l}\text { 2. There are many things that are normally } \\
\text { thrown away that are still quite useful. }\end{array}$ & 4.63 & 0.52 & 264 & 4.65 & 0.52 & 737 & n.s \\
\hline $\begin{array}{l}\text { 3. Making better use of my resources makes } \\
\text { me feel good. }\end{array}$ & 4.41 & 0.66 & 263 & 4.45 & 0.63 & 734 & n.s \\
\hline $\begin{array}{l}\text { 4. If you can re-use an item you already have, } \\
\text { there's no sense in buying something new. }\end{array}$ & 4.34 & 0.67 & 264 & 4.41 & 0.66 & 737 & n.s \\
\hline $\begin{array}{l}\text { 5. I believe in being careful in how I spend my } \\
\text { money. }\end{array}$ & 4.22 & 0.66 & 262 & 4.34 & 0.65 & 735 & .01 \\
\hline $\begin{array}{l}\text { 6. I discipline myself to get the most from my } \\
\text { money. }\end{array}$ & 3.62 & 0.88 & 260 & 3.83 & 0.88 & 733 & .00 \\
\hline $\begin{array}{l}\text { 7. I am willing to wait on a purchase I want so } \\
\text { that I can save some money. }\end{array}$ & 3.92 & 0.79 & 262 & 4.08 & 0.76 & 733 & .01 \\
\hline $\begin{array}{l}\text { 8. There are things I resist buying today so I } \\
\text { can save for tomorrow. }\end{array}$ & 3.53 & 1.01 & 254 & 3.72 & 0.91 & 717 & .01 \\
\hline Frugality scale & 4.15 & 0.43 & 263 & 4.25 & 0.43 & 703 & .00 \\
\hline $\begin{array}{l}\text { 9. Compared with others in my environment, I } \\
\text { am disciplined with money and make less } \\
\text { impulse purchases. }\end{array}$ & 3.94 & 0.85 & 263 & 4.05 & 0.85 & 730 & n.s \\
\hline $\begin{array}{l}\text { 10. I try to live as my own life as much as } \\
\text { possible and ignore other peoples' views. }\end{array}$ & 4.03 & 0.79 & 261 & 4.24 & 0.76 & 735 & .00 \\
\hline
\end{tabular}




\subsubsection{Consumption practices (indicators for simple living and eco-friendly behaviour)}

Table 5.14 reports the consumption practices of voluntary and involuntary downshifters and Table 5.15 shows the consumption practices of downshifters and non-downshifters. Below, we first discuss the scores in each domain and then address the research questions.

\section{Purchasing activities}

The purchasing practices of non-downshifters, and voluntary and involuntary downshifters appeared to be rather close. All reported regularly buying fair trade and green products, although voluntary downshifters reported doing so significantly more often $(P=.01)$ and they were also more likely to buy second hand goods. The second remarkable difference was noted for ignoring advertisements. In this respect, nondownshifters tended to ignore advertisements more frequently than (involuntary) downshifters $(P=.04)$.

\section{Food}

With regard to food consumption, the most salient result was the finding that all three groups reported very frequently cooking from scratch instead of eating prepared meals (mean $=\geq 4.35$ ). Striking differences have been noted for non-downshifters eating more frequently organic food than downshifters $(P=.01)$; downshifters on the other hand reported consuming more fish than non-downshifters $(P=00)$.

\section{Leisure activities}

The three groups showed comparable scores (mean $=\geq 3.66$ ) for reading, walking and biking and social contacts. The least frequently reported leisure activities were meditation and exercise/sports (mean $=\geq 2.53$ ). Further, participants reported fairly often engaging in activities related to personal growth and development. Watching television was also a popular leisure activity. Sriking differences between the three groups were noted with respect to shopping, traveling and personal growth. Shopping occurred considerably more among involuntary downshifters than among voluntary downshifters $(P=.01)$. Traveling occurred significantly more often among nondownshifters than downshifters $(P=.00)$. Personal growth activities were practiced more often by downshifters than by non-downshifters $(P=.00)$.

\section{Environment}

In the environment category, we found that non-downshifters, as well as involuntary and voluntary downshifters, reported very frequently recycling glass and other materials (mean $=\geq 4.64$ ). The three groups were also very resourceful with respect to energy consumption (mean $=\geq 4.2$ ) and all reported a tendency to bring unnecessary items to second hand shops (mean $=\geq 4.12$ ). The least frequently reported activity in this domain was organic composting (mean $=\geq 2.24$ ). Compensating for $\mathrm{CO}_{2}$ emissions due to air and car travel was also less frequently reported. Remarkably, we noted that 
downshifters were significantly more resourceful with energy than non-downshifters $(P=.01)$.

\section{Do-It-Yourself}

In the do-it-yourself category conducting one's own home maintenance appeared to be the most favorable activity for the three groups, with a striking difference in the scores of downshifters compared to non-downshifters $(P=.04)$. Results for sewing clothes and growing vegetables indicated rather low frequencies.

\section{Mobility}

Biking was reported to be the most popular mode of transport for all types

(mean $=\geq 3.93)$. Non-downshifters reported biking most often $(P=.00)$. Additionally, the three groups reported rarely traveling by air plane (mean $=\leq 1.92$ ).

Further, results indicated that downshifters were slightly more frequent car users (mean $=2.94)$ than non-downshifters (mean $=2.79)$, although the difference was not significant. With respect to public transport, conversely non-downshifters showed higher means than downshifters (3.06 versus 2.93), but again the difference was not significant. 
Table 5.14: Consumption practices (voluntary versus involuntary downshifters)

\begin{tabular}{|c|c|c|c|c|c|c|c|}
\hline & \multicolumn{3}{|c|}{ Voluntary downshifters $N=461$} & \multicolumn{3}{|c|}{ Involuntary $\mathbf{N}=\mathbf{2 8 0}$} & \multirow[b]{2}{*}{ P-value } \\
\hline & Mean & SD & $\mathbf{N}$ & Mean & SD & $\mathbf{N}$ & \\
\hline \multicolumn{8}{|l|}{ A Purchasing } \\
\hline 1 Buy fair trade & 3.17 & 0.808 & 459 & 3 & 0.801 & 277 & .01 \\
\hline 2 Buy green & 3.43 & 0.751 & 460 & 3.4 & 0.718 & 278 & n.s. \\
\hline 3 Buy second hand & 3.34 & 0.831 & 460 & 3.26 & 0.89 & 277 & n.s. \\
\hline 4 Dumpster diving & 2.12 & 1.039 & 460 & 2.03 & 0.987 & 278 & n.s. \\
\hline $\begin{array}{l}5 \text { Buy at local } \\
\text { stores }\end{array}$ & 2.74 & 1.042 & 460 & 2.67 & 1.072 & 277 & n.s. \\
\hline $\begin{array}{l}6 \text { Ignore } \\
\text { advertisements }\end{array}$ & 3.45 & 1.382 & 457 & 3.22 & 1.442 & 278 & .04 \\
\hline \multicolumn{8}{|l|}{ B Food } \\
\hline 7 Eat organic food & 3.17 & 0.995 & 460 & 3.07 & 1.033 & 278 & n.s. \\
\hline 8 Eat meat & 3.15 & 1.075 & 460 & 3.14 & 1.125 & 277 & n.s. \\
\hline $\begin{array}{l}9 \text { Cook from } \\
\text { scratch }\end{array}$ & 4.35 & 0.638 & 460 & 4.38 & 0.652 & 277 & n.s. \\
\hline 10 Eat local food & 3.44 & 0.951 & 457 & 3.49 & 0.963 & 276 & n.s. \\
\hline 11 Eat fish & 3.18 & 0.915 & 460 & 3.19 & 0.916 & 278 & n.s. \\
\hline \multicolumn{8}{|l|}{ C Leisure } \\
\hline 12 Watch television & 3.27 & 0.869 & 460 & 3.36 & 0.925 & 276 & n.s. \\
\hline 13 Read & 3.98 & 0.524 & 460 & 4.01 & 0.579 & 278 & n.s. \\
\hline 14 Exercise/sport & 2.81 & 1.077 & 459 & 2.73 & 1.055 & 277 & n.s. \\
\hline 15 Walk and bike & 3.76 & 0.84 & 460 & 3.83 & 0.807 & 277 & n.s. \\
\hline 16 Meditate or pray & 2.53 & 1.199 & 459 & 2.63 & 1.261 & 277 & 0.3 \\
\hline 17 Shop & 2.69 & 0.706 & 460 & 2.83 & 0.811 & 278 & .01 \\
\hline 18 Personal growth & 3.41 & 0.89 & 456 & 3.52 & 0.893 & 275 & n.s. \\
\hline 19 Social contact & 3.68 & 0.64 & 460 & 3.68 & 0.727 & 278 & n.s. \\
\hline 20 Go out & 2.59 & 0.725 & 460 & 2.53 & 0.791 & 278 & n.s. \\
\hline 21 Travel & 2.75 & 0.779 & 459 & 2.64 & 0.828 & 278 & n.s. \\
\hline 22 Garden & 2.96 & 1.193 & 458 & 3.06 & 1.208 & 278 & n.s. \\
\hline \multicolumn{8}{|l|}{ D Environment } \\
\hline 23 Recycle & 4.68 & 0.619 & 459 & 4.64 & 0.716 & 278 & n.s. \\
\hline 24 Compost & 2.42 & 1.676 & 459 & 2.24 & 1.595 & 277 & n.s. \\
\hline $\begin{array}{l}25 \text { Limit energy } \\
\text { consumption }\end{array}$ & 4.33 & 0.683 & 459 & 4.34 & 0.655 & 277 & n.s. \\
\hline $\begin{array}{l}26 \text { Bring items to } \\
\text { second hand shop }\end{array}$ & 4.12 & 1.095 & 459 & 4.2 & 1.02 & 278 & n.s. \\
\hline $\begin{array}{l}27 \text { Compensate } \\
\mathrm{CO} 2 \text { emissions }\end{array}$ & 2.72 & 2.197 & 459 & 2.94 & 2.267 & 277 & n.s. \\
\hline \multicolumn{8}{|l|}{ E Do-it-yourself } \\
\hline 28 Sewing & 1.95 & 1.088 & 461 & 1.98 & 1.173 & 280 & n.s. \\
\hline 29 Grow vegetables & 2.18 & 1.306 & 460 & 2.08 & 1.406 & 280 & n.s. \\
\hline $\begin{array}{l}30 \text { Do home } \\
\text { maintenance }\end{array}$ & 3.56 & 1.089 & 461 & 3.42 & 1.125 & 279 & n.s. \\
\hline \multicolumn{8}{|l|}{ F Mobility } \\
\hline 31 Car use & 2.93 & 1.139 & 460 & 2.96 & 1.206 & 279 & n.s. \\
\hline 32 Public transport & 2.91 & 1.072 & 461 & 2.95 & 1.066 & 279 & n.s. \\
\hline 33Biking & 3.93 & 0.992 & 460 & 3.96 & 1.012 & 278 & n.s. \\
\hline 34 Plane & 1.85 & 0.825 & 461 & 1.85 & 0.792 & 280 & n.s. \\
\hline
\end{tabular}


Table 5.15 Consumption practices (non-downshifters versus downshifters)

\begin{tabular}{|c|c|c|c|c|c|c|c|}
\hline & \multicolumn{3}{|c|}{ Non-downshifters $N=265$} & \multicolumn{3}{|c|}{ Downshifters N=741 } & \multirow[b]{2}{*}{ P-value } \\
\hline & Mean & SD & $\mathbf{N}$ & Mean & SD & $\mathbf{N}$ & \\
\hline \multicolumn{8}{|l|}{ A Purchasing } \\
\hline 1 Buy fair trade & 3.21 & 0.784 & 264 & 3.1 & 0.809 & 736 & n.s. \\
\hline 2 Buy green & 3.47 & 0.77 & 264 & 3.42 & 0.738 & 738 & n.s. \\
\hline 3 Buy second hand & 3.22 & 0.86 & 264 & 3.31 & 0.854 & 737 & n.s. \\
\hline 4 Dumpster dive & 2.04 & 1.066 & 263 & 2.09 & 1.02 & 738 & n.s \\
\hline $\begin{array}{l}5 \text { Buy at local } \\
\text { stores }\end{array}$ & 2.77 & 0.984 & 264 & 2.71 & 1.053 & 737 & n.s. \\
\hline $\begin{array}{l}6 \text { I gnore } \\
\text { advertisements }\end{array}$ & 3.57 & 1.377 & 264 & 3.36 & 1.408 & 735 & .04 \\
\hline \multicolumn{8}{|l|}{ B Food } \\
\hline 7 Eat organic food & 3.33 & 1.019 & 263 & 3.13 & 1.01 & 738 & .01 \\
\hline 8 Eat meat & 3.1 & 1.136 & 264 & 3.15 & 1.094 & 737 & n.s. \\
\hline $\begin{array}{l}9 \text { Cook from } \\
\text { scratch }\end{array}$ & 4.37 & 0.628 & 263 & 4.36 & 0.643 & 737 & n.s. \\
\hline 10 Eat local food & 3.32 & 0.936 & 263 & 3.46 & 0.955 & 733 & n.s. \\
\hline 11 Eat fish & 2.94 & 0.91 & 264 & 3.18 & 0.914 & 738 & .00 \\
\hline \multicolumn{8}{|l|}{ C Leisure } \\
\hline 12 Watch television & 3.27 & 0.786 & 264 & 3.3 & 0.891 & 736 & n.s. \\
\hline 13 Read & 3.94 & 0.622 & 265 & 3.99 & 0.545 & 738 & n.s. \\
\hline 14 Exercise/sport & 2.91 & 1.137 & 263 & 2.78 & 1.069 & 736 & n.s. \\
\hline 15 Walk and bike & 3.85 & 0.685 & 265 & 3.79 & 0.828 & 737 & n.s. \\
\hline 16 Meditate or pray & 2.55 & 1.226 & 264 & 2.57 & 1.223 & 736 & n.s. \\
\hline 17 Shop & 2.7 & 0.695 & 265 & 2.74 & 0.75 & 738 & n.s. \\
\hline 18 Personal growth & 3.23 & 0.992 & 261 & 3.45 & 0.892 & 731 & .00 \\
\hline 19 Social contact & 3.66 & 0.652 & 264 & 3.68 & 0.674 & 738 & n.s. \\
\hline 20 Go out & 2.64 & 0.738 & 264 & 2.57 & 0.751 & 738 & n.s. \\
\hline 21 Travel & 2.88 & 0.777 & 263 & 2.71 & 0.799 & 737 & .00 \\
\hline 22 Garden & 3.11 & 1.124 & 263 & 3 & 1.199 & 736 & n.s. \\
\hline \multicolumn{8}{|l|}{ D Environment } \\
\hline 23 Recycle & 4.75 & 0.521 & 265 & 4.67 & 0.657 & 737 & .05 \\
\hline 24 Compost & 2.54 & 1.672 & 265 & 2.35 & 1.647 & 736 & n.s. \\
\hline $\begin{array}{l}25 \text { Limit energy } \\
\text { consumption }\end{array}$ & 4.2 & 0.72 & 265 & 4.34 & 0.672 & 736 & .01 \\
\hline $\begin{array}{l}26 \text { Bring items to } \\
\text { second hand shop }\end{array}$ & 4.14 & 1.009 & 265 & 4.15 & 1.067 & 737 & n.s. \\
\hline $\begin{array}{l}27 \text { Compensate for } \\
\mathrm{CO} 2 \text { emissions }\end{array}$ & 2.92 & 2.236 & 264 & 2.8 & 2.225 & 736 & n.s. \\
\hline \multicolumn{8}{|l|}{ E Do-it-yourself } \\
\hline 28 Sewing & 1.87 & 1.037 & 265 & 1.96 & 1.12 & 741 & n.s. \\
\hline 29 Grow vegetables & 2.18 & 1.324 & 265 & 2.14 & 1.345 & 740 & n.s. \\
\hline $\begin{array}{l}30 \text { Do home } \\
\text { maintenance }\end{array}$ & 3.35 & 1.019 & 265 & 3.51 & 1.104 & 740 & .04 \\
\hline \multicolumn{8}{|l|}{ F Mobility } \\
\hline 31 Car use & 2.79 & 1.15 & 264 & 2.94 & 1.164 & 739 & n.s. \\
\hline 32 Public transport & 3.06 & 1.084 & 265 & 2.93 & 1.069 & 740 & n.s. \\
\hline 33 Biking & 4.18 & 0.853 & 265 & 3.94 & 0.999 & 738 & .00 \\
\hline 34 Plane & 1.92 & 0.759 & 265 & 1.85 & 0.812 & 741 & n.s. \\
\hline
\end{tabular}




\subsubsection{Consumption practices and sustainability}

Q 8 How does downshifting contribute to sustainability and do voluntary downshifters, involuntary downshifters and non-downshifters differ in this respect?

\section{H 7 Downshifters maintain a more sustainable lifestyle than non-downshifters.}

In our study, we found that both downshifters and non-downshifters scored fairly high on all practices indicative of sustainable behaviour. In this regard, results were similar between the two groups. Yet, there were some remarkable differences between downshifters and non-downshifters with respect to energy use and fish consumption. Further downshifters practiced activities related to personal growth and home maintenance more often than non-downshifters. Finally, downshifters reported dumpster diving more frequently than non-downshifters.

Within the downshifter group, we noted additional indications of sustainability for voluntary downshifters. They reported ignoring advertising more often than involuntary downshifters and buying fair trade products more frequently than involuntary downshifters. Voluntary downshifters also reported shopping less frequently than involuntary downshifters. Besides, non-downshifters reported eating more organic food than downshifters. They also reported ignoring advertisements more often. Further, they were traveling more often as the results showed that they bike more frequently than downshifters.

Our expectation that downshifters exhibit a more sustainable lifestyle than nondownshifters is affirmed by these findings. In general many indications of sustainability could be found in downshifting. Rather, the picture is nuanced and reflects of broad range of sustainable practices. All in all, we conclude that our results do suggest that there is a positive association between downshifting and sustainable living.

\subsection{Discussion and conclusions}

In this study, we addressed the major research question of this dissertation: 'How can living with less contribute to sustainability? We proceeded by exploring three themes: downshifting, frugality and sustainability. What new findings and insights did this empirical study yield? How do these results compare to those of other studies of downshifting? What conclusions can be drawn? These questions are dealt with below. But, prior to the discussion of our findings, we want to briefly reflect upon two central characteristics of the study: the research population and our definition of downshifting.

The decision to survey the readers of the Dutch magazine Genoeg is considered more than adequate for achieving the main objectives of this study, namely to explore the 
characteristics, experiences and practices of downshifters and to connect those to sustainability and frugality. Because the magazine Genoeg focuses primarily on conscious, moderate forms of consumption, its subscribers were considered a rich source of information and that was essential given the explorative nature of this study. However, the fact that all participants belonged to the same reader population may potentially have hampered the comparison of scores between groups, thereby providing a less differentiated picture than might be expected if a substantially broader research population had been employed.

The second distinct characteristic of this study was our definition of downshifting. Whereas previous studies of downshifters used the voluntary nature of the decision to reduce income as the main selection criterion, we deliberately used a reduction in spending as our selection criterion and then defined sub-groups as voluntary or involuntary. Emphasis was placed on concrete consumption practices and not on motivations, beliefs or emotions. Obviously, the latter are vital elements of consumer behaviour and major determinants of sustainability strategies and policies.

Notwithstanding, the perspective of this study was deliberately chosen to expose a broader range of downshifting experiences and allow for comparisons between groups which were expected to experience downshifting in fundamentally different ways. The definition employed in this study did provide useful results but evidently made comparisons to previous downshifting studies more complicated. Nonetheless, we contend that this study has provided valuable insights that allow us to better understand the phenomenon of downshifting as a new consumer trend in postmodern consumer society. It has allowed us to explore the potential of downshifting for the promotion of sustainability. The most remarkable findings are discussed below.

\subsubsection{Dutch downshifters and their foreign counterparts}

Although our definition of downshifting was purely financial (i.e. a reduction in expenses) and was not connected to motivations or the broader concept of lifestyle change as is commonly the case in other studies, comparison of findings is still, to some extent, possible. The weighted findings of our study are comparable to three nationwide studies of downshifting: Schor's study (1998) in the USA, Hamilton and Mail's (2003) study in Australia and the Hamilton's (2003) study in the UK.

If the Genoeg readers are considered members of a downshifting community, the sample populations of at least three other studies are comparable to ours. These studies include Elgin and Mitchell's (1977) voluntary simplicity survey of the readers of the magazine Co-Evolution Quarterly, Pierce's (2000) study of voluntary simplifiers from a simplicity website and Huneke's (2005) voluntary simplicity study which drew its study participants from online forums related to voluntary simplicity. Comparison with these studies is further enabled by the fact that they essentially employed similar definitions of a voluntary simplifier.

The weighted findings of our study indicate that Dutch downshifters have relatively high levels of education attainment and are between 20 and 40 years old. They are 
also more likely to be women than men, although the difference is small. Further, downshifters are more likely to have paid employment, often part-time.

The percentage of downshifters with a full-time job or even more is far below the Dutch average. Finally, our results showed that downshifters generally tend to have more children and are more likely to live in cooperative housing projects or have a different type of household than the average Dutch population. When we compare these findings to those of other studies, a number of similarities becomes apparent. First, with regard to age, our findings correspond with those of previous studies conducted in the USA, Australia and the UK. As mentioned earlier, these studies showed that people in their thirties were more likely to downshift than those in their forties or fifties (Schor 1998; Hamilton \& Mail 2003; Hamilton 2003). Also, all of the abovementioned studies, thus the national studies and those conducted within downshifting communities, found that downshifters tended to be better educated than the general population (Elgin \& Mitchell 1977; Schor 1998; Hamilton \& Mail 2003; Hamilton 2003; Pierce 2000; Huneke 2004).

Our finding that women were more likely to be downshifters replicated the findings of two downshifting community studies, namely Pierce's study (2000) and Huneke's study (2005). Both reported larger numbers of women than men in downshifting communities (up to three quarters of the population). Elgin \& Mitchell (1977) however did not distinguish the gender of respondents. Obviously, the characteristics of the general Dutch population differ with regard to gender and household composition. Although our study showed greater numbers of female downshifters (albeit only by a narrow margin), the nationwide studies in Australia, the UK and the USA, male and female downshifters were equally represented, as were households with and without children.

With regard to socio-economic and class variables, it remains difficult to make direct comparisons. We did not include a class element in our study and income data could not be weighted for the general Dutch population. Comparisons with other nationwide studies are therefore not possible. Yet some noteworthy observations can be made. Contrary to the belief that downshifting is predominantly an upper middle class phenomenon, several studies present a different picture. British (2003) and Australian (2003) downshifters were spread fairly evenly across social strata, and blue-collar and white-collar workers were equally represented.

Schor (1998: 114-115), however, found fewer numbers of downshifters in both the upper income groups and in the lowest income groups. As previously noted, precise data for the class position of Dutch downshifters were unavailable, but the results for income and education indicate that around $40 \%$ of Dutch downshifters had low to intermediate educational attainment and net incomes less than $€ 1850$ per month. These findings suggest that, in the Netherlands, as in other parts of the world, voluntary downshifting is not a lifestyle choice exclusive to the social elite, but might be an attractive way of life for people across all social strata. We would suggest that the extent to which people downshift, the conditions under which they do so and their motivations are important topics for further research. 
Another similarity between our study and the results of other studies concerns the rather counterintuitive finding that only a quarter of voluntary downshifters had experienced a decrease in income when they began downshifting.

Remarkably, $25 \%$ reported having an increased income and $50 \%$ reported no change in income. These findings are comparable to those found in Huneke's study of voluntary simplifiers: 'Just over one third of the households stayed in the same income level. ...Almost one quarter reported their income level increased.' (2005: 535). The two other downshifting community studies (Elgin \& Mitchell 1977; Pierce 2000) did not report income variations, but only mentioned that incomes were lower than expected considering the participants' level of education.

These results further support our conclusion that voluntariness impacts the experience of downshifting. This conclusion counters the prevailing image of the postmodern consumer as a materialistic big spender, driven by hedonistic motives.

\subsubsection{Downshifters in a consumption society}

Contrary to popular belief, our results suggest that spending less coincides with a number of positive experiences. Both voluntary and involuntary downshifters reported that they were content with a lower level of spending. Breakspear and Hamilton (2004) reported that almost $90 \%$ of (voluntary) downshifters were happy with their lifestyle change and that $34 \%$ did not miss the higher income. Results of our study show that even involuntary downshifters experienced living with less money in many positive ways. In this respect, previous studies have found that voluntary downshifting increases quality of life (Schor 1998; Breakspear \&Hamilton 2004; Huneke 2005; Etzioni 1998; Datamonitor 2003). This is reflected in the nine categories of positive experiences established in our study and may be interpreted as indications of life improvement.

With regard to negative aspects of downshifting, we found some commonalities such as financial worries and being subjected to criticism. Financial worries were reported by one sixth of the downshifters who were happy with the change but who found reduced spending difficult (Breakspear \& Hamilton 2004: 23). Our finding that downshifting also receives criticism from the social environment is reflected in the results of other studies as well (Breakspear \& Hamilton 2004; Jackson 2005). Downshifters are often confronted with skepticism and, at times, even hostility. Apparently, outsiders continue to see downshifters as selfish when in fact most downshifters increase their social involvement after downshifting (Breakspear \& Hamilton 2004; Jackson 2005). Our study also found that involuntary downshifters, in particular, increased their unpaid activities as volunteers.

The fact that downshifters protect themselves against pressures to conform to the mores of consumer society is exemplified by our finding that downshifters ignore and avoid advertising more than non-downshifters. Further, they endeavor to live their own life and attempt to pay little heed to other peoples' consumerist views. This 
attitude makes them less susceptible to personal influence, less materialistic and less compulsive when buying.

In sum, our data and the results of previous studies suggest that (voluntary) downshifting is associated with various significant positive experiences and may contribute to quality of life. It must be admitted though, that the reported negative reactions from the social environment suggest that downshifting still is viewed as a deviant lifestyle.

\subsubsection{Perspectives for sustainability}

Finally, we discuss the question of whether downshifting can contribute to sustainability. What opportunities does downshifting offer and to what extent can downshifting be defined as a sustainable lifestyle?

In order to answer these questions, we first look to Callenbach's (2002) green triangle which we converted into the Dutch triple Gs of a sustainable lifestyle: geld (money), groen (eco-friendliness) and gezondheid/welzijn (health/wellbeing). This view posits that a sustainable lifestyle results from putting the right input into each of the three pillars. The basic assumption is the concurrency between the pillars and their mutual interdependence: changes in one influence the outcome of the other two. In line with this, we discuss results pertaining to: a) The financial behaviour associated with downshifting; b) Eco-friendly behaviour; and c) Personal well being and happiness. We conclude by applying our results on downshifting to sustainability.

\section{a) Financial behaviour}

Downshifters tend to be conscious, careful spenders as revealed by their scores on the Frugality scale and by their responses to the list of consumption expenditures. Their product use and their buying behaviour are frugal and restrained, and budgeting is generally perceived as one of many positive experiences associated with downshifting. Downshifters seek to increase their savings and pay off their debts. This may be interpreted as an indication of sound financial management. Studies in other countries show that the wise stewardship of resources is a common trait among downshifters (Schor 1998; Breakspear \& Hamilton 2004; Huneke 2005). However, this is not the explicit goal but rather a means - a deliberately chosen strategy to serve other goals.

Similarly, we found that downshifters seek to maintain their lifestyle by ignoring advertisements and strengthening their own convictions. This attitude may function as a protective measure to counter marketing stimuli for impulse buying. Moreover, it may protect downshifters from the criticism that particularly voluntary downshifters receive from their social environment.

\section{b) Eco-friendly behaviour}

Our study showed various indications of eco-friendly behaviour among downshifters. First, downshifters reported handling their possessions consciously and carefully. Overall, they recycle glass and other materials, take good care of their possessions, avoid waste and resourcefully use their possessions. Additionally, downshifters used significantly less energy than the non-downshifters in our study. This is an interestin 
finding as Genoeg readers are likely to be already more committed to reducing energy consumption than the general population in the Netherlands. As such, downshifters consistently met the standards for eco-friendly behaviour that seeks to reduce, re-use and recycle. When it comes to eco-friendly food consumption and mobility, the picture is less evident. Although downshifters consume local food products and fish more frequently, they consume significantly less organic food than non-downshifters. Additionally, downshifters did use the car slightly more and the bike significantly less than non-downshifters. These mixed results correspond with the results of previous studies that have linked downshifting to eco-friendliness (Breakspear \& Hamilton 2004; Jackson 2009; Huneke 2005).

\section{c) Personal wellbeing and happiness}

Unlike other studies on the subject of downshifting, our study did not specifically explore the emotions or judgments downshifters express about their way of life. However, given our results, we can conclude that downshifting may increase quality of life and therefore contribute to feelings of personal wellbeing and happiness. This is plausible, especially given the fact that downshifters reported a broad range of positive experiences. This is particularly the case for voluntary downshifters, although involuntary downshifters as well reported positive experiences such as stress reduction and improved psychological outlook. We can also assume that the reported increase in activities in the sphere of personal growth promotes personal wellbeing and contributes to a better quality of life. Yet, the results of previous studies found a more direct association between downshifting and increased quality of life and satisfaction with the lifestyle change (Breakspear \& Hamilton 2004). As Breakspear and Hamilton reported: 'The only regret shared by downshifters was that they had not done it sooner.' Conversely, our detailed overview of negative experiences paints a more nuanced picture of wellbeing and happiness. In particular, criticism from one's social environment as well as the financial difficulties connected to trying to make ends meet seem to color the downshifting experience.

In short, it can be concluded that downshifting can contribute to sustainability as this way of life fundamentally resonates with the three pillars of the Dutch triple Gs of a sustainable lifestyle. Downshifters tend to practice the re-use, reduce and recycle mantra of eco-friendly behaviour and they are careful, resourceful spenders that find other values more important than those provided by materialism and consumerism. It seems these positive experiences can also strengthen their attitude.

Despite this, downshifters appear not to be primarily motivated by environmental or ecological concerns but rather by a desire to improve their quality of life or their financial situation. This conclusion is affirmed by the results of previous studies conducted in Australia and the USA, where low numbers of downshifters reported a fundamental desire for a post-materialistic or eco-friendly lifestyle as their basic motivation for downshifting.

With this, we conclude the discussion of the results of our study of downshifting in the Netherlands. Apart from the socio-cultural value of this study, the overall purpose was to determine empirically how downshifting can contribute to sustainability. We will now turn back to this core question of the dissertation and evaluate the main findings. 
Chapter 6

Downshifting and sustainability? 


\section{Abstract}

In this study, we addressed the issue of living with less from both a theoretical and a empirical perspective. The theoretical perspective focused on the concept of 'frugality' and analyzed changing attitudes towards frugality and its manifestations in postmodern consumer society and influence on the epistemic view of consumer studies. The empirical research studies examined practices and experiences of spending reduction within the hyper-consumerist context of postmodern consumer society. Assuming that frugality and expense reduction are indicators for sustainability, we examined the research topics from an exploratory, multidisciplinary approach to uncover new insights and identify new perspectives.

In this final chapter, we explore what new insights can be added to the current discussion on making consumer behaviour more sustainable. We evaluate the main findings of this dissertation in the light of sustainability and discuss opportunities for sustainability in postmodern consumer culture and behaviour. A sketch of a strategy that can encourage sustainable consumption is also presented. The chapter concludes with an evaluation of this research project, a discussion of the limitations of the studies presented so far and suggestions for future research. 


\subsection{Introduction}

The commercialization of consumption has brought about radical changes in both the volume and the cultural significance of consumption (Assadourian 2010; Cohen 2004; De Geus 2003; Levine 2006; Maniates 2001, 2010; Miller 1995; Schor 1998; Worldwatch 2004). Nowadays discretionary consumption has become a mass phenomenon and not merely the privilege of the rich and middle class (Schor 1998: 217). As a result consumerism and the consumerist lifestyle have become dominant cultural features in the Western world and are rapidly spreading to other parts of the world. This unprecedented growth of consumption evidently puts a strain on the environmental resources and aggravates social and economic inequalities. The social and ecological costs that come with consumerism and the consumerist lifestyle, despite its attractions, are rising substantially. Concurrently, risks are increasing: in personal life because of prohibitive debts, stress, illnesses or impoverishment; and at a global scale because of climate change, and social and political instability as a result of the growing gap between rich and poor. Therefore, one of the major challenges in the coming years will be to stimulate sustainable consumption and a more sustainable lifestyle (Assadourian 2010; Jackson 2010).

Since the Rio Earth Summit in 1992 placed sustainable consumption on the public agenda, academic interest for sustainable consumption has gradually increased. To date, most research has explored motivations, abilities or opportunities for making environmentally friendly choices (Kilbourne \& Protero 2010). The scope of academic analysis however has broadened, moving from the micro-level of individual choices to the macro-level including the social cultural context as well as the consumption infrastructure (Gatersleben 2000; Martens \& Spaargaren 2005; Moll 2002; Spaargaren 2002, 2003; Staats et al. 2004; Vlek 1995). Coincidently, the prevailing view that sustainable consumption is about consuming the right products and can be encouraged using the right tools is being replaced by the new awareness that "doing the right thing" is equally or even more important. A general reduction in the consumption level is now becoming more explicit and even endorsed by world leaders such as U.S. president, Barack Obama: 'His goals include diminishing the consumerism that has long been the main source of economic growth 
in the United States and encouraging more saving and investment' (Herald Tribune, 20 April 2009).

Despite the fact that academic attention for sustainable consumption is increasing, as recently evidenced by the Transformative Consumer Research - Sustainability Conference held in June 2009 (Kilbourne \& Prothero 2010) and by the number of new publications (Jackson 2006; 2007; 2008; 2009; Worldwatch 2010), our understanding of how sustainable consumption and consumer behaviour can best be encouraged is limited. Our starting point has been the consideration that studying people who actually try to reduce consumption could be very informative. Knowledge regarding experiences with downshifting and voluntary lifestyle changes might reveal new perspectives on sustainability and fuel the discussion on the consumerist lifestyle.

What does it mean to deliberately reduce consumption - and thus live with a considerably smaller carbon footprint - in a social-cultural environment that constantly encourages people to consume? How can living with less money support sustainability? Answers to these questions are indispensable if sustainable development is to be successful in the nearby future. This dissertation was meant to fuel the discussion with new facts and findings.

Specifically, the central aim was to contribute to a better understanding of how reduced means impact consumer behaviour within the context of consumerism and consumption society. Further, this study identified new possibilities for sustainable living by addressing the following main research questions:

Question 1:

What is the epistemic development of consumer studies and how did it shape the consumption theories?

Question 2

How is frugality conceptualised and manifested in postmodern consumer society; and which influences on the epistemic view in consumer studies can be identified?

Question 3:

Which changes do occur in people's life after a substantial decrease in income and spending? 
Question 4:

Which social-economic characteristics have Dutch downshifters?

Question 5:

How can living with less contribute to more sustainability? Where lay opportunities and barriers for sustainable lifestyles?

\subsection{Prospects for sustainability}

The final and central question of this dissertation reads: How can living with less contribute to more sustainability? Where lay opportunities and barriers for sustainable lifestyles? (Research question 5). To answer this question, we recapitulate the main findings and insights, and discuss them in the light of sustainability. Successively, the three major research themes are addressed: a) Frugality and sustainability in postmodern consumer society; b) The transformation process of living with less; and c) Downshifting practices and sustainability.

In the final section of this chapter, we present our general conclusions. 
6.2.1 Frugality and sustainability in postmodern consumer culture

In this study, we addressed frugality in a twofold way: 1) as a cultural feature, thus as an idea; and 2) as a consumer behaviour strategy, thus as a practice. Accordingly, we used the following theoretical framework.

In accordance with Aristotle, Xenophon and the recent thoughts of Nussbaum $(1999 ; 2002)$ and Miller, frugality was considered a universal human life principle that guides life practices. Social- cultural anthropological studies (Douglas 1996; Gudeman \& Rivera 1990; Miller 1995a, 1998; Wilk 2002) and sociological consumer studies (Holt 1997, 1998, 2003; Illouz 1997; Jackson 2003, 2005, 2006, 2009; Maniates 2002, 2009; Spaargaren 2000, 2003; Spaargaren, Beckers et al. 2002; Thompson 1989, 1995, 2004; Schor 1998, 2000, 2001, 2002, 2003) report that consumption is contextually driven and that consumer behaviour has a social-cultural function. From this academic perspective, we conceptualized frugality as a way of acting - of responding to what is available. How frugality is expressed, the considerations that are made and the significance assigned are all determined by the social-cultural and economic context.

Because frugality is closely connected with reduced consumption and practices of living with less, thoughts about frugality likely influence discussions on how to stimulate sustainability (De Geus 2003; Nussbaum 1999; Witkowski 2009; Zavestovski 2002). Therefore, a culturalphilosophical analysis of frugality in postmodern consumer society, presented in Chapter 3, is a main part of this dissertation.

Contrary to the prevailing view that frugality is an outdated concept, we found that frugality has not disappeared as a leading principle of postmodern consumer culture, but continues to be a vital cultural characteristic. This finding is in accordance with Miller's conclusion that thrift is probably a more important status marker in peer groups than spendthrift. The second finding of our cultural-philosophical analysis concerns the dichotomous nature of frugality. Our analysis of frugality practices in three areas, namely public policy, consumption behaviour and marketing, confirmed this view. The dichotomous nature consists of a range of positive and negative connotations that go beyond the obvious contradiction of virtue and vice. Gudeman \& Rivera's model of the house economy and the corporate economy provided a potential explanation for the dual nature of frugality in postmodern consumer 
society and shed light on the tensions surrounding frugality, noted by Witkowski (2009).

The empirical findings of living with less money coincide with our theoretical findings. We found high scores on the Frugality Scale and the results of our empirical research on downshifting showed that even voluntary economizing can be practiced in postmodern consumer society. Other empirical results indeed point at the contested character of frugality, in accordance with the the marginalizing effects of living with less - thus practicing frugality - as described by Bauman (2005) and reported in empirical studies of low income consumers (Hamilton \& Catterall 2005) and downshifters (Schor 1998). 
Results of the Transformation Model Living with Less (reported in Chapter 4), and the negative experiences reported in our survey of Dutch downshifters (Chapter 5), showed that although frugal behaviour is commonly practiced, it is often in disrepute and considered taboo. Frugal living may be perceived as deviating from mainstream consumer aspirations (more is better). In addition, we found indications that feelings of being deviant are internalized as negative self-images and feelings of being a social misfit or failure. This was especially the case in involuntary downshifters. Though, voluntary downshifters as well struggled to redefine their negative self-images were enhanced by the negative messages received from their social environment.

\subsubsection{Implications for sustainability}

We contend that the findings of our study may have important implications for promoting sustainability in the postmodern consumer culture. First, we did not find any substantiation for the prevailing view of human beings as hedonistic, materialistic creatures, which have the innate desire to lavishly consume. Instead of explaining frugal or non frugal consumer practices in terms of irrational consumer motives (Douglas 1996) such as hedonism, anti-materialism, being old fashioned or being ethical, the discussion could better be situated in a structuralfunctional perspective. In this way we can overcome the dichotomous approach which continues to influence the epistemic view of consumer research, as well as the discourse on sustainable consumption.

Second, our finding that frugality still is a vital cultural feature and a guiding principle for consumer practices, can add a new dimension to the design of sustainability strategies. Apparently, the negativity that simultaneously is connected with frugality, should be a major point of attention. We would argue that how frugality is expressed; the considerations that are made and the significance assigned are all determined by the socio-cultural and economic context. Because these contexts are not natural laws but socio-economic constructions, interventions should be possible.

Finally, the increasing social pressure for sustainable alternatives (Witkowski 2009), as well as the growing numbers of downshifters and other new consumer trends could be interpreted as evidence for the willingness of society to accept profound change towards sustainable 
consumption. Within this perspective frugalizing is likely to be a more realistic option than generally assumed.

\subsubsection{Transformation process and sustainability}

To date, living with less has hardly been addressed as a consumer behaviour change process, thus from a transformational perspective. Generally, living with less is associated with a social, political or cultural problem. Consequently, the issue is polarized either as a problem cause or problem solution. By examining living with less from an experiential perspective this study aims to avoid the common polarization. A phenomenological field study was conducted to examine the transformation process 
within the context of consumer society. This resulted in The Transformation Model Living with Less. So, we addressed living with less from a change perspective, investigating which changes tend to occur after a decrease in income and spending. What new insights are yielded in this empirical field research?

We would argue that three findings in particular are important for the discussion on sustainability: 1) The finding that living with less is a multi-layered life change process;

2) Reported positive experiences; and 3) The issue of quality of life.

First, the Transformation Model Living with Less indicates that a living with less experience is basically a major life-transforming event. The model provides a multi-layered picture of this process, integrating determinant aspects of consumption as a coherent whole. By determining which aspects of peoples' lives were affected by a substantial decrease in spending, the study goes beyond single factor consumption studies, such as consumption and identity, consumption and social status or lifestyle studies. Consequently, we concluded that living with less was experienced primarily in the life sphere rather than in the financial sphere; reorganizing expenses meant reorganizing life.

Second, the finding that the even involuntary downshifters had positive experiences during the transformation process was significant, because this contradicts the prevailing view that a reduction in income results in only negative experiences.

Moreover, the process itself was considered by many to be a positive experience. The outcome of the study: Meet the Dutch downshifters (see Chapter 5) affirmed and further specified this quite unexpected result. Positive experiences included feelings of relief when downshifters discovered that they could actually live on much less than before, pleasure derived from practicing new skills or activities, satisfaction with the success of the transformation, and feelings of contentment due to improved social connections. At this point a range of negative experiences were also identified, varying from difficulties with budgeting to family problems and stress or worry to criticism and a lack of understanding from one's social environment.

Third, the results of our study have also shed new light on the issue of consumption reduction and quality of life. To date, the quality of life aspect of living with less has been evaluated in terms of consumer goods 
(e.g. the belief that owning fewer material possessions makes life easier or that a smaller house is cheaper to maintain and easier to clean) or in terms of realizing a more fulfilling life. Simplicity studies exemplify the latter and are in line with Duane Elgin's statement: 'Outwardly simple, inwardly rich' (1981). The results of our study not only seem to support these findings but additional dimensions of the quality of life emerged. Living with less often provided an unexpected life experience of adventure and coincided with personal growth, even for respondents with very low incomes. Moreover, the transformation process itself appeared to be an essential aspect of quality of life. 


\subsubsection{Implications for sustainability}

The insight that reorganising expenses means reorganising life, can offer a useful perspective for promoting sustainability. Indeed, this conclusion puts the current absolute importance of money in perspective. When money and material possessions

are just means for constructing and organizing life, then we expect that once more valuable immaterial alternatives become available and material consumerism will decline. Hence, a sustainability lifestyle change should be considered a multidimensional change process and focus should not be placed on a single aspect such as promoting the purchase of a green car or reducing household electricity use by systematically washing with cold water.

The finding that consuming less may be associated with positive experiences reveals new possibilities for promoting sustainability and behavioural change. The list of positive and negative experiences, presented in Chapter 5, could provide input for creating effective strategies and define motivators for behavioural change.. For example, better social contacts could constitute a safety net for the exchange of goods and services. Feelings Increased feelings of autonomy and selfesteem could increase motivation for consumption change and negate the influence of insidious commercial incentives. However, it must be noted that it is not the decline in spending, per se, that produces positive experiences but the far-reaching life changes that result.

In conclusion, interventions that seek to direct consumer behaviour towards sustainability could be successful if the scope of analysis and strategy are expanded from mere financial solutions to non-material alternatives, and from promoting the consumption of the 'right' goods to providing the right social, economic and infrastructural conditions and circumstances.

\subsubsection{Downshifters and sustainability}

The sociological impact of downshifting is considered to be not incidental but a growing trend of major importance. Researchers conclude that the increasing number of downshifters indicate that it is a social force with far reaching political implications, because downshifters succeed in resist strong critical social pressures and persist in their decision to change their way of life. From the wide spreading of 
downshifting they draw the conclusion that downshifting is no longer an act of personal deviancy but an indication of a radical change of consumer society (Cherrier \& Gandolfi 2009; Datamonitor 2003; De Geus 2003; Hamilton \& Breakspear 2004; Schor 1998).

In this dissertation, we investigated how this new consumer trend is manifested in the Netherlands and explored its potential for sustainability. In our study, we placed emphasis on concrete, phenomenal consumption practices and not on motives, beliefs or emotions. Obviously, the latter are vital elements of consumer behaviour choices and major determinants of sustainability strategies and policies. The perspective in this dissertation, however, was chosen in such a way that a broader range of downshifting experiences could be identified and the study's objective to explore new prospects for sustainability could be met. 
So, which new findings and insights are yielded by this approach? To discuss these findings in an integrated fashion, we applied the Dutch triple Gs of a sustainable lifestyle: geld, groen, gezondheid/welzijn (finances, eco-friendliness, and health/wellbeing) which are based on the green triangle posited by Callenbach (2002).

According to this concept, which we introduced in Chapter 5, a sustainable lifestyle results from the right input into each of the three pillars. The basic assumption is that there is concurrence and mutual dependence between the pillars: changes in one pillar will influence outcomes in the other two. Thus, to establish the potential for sustainability through downshifting, we must evaluate the results of each pillar and their interconnectedness.

With respect to finances, downshifters tend to be conscious, careful spenders, as is revealed by the scores at the Frugality Scale, as well as from the results of the list of consumption expenditures. Their productuse, as well as buying behaviour is rather frugal and restraint, while budgeting is generally perceived a positive experience. Further we found that downshifters increase saving and paying debt, which may be interpreted as an indication for wise financial management. Studies in other countries show as well that the wise stewardship of resources is a common trait for downshifters (Breakspear \& Hamilton 2004; Huneke 2005; Schor 1998). Notably, this is not a goal per se, but a means, a deliberately chosen strategy to serve other goals.

We found various indications of eco-friendly behaviour of downshifters, which is the second pillar of sustainable lifestyle. Firstly, downshifters, are very dedicated in handling with goods: they recycle glass and other materials; they take good care of their possessions, avoid waste and resourcefully use what they possess. In particular, the energy use of downshifters is significantly less than of non-downshifters in this study. This is a noteworthy finding, since it may be fair to assume that Genoeg readers are more than average committed to energy use reduction. Downshifters thus considerably meet the standard for eco-friendly behaviour: reduce, re-use, and recycle.

At the same time, downshifters do not appear to be primarily motivated by environmental concerns but rather by an expectation of improved quality of life or financial concerns. This conclusion is consistent with the results of Australian and American studies, where few downshifters 
reported the desire for a post-materialistic or eco-friendly lifestyle as a primary reason for downshifting.

Concerning the latter pillar: wellbeing/health, we found that there is a number of personal benefits of downshifting, such as improved quality of life and a more stable financial position once debt is reduced and savings increase. Also, the experience of downshifting itself may increase feelings of satisfaction, or even happiness. This is particularly true forvoluntary downshifters; although involuntary downshifters as well reported positive experiences.

It must be noted though, that results of previous studies show a more direct association between downshifting and increase of life quality and satisfaction with the lifestyle change. As Breakspear and Hamilton reported: "The only regret shared by downshifters was that they had not done it sooner '(2004:1). But the detailed overview 
of negative experiences in this study shows a more nuanced picture. In particular should be noticed the criticism from the social environment as well as financial difficulties to make all ends meet. Based on the results we found, we may plausibly conclude that downshifting may increase quality of life and therefore contributes to feeling of personal well being and happiness.

\subsubsection{Implications for sustainability}

Downshifting can contribute to sustainability as this way of life resonates with the three pillars of the Dutch triple Gs model of sustainable consumer behaviour. Although the motivation for downshifting appears to be rather personally than environmentally driven, the outcome of downshifting could be ecofriendly. It was found that interest for the environment could very well coincide with financial or personal interests. Also the idea that downshifters primarily seek an improvement of quality of life beyond materialism and consumerism may be useful to promote sustainability. It can inspire to define new - less material - dimensions of sustainability and strengthen as well social and economic conditions of a sustainable lifestyle, besides the current focus on environment.

In conclusion, we contend that living with less can promote sustainability either directly through reduced consumption or indirectly through a more fundamental transformation of lifestyle. The following general prospects for sustainability have been identified:

1. In our time, frugality still is a vital cultural feature and a guiding principle for consumer behaviour and practices. This finding resonates with the reported cultural change towards a less materialistic way of life and indicates broader support for reduction than was previously assumed. 2. Living with less may indeed contribute to a better quality of life. Positive experiences with downshifting contradict the popular belief that spending less or a decrease in income is a purely negative event.

3. The Dutch triple Gs of a sustainable lifestyle can supply the parameters for measuring the sustainability of downshifting.

\subsection{A strategy to encourage sustainable living}

Based on the findings of this study and recent literature, we present a list of recommendations for the promotion of sustainable consumer behaviour and a sustainable way of living. 
Creating policy to promote sustainable living is very complex. As this study demonstrated, the transformation of consumer behaviour is a multidimensional process that is influenced by the social context, habits, attitudes, beliefs, self perceptions, consumption infrastructure, advertising, marketing and personal characteristics, as well macro-level determinant such as politics, cultural traditions. 
and economics. However, despite the challenges, there are strong indications that suggest that change is a real possibility.

First, the sense of urgency for change appears to be greater than ever before. Measures to counter the impact of climate change are broadly supported by governments and the public. As well, the economic crisis is a condition for change. Larger numbers of involuntary downshifters are created as the economic downturn decreases incomes. Notwithstanding the personal tragedies that are associated with a loss of income or savings, the economic crisis may create opportunities for redirection towards social and economic sustainability. A promising example is the proliferation of sustainable banks in the Netherlands such as Triodos Bank and ASN. Private savings are increasing, as is public interest in energy and carbon reduction measures. The combination of supportive political measures such as the ambitious EU 2020 strategies for education, job innovation and the environment and large scale sustainable production initiatives have created an excellent environment for change which, in turn, creates possibilities for accelerated sustainable social development.

It seems that, large-scale behavioural change is only possible if a variety of measures is undertaken simultaneously. This requires a concerted strategy (Jackson 2005) that will not only increase the value and effectiveness of the sub-strategies, as they are reinforced by the other initiatives, but have a strong synergetic effect as well.

\subsubsection{Four priorities in a strategy for sustainable living}

It is impossible to provide a complete blueprint for such a strategy in this concluding chapter. However, an effective concerted strategy should meet the following four conditions.

\section{1) Dutch Triple G model as guiding principle}

Sustainable behaviour requires far more than the consumption of ecofriendly products. We propose that sustainable behaviour is the joint outcome of the three pillars of the Triple G model: money (geld), ecofriendliness (groen), health/well-being (gezondheid/welzijn). Therefore, actions should be directed towards this trio of interlinked domains in order to strengthen personal economics, eco-friendliness and well-being. Although there is a broad range of possible actions, we will here address 
the first pillar of the Triple Gs, namely how to increase sustainable personal finances.

This study has demonstrated that aversion to frugality is not due to a universal law but rather a reaction to specific circumstances. Because of the current financial and economic crisis, circumstances are such that campaigns to stimulate thrift are likely to be successful. Some suggestions include:

*Stimulate knowledge of personal finance and budgeting and provide insight regarding personal spending behaviour.

*Stimulate thrifty behaviour and living within one's means.

*Limit credit facilities and restrict loans for consumer purchases. 
*Stimulate sustainable alternatives to buying that are aligned to the principles of reduce, reuse, recycle for sustainable behaviour.

* Simultaneously, promote practices to augment the two other pillars of sustainable behaviour: eco-friendliness and health/wellbeing.

We thus advise providing education and adequate health care, encouraging proper nutrition and promoting social engagement as additional methods to strengthen public health and well-being. Finally, to promote eco-friendly behaviour, current campaigns should be extended with programs to measure and offset individual $\mathrm{C} 02$ emissions, limit car use for short trips and introduce more measures to reduce household energy consumption. We also recommend green educational programs for children.

\section{2) Transform consumption infrastructure}

Radical interventions are needed in the consumption infrastructure in order to make sustainable living easier and more attractive. Currently, environmentally friendly behaviour is often penalized and is literally and figuratively more expensive. For example, the prevailing image of public transport is that it is the second best option. It should be promoted as a high quality experience in terms of comfort, facilities and price. The same holds for food, housing, leisure activities and clothing. In general, institutions in a mass consumer society encourage individualism and competition instead of communal behaviour and cooperation. For example, the low wages of public sector and health care jobs are subtle signals of their social value (State of the World, 2008).

Because governments play an important role in shaping the situational context for sustainable behaviour, we advocate more courageous leadership for social engineering. A striking example is the London Agri program, a covenant between the city of London and farmers that aims to realize a regional food supply of $80 \%$ by 2025 . Further, advertising restrictions, already in place in several European countries, need to be expanded. Particularly, children should be protected against commercial manipulation but adults as well should be protected against unwanted commercials through public media.

3) Strengthen existing initiatives

Numerous consumer/citizen initiatives have been undertaken to promote a sustainable society. A recent example of a very successful initiative is the transition town movement that is rapidly growing worldwide and in the Netherlands as well 
(www.transitiontowns.org). Other examples of behavioural change initiatives are simplicity-circles, climate clubs and eco-teams of the Global Action Plan, which after a period of inactivity have made a strong come back in Great Britain.

These and other similar initiatives could be encouraged and strengthened to maximize their effect and create broader support for change. The role of the government should be one of co-creator of the transformation process, facilitating financial and emotional support (Jackson 2005). Successful downshifters and adherents of other eco-friendly lifestyles could become role models making a sustainable lifestyle more acceptable to mainstream society. Or at least their example could provide an effective response to critique of sustainable lifestyles. 
4) Brand sustainable living as prestigious

'All people today deep down are probably already beginning to consider greater self-restraint as a way of life.' This statement is not from a spiritual leader's handbook nor is it derived from an anti-globalist group's leaflet; it is part of the mission statement of the Japanese department store, MUJI. This business - with prime location stores in major cities of the Western world - accesses the changing attitudes of consumers and embodies it in its product-choice, management and marketing strategy. For MUJI, the Triple $\mathrm{P}$ of social responsibility People, Profit, Planet - is so ubiquitous that it is not specifically mentioned in the mission statement. Meanwhile, the store is explicit about its main characteristic, namely economy.

MUJI could function as an important source of inspiration for branding a sustainable lifestyle. Instead of the existing connotations of sacrifice or the image of a 1950s rerun, a sustainable lifestyle could become a futuristic new brand and could be launched with images of modernity, sophistication and sound financial management. The idea is that the same tools and strategies that marketing used to promote consumerism could now be used to promote sustainable living. We advocate a concerted, professional, multi-annual, segmented, multimedia marketing campaign to increase awareness, create new role models, promote green products and engender behavioural change. In sum, we recommend a new 'Delta plan'* to promote a sustainable lifestyle.

This approach breaks with traditional campaigns to promote eco-friendly consumption or behaviour as most campaigns - except for the successful Dutch eco-team campaign (Staats et al 2004) - are based on the rational learning model. The assumption that product choice results from rational information seeking still guides many sustainability campaigns, for example the one on product labeling. Another aim of this approach is to replace the automatic response to a problem whereby we buy the solution with a more sustainable product. We should avoid creating the perception that sustainable living is simply a matter of buying eco-friendly products. Today, sustainability is becoming commoditized and integrated in consumerism. Changes should be made to counter this mentality. It might be more sustainable not to buy at all and use products for longer. A striking new method of changing prevailing attitudes in the Netherlands is the tax on waste for citizens. As a result of this new incentive, the number of Dutch recycle shops has grown rapidly. So, this measure 
keeps reusable products out of the landfill and makes good products available at reasonable prices.

All in all, we think that today's circumstances are strongly conducive to change consumption behaviour into a more sustainable lifestyle. The aforementioned conditions for a strategy, however, can only be successful if sufficient political motivation and support is present.

* Following the dramatic floods in 1953, the Delta Plan was realized in the Netherlands. Under the Delta Plan ten large dams and three surge barriers were constructed, largely to protect against flooding, reclaim land, store freshwater and improve the waterways (Netcold, 2006). 


\subsection{Limitations of the study}

Goethe's characterization: 'Mastery is revealed in limitation' doesn't apply to this study. Evidently, the theoretical and empirical studies reported in this dissertation were rather broad in scope.

Firstly, the theoretical framework for analyzing the concept frugality was constructed through analyses of philosophy, anthropology, economics and psychology in combination with insights from consumer studies, environmental studies and the political sciences. In search of a viable connection between philosophy, religious thought and economics, we described the development of frugal thinking from the classical age to postmodern thinkers. A comparably broad scope was also used for our review of consumer studies by addressing the epistemological development from the inception of consumer studies to today. In this sense, our research is characterized by a multidisciplinary approach, or postmodern eclecticism. Because a main purpose of this study was to explore new perspectives and seek new insights, a multidisciplinary approach was considered necessary.

This tendency to extensiveness can also be found in both empirical studies. The phenomenological research method that was applied in the field study, although conducted locally, may be comparable with an anthropological field trip considering its openness to reported facts and experiences. The outcome - the Transformation Model Living with Less attempts to formulate the illimitable by defining the open ends: 'prelude' and 'postlude'. Finally, the scope of the research is also reflected in the way we presented the general research question (Chapter 1). We covered four themes: frugality, consumer behaviour, sustainability and downshifting as cultural phenomena. In this respect we deliberately sought this comprehensiveness to maximize the explorative potential of the research. However, the methodological and disciplinary choices we made, as well as the specific circumstances of the study, inevitably generated limitations. The most important will be discussed below.

First, the survey population - readers of the magazine Genoeg - has limited the generalizability of the results. Readers of this magazine are potentially more inclined towards moderation and downshifting than the average Dutch consumer is. It is therefore necessary to interpret the results carefully and to apply caution in making generalizations. The homogeneity of the research population was useful for the explorative 
purpose of the study but limited differentiation in certain areas. Associations between variables were sometimes difficult to determine because the subpopulations were relatively small. For example, refinements with regard to frugality or shifts in consumer practices were far less distinct than we hoped.

Further, there were two main limitations in the field study. The study had a limited number of respondents. Respondents showed no indications of problematic financial behaviours resulting from psychological or emotional problems. This leads us to suspect that the transformation process would be far more complicated in cases 
where serious personal problems were present. A second limitation might be geographical, considering that our study was conducted solely in the Netherlands. People might respond differently to a living with less challenge in a region without a public financial safety net.

The study puts sustainability in a broader context than the prevailing context: eco-friendly behaviour as merely a reduction in $\mathrm{CO} 2$ emissions. We added the dimensions of personal finances and health/wellbeing to our definition of sustainable behaviour, thus positioning sustainability at the junction of several domains..From the perspective of each of the domains, it may be stated that our results are rather speculative in meeting the standards of the relevant domain.

The research reported in this dissertation addresses a number of relevant issues pertaining to living with less money but sidesteps the issue of poverty. Questions such as 'Does a lower limit of downshifting exist' and 'under what circumstances does living with less money become poverty and deprivation?' were not addressed. Within the conceptual framework of this study, poverty is perceived as a socio-cultural interpretation based on standards that are temporally and spatially bound. Therefore, we placed it outside the purview of this study in order to focus on consumption processes and sustainability.

Although we are fully aware of the social, political and psychological dimensions of poverty and the vital role the perception of poverty plays in shaping experiences of downshifting, this study placed its focus on general processes and sought to investigate downshifting from a more detached perspective. However, the results of this study may shed new light on poverty. In line with the Dutch Triple Gs of sustainable living, we might argue.that poverty (so far merely defined in financial terms) is more the result of a lack of knowledge, skills, appropriate personal competencies and adequate social services.

In addition, the characteristics of the consumption infrastructure, the socio-cultural traditions of frugality and other specific conditions in the Netherlands likely influenced experiences of living with less, and attitudes. Further international research is needed to determine what results of this study are contextually specific determinants of downshifting and which are universal.

In sum, the limitations of this study are the consequence of the explorative character of the study, and the specific conditions in which 
the study was conducted. The choices we made yet provoked valuable new insights and findings but also provided directions for future research. 


\subsection{Future research}

Through our innovative approach, new connections have been made through which new insights could emerge. In the course of this dissertation, several questions were raised that could be addressed in future research.

For example, 1. The Transformation Model Living with Less Transformation Model of Living with Less could form the basis for further theoretical and empirical research. Theoretically, the model could function as a stepping stone or integrative scheme that could classify main theoretical streams within consumption studies as a coherent whole. We challenge others to draw a multidisciplinary map of consumer behaviour change theories, to discuss their mutual coherence and define the missing links.2. In addition, further academic research that empirically tests the explanatory value of the model is needed. Relevant questions could include the pace of change, the sequence of stages, possible interconnectedness between causes of living with less and characteristics of the change process, the identification of variables of personal characteristics and social and economic conditions, as well as the empirical testing of consumer behaviour theories.

Besides, Gudeman \& Rivera's (1990) theory of the house economy versus the corporate economy offered a new explanatory perspective to the ongoing, polarized discussion about frugality in postmodern consumer society. Future research could investigate this structuralfunctional perspective of frugality empirically to overcome the dichotomous approach that influenced the epistemic view of consumer research. In general, anthropological theories, albeit cultural or economic, could bring innovation to consumer studies because they offer a universal human cultural perspective to the discussion instead of the onedimensional view of economic psychology. Similarly, thrift theories and practices should be further examined following the methods of Daniel Miller's shopping study (1998).

The posited dual nature of frugality was derived from Foucault's History of Sexuality (1990). It seems that the strong negative image of frugality in Western society and its rejection is reminiscent of the perception of sexuality during the Victorian era. The clarifying cultural analysis of the dual nature of sexuality put forth by Foucault inspired us to analyse 
frugality's ideological position in today's culture (Foucault 1990). His theory may offer additional leads for further analysis that may reveal the controversy between the taboo of frugality and its determining influence on society.

In accordance with Foucault's study, the specific functions of education, religion, architecture, institutes, science, mass media content and the like, could be analysed using the dialectical cultural perspective of taboo and obsession.

Despite our broad approach, our study of Dutch downshifters is far from comprehensive. Our study provided an exploration of characteristics and practices but many questions remain unanswered. Our research population, namely readers of the 
magazine Genoeg, limited the representative value of the results for the Dutch population in general. This could be an valuable next step, preferably in close cooperation with other European countries, since the sociological trend of voluntary downshifting is rapidly growing outside our frontiers. In general, the results of our study of downshifters provide stimulus for further research. First, we found that positive experiences of downshifting are mostly an indirect effect of the decline. This result raises questions such as 'Which contextual and personal factors contribute to which specific positive experiences?' and 'What motivates downshifters to choose a happier life now instead of staying stuck in the deferred happiness syndrome?', as Hamilton concluded in his study of downshifting in Australia (2003).

Finally, we provide some ( It is made by man, so it can be changed by men)research suggestions to strengthen policy making towards sustainability. International studies indicate that downshifting is increasingly becoming a sociological trend of major importance. Therefore, more policies could be developed to mitigate the effects of downshifting as part of a sustainable consumption policy..Some suggestions for a strategy of sustainable living are formulated at the beginning of this chapter but their effectiveness could be supported by further empirical research. For example, a pilot study identifying the success factors in promotional campaigns could be very useful. 


\section{Bibliography}

Aarts, W. (1999). De status van soberheid. Een onderzoek naar milieuvriendelijke zelfbeperking (The status of frugality; A study of ecofriendly selfrestraint). Faculteit der Politieke en Sociale Wetenschappen Universiteit van Amsterdam.

Abrahamson, P. R. and R. F. Inglehart (1995). Value change in global perspective. Ann Arbor, University of Michigan Press.

Ajzen, I. and M. Fishbein (1980). Understanding attitudes and predicting social behavior. Englewood Cliffs, Prentice-Hall.

Anderson, C. L. and N. Nevitte (2006). "Teach your children well. Values of thrift and saving." Journal of Economic Psychology 27: 247-261.

Andrews, C. (1998). The Circle of simplicity. Return to the good life. New York, HarperPerennial.

Andrews, C. (2008). Slow is beautiful ; new visions of community, leisure and joie de vivre;. Gabriola CA, New Society Publishers.

Aristoteles (2005). Ethica Nicomachea [pp. 203-218]. Budel, Damon.

Arndt, J., S. Solomon, et al. (2004). "The urge to splurge revisited. Further reflections on applying terror management theory to materialism and consumer behavior." Journal of Consumer Psychology 14(3): 225-229.

Arndt, J., S. Solomon, et al. (2004). "The urge to splurge. A terror management account of materialism and consumer behaviour." Journal of Consumer Psychology 14(3): 198-212.

Arnould, E. J. and C. J. Thompson (2005), “Consumer Culture Theory (CCT): Twenty Years of Research, Journal of Consumer Research, 31 (3): 868-882.

Assadourian, E. e. (2009). State of the World 2010: Transforming Cultures from Consumerism to Sustainability. London, Earthscan.

Barthes, R. (1972). Myth today. Mythologies. R. Barthes. London, Jonathan Cape: 109-159.

Bataille, G. (1991). The accursed share. An essay on general economy. Volume 1: Consumption. New York, Zone Books.

Baudrillard, J. (1998). The consumer society. Myths and structures. Thousand Oaks, Sage.

Bauman, Z. (2007). Consuming life. Cambridge, Polity Press.

Becker, H. S. (1963). Outsiders. Studies in the sociology of deviance. New York, Free Press.

Beckers, T. A. M., E. W. F. P. M. Harkink, et al. (2004). Maatschappelijke waardering van duurzame ontwikkeling. Achtergrondrapport bij de duurzaamheidsverkenning (Social valuation of sustainable development. Background report to the sustainability enquiries). Bilthoven, RIVM. Bilthoven, RIVM.

Beckers, T. A. M., G. Spaargaren, et al. (2000). Van gedragspraktijk naar beleidspraktijk. Een analytisch instrument voor een consument-georiënteerd milieubeleid (From behavioural practice to policy practice. An analytical tool for a consumer oriented environmental policy). Tilburg, Instituut voor Globalisering en Duurzame Ontwikkeling. 
Belk, R. W. (1995). Studies in the new consumer behaviour. Acknowledging consumption. D. Miller. London, Routledge: 58-95.

Belk, R. W. (2001). Collecting in a consumer society. London, Routledge.

Belk, R. W., G. Ger, et al. (2002) "The fire of desire: a multi-sided inquiry in consumer passion " University of Utah, Marketing Working Paper No. 02-31

Benammar, K. (2005). Overvloed (Abundance). Diemen, Veen Magazines.

Bliss, C. (1993). Life-style and the standard of living. The quality of life. M. Nussbaum and A. Sen. Oxford, Clarendon Press: 417-436.

Bouchet, D. (1998). "Information technology, the social bond and the city. Georg Simmel updated. About the changing relationship between identity and the city." Built Environment 24(2/3): 104-133.

Bourdieu, P. (1984). Distinction. A social critique of the judgement of taste. Cambridge, Harvard University Press.

Breakspear, C. and C. Hamilton (2004). Getting a life; understanding the downshfiting phenomenon in Australia. Canberra, The Australia Institute.

Brewer, J. D. (2000). Ethnography. Buckingham, Open University Press.

Brown, K. W. and T. Kasser (2005). "Are psychological and ecological well-being compatible? The role of values, mindfulness, and lifestyle." Social Indicators Research 74(2): 349-368.

Bruckner, P. (2002). Gij zult rijk worden; misère van de economische mens (Orig.:Misère de la prosperité. La religion marchande et ses ennemis). Amsterdam, Uitgeverij Boom.

Callenbach, E. (1990) "The green triangle." In Context; a quaterly of humane sustainable culture. Retrieved 10-02-2010, from http://www.context.org/ICLIB/IC26/Callnbch.htm.

Campbell, C. (1987). The romantic ethic and the spirit of modern consumerism. Oxford, Blackwell.

Campbell, C. (1994). Capitalism, consumption and the problem of motives. Consumption and identity. J. Friedman. Chur, Harwood Academic Publishers: 23-46.

Campbell, C. (1995). The sociology of consumption. Acknowledging consumption. A review of new studies. D. Miller. London, Routledge: 96-126.

Campbell, J. (2005). De held met de duizend gezichten. Amsterdam, Olympus.

Campbell, J. and B. Moyers (1991). The power of myth [Interview]. New York, Anchor Books.

CBS (2010). Sociaaleconomische trends, 1e kwartaal 2010 (Netherlands Statistics: Socialeconomic Trends, 1st Quarter 2010).

Cherrier, H. and J. Murray (2002). "Drifting away from excessive consumption. A new social movement based on identity construction." Advances in Consumer Research 29: 245-247.

Clarke, I., III and K. S. Micken (2002). "An exploratory cross-cultural analysis of the values of materialism." Journal of International Consumer Marketing 14(4): 65-89.

Cohen, L. (2004). A Consumer's republic. The politics of mass consumption in postwar America. New York, Random House. 
Collins, J., Gillian Thomas, Rebecca Willes, James Wilsdon (2003). Carrots, sticks and sermons: influencing public behaviour for environmental goals. Demos, Demos / Green alliance.

Craig-Lees, M. and C. Hill (2002). "Understanding voluntary simplifiers." Psychology \&

Csikszentmihalyi, M. (2000). "The costs and benefits of consuming." Journal of Consumer Research 27(2): 267-272.

Csikszentmihalyi, M. and E. Rochberg-Halton (1981). The meaning of things. Domestic symbols and the self. New York, Cambridge University Press.

Curry, N. A. and T. Kasser (2005). "Can coloring mandalas reduce anxiety?" Art Therapy 22(2): 81-85.

Dacyczyn, A. (1998). The complete tightwad gazette. Promoting thrift as a viable alternative lifestyle. New York, Villard Books.

Daniel, T. R. (1997). Delay of consumption and saving behavior. Some preliminary, empirical outcomes. Advances in economic psychology. G. Antonides, W. F. v. Raaij and S. Maital. Chichester, Wiley: 171-185.

Datamonitor (2003). The consumer quest for simplicity. Datamonitor.

De Geus, M. (1999). Ecological utopias; envisioning the sustainable society. Utrecht, International books.

De Geus, M. and T. v. Slobbe (2003). Fences \& freedom; the philosophy of hedgelaying. Utrecht, International Books.

De Geus, M. (2003). The end of overconsumption. Towards of lifestyle of moderation and self-restraint. Utrecht, International Books.

De Graaf, J. (2003). Take back your time; fighting overwork and time poverty in America. San Francisco, Berreth-Koehler Publishers, Inc.

De Graaf, J., D. Wann, et al. (2002). Affluenza. The all-consuming epidemic. San Francisco, Berreth-Koehler Publishers.

De Heus, P., H. Staats, et al. (1992). Eindige voorraden. Gedachten, gevoelens en voornemens van Nederlanders over verspilling (Finite resources. Thoughts, feelings and intentions of Dutch about waste). Leiden, Werkgroep Energie- \& Milieuonderzoek.

De Tocqueville, A. (2003). Democracy in America: and two essays on America London, Penguin.

De Young, R. (1996). "Some psychological aspects of reduced consumption behavior. The role of intrinsic satisfaction and competence motivation." Environment and Behaviour 28: 358-409.

Derkse, W. (2001). Een levensregel voor beginners; Benedictijnse spiritualiteit voor het dagelijkse leven. (A rule of life for beginners; Benedictine spirituality for everyday life) Tielt, Lannoo.

Dernbach, J. C., Ed. (2009). Agenda for a sustainable America. Washington, Eli Press.

Dickens, C. (1890). A Christmas Carol. London, Stock.

Doherty, D. and A. Etzioni, Eds. (2003). Voluntary simplicity. Responding to consumer culture. Lanham, Rowman \& Littlefield. 
Dohmen, J. (2007). Tegen de onverschilligheid. Pleidooi voor een moderne levenskunst. (Against indifference. Plea for a modern savoir-vivre). Amsterdam, Ambo.

Dominguez, J. and V. Robin (1999). Your money or your life. Transforming your relationship with money and achieving financial indepence. New York, Penguin Group.

Douglas, M. (1996). Prospects for ascetism. Thought styles. Critical essays on good taste. M. Douglas. London, Thousand Oaks: 161-192.

Douglas, M. and B. Isherwood (1996). The world of goods. Towards an anthropology of consumption. London, Routledge.

Durning, A. T. (1992). How much is enough? The consumer society and the future of the earth. London, Earthscan Publications.

Edwards, T. (2000). Contradictions of consumption. Concepts, practices and politics in consumer society. Buckingham, Open University Press.

Ehrenreich, B. (1990). Fear of falling; The inner life of the middle class. New York, Harper Perennial.

Ehrenreich, B. (1991). The worst years of our lives; irreverent notes from a decade of greed. New York, Harper Perennial.

Ehrenreich, B. (2005). Bait and switch the (futile) pursuit of the american dream. New York, Henry Holt and Company.

Ehrenreich, B. (2006). Nickel and dimed; On (not) getting by in America. New York, Henry Holt and Company.

Ehrenreich, B. (2008). This land is their land; reports from a divided nation. New York, Henry Holt and Company.

Ekins, P. (1993). "'Limits to Growth' and 'Sustainable Development': Grappling with Ecological Realities." Ecological Economics, 8: 269-288.

Elgin, D. (1981). Voluntary simplicity. Towards a life that is outwardly simple, inwardly rich. New York, Morrow.

Elgin, D. (2000). Promise ahead. A vision of hope and action for humanity's future. New York, Morrow.

Emerson, R. W. (1985). Selected Essays. New York, Penguin Books.

Engbersen, G. and R. v. d. Veen (1987). Moderne armoede. Overleven op het sociaal minumum. Een onderzoek onder 120 Rotterdamse huishoudens. (Modern poverty. Surviving on a social minimum; A survey of 120 households in Rotterdam) Leiden, Stenfert Kroese.

Engle, Y. and T. Kasser (2005). "Why do adolescent girls idolize male celebrities?" Journal of Adolescent Research 20(2): 263-283.

Etzioni, A. (1998). "Voluntary simplicity. Characterization, select psychological implications, and societal consequences." Journal of Economic Psychology 19: 619-643.

Featherstone, M. (1991). Consumer culture and postmodernism. London, Sage.

Featherstone, M. (1992). The heroic life and everyday life. Cultural theory and cultural change. M. Featherstone. London, Sage: 159-182.

Fine, B. (1995). From political economy to consumption. Acknowledging consumption. A review of new studies. D. Miller. London, Routledge: 127-164. 
Firat, A. F. (1987). The social construction of consumption patterns. Understanding macro consumption phenomena. Philosophical and radical thought in marketing. A. F. Firat, N. Dholakia and R. P. Bagozzi. Lexington, Lexington Books: 251-267.

Firat, A. F. (2000). "Rethinking Consumption." Consumption, Markets \& Culture 3(4): 283-295.

Firat, A. F. and N. Dholakia (1998). Consuming people. From political economy to theaters of consumption. London, Routledge.

Firat, A. F. and A. Venkatesh (1995). "Liberatory postmodernism and the reenchantment of consumption." Journal of Consumer Research 22(3): 239267.

Foucault, M. (1990). The History of sexuality. Vol 1. London, Penguin Books.

Franklin, B. (1848). The way to wealth. New York, Leavitt, Trow \& Co.

Furnham, A. and R. Okamura (1999). "Your money or your life. Behavioral and emotional predictors of money pathology." Human Relations 52(9): 11571177.

Gabriëls, R. (2001). Intellectuelen in Nederland. Publieke controversen over kernenergie, armoede en Rushdie.(Intellectuals in the Netherlands. Public controversies over nuclear power, poverty and Rushdie). Amsterdam, Boom.

Gadjil, M. and R. Guha (1995). Ecology and Equity; The Use and Abuse of Nature in Contemporary India. New York: Routledge: 34.

Galbraith, J. K. (1962). The affluent society. Hammondsworth, Penguin Books.

Gandolfi, F. and H. Cherrier, Eds. (2008). Downshifting. A theoretical and practical approach to living a simple life. Hyderabad, Icfai University Press.

Gardner, H. (2002, Febr. 22). Good work, well done. A psychological study. The Chronicle of Higher Education: B7-B9.

Gatersleben, B. (2000). Sustainable household metabolism and quality of life: examining the perceived social sustainability of environmentally sustainable household consumption patterns. Kurt Lewin Instituut. Groningen, Rijksuniversiteit Groningen: 242, VIII.

Geldof, D. (2007). We consumeren ons kapot (We are consuming ourselves to death). Antwerpen, Houtekiet.

Geldof, D. (2008). Onzekerheid; over leven in de risicomaatchappij (Insecurity; about living in a risk society). Leuven/Voorburg, Acco.

Giddens, A. (1973). The class structure of the advanced societies. London, Hutchinson.

Goudzwaard, B. (2006). Grenzen en paradoxen. Van grenzen weten. Aanzetten tot een nieuw denken over duurzaamheid (Limits and paradoxes. Knowing limits. Incitement to new thinking on sustainability). B. Goudzwaard and K. v. d. Wal. Budel, Damon: 79-97.

Goudzwaard, B. and H. M. d. Lange (1995).Genoeg van teveel, genoeg van te weinig. Wissels omzetten in de economie (Tired of too much, tired of too little; Track changes in economy). C. Baarn, Ten Have.

Greendex: consumer choice and the environment; Retrieved 06-03-2010, from http://www.nationalgeographic.com/greendex/.

Gregg, R. B. (1936). The value of voluntary simplicity. Wallingford, Pendle Hill. 
Gudeman, S. and A. Rivera (1990). Conversations in Colombia; the domestic economy in life and text. Cambridge, Cambridge University Press.

Hamilton, C. (2003). Downshifting in Britain: a sea-change in the pursuit of happiness. Canberra, The Australia Institute.

Hamilton, C. and E. Mail (2003). Downshifting in Australia. A sea-change in the pursuit of happiness. Canberra, The Australia institute.

Harland, P. S., Henk Effectiveness of The EcoTeam Program in the Netherlands: A Long Term View.

Harwood Group (1995). Yearning for balance. Views of Americans on consumption, materialism, and the environment. Takoma Park, The Merck Family Fund.

Heertje, A. (2007). Echte economie. Een verhandeling over schaarste en welvaart en over het geloof in leermeesters en lernen (The true economy. A treatise on scarcity and prosperity and about faith in teachers and Lernen). Nijmegen, Valkhof Pers.

Hill, R. P. (2002). "Stalking the poverty consumer: a retrospective examination of modern ethical dilemmas." Journal of Business Ethics 37: 209-219.

Hills, J. (2004). Income dynamics and social mobility. Inequality and the state. J. Hills. Oxford, Oxford university Press: 97-123.

Hills, J. (2004). Social spending and the boundaries between public and private sectors. Inequality and the state. J. Hills. Oxford, Oxford University Press: 127-159.

Hilton, M. (2004). "The legacy of luxury. Moralities of consumption since the 18th century." Journal of Consumer Culture 4(1): 101-123.

Hodgkinson, T. (2006). How to be free. London, Hamish Hamilton Ltd.

Holbrook, M. B. (1995). Consumer research. Introspective essays on the study of consumption. Thousand oaks, Sage.

Holbrook, M. B. and G. Dixon (1985). Mapping the market for fashion. Complementarity in consumer preferences. The psychology of fashion. M. R. Solomon. Lexington, Heath: 109-126.

Holt, D. B. (1997). "Distinction in america? Recovering Bourdieu's theory of tastes from his critics." Poetics 25: 93-120.

Holt, D. B. (1998). "Does cultural capital structure american consumption?" Journal of Consumer Research 25: 1-25.

Holt, D. B. (2003). How brands become icons. The principles of cultural branding. Boston, Harvard Business School Press.

Holt, D. B. (2005). "An interview with Juliet Schor." Journal of Consumer Culture 5(1): 521.

Huneke, M. E. (2005). "The face of the un-consumer. An empirical examination of the practice of voluntary simplicity in the United States." Psychology \& Marketing 22 (7): 527-550.

Huneke, M. E. (2006). The influence of personal values on the practice of voluntary simplicity in the United States. Unpublished Manuscript.

Illouz, E. (1997). Consuming the romantic utopia. Love and the cultural contradictions of capitalism. Berkeley, University of California Press. 
Inglehart, R. (1977). The silent revolution. Changing values and political styles among Western publics. Princeton, Princeton University Press.

Inglehart, R. (1997). Modernization and postmodernization. Cultural, economic, and political change in 43 societies. Princeton, Princeton University Press.

Jackson, T. (2006). Readings in sustainable consumption. Earthscan reader in sustainable consumption. T. Jackson. London, Eartscan: 1-23.

Jackson, T. (2007). The challenge of sustainable lifestyles. State of the World 2008. Ideas and opportunities for sustainable economies. T. W. Institute. London, Earthscan.

Jackson, T. (2007). Motivating Sustainable Consumption. SDRN briefing one. S. D. R. Network.

Jackson, T. (2008). Sustainable Consumption and Lifestyle Change. Handbook of Economic Psychology. A. Lewis. Cambridge, Cambridge University Press: 335362.

Jackson, T. (2009). Prosperity lost. Prosperity without growth. Economics for a Finite Planet. T. Jackson. London, Earthscan: 1-16.

Jackson, T. L. M. (2003). Policies for Sustainable Consumption; a report to the Sustainable Development Commission, Sustainable Development Commission.

Janssen, R. F. H. (1990). Armoede of soberheid. De verarming van mens en milieu als nieuwe sociale kwestie (Poverty or austerity. The impoverishment of people and the environment as a new social issue). Proefschrift Rijksuniversiteit Leiden. Utrecht, Commissie Oriënteringsdagen.

Johnson, W. (1979). Muddling toward frugality. A blueprint for survival in the 1980s. Boulder, Shambala.

Johnston, T. and J. B. Burton (2002, April). Voluntary simplicity: Popular definitions and major themes. Nashville Conference, Nashville.

Juffermans, J. (2006). Nut \& Noodzaak van de Mondiale voetafdruk; over de mondiale gebruiksruimte, duurzaamheid en mensenrechten (The usefulness and necessity of the global footprint, About global resources, sustainability and human rights). Rotterdam, Lemniscaat.

Karsten, C. and K. S. Laansma (2003). Shoppen. De lust, het lijden en de last (Shoppen. Pleasure, pain and problem). Rijswijk, Elmar.

Kasser, T. (2002). The high price of materialism. Cambridge, The MIT Press.

Kasser, T. (2004). The good life or the goods life? Positive psychology and personal well-being in the culture of consumption. Positive psychology in practice. P. A. Linley and S. Joseph. New York, Wiley: 55-67.

Kasser, T. (2005). Frugality, generosity, and materialism in children and adolescents. What do children need to flourish? Conceptualizing and measuring indicators of positive development. K. A. Moore and L. H. Lippman. New York, Springer: 357-373.

Kasser, T. (2005, October). Can thrift bring happiness? Working Conference on Thrift and American Culture, Institute for Advanced Studies in Culture, University of Virginia. 
Kasser, T. (2006). Materialism and its alternatives. A life worth living. Contributions to positive psychology. M. Csikszentmihalyi and I. S. Csikszentmihalyi. New York, Oxford University Press: 200-214.

Kasser, T., S. Cohn, et al. (2007). "Some costs of American corporate capitalism. A psychological exploration of value and goal conflicts." Psychological Inquiry 18(1): 1-22.

Kasser, T. and V. Grow Kasser (2001). "The dreams of people high and low in materialism." Journal of Economic Psychology 22(6): 693-719.

Kasser, T. and A. D. Kanner, Eds. (2004). Psychology and consumer culture. The struggle for a good life in a materialistic world. Washington, American Psychological Association.

Kasser, T. and A. D. Kanner (2004). Where is the psychology of consumer culture? Psychology and consumer culture. The struggle for a good life in a materialistic world. T. Kasser and A. D. Kanner. Washington, American Psychological Association: 3-7.

Kasser, T., R. M. Ryan, et al. (2004). Materialistic values. Their causes and consequences. Psychology and consumer culture. The struggle for a good life in a materialistic world. T. Kasser and A. D. Kanner. Washington, American Psychological Association: 11-28.

Kasser, T. and K. M. Sheldon (2004). Nonbecoming, alienated becoming, and authentic becoming. A goal-based approach. Handbook of experimental existential psychology. J. Greenberg, S. L. Koole and T. Pyszczynski. New York, Guilford Press: 480-493.

Kasser, T. and K. M. Sheldon (2009). "Time affluence as a path toward personal happiness and ethical business practice. Empirical evidence from four studies." Journal of Business Ethics 84(2): 243-255.

Keller, M. (2005). "Needs, desires and the experience of scarcity." Journal of Consumer Culture 5(1): 65-85.

Keynes (1936).General Theory of Employment, Interest and Money. London, MacMillan

Kilbourne, W. E. A. P. (2010). Sustainable consumption - the role of TCR in shaping a sustainable future. (Unpublished paper).

Klamer, A. (1991). Consumption as a Communicative Activity. A proposal to change the metaphor. The consumption of time and the timing of consumption. $\mathrm{G}$. Antonides, W. Arts and W. F. v. Raaij. Amsterdam, North Holland: 39-49.

Kotlowitz, A. (2000). False connections. The consumer society reader. J. B. Schor and D. B. Holt. New York, New Press: 251-256.

Kozinets, R. and J. M. Handelman (2004). "Adversaries of consumption: consumer movements, activism, and ideology." Journal of Consumer Research 31: 691704.

Lamal, P. A. (2003). "Review of The high price of materialism [by T. Kasser]." Psychological Record 53(1): 153-154.

Lastovicka, J. L., L. A. Bettencourt, et al. (1999). "Lifestyle of the tight and frugal. Theory and measurement." Journal of Consumer Research 26(June): 85-98. 
Laszlo, E. (2004). Je kunt de wereld veranderen; Naar duurzaamheid en vrede in een nieuwe wereld. (You can change the world - the global citizen's handbook for living on Planet earth). Deventer, Ankh-Hermes bv.

Laszlo, E. (2006). Het chaos punt; De wereld op een tweesprong (The Chaos point) Deventer, Ankh-Hermes bv.

LeCompte, M. D. and J. J. Schensul (1999). Designing \& conducting ethnographic research. Walnut Creek, AltaMira Press.

Leonard-Barton, D. (1981). "Voluntary simplicity lifestyles and energy conservation." Journal of Consumer Research 8: 243-252.

Levering, F. and W. Urbanska (2003). Simple living. One couple's search for a better life. Winston-Salem, Blair.

Levine, D. P. (2001). "The attachment of greed to self-interest." Psychoanalytic Studies 3(3-4): 131-140.

Levine, J. (2006). Not buying it; my year without shopping. New York, Simon \& Schuster, inc.

Linkages (2010). A multimedia resource for environment and development policy makers. Retrieved 10-02-2010 from http://www.iisd.ca/consume/oslo004.html.

Maffesoli, M. (1996). Ordinary knowledge. Introduction to interpretative sociology. Cambidge, Polity Press.

Malthus, T. R. (1951). Principles of political economy. New York, Augustus M. Kelley. Maniates, M. (2002). In search of consumptive resistance. The voluntary simplicity movement. Confronting consumption. T. Princen, M. F. Maniates and K. Conca. Cambridge, The MIT Press: 199-236.

Maniates, M. (2010). Editing out unsustainable behavior. State of the world 2010: Transforming Cultures from Consumerism to Sustainability. E. e. Assadourian. London, Earthscan: 119-126.

Marcuse, H. (2002). One-dimensional man. London: Routledge.

Martens, S. G. S. (2005). "The politics of sustainable consumption: the case of the Netherlands." Sustainability: Science, Practice, \& Policy; 1(1): 29-42. Retrieved 08-09-2009 from http://ejournal.nbii.org Marx, K. (1977). Capital; a critique of political economy Moscow, Progress Publishers.

Maslow, A. H. (1968). Toward a psychology of being. Princeton, Von Nostrand.

Mason, R. (1981). Conspicious consumption. A study of exceptional consumer behaviour. Farnborough, Gower.

Mauss, M. (1970). The gift. Forms and functions of exchange in archaic societies. London, Cohen and West.

McCracken, G. D. (1985). The trickle-down theory rehabilitated. The Psychology of Fashion. Lexington, Heath: 39-54.

McCracken, G. D. (1987). "The history of consumption. A literature review and consumer guide." Journal of Consumer Policy 10: 139-166.

McCracken, G. D. (1988). Culture and consumption. New approaches to the symbolic character of consumer goods and activities. Bloomington, Indiana University Press.

McCracken, G. D. (1988). The long interview. Newbury Park, Sage. 
Merck Family Fund (1995). Yearning for balance. Takoma Park, MD.

Merkel, J. (2003). Radical simplicity. Small footprints on a finite earth. Gabriola Island, New Society Publishers.

Mill, John Stuart. [1848] 1929. Principles of Political Economy. London: Longmans, Green

Miller, D., Ed. (1995). Acknowledging consumption. A review of new studies. Material cultures. London, Routledge.

Miller, D. (1995a). Consumption studies as the transformation of anthropology. Acknowledging consumption. A review of new studies. D. Miller. London, Routledge: 264-296.

Miller, D. (1995b). Consumption as the vanguard of history. A polemic by way of an introduction. Acknowledging consumption. A review of new studies. D. Miller. London, Routledge: 1-58.

Miller, D., Ed. (1998). Material cultures. Why some things matter. Consumption and space. London, UCL Press.

Miller, D. (1998). A theory of shopping. Cambridge, Polity Press.

Miller, D. (2001). Behind closed doors. Home possessions. D. Miller. Oxford, Berg: 1-19.

Miller, D. (2001). The dialectics of shopping. Chicago, University of Chicago Press.

Miller, D. (2001). Possessions. Home possessions. D. Miller. Oxford, Berg: 107-121.

Miller, D. (2006). Consumption. Handbook of material culture. C. Tilley, W. Keane, S. Küchler, M. Rowlands and P. Spyer. London, Sage: 341-354.

Miller, D. and D. Slater (2000). The Internet. An ethnographic approach. Oxford, Berg.

Moll, H. and A. Groot-Marcus (2002). Households past and present, and opportunities for change. Global warming \& social inovation. The challenge of a climateneutral society. M. Kok, W. Vermeulen, A. Faaij and D. d. Jager. London, Earthscan: 83-105.

Montijn, I. (1998). Leven op stand 1890 - 1940. Amsterdam, Rap.

Naish, J. M. (2008). Genoeg (Enough). Utrecht, Bruna.

Nash, J. A. (1998). On the subversive virtue: Frugality. Ethics of consumption. The good life, justice and global stewardship. D. A. Crocker and T. Linden. Lanham, Rowman and Littlefield: 416-436.

Nelissen, N. (1995). Beleid gericht op gedragsverandering: eerder gezegd, dan gedaan! Verslavend lekker en nooit genoeg. Over consumptiemotieven in deze tijd. G. v. Dijk and G. Potman. Kampen, Kok Agora: 125-143.

Nussbaum, M. (1998). The good as discipline, the good as freedom. Ethics of consumption. The good life, justice and global stewardship. D. A. Crocker and T. Linden. Lanham, Rowman and Littlefield: 312-341.

Nussbaum, M. (1999). Nicht-relative Tugenden. Ein aristotelischer Ansatz. Gerechtigkeit oder Das gute Leben. Frankfurt am Main, Suhrkamp: 229-239.

Nussbaum, M. (2002). De universele aspecten van het menszijn (The universal aspects of human existence). Over levenskunst. De grote filosofen over het goede leven. (About savoir-vivre; the great philosophers about the good life) J. Dohmen. Amsterdam, Ambo: 369-378.

Osti, G. (2006). Nuovi asceti. Bologna, II Mulino 
Oxford Dictionary (2008). Oxford English Dictionary Online. Retrieved 10-12- 2008 from http://www.oed.com/

Packard, V. (1960). The waste makers. New York, Van Rees.

Peters, C. P. (2000). The vulnerable hours of leisure. New patterns of work and free time in the Netherlands, 1975-95. Dissertation. Katholieke Universiteit Brabant, Tilburg. Tilburg, Thela Thesis.

Peters, P. F. (1997). Tijd in relatie tot duurzaam consumeren(Time in relation to sustainable consumption). Maastricht, Universiteit Maastricht, Faculteit der Cultuurwetenschappen.

Pierce, L. B. (2000). Choosing simplicity. Real people finding peace and fulfillment in a complex world. Carmel, Gallagher.

Postma, P. (2001). Gek van winkelen; 91 bizarre belevenissen bij het boodschappen doen. (Crazy about shopping; 91 bizarre experiences when shopping) Utrecht, Het Spectrum.

Princen, T. (1997). "Toward a theory of restraint." Population \& Environment 18(3): 233-254.

Princen, T. (2003). "Principles for sustainability. From cooperation and efficiency to sufficiency." Global Environmental Politics 3(1): 33-50.

Prus, R. C. (1996). Symbolic interaction and ethnographic research. Intersubjectivity and the study of human lived experience. Albany, New York Press.

Raaij, W. F. v. and G. Antonides (2002). Consumentengedrag. Een sociaalwetenschappelijke benadering( Consumer behavior. A social science approach) Utrecht, Lemma.

Ray, P. H. and S. R. Anderson (2000). The cultural creatives; how 50 million people are changing the world. New York, Harmony Books.

Rees, W. E. (1998). Reducing the ecological footprint of consumption. The business of consumption. Environmental ethics and the global economy. L. Westra and P. H. Werhane. Lanham, Rowman and Littlefield: 113-130.

Ritzer, G. (1993). The McDonaldization of society. Thousand Oaks, Pine Forge Press.

Ritzer, G. (2000). Modern sociological theory. Boston, Mcgraw Hill.

Rubin, L. B. (1976) Pijn en moeite; hoe arbeidersgezinnen leven(Worlds of Pain: Life in the Working-Class Family) Baarn, Ambo-herdruk.

Rubin, L. B. (1995). Armoede; gezinnen op de armoede grens (Families on the fault line). Baarn, Ambo.

Rudmin, F. W. and W. E. Kilbourne (1996). The meaning and morality of voluntary simplicity. History and hypotheses on deliberately denied materialism. Consumption and marketing macro dimensions. R. W. Belk, N. Dholakia and A. Venkatesh. Cincinnati, South-Western College Publishing: 166-215.

Sachs, J. (2007). Het einde van de armoede; hoe we dit doel binnen twintig jaar kunnen bereiken (The end of poverty: economic possibilities for our time). Rotterdam, Lemniscaat.

Salzman, A. (1992). Downshifting Reinventing success on a slower track. New York, Harper Perennial. 
Salzman, A. (1992). Downshifting. Reinventing succes on a slower track. New York, HarperPerennial.

Schama, S. (1988). Overvloed en onbehagen. De Nederlandse cultuur in de Gouden Eeuw (Abundance and discomfort. Dutch culture in the Golden Age). Amsterdam, Contact.

Schlosser, E. (2002). Fast food nation. The dark side of the all-american meal. New York, Houghton Mifflin.

Schlosser, E. (2003). Refer madness; sex, drugs, and cheap labor in the american black market. Boston- New York, Houghton Mifflin company.

Schmidt, T. and A. D. Postma (1999). Minder energiegebruik door een andere leefstijl? (Less energy use by another lifestyle?). Project Perspectief, december 1995-juni 1998. Eindrapportage. Den Haag, Ministerie van Volkshuisvesting, Ruimtelijke Ordening en Milieubeheer.

Schonberg, A. v. (2006). Die kunst des stilvollen verarmens; wie man ohne geld reich wird (The art of stylish impoverishment, getting rich without money?) Berlin, Rowohlt Taschenbuch Verlag.

Schor, J. B. (1991). The overworked American. The unexpected decline of leisure. New York, Basic Books.

Schor, J. B. (1998). The overspent American. Upscaling, downshifting, and the new consumer. New York, Basic books.

Schor, J. B. (2004). Born to buy. The commercialized child and the new consumer culture. New York, Scribner.

Schor, J. B. (2008). "Understanding the child consumer." Journal of the American Academy of Child \& Adolescent Psychiatry 47(5): 486-490.

Schor, J. B. and D. B. Holt (2000). The consumer society reader. New York, New Press.

Schor, J. B., S. Jhally, et al. (2003). The overspent American. Why we want what we don't need. New York, The Media Education Foundation.

Schor, J. B. and B. Taylor, Eds. (2002). Sustainable planet. Solutions for the twenty-first century. Boston, Beacon Press.

Schreurs, J., Martens, P., Kok, G. (2010). "Out of sight, into the political arena and beyond: Consumer studies in historic epistemic perspective"; Submitted to : Journal of Historical Research in Marketing as contribution for a special issue on 'The evolution of Key Marketing Concepts' (April 2010).

Schreurs, J., Martens P., Kok, G. (2009). "Frugality as a core Principle in Postmodern Consumer Society"; Reviewed twice; Journal of Marketing Theory (April 2010)

Schreurs, J., Martens P., Kok, G. (2010). "Living with less as a Transformation Process: Existential phenomenological Study of Consumer Behaviour Reform". In review; Journal of Qualitative Market Research (Apreil 2010).

Schreurs, W. (1989). Geschiedenis van de reclame in Nederland 1870-1990 (History of advertising in The Netherlands). Utrecht, Het Spectrum.

Schumacher, E. F. (1989). Small is beautiful. Economics as if people mattered. New York, HarperPerennial.

Schumpeter, J. A. (1955). History of Economic Analysis. London, Allen \& Unwin.

Schumpeter, J. A. (1976). Capitalism, socialism \& democracy. London, Routledge.

SCP (2009). Armoedemonitor 2007 (Poverty monitor). Den Haag, Sociaal en Cultureel Planbureau. 
Segal, J. M. (1999). Graceful simplicity. Toward a philosophy and politics of simple living. New York, Holt.

Sen, A. (1993). Christopher Bliss: Life-style and the standard of living. Commentary. The quality of life. M. Nussbaum and A. Sen. Oxford, Clarendon Press: 437-444.

Shaw, D. and T. Newholm (2002). "Voluntary simplicity and the ethics of consumption." Psychology \& Marketing 19(2): 167-185.

Sheldon, K. M., T. Kasser, et al. (2005). "Doing one's duty: Chronological age, felt autonomy, and subjective well-being." European Journal of Personality 19(2): 97-115.

Sheldon, K. M., R. M. Ryan, et al. (2004). "The independent effects of goal contents and motives on well-being: It's both what you pursue and why you pursue it." Personality and Social Psychology Bulletin 30(4): 475-486.

Shoham, A. and M. M. Brencic (2004). "Value, price consciousness, and consumption frugality. An empirical study." Journal of International Consumer Marketing 17(1): 55-69.

Simmel, G. (1971). Social types. Georg Simmel. On Individulaity and social forms. D. N. Levine. Chicago, University of Chicago Press: 141-189.

Simmel, G. (1977). Philosophie des Geldes (Philosophy of money). Berlin, Duncker \& Humblot.

Simmel, G. (1997a). Sociology of the meal. Simmel on culture. D. Frisby and M. Featherstone. London, Sage: 130-135.

Simmel, G. (1997b). The metropolis and mental life. Simmel on culture. D. Frisby and M. Featherstone. London, Sage: 174-185.

Simmel, G. (1997c). The philosophy of fashion. Simmel on culture. D. Frisby and M. Featherstone. London, Sage: 187-206.

Smith, A (1776/1937) The Wealth of Nations, New York: Random-House.

Spaargaren, G. (2001). Milieuverandering en het alledaagse leven(Environmental change and everyday life). Tilburg, Katholieke Universiteit Brabant.

Spaargaren, G. (2003). "Sustainable consumption: a theoretical and environmental policy perspective." Society and natural resources(16): 687-701.

Spaargaren, G., T. Beckers, et al. (2002). Gedragspraktijken in transitie. De Gedragspraktijkenbenadering getoetst in twee gevallen: duurzaam wonen en duurzame toeristische mobiliteit(Behaviour practices in transition. The behaviour practices approach tested in two cases: sustainable housing and sustainable tourist mobility). Tilburg, Globus.

Spaargaren, G. and B. van Vliet (2000). "Lifestyles, consumption and th environment:

The ecological modernization of domestic consumption." Environmental Politics 9(1): 50-76.

St James, E. (2002). Rijkdom van de eenvoud (Living the Simple life). Rijswijk, Elmar B.V. Staats, H., Harland, P., \& Wilke, H. A. M (2004). "Effecting Durable Change. A Team Approach to Improve Environmental Behavior in the Household" Environment and Behavior (36): 341-367.

Strasser, S. (2003). "The alien past. Consumer culture in historical perspective." Journal of Consumer Policy (26): 375-393. 
Tawney, R. H. (1938). Religion and the rise of capitalism. A historical study. Harmondsworth, Penguin Books.

Tawney, R. H. (1964). Equality. London, Allen and Unwin.

Tawney, R. H. (1982). The acquisitive society. Brighton, Wheatsheaf Books.

Taylor, B. (2003). What kids really want that money can't buy. Tips for parenting in a commercial world. New York, Warner Books.

Thaler, R. H. (1981). "An economic theory of self-control." Journal of Political Economy 89(2): 392-406.

Thaler, R. H. (1994). "Psychology and savings policies." The American Economic Policies 84(2): 186-192.

Thomas, D. (2008). Deluxe; Hoe luxeartikelen hun glans verliezen (How luxury lost its luster). Amsterdam, Forum

Thompson, C. J. (2004). "Marketplace mythology and discourses of power." Journal of Consumer Research 31(June): 162-180.

Thompson, C. J. (2004). "Natural health's narratives of healing and the ideological production of consumer resistance." The Sociological Quarterly 44(Winter): 81-108.

Thompson, C. J. and E. C. Hirschman (1995). "Understanding the socialized body. A poststructuralist analysis of consumers' self-conceptions, body images, and self-care practices." Journal of Consumer Research 22: 139-153.

Thompson, C. J., W. B. Locander, et al. (1989). "Putting consumer experience back into consumer research. The philosophy and method of existentialphenomenology." Journal of Consumer Research 16(2): 133-146.

Thoreau, H. D. (1854/1961). Walden. New York, The New American Library.

Todd, S. and R. Lawson (2003). "Towards an understanding of frugal consumers." Australian Marketing Journal 11(3): 8-18.

UNDP (1998). Human Development Report 1998: Consumption for Human Development. Retrieved 12-15- 2009, from: http://hdr.undp.org/en/media/hdr_1998_en_overview.pdf.

Van Veen, P. A. F. and N. Van der Sijs (1997). Etymologisch woordenboek. De herkomst van onze woorden (Etymologic dictionary. The origin of our words).Utrecht, Van Dale Lexicografie.

Vaughan, D. (1990). Uncoupling. Turning points in intimate relationships. New York, Vintage Books.

Veblen, T. (1948). The theory of the leisure class. The portable Veblen. M. Lerner. New York, The Viking Press: 53-214.

Vlek, C. and B. Gatersleben (1995). Consumptiegroei en consumptiebeheersing. Op zoek naar duurzame kwaliteit (Consumption growth and consumption control. In search for sustainable quality). Verslavend lekker en nooit genoeg. Over consumptiemotieven in deze tijd. G. v. Dijk and G. Potman. Kampen, Kok Agora: 62-98. 
Waagmeester, K. (2006). De wereld en ik; (The world and I) dossier Jan Juffermans/ Ik en de wereld; het verhaal van Bold en Janine (Me and the world; the story of Bold and Janine). Rotterdam, Lemniscaat.

Weatherill, L. (1993). The meaning of consumer behaviour in late seventeenth- and early eighteenth-century England. Consumption and the world of goods. J. Brewer and R. Porter. London, Routledge: 206-228.

Weber, M. (1976). Wirtschaft und Gesellschaft (Economy and society). Tübingen, Mohr.

Weber, M. (1987). Over klassen, standen en partijen (About classes, status and parties). Kampen, Kok Agora.

Weber, M. (2002). The protestant ethic and the spirit of capitalism. Los Angeles, Roxbury.

Webley, P. and E. K. Nyhus (2006). "Parents' influence on children's future orientation and saving." Journal of Economic Psychology \& Marketing 27: 140-164.

Wilk, R. R. (1996). Economies \& cultures. Foundations of economic anthropology. Boulder, Westview press.

Wilk, R. R. (1996) "Emulation and global consumerism. Publication version." Retrieved 28-09-2007, from http://www.indiana.edu/ wanthro/nrc2.html.

Wilk, R. R. (2000). Being transdisciplinary. Retrieved 02-08-2004, from http://dizzy.library.arizona.edu/ej/jpe/transdisciplinarity.htm

Wilk, R. R. (2001). "Consuming morality." Journal of Consumer Culture 1(2): 245-260.

Wilk, R. R. (2002). "It's destroying a whole generation". Television and moral discourse in Belize. The anthropology of media. A reader. K. Askew and R. R. Wilk. Malden, Blackwell: 286-298.

Wilk, R. R. (2004). Morals and metaphors. The meaning of consumption. Elusive consumption. K. Ekström and H. Brembeck. Oxford, Berg: 11-26.

Witkowski, T. H. (in press). "A brief history of frugality discourses in the United States." Consumption, Markets and Culture (forthcoming 2010).

Worldwatch (2007). Vital signs 2007 - 2008. New York, Worldwatch Institute.

Worldwatch Institute (2004). State of the World 2004: The Consumer Society. New York.

Xenophon "Oikonomikos [English translation]." Retrieved 15-09-2009, from http://stuff.mit.edu/afs/athena/course/21/21h.401/www/local/xenophon_oi konomikos.html.

Yamauchi, K. T. and D. I. Templer (1982). "The development of a money attitude scale." Journal of Personality Assessment 46(5): 522-528.

Young, W., K. Hwang, et al. (2004, April). Understanding individual decision-making for sustainable consumption. International Workshop on Driving Forces and Barriers to Sustainable Consumption, University of Leeds, Leeds Institute for the Environment.

Zavestoski, S. (2002). "The social-psychological bases of anticonsumption attitudes." Psychology \& Marketing 19(2): 149-165. 


\section{APPENDIX}

\section{Survey: The Genoeg Readers Study (2007)}

\section{Part 1 Background Information}

1. What is your date of birth? $\square \square \square \square$ 2. What is your gender? $\square$ Male $\square$ Female

3. What are the 4 numbers in your postal code?

4. What is your current or highest level of education?

$\square$ No education $\square$ Elementary school

$\square$ LBO / VMBO (Preparatory Secondary Vocational Education)

MBO (Senior Secondary Vocational Education and Training)

$\square$ HAVO / VWO (Senior Secondary Education/ University Preparatory Education)

HBO (Higher Professional education)

WO (Research-oriented higher education/university)

Other, namely...

$\square$ No answer

5. What is your family and household composition?

$\square$ Single without children

$\square$ Single with $\square$ (number) children

$\square$ Couple / cohabitating without children

$\square$ Couple / cohabitating with $\square$ (number) children

$\square$ Cooperative housing project with $\square$ (number) persons

Other, namely...

No answer

6. How do you earn your living? Multiple answers possible

Freelance work, namely.....

Salary

Pension / early retirement

Scholarship

Social benefits

$\square$ Unemployment benefits

WAO (Occupational Disability Insurance Act)

Income from parents/relative

Income from partner

Equity

No income

Other, namely...

$\square$ No answer

7. Are you engaged in paid employment?

Yes (Go to question 8)

No, I do unpaid activities (care of household, volunteering etc.) (Go to question 9)

No, I do not work 
8. How many paid hours per week do you work?

$\square$ Less than 10 hours

Between 10 and 20 hours

Between 20 and 30 hours

Between 30 and 40 hours

More than 40 hours

9. What kind of unpaid activities do you do? Multiple answers possible

$\square$ Housekeeping $\square$ Child care $\square$ Elderly care

Volunteer in the one of the following sectors

$\square$ Religious organization $\square$ Nature / environment

$\square$ Social work $\square$ Education $\square$ Sport and Fitness

$\square$ Culture $\square$ Welfare and care $\square$ Elsewhere ...

Other, namely...

No answer

10. How many hours per week do you engage in unpaid activities?

(Not included in the Living with Less study)

11. Is religion or spirituality important to you?

$\square$ Important $\square$ Not important

12. Which organizations or institutions do you support with a charitable donation(s) and/or membership? (Not included in the Living with Less study)

Part 2 Opinions about the magazine Genoeg (Not included in the Living with Less study)

\section{Part 3 Finances and lifestyle}

34. What is your average net household income per month*?

*This means the amount remaining after tax deduction that you can spend (possibly in addition to incomes of other (s) with whom you share the household).

$\square$ Less than $€ 900$ per month

$\square$ Between $€ 900$ and $€ 1,250$

$\square$ Between $€ 1,250$ and $€ 1,850$

Between $€ 1,850$ and $€ 3,050$

Between $€ 3050$ and $€ 5000$

More than $€ 5,000$

35 Did you, at some point in your life, deliberately reduce your expenditure pattern?

$\square$ Yes (Go to question 36)

No (Go to question 43)

36 What was the situation with respect to your household income when you started reducing your expenditure pattern?

$\square$ There was more income (Go to question 39)

There was less income (Go to question 38)

The income was unchanged (Go to question 39) 
The fact that you and your household received less income may have occurred because of resignation, retirement or divorce. However, it could have also been a choice. This is the theme of the next question.

37 What was the reason for the decrease in the average net monthly household income?

Multiple answers possible

$\square$ Voluntary choice $\square$ Dismissal (also part-time)

$\square$ (Early) retirement or pension $\square$ Social welfare

$\square$ Reduction of benefits $\square$ Illness

$\square$ Savings exhausted $\square$ T ermination of child allowance

$\square$ Divorce $\square$ Debt repayment

Other, namely ...

No answer

38. Did you reduce your expenditure pattern because you wanted to pay off debt?

$\square$ Yes $\square$ No

$\square$ Not applicable

$\square$ No answer

39. Did you reduce your expenditure pattern because you wanted to save more?

$\square$ Yes $\square$ No

$\square$ Not applicable

No answer

40. When you consciously reduced your expenditure pattern, by how much did you reduce expenses per month?
$\square$ Less than $€ 100$
Between $€ 100$ and $€ 250$
Between $€ 250$ and $€ 500$
$\square$ Between $€ 500$ and $€ 1000$
$\square$ Between $€ 1000$ and $€ 1500$
$\square$ More than $€ 1500$, namely......
Don't know / no answer

41. When you consciously reduced your expenditure pattern, did you spend less, more or the same on the following items?

Food:

$\square$ Less $\square$ More $\square$ The same $\square$ Not applicable $\square$ No answer

Clothing:

$\square$ Less $\square$ More $\square$ The same $\square$ Not applicable $\square$ No answer

Restaurants/Cafes:

$\square$ Less $\square$ More $\square$ The same $\square$ Not applicable $\square$ No answer

Holidays:

Charities:

Saving:

Debt repayment:

Gifts:

Hobbies:

Impulse purchases:

Furniture:

$\square$ Less $\square$ More $\square$ The same $\square$ Not applicable $\square$ No answer

$\square$ Less $\square$ More $\square$ The same $\square$ Not applicable $\square$ No answer

$\square$ Less $\square$ More $\square$ The same $\square$ Not applicable $\square$ No answer

$\square$ Less $\square$ More $\square$ The same $\square$ Not applicable $\square$ No answer

$\square$ Less $\square$ More $\square$ The same $\square$ Not applicable $\square$ No answer

Books, CDs:

$\square$ Less $\square$ More $\square$ The same $\square$ Not applicable $\square$ No answer

$\square$ Less $\square$ More $\square$ The same $\square$ Not applicable $\square$ No answer

Theatre and concerts:

$\square$ Less $\square$ More $\square$ The same $\square$ Not applicable $\square$ No answer

$\square$ Less $\square$ More $\square$ The same $\square$ Not applicable $\square$ No answer

Housing:

$\square$ Less $\square$ More $\square$ The same $\square$ Not applicable $\square$ No answer

Energy:

$\square$ Less $\square$ More $\square$ The same $\square$ Not applicable $\square$ No answer

$\square$ Less $\square$ More $\square$ The same $\square$ Not applicable $\square$ No answer 
Transportation: $\quad \square$ Less $\square$ More $\square$ The same $\square$ Not applicable $\square$ No answer

Other, namely... $\quad \square$ Less $\square$ More $\square$ The same $\square$ Not applicable $\square$ No answer

The next two questions concern your positive and negative experiences with consciously reducing expenses. If you did not have any positive or negative experiences, please select 'not applicable'.

42. When you consciously reduced your expenditure pattern, what positive experiences did you have?

$\square \mathrm{N} / \mathrm{A}$

1. The most positive experience was...

2. Another positive experience was...

3. Furthermore, the following was a positive experience...

43. When you consciously reduced your expenditure pattern, what positive experiences did you have?

$\square \mathrm{N} / \mathrm{A}$

1. The most negative experience was...

2. Another negative experience was...

3. Furthermore, the following was a negative experience...

44. To what extent do you agree or disagree with the following statements?

1. If you take good care of your possessions, you will definitively save money in the long run.

$\square$ Strongly agree $\square$ Agree $\square$ Neutral $\square$ Disagree $\square$ Strongly disagree $\square$ No answer

2. There are many things that are normally thrown away that are still quite useful.

$\square$ Strongly agree $\square$ Agree $\square$ Neutral $\square$ Disagree $\square$ Strongly disagree $\square$ No answer

3. Making better use of my resources makes me feel good.

$\square$ Strongly agree $\square$ Agree $\square$ Neutral $\square$ Disagree $\square$ Strongly disagree $\square$ No answer

4. If you can re-use an item you already have, there's no sense in buying something new.

$\square$ Strongly agree $\square$ Agree $\square$ Neutral $\square$ Disagree $\square$ Strongly disagree $\square$ No answer

5 . I believe in being careful in how I spend my money.

$\square$ Strongly agree $\square$ Agree $\square$ Neutral $\square$ Disagree $\square$ Strongly disagree $\square$ No answer

6. I discipline myself to get the most from my money.

$\square$ Strongly agree $\square$ Agree $\square$ Neutral $\square$ Disagree $\square$ Strongly disagree $\square$ No answer

7. I am willing to wait on a purchase I want so that I can save some money.

$\square$ Strongly agree $\square$ Agree $\square$ Neutral $\square$ Disagree $\square$ Strongly disagree $\square$ No answer

8. There are things I resist buying today so I can save for tomorrow.

$\square$ Strongly agree $\square$ Agree $\square$ Neutral $\square$ Disagree $\square$ Strongly disagree $\square$ No answer

9. Compared with others in my environment, I am disciplined with money and make less impulse purchases.

$\square$ Strongly agree $\square$ Agree $\square$ Neutral $\square$ Disagree $\square$ Strongly disagree $\square$ No answer

10. I try to live as my own life as much as possible and ignore other peoples' views.

$\square$ Strongly agree $\square$ Agree $\square$ Neutral $\square$ Disagree $\square$ Strongly disagree $\square$ No answer

45. The following is a list of 35 activities. Please indicate how often you do each activity?

\section{A PURCHASING}

1. I buy socially responsible products.

$\square$ Always $\square$ Frequently $\square$ Occasionally $\square$ Rarely $\square$ Never $\square$ Not applicable $\square$ No answer

2. I buy environmentally-friendly products.

$\square$ Always $\square$ Frequently $\square$ Occasionally $\square$ Rarely $\square$ Never $\square$ Not applicable $\square$ No answer 
3. I buy second hand products.

$\square$ Always $\square$ Frequently $\square$ Occasionally $\square$ Rarely $\square$ Never $\square$ Not applicable $\square$ No answer 4. I dumpster dive.

$\square$ Always $\square$ Frequently $\square$ Occasionally $\square$ Rarely $\square$ Never $\square$ Not applicable $\square$ No answer 5. I buy from the local store.

$\square$ Always $\square$ Frequently $\square$ Occasionally $\square$ Rarely $\square$ Never $\square$ Not applicable $\square$ No answer 6 . I buy my groceries at the discount supermarket.

$\square$ Always $\square$ Frequently $\square$ Occasionally $\square$ Rarely $\square$ Never $\square$ Not applicable $\square$ No answer

\section{B FOOD}

1. I buy organic food.

$\square$ Always $\square$ Frequently $\square$ Occasionally $\square$ Rarely $\square$ Never $\square$ Not applicable $\square$ No answer

2. I eat meat.

$\square$ Always $\square$ Frequently $\square$ Occasionally $\square$ Rarely $\square$ Never $\square$ Not applicable $\square$ No answer

3. I cook from scratch, instead of using pre-made meals.

$\square$ Always $\square$ Frequently $\square$ Occasionally $\square$ Rarely $\square$ Never $\square$ Not applicable $\square$ No answer

4. I eat local food products (produced within 50 kilometers of my home).

$\square$ Always $\square$ Frequently $\square$ Occasionally $\square$ Rarely $\square$ Never $\square$ Not applicable $\square$ No answer

5. I eat fish.

$\square$ Always $\square$ Frequently $\square$ Occasionally $\square$ Rarely $\square$ Never $\square$ Not applicable $\square$ No answer

\section{LEISURE}

The following questions are about how you spend your free time. Would you please indicate how much time, on average, you engage in the following activities? Multiple answers possible

1. Watching television

$\square$ Always $\square$ Frequently $\square$ Occasionally $\square$ Rarely $\square$ Never $\square$ Not applicable $\square$ No answer

2. Reading

$\square$ Always $\square$ Frequently $\square$ Occasionally $\square$ Rarely $\square$ Never $\square$ Not applicable $\square$ No answer

3. Sport/exercise

$\square$ Always $\square$ Frequently $\square$ Occasionally $\square$ Rarely $\square$ Never $\square$ Not applicable $\square$ No answer

4. Walking or biking

$\square$ Always $\square$ Frequently $\square$ Occasionally $\square$ Rarely $\square$ Never $\square$ Not applicable $\square$ No answer

5. Meditation or prayer

$\square$ Always $\square$ Frequently $\square$ Occasionally $\square$ Rarely $\square$ Never $\square$ Not applicable $\square$ No answer

6. Shopping

$\square$ Always $\square$ Frequently $\square$ Occasionally $\square$ Rarely $\square$ Never $\square$ Not applicable $\square$ No answer

7. Personal growth and education

$\square$ Always $\square$ Frequently $\square$ Occasionally $\square$ Rarely $\square$ Never $\square$ Not applicable $\square$ No answer

8. Social contacts

$\square$ Always $\square$ Frequently $\square$ Occasionally $\square$ Rarely $\square$ Never $\square$ Not applicable $\square$ No answer

9. Entertainment

$\square$ Always $\square$ Frequently $\square$ Occasionally $\square$ Rarely $\square$ Never $\square$ Not applicable $\square$ No answer 10. Traveling

$\square$ Always $\square$ Frequently $\square$ Occasionally $\square$ Rarely $\square$ Never $\square$ Not applicable $\square$ No answer 11. Gardening

$\square$ Always $\square$ Frequently $\square$ Occasionally $\square$ Rarely $\square$ Never $\square$ Not applicable $\square$ No answer 


\section{ENVIRONMENT}

1. I ignore advertising (print).

$\square$ Always $\square$ Frequently $\square$ Occasionally $\square$ Rarely $\square$ Never $\square$ Not applicable $\square$ No answer

2. I recycle glass, paper and cans.

$\square$ Always $\square$ Frequently $\square$ Occasionally $\square$ Rarely $\square$ Never $\square$ Not applicable $\square$ No answer

3. I compost my organic waste.

$\square$ Always $\square$ Frequently $\square$ Occasionally $\square$ Rarely $\square$ Never $\square$ Not applicable $\square$ No answer

4. I conserve energy.

$\square$ Always $\square$ Frequently $\square$ Occasionally $\square$ Rarely $\square$ Never $\square$ Not applicable $\square$ No answer

5. I bring unnecessary items to the second hand store.

$\square$ Always $\square$ Frequently $\square$ Occasionally $\square$ Rarely $\square$ Never $\square$ Not applicable $\square$ No answer 6. I compensate for the carbon emissions (car and air travel) by, for example, contributing to the planting of trees.

$\square$ Always $\square$ Frequently $\square$ Occasionally $\square$ Rarely $\square$ Never $\square$ Not applicable $\square$ No answer

\section{E. DO-IT-YOURSELF}

1. I sew.

$\square$ Always $\square$ Frequently $\square$ Occasionally $\square$ Rarely $\square$ Never $\square$ Not applicable $\square$ No answer

2. I grow my own vegetables.

$\square$ Always $\square$ Frequently $\square$ Occasionally $\square$ Rarely $\square$ Never $\square$ Not applicable $\square$ No answer

3. I do my own home maintenance.

$\square$ Always $\square$ Frequently $\square$ Occasionally $\square$ Rarely $\square$ Never $\square$ Not applicable $\square$ No answer

\section{F MOBILITY}

The following questions are about transportation (how you get to work, the grocery store, visiting friends and family, going on holidays).

1. How often you use the car?

$\square$ Always $\square$ Frequently $\square$ Occasionally $\square$ Rarely $\square$ Never $\square$ Not applicable $\square$ No answer

2. How often do you use public transportation?

$\square$ Always $\square$ Frequently $\square$ Occasionally $\square$ Rarely $\square$ Never $\square$ Not applicable $\square$ No answer

3. How often you use a bike?

$\square$ Always $\square$ Frequently $\square$ Occasionally $\square$ Rarely $\square$ Never $\square$ Not applicable $\square$ No answer

4. How often do you travel by plane?

$\square$ Always $\square$ Frequently $\square$ Occasionally $\square$ Rarely $\square$ Never $\square$ Not applicable $\square$ No answer

The final question:

46 Do you consider yourself to be a consuminderaar (someone who consumes less)?

Yes, because...

No, because... 


\section{Summary}

The 20th century's unprecedented growth of consumption puts a strain on the environmental resources and aggravates social and economic inequalities. The costs that come with consumerism and the consumerist lifestyle, despite its attractions, are rising substantially. Concurrently, risks are increasing: in personal life because of prohibitive debts, stress illnesses or impoverishment; at a global scale because of climate change, and social and political instability as a result of the growing gap between rich and poor.

It is now commonly accepted that a more eco-friendly way of living is required in order to save the planet. Also there is increasing support for the idea of limiting consumption to stop the depletion of earth resources. Therefore, studying people who actually try to reduce consumption could be very informative. Knowledge regarding experiences with downshifting and voluntary lifestyle changes might reveal new perspectives on sustainability and fuel the discussion on the consumerist lifestyle. What does it mean to reduce expenses? What does it mean to have a smaller carbon footprint in a social-cultural environment that constantly encourages people to spend money? How can living with less money support sustainability? Answers to these questions are indispensable if sustainable development is to be successful.

The aims of this dissertation are to contribute to a better understanding of how reduced means impact consumer behaviour within the context of consumerism and today's consumption society. Further, findings are expected to contribute to a better understanding of the rise of new consumer movements such as downshifters and simplifiers. Finally, this study seeks to identify new prospects for sustainable living.

\section{Chapter 1}

Chapter one starts with a brief description of the development of consumerism and its dissemination over the world. The popularity of the consumerist lifestyle is explained from sociological, psychological and economic perspectives. Further, two socialcultural innovation movements are explored, which are considered to be reactions on the negative aspects of consumerism: a) Downshifting and b) The sustainability movement.

The description of the social-cultural context of the study is followed by a clarification of the academic context of the study. Obviously, the issue of living with less should be examined within the context of consumer studies, which is interpreted a collective term comprising studies on consumption and consumer behaviour. Another important academic context is the environmental studies. Finally, four categories of studies of living with less are discussed, each characterized by a specific precept with regard to living with less that determines the intellectual frame of reference for the study.

It is argued that academic attention for the issue of living with less is not only rather limited; in the relatively few studies at hand living with less is associated, moreover, 
with a social, political, environmental or cultural problem. Consequently, the issue is polarized either as a problem cause or problem solution.

Therefore this dissertation seeks to examine the interconnectedness of consumerism, downshifting, frugality and sustainability beyond the common conceptual framework. Hereby Simmel's sociological theory and phenomenological theory provided an important inspiration for the epistemological framework for the study. His dialectical approach and concern with interactions between opposed phenomena laid the foundation for our analysis of living with less. Further we considered the phenomenological approach to be most appropriate for our explorative empirical studies, because it focuses on registering experiences and concrete behaviour, which we considered most useful to meet academic standards of factuality and accountability.

Then, the theoretical frame of reference is elaborated; thereby illuminating the multidisciplinary positioning and conceptualization. The first chapter concludes with an overview of the central research questions and an outline of the dissertation.

\section{Chapter 2}

Since in consumer studies comparatively little attention has been paid to the topic of living with less, the starting point of this dissertation was to study the fundamental question of how and under which conditions has thinking about consumption developed in the past 150 years. The epistemic development of consumer studies is analyzed on the basis of the changed meaning of its core concepts of 1) Social stratification; 2) Consumption; and 3) The prevailing images of the consumer in consumer studies. Hereby, the thesis is examined that consumption and consumer behaviour are predominantly studied outside the social, cultural and historical context, thus studied using a decontextualised approach. Simultaneously, and probably as a result of this epistemic process, consumer studies have entered the political arena. The politicization of the discipline is elaborated and the impact on recent trends in consumer studies as well as on the prevailing paradigms is discussed.

The chapter concludes with a discussion of recent trends in consumer studies and suggests the use of an integrated approach to guarantee for a more fruitful theory development.

\section{Chapter 3}

In this chapter is explored how frugality is conceptualized, expressed and manifested in postmodern consumer society, as well as its influence on the epistemic view of consumer studies. The central focus in this cultural philosophical study is frugality's dichotomous nature, exemplified by the duality of virtue and vice but expressed in a range of oppositional connotations. Firstly, an explorative study is made to illustrate how frugality is manifested in public policy; in consumption and consumer behaviour; and in marketing. Further, the effects are discussed of the dual nature of frugality on 
the epistemic view in empirical studies. Three areas of research are investigated in which frugality has received specific academic attention: 1) Frugality as the object of consumer studies 2) Frugality in environmental studies, 3) Studies of frugality and the 'new consumer'. It is concluded that the epistemic view mainly reflects the notion of frugality as form of deviancy.

In the final section the discussion is situated outside the context of postmodern consumer society. At this point the question of the dual nature of frugality is addressed from a theoretical historical perspective. Applying Gudeman \& Rivera's model of house economy and corporate economy as a frame of reference, we discuss the development of thinking on frugality in classic philosophy, medieval religious thought, Enlightenment economics and philosophy and in modern economics. A turning point in a rather homogenous narrative of frugality is noted with the rise of a capitalistic market economy as an economic sphere distinct from the home economy. Evidently, the marketing vocabulary and strategies are translated into the 'language' of the house economy because frugality continues to be the main principle in the domain of the house economy.

Instead of explaining frugal or non frugal consumer practices in terms of subjective consumer motives such as hedonism, anti-materialism, being old fashioned or being ethical, it is argued that the discussion could better be situated in a structuralfunctional perspective to overcome the dichotomous approach which continues to influence the epistemic view of consumer research.

\section{Chapter 4}

Chapter four discusses the first empirical study of living with less. Using the phenomenological approach, consumer practices and behaviour after a financial decrease were explored as a process of consumer behavioural reform. Generally living with less is associated with a social, political or cultural problem. Results of this qualitative field study indicated a consistent pattern independent of voluntary or involuntary downshifting, or the amount of reduction. This led to the construction of a behavioural change model: The Transformation Model Living with Less. This transformation model is presented as an ideal typical sequence model for consumer behaviour change. Each stage is discussed according to the characteristics: event, action, barrier, and stimulus.

A striking result of the study was the finding that living with less was primarily an existential question instead of a purely financial matter. Consequently, reorganizing expenses meant reorganizing life. The study thus provides a multi layered picture of the process of living with less, integrating determinant aspects of consumption as a coherent whole. By determining which aspects of peoples' lives were affected by a substantial financial decrease, the study goes beyond single factor consumption studies, such as consumption and identity, consumption and social status or lifestyle studies. Furthermore, this study showed that the transformation process itself, appeared to be an important quality aspect as well. It is argued that the Transformation model Living with Less may offer an interesting direction for future 
research, either applied, or theoretical. Various implications for further theoretical study as well as the practical applicability are discussed.

\section{Chapter 5}

Chapter five presents the results of the second empirical study: a quantitative and qualitative study of downshifting in the Netherlands. Results of previous studies in U.S.A., Australia and Great Britain are discussed and induced to broaden the common definition of downshifting. In this study downshifters are quite simply defined as people who are living with less money than they did before, regardless of whether the change is voluntary or involuntary. In line with the field study, we focused on consumer practices, experiences and concrete behaviour rather than on motivations, feelings or intentions. As such, in the second empirical study of this dissertation again the phenomenological approach is applied. Demographic, social-cultural characteristics of downshifters are presented, as are extensive quantitative data on changed consumption practices and expenditures.

The qualitative section of the survey is an exploration of the participants' experiences with downshifting. Participant reports resulted in the categorization of nine positive and eight negative experiences. Thus contrary to popular belief, results suggest that spending less coincides with positive experiences. Further, findings suggest that, in the Netherlands, as in other parts of the world, voluntary downshifting is not a lifestyle choice exclusive to the social elite but rather an attractive way of life for people across social strata. Although the reported negative reactions from the social environment suggest that downshifting is still viewed as a deviant lifestyle.

The chapter ends with a discussion of the results for sustainability. As a frame of reference Callenbach's (2002) green triangle is applied, converted into the Dutch triple Gs of a sustainable lifestyle: geld (money), groen (eco-friendliness) and gezondheidwelzijn (health/wellbeing). It is concluded that downshifting can contribute to sustainability as this way of life fundamentally resonates with the three pillars of the Dutch triple Gs of a sustainable lifestyle. Downshifters tend to practice the re-use, reduce and recycle mantra of eco-friendly behaviour and are careful, resourceful spenders that find other values more important than those provided by materialism and consumerism. It seems that the positive experiences may also strengthen their attitude.

\section{Chapter 6}

The final chapter recapitulates the main conclusions drawn in this dissertation. The main findings are evaluated in the light of sustainability and opportunities are identified for sustainability in postmodern consumer culture and behaviour. It was found that frugality has not disappeared as a leading principle of postmodern consumer culture, but continues to be a vital cultural characteristic. The empirical findings of living with less money coincide with these theoretical findings. Results of 
the Transformation Model of Living with Less, as well as the negative experiences reported in our survey of Dutch downshifters, showed that although frugal behaviour is commonly practiced, it is often in disrepute and considered taboo.

Even so, it is hold that frugalizing is likely to be a more realistic option for sustainability than generally assumed. Further it is argued that living with less can promote sustainability either directly through reduced consumption or indirectly through a more fundamental transformation of lifestyle. Interventions that seek to direct consumer behaviour towards sustainability could be successful if the scope of analysis and strategy are expanded from mere financial solutions to non-material alternatives, and from promoting the consumption of the 'right' goods to providing the right conditions and circumstances.

This section closes with a list of recommendations for the promotion of a sustainable lifestyle and sustainable consumer behaviour.

We conclude with an evaluation of this research project, a short discussion of the limitations of the studies presented in this dissertation and suggestions for future research. 


\section{Samenvatting}

De ongeëvenaarde consumptietoename in de twintigste eeuw legt een zware druk op de natuurlijke hulpbronnen en verscherpt de sociale en economische ongelijkheid. Hierdoor zijn de kosten van het consumentisme en de consumptieve levensstijl sterk gestegen. Tevens nemen de risico's toe: in het persoonlijk leven als gevolg van onbetaalbare schulden, stress ziekten of verarming; en op wereldschaal als gevolg van de uitputting van natuurlijke hulpbronnen en klimaatverandering. Door de groeiende kloof tussen arm en rijk neemt bovendien de sociale en politieke instabiliteit toe. Het idee dat een meer eco-vriendelijke manier van leven nodig is om de planeet te redden is inmiddels algemeen accepteerd. Ook de opvatting dat consumptie beperkt moet worden om de uitputting van aardse hulpbronnen te stoppen, krijgt steeds meer aanhang.

In dit perspectief kan een studie van mensen die daadwerkelijk proberen hun consumptieniveau terug te brengen heel informatief zijn. Kennis over downshifting en vrijwillige wijzigingen in de consumptieve levensstijl kan een nieuwe impuls geven aan de discussie over de huidige consumptieve levensstijl en mogelijk aanknopingspunten bieden voor een meer duurzame leefstijl.

Wat betekent het om minder uit te geven aan consumptieve bestedingen? Wat betekent het om met een kleinere ecologische voetafdruk te leven in een sociaalculturele omgeving die voortdurend prikkelt om meer geld uit te geven? Hoe kan leven met minder geld bijdragen aan meer duurzaamheid? Antwoorden op deze vragen zijn essentieel om duurzame ontwikkeling succesvol te laten zijn .

Deze dissertatie wil een nieuw licht werpen op deze kwestie. De centrale vraag luidt dan ook: hoe kan consumptiebeperking, opgevat als leven met minder geld, bijdragen aan meer duurzaamheid? De studie beoogt meer inzicht te krijgen in de impact van financiële beperking op (consumptie)gedrag binnen de context van consumentisme en de consumptiemaatschappij. Verder is deze studie bedoeld om meer inzicht te krijgen in de opkomst van nieuwe consumentenbewegingen zoals downshifting en simpleliving. Het laatste oogmerk van deze dissertatie is om nieuwe mogelijkheden voor een duurzame leefstijl te identificeren.

\section{Hoofdstuk 1}

Het eerste hoofdstuk begint met een korte beschrijving van hoe het consumentisme zich heeft ontwikkeld en verspreid over de wereld. De populariteit van de consumptieve levensstijl wordt verklaard vanuit de sociologie, psychologie en economie. Vervolgens worden de twee sociaal-culturele vernieuwingsbewegingen besproken, die ontstaan zijn als reactie op de negatieve aspecten van het consumentisme: a) downhiften en b) De duurzaamheidsbeweging. Nadat de sociaal-culturele context van de studie is beschreven, volgt een schets van de 
wetenschappelijke context van de studie. Het spreekt voor zich dat het vraagstuk van leven met minder geld bestudeerd dient te worden binnen de consumer studies, de verzamelterm van studies naar consumptie en consumentengedrag. De tweede relevante wetenschappelijke context zijn de milieu-studies. En als laatste bespreken we de bestaande studies naar leven met minder, die al naar gelang de visie op leven met minder in vier categorieen verdeeld kunnen worden: 1) 'minder' gezien als armoede en deprivatie; 2) 'minder' als oplossing voor milieuproblematiek; 3)'minder' als reactie op overconsumptie; 4) 'minder' als moreel of religieus item. We concluderen dat in het betrekkelijk geringe aantal studies leven met minder geassocieerd wordt met een sociaal, politiek, ecologisch of cultureel probleem. De kwestie blijkt gepolariseerd - leven met minder wordt hetzij als probleem of als probleem oplossing gezien - en is bijgevolg gepolitiseerd.

Deze dissertatie beoogt het gebruikelijke conceptuele kader te overstijgen en richt zich daarom op de samenhang tussen consumentisme en zuinigheid en tussen downshiften en duurzaamheid. Simmel's sociologische theorie en fenomenologische theorie zijn een belangrijke inspiratiebron geweest voor het epistemologische kader. Zijn dialectiek en uitwerking van interacties tussen tegengestelde sociaal-culturele fenomenen zijn de grondslag voor de analyse van het hoofdthema. De fenomenologische benadering achten we het meest geschikt voor de exploratieve empirische onderzoeken, omdat deze zich richt op ervaringen en concreet gedrag. Vervolgens wordt het theoretische referentiekader verder uitgewerkt, met name wordt de multidisciplinaire positionering en beeldvorming toegelicht. Het eerste hoofdstuk wordt afgesloten met een overzicht van de centrale onderzoeksvragen en toelichting bij de opbouw van deze dissertatie.

\section{Hoofdstuk 2}

Aangezien in consumer studies relatief weinig aandacht is besteed aan het thema leven met minder, behandelt deze dissertatie als eerste de vraag: hoe en onder welke voorwaarden heeft het denken over consumptie zich ontwikkeld in de afgelopen 150 jaar? De epistemische ontwikkeling van de consumer studies wordt geanalyseerd aan de hand van de veranderde betekenis van de volgende kern-concepten: 1) Sociale stratificatie; 2) Consumptie; en 3) Het beeld van de consument. We onderzoeken de hypothese dat consumptie en consumentengedrag voornamelijk buiten de sociale, culturele en historische context zijn bestudeerd, dus vanuit een gedecontextualiseerde benadering. Tegelijkertijd, en waarschijnlijk als gevolg van dit epistemische proces zijn de consumer studies in de politieke arena beland. Deze politisering van de discipline wordt verder uitgewerkt. De effecten op de recente onwikkelingen in consumer studies, alsmede op de bestaande paradigma's worden besproken. We sluiten hoofdstuk twee af met een bespreking van de recente ontwikkelingen in consumer studies en met het voorstel van een geïntegreerde aanpak teneinde een meer vruchtbare theorie-ontwikkeling te garanderen. 


\section{Hoofdstuk 3}

In dit hoofdstuk wordt onderzocht hoe zuinigheid is geconceptualiseerd en zich manifesteert in de postmoderne consumptiemaatschappij. Verder wordt de invloed onderzocht op de epistemische visie binnen de consumer studies.

Deze cultuur- filosofische analyse focused op het tweeledige karakter van zuinigheid; exemplarisch is de dualiteit van deugd en ondeugd, die tot uitdrukking komt in een reeks van oppositionele connotaties. Als eerste is een verkennende studie gedaan die illustreert hoe zuinigheid manifest wordt in het openbaar bestuur (public policy), in consumptie en consumentengedrag en in marketing. Vervolgens bespreken we de effecten van het dichotome karakter van zuinigheid op de epistemische visie in empirische studies. Drie onderzoeksgebieden worden geanalyseerd, waarin zuinigheid specifieke wetenschappelijke aandacht heeft gekregen: 1) zuinigheid als object binnen consumer studies; 2) zuinigheid binnen milieu studies; 3 ) studies van zuinigheid en de 'nieuwe consument'. Geconcludeerd wordt dat de epistemische visie vooral de opvatting van zuinigheid als afwijkend gedrag weerspiegelt.

In het laatste deel van dit hoofdstuk, wordt de discussie geplaatst buiten de context van de postmoderne consumptiemaatschappij. De kwestie van het tweeledige karakter van zuinigheid wordt nu vanuit een theoretisch historisch perspectief bestudeerd. Als referentiekader gebruiken we Gudeman \& Rivera's model van de house economy versus de corporate economy. We bespreken de ontwikkeling van het denken over zuinigheid in de klassieke filosofie, het middeleeuwse religieuze denken, de verlichtings economie en - filosofie en in de moderne economische wetenschappen. We constateren een keerpunt in de betrekkelijk homogene geschiedenis van zuinigheid bij de opkomst van de kapitalistische markteconomie, als een nieuw economisch domein los van de house economy. Echter, het marketing vocabulaire en de strategieën worden vertaald in de 'taal' van de huis economie, omdat zuinigheid het belangrijkste principe blijft in het domein van de huis economie. We betogen dat in plaats van de motieven voor zuinige of niet-zuinige consument praktijken te verklaren in irrationele termen als hedonisme, anti-materialisme, ouderwets dan wel ethisch verantwoord, deze discussie beter gevoerd kan worden binnen een structureel-functioneel kader.

\section{Hoofdstuk 4}

Zoals we in Hoofdstuk 3 constateerden, wordt leven met minder gewoonlijk geassocieerd met problematiek van uiteeenlopende van aard. In het eerste empirische onderzoek is gekozen voor een fenomenologische onderzoeksaanpak teneinde de verschijnselen die samenhangen met leven met minder in beeld te kunnen brengen zoals ze zich voordoen, dus los van interpretatie. Hoofdstuk 4 behandelt dit explorerend veldonderzoek, waarin geregistreerd is welke veranderingen in consumptie praktijken en -gedrag zich voordoen na een substantiële daling van inkomen. We constateren dat het veranderingsproces een consistent patroon laat zien, 
onafhankelijk van factoren als vrijwilligheid of onvrijwilligheid of van de omvang van de inkomensdaling. Op grond hiervan construeren we een ideaaltypisch sequentiemodel van consumptiegedragsverandering: het Transformatie Model Leven met Minder. De stadia - zeven in totaal - worden besproken aan de hand van de kenmerken: gebeurtenis, actie, obstakel en stimulans.

Het onderzoek laat verder zien dat leven met minder eerder een existentieel vraagstuk is dan louter een financieel vraagstuk. Gebleken is dat het opnieuw organiseren van het uitgavenpatroon in belangrijke mate een reorganisatie van het leven impliceert. Aldus toont dit onderzoek een multi-dimensionaal beeld van het veranderingsproces van leven met minder en worden de aspecten die consumptiegedrag bepalen, geïntegreerd tot een samenhangend geheel. Daarmee gaat deze studie verder dan de consumptiestudies die zich richten op een enkele factor, zoals consumptie en identiteit, consumptie en sociale status of de lifestyle studies. We betogen dat het Transformatie Model Leven met Minder een interessante nieuwe richting kan geven aan toekomstig onderzoek. De verschillende mogelijkheden hiertoe worden aan het slot van dit hoofdstuk uitgewerkt zowel voor theoretisch onderzoek als voor praktijk gerichte studies.

\section{Hoofdstuk 5}

Hoofdstuk 5 presenteert de resultaten van het tweede empirische onderzoek van deze dissertatie: een kwantitatieve en kwalitatieve studie van downshiften in Nederland. Allereerst worden resultaten van studies naar downshiften in de Verenigde Staten, Australië en Groot-Brittannië besproken. Naar aanleiding hiervan komen we tot een bredere definitie van downshiften dan de gebruikelijke. In deze dissertatie worden downshifters eenvoudigweg gedefinieerd als mensen die leven met minder geld dan voorheen, ongeacht of deze verandering vrijwillig of onvrijwillig is. Evenals het veldonderzoek, richt ook de tweede empirische studie zich primair op consumptie praktijken, ervaringen en concreet gedrag en nauwelijks op motivaties, gevoelens of intenties. In die zin is wederom de fenomenologische benadering toegepast.

Demografische, financiële en sociaal-culturele kenmerken van downshifters worden gepresenteerd, evenals uitgebreide gegevens over wijzigingen in uitgaven en consumptiepraktijken. Verder is de attitude ten aanzien van zuinigheid gemeten met behulp van Lastovicka's zuinigheidsschaal. Het kwalitatieve deel van het onderzoek behelst een verkenning van de positieve en negatieve ervaringen van downshiften. Dit resulteerde in de categorisering van negen positieve en acht negatieve ervaringen.

In tegenstelling tot de communis opinio wijzen de resultaten erop dat minder uitgeven gepaard kan gaan met positieve ervaringen. Verder lijken de bevindingen te suggereren dat in Nederland, net als in andere delen van de wereld, vrijwillig downshiften als lifestyle keuze niet exclusief voorbehouden is aan de sociale elite, maar mogelijk ook een aantrekkelijke manier van leven kan zijn voor minder gefortuneerde sociale klassen. Daarintegen suggereren de negatieve reacties uit de sociale omgeving dat downshiften nog steeds gezien wordt als een afwijkende 
levensstijl. Ten slotte bespreken we de onderzoeksresultaten in het perspectief van duurzaamheid. Op basis van Callenbach's (2002) principe van de Groene Driehoek introduceren wij de Triple $G$ van de duurzame levensstijl met de drie pijlers: Geld, Groen en Gezondheid / welzijn. Geconcludeerd wordt dat downshiften kan bijdragen aan duurzaamheid aangezien deze levensstijl fundamenteel resoneert met de drie pijlers van de Nederlandse Triple G van een duurzame levensstijl. Downshifters zijn geneigd de re-use, reduce, recycle mantra van milieuvriendelijk gedrag te praktiseren, ze gaan zorgvuldig met hun geld om, zijn vindingrijke consumenten en ze vinden andere waarden belangrijker dan materialisme en consumptisme. De geconstateerde positieve ervaringen van downshiften kunnen hierbij versterkend werken.

\section{Hoofdstuk 6}

Het laatste hoofdstuk brengt de belangrijkste conclusies van deze dissertatie samen. De bevindingen worden geëvalueerd in het licht van duurzaamheid en tevens worden mogelijkheden geïdentificeerd voor duurzaamheid in de postmoderne consumptiecultuur en -gedrag.

Op basis van de theoretische studies constateerden we dat zuinigheid niet verdwenen is als sturend beginsel binnen de postmoderne consumptiecultuur; het blijkt daarentegen nog steeds een vitaal cultuur kenmerk te zijn. De empirische resultaten in deze dissertatie lijken in belangrijke mate congruent te zijn met deze theoretische bevindingen. Ook al wordt zuinig gedrag algemeen gepraktiseerd, het Transformatie Model Leven met Minder, evenals de negatieve ervaringen van Nederlandse downshifters, toonden aan dat het gedrag als zodanig verguisd is en in de taboesfeer zit.Toch betogen we dat zuiniger leven een realistischer optie voor duurzaamheid kan zijn dan algemeen verondersteld wordt. Verder betogen we dat leven met minder duurzaamheid kan bevorderen hetzij rechtstreeks door minder te consumeren, hetzij indirect door een meer fundamentele verandering van levenssstijl. Interventies om consumentengedrag te sturen richting duurzaamheid kunnen succesvol zijn mits de reikwijdte van analyse en strategie verruimd wordt van louter financiële oplossingen naar niet-materiële alternatieven, en van het promoten van de consumptie van de 'juiste' producten naar het verschaffen van de juiste condities en omstandigheden. In het laatste deel van deze dissertatie formuleren we aanbevelingen om een duurzame levensstijl en duurzaam consumptiegedrag te bevorderen.

Ten slotte evalueren we dit onderzoeksproject, bespreken we de beperkingen van de onderzoeken in deze dissertatie en doen we suggesties voor verder onderzoek. 


\section{Acknowledgments}

The vast grasslands of Mongolia are among the most beautiful scenes in the world.

I have never seen them with my own eyes, but this is not necessary to enjoy them. In my mind I have been there often, wandering through the endless, spacious world. Working on this dissertation was a similar experience. I could wander around intellectually in almost complete freedom. Moreover, in the past two years my agenda was nearly blank, so that even time seemed limitless. Seldom have I felt so free. Therefore working on this thesis has been one of the happiest periods in my life.

But the nomads of Mongolia never travel alone. My research- adventure could not have been successfully concluded if I had not been supported by others. Many people have done so, in various kinds of ways.

At the inception of this project stood Marius de Geus. He suggested a PhD-research, rather than the journalistic production we had talked about so far. Indeed, I am very grateful for his suggestion, although it implied that, in view of academic procedure, another supervisor had to be sought. I found two: Pim Martens, professor of sustainable development and Gerjo Kok, professor of social psychology, both at Maastricht University.

I am greatly indebted to Pim Martens for the fact that he 'adopted' this research project and was willing to give it his academic support. Our vivid discussions were highly stimulating. Illustrative of his boundless confidence in a successful completion is the mail he sent me, which included a photograph he had made at the American Museum of Natural History. It turned out to be a poster of a smiling Einstein. 'He once was a student too' was the caption... Allowing me to work at the ICIS office was invaluable as well, not only for its many facilities, but most of all for its true academic spirit. Thank you so much.

The sharp eye of the second promotor, Gerjo Kok, taught me always to question my ideas and assumptions. Comments that seemed to be made merely in passing showed me interesting intellectual paths and would slowly strike root. Moreover, he soon discovered my blind spot for figures, and he continued to remind me always to doublecheck these up to the final draft of this dissertation. For all this I would like to thank him very much. Besides I am very grateful to him for financing the work done by research office Flycatcher and various translations.

My ICIS colleagues showed me the ropes of many issues which were directly or indirectly relevant when working on a PhD research: basic knowledge of SPSS and other computer programs, principles of integrated assessment models, fundraising, presentation skills, printing and so on. Of even greater value was the colorful collection of specializations and nationalities they represent: this is what makes ICIS such an inspiring environment. For the heartwarming fellowship that I experienced over the 
past years I would like to thank particularly: Akua, Alvaro, Anja, Annemarie, Annet, Astrid, Carijn, Chia Chung, Chiung, Gert-Jan, Harro, January, Machiel, Marc, Maud, Mohsin, Nicole, Stefano, Su-Mia, Peter, Rene, Ron, Veronique.

The idea for an empirical study into Living with Less came to me when I was editor of the periodical Genoeg. I became fascinated with the diversity of its readers, in education and income, cultural background, religious denomination, geographical distribution and so on. Apparently birds of all kind of feather felt attracted to a more modest lifestyle, and this seemed to resonate within wider social-cultural developments both in other parts of Europe and in the U.S.A. I am very grateful to the publisher Uitgeverij Genoeg, and in particular to its new owner, Heleen van der Sanden, who immediately after she had bought the magazine, did her all to realize the magazine's share in the research project. She provided funding, managed the logistics of the survey among its readers and supported the dissemination of its results. Without her support the research for this dissertation would have been impossible. In this phase of the research project the magazine's editor Joke Reijnders also lent a highly qualified hand. Obviously the magazine's readers played the crucial role: because an unexpectedly high number took the trouble to fill in our lengthy questionnaires, the identity of the 'Dutch downshifters' could be recorded. I want to show my great appreciation for the commitment of this entire 'community' of Genoeg.

At the start of my field research Josh Moll volunteered in my testing of the interview methodology. She was my first guinea pig and took to this role in a very professional manner. Her analytical mind and her enthusiasm were a great help. I also owe many thanks to the other interviewees I met in this phase of the research project. All of them invested so much time and energy. Their courage to break the taboo of living with less and to share their personal experiences impressed me greatly. Other volunteers, including members of Zuinigheid met stijl, the Dutch foundation dedicated to simple living, have collaborated by testing the questionnaire of the survey. Jimmie Leppink and Mark Hanrath were indispensable in processing the data. I owe many thanks to research bureau Flycatcher, in particular Anneke de Jongh, Bram de Volder and especially Lieke Helmes, for their expertise and the pleasant cooperation.

I met many co-thinkers and co-readers as I went along. Running the risk of forgetting someone - for which I apologize in advance - I would like to thank especially: Jeroen van den Bergh, Ron Bernstein, Annemiek van Deurzen, Veronica Dirksen, Godelieve Engbersen, Bart Geurts, Bob Goudzwaard, Frits Hoff, Liesbeth van Hoef, Dirk Jansen, Riekje Jouvenaz, Jan Juffermans, Maarten Kamper, Tim Kasser, Paulien Kuipers, Ton Lemaire, Appie Luermans, Nico Nelissen, Andrea Nelissen - de Pont, Mar Oomen, Jef Peeters, Marjan Peeters, Erik Schoones, Sarah Stutterheim, Lisette Thooft, David Valenta, Jeanneke van de Ven and Greetje Witte-Rang.

My sisters Marie-Louise and Evelyne gave me expert information about statistics and fundraising, promptly and patiently. Thank you so much. In these thanks I also include 
my dear brother and my other sisters for their sisterhood that becomes stronger in the course of time.

In the final phase financial support was given by accountancy bureau Boqx0, and by Jenny Westrik who, after editing my fundraising letter, donated a generous gift herself. This gesture is unforgettable. The dedicated assistance of Chantal van der Put in the final stage of this research project was heartwarming as well.

In the past years I lost four loved ones with whom I wish I still could celebrate the finals. My three mothers and my dear firiend, 'power-girl' Paula ('you do it anyway') all deceased while I was working at this dissertation. At a time like this the absence of my mother feels a particularly great loss. She was a big fan of magazine Genoeg, and appreciated my pioneering work. She taught me that enjoying the good life and carefully handling money go very well together. When I decided to get my PhD, I felt I was reflecting her, a bridge champion still in her eighties.

An unintended effect of this research adventure is that I myself, along with my family, gradually have become the fattest guinea pigs. The grant amounts were not always sufficient and of course it all took longer than planned. Though we are no big spenders anyway, at one moment the family income had declined so far that we were thrown back on the tax refund for bare survival. This adventure could only come to a successful conclusion thanks to the support - in all ways - of my husband Eric and my fine children: Manuel, with Ljilja, and Charley. They taught me that it is not the price tag, but a loving commitment, that provides the fuel for a sustainable relationship. Our family secret that we have ended up as enthusiastic experts in dumpster diving is hereby disclosed.

This work is dedicated to Erik. Without him, I would be lost. 


\section{Dankwoord}

De weidse grasvelden van Mongolië behoren tot de mooiste landschappen in de wereld. Ik heb ze overigens nooit met eigen ogen gezien, maar dit is ook niet nodig om ervan te kunnen genieten. In gedachten heb ik er vaak vertoefd, zwervend door die onbegrensde, wijde wereld.

Werken aan dit proefschrift was een vergelijkbare ervaring. In alle vrijheid heb ik intellectueel rond kunnen struinen. Bovendien was er in het laatste anderhalf jaar een bijna blanco agenda, zodat zelfs de tijd onbegrensd leek. Zelden heb ik me zó vrij gevoeld. Hierdoor is het werken aan dit proefschrift een van de gelukkigste periodes geworden in mijn leven. De nomaden in Mongolië trekken echter nooit alleen. Ook ik had dit avontuur nooit tot een goed einde kunnen brengen zonder hulp. Veel mensen hebben die geleverd, in allerlei vorm.

Aan de wieg van dit project stond Marius de Geus. Hij bracht me op het idee van een promotie onderzoek, in plaats van de journalistieke productie waar we tot dan toe over praatten. Zijn suggestie - waarvoor mijn grote dank - betekende wel dat ik een andere begeleider moest vinden. Die vond ik in de beide promotores: Pim Martens, hoogleraar duurzame ontwikkeling en Gerjo Kok, hoogleraar sociale psychologie, beiden verbonden aan de Universiteit Maastricht.

Ik ben Pim Martens buitengewoon erkentelijk voor het feit dat hij mijn project 'geadopteerd' heeft en wetenschappelijk heeft willen ondersteunen. De stimulerende discussies die we hadden, inspireerden me zeer. Illustratief voor zijn grenzeloze vertrouwen in een goede afloop is zijn mail met een foto, gemaakt in het American Museum of Natural history. Het bleek een affiche van een glunderende Einstein. 'He once was a student too' luidde het onderschrift. Dat ik een werkplek kreeg bij zijn onderzoeksinstituut ICIS was eveneens van onschatbare waarde, niet alleen door de vele faciliteiten die mijn werk vergemakkelijkten, maar vooral door de academische spirit die er heerst en de hartelijke collegialiteit. Zeer bedankt.

De scherpe blik van de tweede promoter, Gerjo Kok, leerde me kritisch te blijven doordenken. Opmerkingen die - terloops leek het wel - gemaakt werden, openden interessante intellectuele paden voor me en schoten wortel. Mijn blinde vlek voor cijfers is door hem tot in de laatste versie van dit proefschrift ontmaskerd. Hiervoor ben ik hem veel dank verschuldigd. Daarbij ben ik hem zeer erkentelijk voor de financiële bijdragen aan de vertalingen en voor het werk van onderzoeksbureau Flycatcher.

Mijn ICIS collega's maakten met wegwijs in tal van zaken die direct of indirect van belang waren bij het werken aan dit proefschrift: grondbeginselen van SPSS en andere computerprogramma's, principes van integrated assessment modellen, fondswerving, presentatievaardigheden, enzovoorts, enzovoorts. De bonte verzameling van specialismen en nationaliteiten maakt van ICIS een inspirerende werkomgeving. Voor alle vriendelijkheid die ik de afgelopen jaren ervaren heb wil ik bijzonder graag 
bedanken: Akua, Alvaro, Anja, Annemarie, Annet, Astrid, Carijn, Chia Chung, Chiung, Gert-Jan, Harro, Jan, Machiel, Marc, Maud, Mohsin, Nicole, Stefano, Su-Mia, Pieter, René, Ron, Véronique.

Het idee voor een empirisch onderzoek naar leven met minder is ontstaan toen ik hoofdredacteur van magazine Genoeg was. Ik raakte gefascineerd door de diversiteit van de lezers, in opleiding en inkomen, culturele achtergrond, religieuze gezindte, spreiding over Nederland enzovoorts. Vogels van allerlei pluimage voelden zich blijkbaar aangesproken tot een meer ingetogen leefstijl, die bovendien leek te resoneren met een grotere, sociaal-culturele ontwikkeling in de VS en Europa. Uitgeverij Genoeg, en vooral de toendertijd nieuwe eigenaar Heleen van der Sanden ben ik bijzonder erkentelijk voor het feit dat ze meteen nadat ze het blad gekocht had, de schouders zette onder het realiseren mijn onderzoeksplan. Zij zorgde voor subsidie, regelde de logistiek van de uitvoering en adviseerde bij de verspreiding van de resultaten. Zonder haar was dit proefschrift er niet gekomen. Joke Reijnders als eindredeacteur was eveneens een bijzondere kracht in deze fase van het onderzoeksproject. Vanzelfsprekend speelden ook de lezers een cruciale rol. Dankzij het feit dat een - overigens boven verwachting hoog - aantal lezers de moeite nam om de ellenlange vragenlijsten in te vullen, konden de Dutch downshifters een gezicht krijgen.

Bij de start van het veldonderzoek heeft Josh Moll een belangrijke bijdrage geleverd aan het uittesten van de interviewmethode. Haar analytische geest en bevlogenheid hebben me goed geholpen. Ook alle geïnterviewden dank ik hierbij bijzonder voor de tijd en energie die ze in mijn project wilden investeren. Hun persoonlijke moed om het taboe op leven met minder te doorbreken en om mij deelgenoot te laten zijn van zo'n ingrijpende, persoonlijke levensgebeurtenis, heeft grote indruk op mij gemaakt.

Andere vrijwilligers, onder wie de mensen van Zuinigheid met Stijl, ben ik dank verschuldigd voor hun medewerking bij het telkens opnieuw uittesten van de vragenlijsten van de survey. Bij het verwerken van de data bleken Jimmie Leppink en Mark Hanrath onmisbare steunpilaren. Ook onderzoeksbureau Flycatcher, met name Anneke de Jongh, Bram de Volder en speciaal Lieke Helmes wil ik graag bedanken, voor hun deskundigheid en zeer prettige samenwerking.

Talloze meedenkers en meelezers ben ik onderweg tegengekomen. Met het risico dat ik iemand vergeet - bij voorbaat mijn excuses - wil ik in het bijzonder bedanken voor hun betrokkenheid: Jeroen van den Bergh, Ron Bernstein, Annemiek van Deurzen, Veronica Dirksen, Godelieve Engbersen, Bart Geurts, Bob Goudzwaard, Frits Hoff, Liesbeth van Hoef, Dirk Jansen, Riekje Jouvenaz, Jan Juffermans, Maarten Kamper, Tim Kasser, Paulien Kuipers, Ton Lemaire, Appie Luermans, Nico Nelissen, Andrea Nelissende Pont, Mar Oomen, Jef Peeters, Marjan Peeters, Erik Schoones, Sarah Stutterheim, Lisette Thooft, David Valenta, Jeanneke van de Ven en Greetje Witte-Rang. 
Mijn zusjes Marie-Louise en Evelyne gaven me deskundig - en geduldig - advies bij de statistische berekeningen en projectfinanciering. Zeer bedankt. Met hen bedank ik ook mijn lieve broer en de andere zusjes voor de sisterhood die almaar sterker wordt.

In de allerlaatste fase kwam er financiële steun van Boqx0, de 'creatieve boekhouders' uit Utrecht en van Jenny Westrik, die nadat ze mijn brief voor fondswerving van deskundig commentaar voorzien had, zelf ook nog eens een royale cheque uitschreef. Deze geste is onvergetelijk. Ook de toegewijde hulp die Chantal van der Put bood bij de productie van het proefschrift was hartverwarmend.

In de voorbije jaren heb ik vier dierbaren verloren met wie ik heel graag de finale gevierd zou hebben. Mijn drie moeders en mijn dierbare vriendin : power-girl Paula ('Je doet het toch maar') zijn in de periode van het werken aan dit proefschrift overleden. Op een moment als dit voelt met name de afwezigheid van mijn moeder als een groot gemis. Zij was een bijzondere fan van magazine Genoeg, en waardeerde mijn pionierswerk. Van haar leerde ik dat genieten van de goede dingen van het leven en verstandig met geld omgaan heel goed samen kunnen gaan. Ik spiegelde me aan haar - bridgekampioen tot in de tachtig - toen ik besloot te promoveren.

Een onbedoeld effect van dit onderzoeks-avontuur is dat ik, samen met mijn gezin, gaandeweg het grootste proefkonijn geworden ben. De subsidiebedragen vielen tegen en natuurlijk duurde het allemaal langer dan gepland. Waren we al niet zo'n big spenders, het gezinsinkomen is op een gegeven moment zover teruggelopen, dat wij het van de belasting moesten hebben; van de belasting teruggave wel te verstaan.

Dit avontuur heeft alleen maar tot een goed einde kunnen komen dankzij de steun - in alle opzichten - van mijn man Erik en van mijn kinderen: Manuel, samen met Ljilja, en Charley. Zij leerden me dat niet het prijskaartje maar liefdevolle betrokkenheid de smeerolie is in een duurzame relatie. Ons familiegeheim dat we inmiddels enthousiaste experts zijn in dumpster diving is hierbij prijs gegeven.

Dit werk draag ik op aan Erik. Zonder hem was ik nergens. 


\section{Curriculum vitae}

Jeanine Schreurs (1953) was born and raised at a farm in Limburg, the Netherlands, close to the river Meuse. After completing secondary education in 1972 (Gymnasium $\alpha$, St Ursula Lyceum, Roermond) she studied Cultural Anthropology at Radboud University Nijmegen (bachelor's degree in 1976), Sanskrit at Utrecht University, and Social and Political Sciences at Amsterdam University (master's degree in 1982), followed by a postgraduate education in management, again at Amsterdam University (1987).

She taught mass communication theories and journalism at the College of Journalism \& Communication (Fontys Hogeschool voor Journalistiek) at Tilburg. From 1992 to 1998 she worked as a communications officer and advisor at the Faculty of Law and at the Faculty of Economics \& Business Administration of Maastricht University.

Somewhere around the turn of the century began her professional-personal turn towards sustainability. At that time she was a staff member of Ecooperation, a semigovernmental Dutch organization in charge of the implementation of the Sustainable Development Agreements with Benin, Bhutan and Costa Rica. After a working visit to Bhutan - the Himalayan kingdom where the Gross National Happiness is put before Gross National Product - she quitted the long march through the institutions and transferred her interest from sustainability through institutional change towards sustainability through behavioral change.

Since then she worked as an independent journalist, trainer and researcher. From 2002 to 2007 she was editor-in chief of the Dutch magazine Genoeg (= Enough) and chair of the Dutch foundation Zuinigheid met Stijl (Simplicity with Style) which introduced the simplicity circles and many other educational activities in the Netherlands. As a member of the US based Simplicityforum she contributed to various annual conferences. Further she is affiliated with the Association of Consumer Researchers and with the Transformative Consumer Research Group/sustainability. In 2010 she joined ICIS, the International Centre for Integrated Assessment and Sustainable development at Maastricht University, as a research fellow in the area of sustainable consumer behaviour.

Jeanine Schreurs is married with painter Erik van der Krogt and mother of two fine children. Currently she lives in Maastricht, along the river Meuse. 
The unprecedented growth of consumption puts a heavy strain on our environmental resources and aggravates social and economic inequalities. So the costs that come with consumerism and the consumerist lifestyle are rising substantially. Despite the increasing awareness that a more sustainable way of living is needed, yet living with less is generally considered an inconvenient option.

Here lies the starting point of this dissertation that addresses the questions: How do reduced means impact consumer behaviour within the context of consumerism and consumer society? And: How can living with less contribute to sustainability? A multidisciplinary, integrated research approach has guided the analyses of academic literature and the qualitative and quantitative empirical studies. Results led to the construction of a behavioural change model: the Transformation Model Living with Less, as well as to the categorization of positive and negative experiences of living with less. Further, an extensive profile of Dutch downshifters is presented and the so-called Dutch Triple G's of sustainable lifestyle is introduced. By way of encore, the dissertation closes with an outline of a marketing strategy for sustainable lifestyle. 